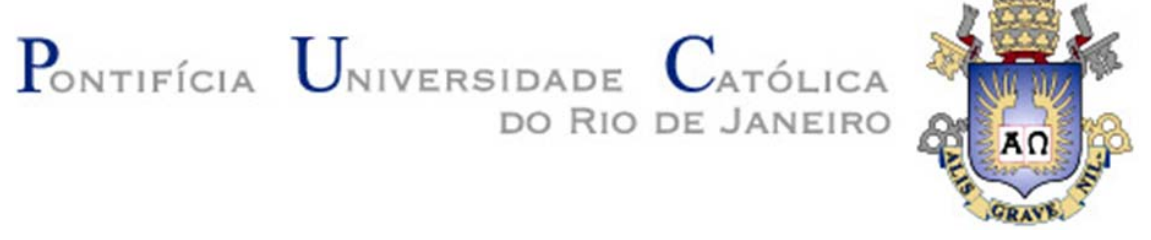

Sylvia Therezinha de Almeida Moraes

\title{
O Papel das Redes de Relacionamento na Internacionalização de Empresas Brasileiras de Software
}

Tese apresentada ao Programa de Pós-Graduação em Administração de Empresas da PUC-Rio como requisito parcial para obtenção do título de Doutor em Administração de Empresas.

Orientadora: Profa. Angela Maria Cavalcanti da Rocha 


\section{Pontifícia Universidade Católlca $_{\text {a }}$ DO RIO DE JANEIRO}

Sylvia Therezinha de Almeida Moraes

\section{O Papel das Redes de Relacionamento na Internacionalização de Empresas \\ Brasileiras de Software}

Tese apresentada como requisito parcial para obtenção do grau de Doutor pelo Programa de Pós-graduação em Administração de Empresas da PUC-Rio. Aprovada pela Comissão Examinadora abaixo assinada.

Profa . Angela Maria Cavalcanti da Rocha

Orientadora

Departamento de Administração - PUC-Rio

Prof. Jorge Ferreira da Silva

Departamento de Administração - PUC-Rio

Prof $^{a}$. Maria Angela Campelo de Melo Departamento de Administração - PUC-Rio

Prof. Luis Antonio da Rocha Dib Instituto Coppead de Administração/UFRJ

Prof. Renato Dourado Cotta de Mello

UFRJ

Profa. Mônica Herz

Vice-Decana de Pós-Graduação do CCS

Rio de Janeiro, 08 de abril de 2016 
Todos os direitos reservados. É proibida a reprodução total ou parcial do trabalho sem autorização da universidade, da autora e da orientadora.

\section{Sylvia Therezinha de Almeida Moraes}

Vinte e sete anos de experiência em Tecnologia da Informação, nas áreas de negócios e de desenvolvimento de software, atuando na Vale, Xerox e EDS. Graduação em Matemática pela PUC - RJ, MBA em Finanças pela FGV, MBA em Informática pela UFRJ, Mestrado em Administração (Marketing) pela PUC - RJ.

Ficha Catalográfica

Moraes, Sylvia Therezinha de Almeida

O papel das redes de relacionamento na internacionalização de empresas brasileiras de software / Sylvia Therezinha de Almeida Moraes; orientadora: Angela Maria Cavalcanti da Rocha. 2016.

231 f. :il. color. ; $30 \mathrm{~cm}$

Tese (doutorado)-Pontifícia Universidade Católica do Rio de Janeiro, Departamento de Administração, 2016.

Inclui bibliografia

1. Administração - Teses. 2. Internacionalização. 3. Redes de relacionamento. 4. Capital social. 5. Empreendedorismo internacional. 6. Empresas de software. I. Rocha, Angela Maria Cavalcanti da. II. Pontifícia Universidade Católica do Rio de Janeiro. Departamento de Administração. III. Título. 


\section{Agradecimentos}

Agradeço, em primeiro lugar, à minha orientadora, professora Angela da Rocha, por todo apoio, pelas revisões, pelo tempo que investiu em nossas discussões e principalmente pela confiança depositada na minha capacidade.

Agradeço a todos os professores com quem convivi nesses seis anos na PUC RJ, em especial ao professor Jorge Ferreira, por seus ensinamentos e carinho, mas em especial por suas críticas, que me fizeram refletir e avançar.

Agradeço a todos os empresários e executivos com os quais tive oportunidade de entrevistar e também àqueles que em algum momento dispuseram de tempo para ajudar a pesquisa acadêmica. Sei como isso é difícil, eu mesma quando estava na posição de executiva tive algumas resistências.

Agradeço ao CNPq pelas bolsas de estudo que me mantiveram nos quatro anos de doutorado, à APEX por ter viabilizado parte do projeto e ao NUPIN pela disponibilização dos dados iniciais da pesquisa, bem como por todo apoio logístico que muito usei.

Agradeço a todos os colegas de doutorado, pela troca de experiências e conhecimento, pelos momentos de estudo e de distração, ao longo dos quatro anos de doutorado. Destaco, no entanto, Renata Kurtz e Ana Carla Bon, que não só compartilharam os momentos mais intensos de trabalho, como se tornaram amigas para sempre.

Agradeço à minha família, meus filhos e meu marido, que suportaram todo esse caminho, desde o mestrado, com todas as angústias e o tempo que tive que dedicar e abdicar da presença deles em alguns fins de semana e noites.

Essa tese é dedicada ao meu pai, que sempre foi meu maior incentivador e exemplo de trabalho, responsabilidade e capacidade intelectual. 


\section{Resumo}

Moraes, Sylvia Therezinha de Almeida; Rocha, Angela Maria Cavalcanti da. O Papel das Redes de Relacionamento na Internacionalização de Empresas Brasileiras de Software. Rio de Janeiro, 2016. 231p. Tese de Doutorado - Departamento de Administração, Pontifícia Universidade Católica do Rio de Janeiro.

Esta tese estuda, a partir da teoria de empreendedorismo internacional, da teoria de redes e de capital social, como as empresas brasileiras de software se beneficiam do uso de suas redes e do capital social delas advindas, em seu processo de internacionalização. O objetivo foi identificar as diversas nuances e estratégias de uso de redes de relacionamento pelos empreendedores ao longo do tempo, observando sua dinâmica no processo de internacionalização da empresa. Para tal realizou-se um estudo longitudinal de oito casos de empresas brasileiras internacionalizadas do setor de software, investigando o processo pelo qual ocorreu cada entrada em mercados externos, desde sua fundação até o início de 2016. Foram ainda levantadas e analisadas, nas empresas pesquisadas, 87 iniciativas de internacionalização. Foi empregada uma abordagem abdutiva, que pressupõe um processo contínuo de evolução entre teoria e dados empíricos. As fontes de dados utilizadas foram primárias e secundárias, incluindo entrevistas pessoais realizadas para o estudo, transcrições de entrevistas anteriores provenientes de base de dados existente, publicações, casos acadêmicos publicados sobre as firmas selecionadas, documentos internos e sites das empresas. A análise dos dados teve como objetivo avaliar a ocorrência ou não de padrões, por meio de quatro dimensões: o perfil das empresas e de seus dirigentes; as características das iniciativas internacionais das empresas; a forma de utilização do capital social e das redes no processo de internacionalização; e a identificação de benefícios associados ao uso das redes nos processos de internacionalização. Além disso, buscou-se identificar padrões de construção do relacionamento no decorrer do tempo. A análise se baseou na comparação de padrões e na análise cruzada de casos. Os resultados apontaram estratégias variadas de uso do capital social pelas empresas estudadas. De forma geral, as empresas brasileiras de software estudadas não seguem um padrão único, mas vários padrões distintos. No entanto, obtiveram-se alguns indicadores de como se constroem os relacionamentos, delineando-se ainda benefícios obtidos por meio de capital 
social e redes. Foi possível identificar um processo genérico de evolução de relacionamento. Conclui-se que o uso das redes de relacionamento é fator primordial para o avanço das empresas brasileiras de software no mercado internacional, o que corrobora estudos recentes que destacam o uso das redes por empresários de países emergentes como o principal instrumento para superar as restrições inerentes ao seu tamanho e ao país de origem.

\section{Palavras-chave}

Internacionalização; redes de relacionamento; capital social; empreendedorismo internacional; empresas de software. 


\section{Abstract}

Moraes, Sylvia Therezinha de Almeida; Rocha, Angela Maria Cavalcanti da. The Role of Social Networks in the Internationalization of Brazilian Software Firms. Rio de Janeiro, 2016. 231p. Doctoral Thesis Departamento de Administração, Pontifícia Universidade Católica do Rio de Janeiro.

Departing from the international entrepreneurship theory, network theory, and social capital theory, this study investigates how Brazilian software companies benefit from the use of their networks and social capital in the internationalization process. The goal was to identify the nuances and strategies associated to the use of social networks by entrepreneurs over time, analyzing its dynamics in the firms' internationalization processes. To this end a longitudinal study was carried out using eight cases of internationalized Brazilian companies in the software industry, in order to investigate the foreign market entry process, covering the period from each firm's inception until early 2016. In addition, 87 international initiatives were identified and analyzed. The study employed an abductive approach, which presupposes a continuous interaction between theory and empirical data. The data sources used were primary and secondary, including personal interviews, transcriptions of previous interviews from a database, publications, company documents, and information from company websites. Data analysis aimed at evaluating the occurrence of patterns considering four dimensions: company and entrepreneur characteristics; characteristics of international initiatives by the firms; use of social capital and networks in the internationalization processes; and the identification of benefits associated to the use of networks in the internationalization processes. In addition, the study explored patterns of the evolution of relationships. The analysis was based on pattern-matching analysis and cross-case analysis. Results showed a variety of different strategies employed by the firms studied. In general, it was not possible to identify a single pattern, but several different patterns emerged. In addition, there are some indicators of how relationships are built, and the benefits aimed by firms when using social capital and networks. We conclude that the use of social networks is a key factor for the advancement of Brazilian software companies in international markets, supporting the findings of recent studies highlighting the 
use of networks by entrepreneurs in emerging markets as the main instrument to overcome the constraints inherent to size and country of origin.

\section{Keywords}

Internationalization; social networks; social capital; international entrepreneurship; software companies. 


\section{Sumário}

1. Introdução 15

1.1. Contexto 15

1.2. Formulação do Problema, Questões de Pesquisa e Objetivo do Estudo

1.3. Relevância do Estudo 21

1.4. Delimitação do Estudo 25

2. Revisão de Lliteratura 26

2.1. Método de Pesquisa Bibliográfica 26

2.2. O Campo do Empreendedorismo Internacional 30

2.2.1. Evolução do Campo 30

2.2.2. Conceitos Básicos 34

2.2.2.1. Empreendedorismo Internacional 34

2.2.2.2. Firma Empreendedora 37

2.3. Redes na Internacionalização da Empresa 39

2.3.1. As Redes no Modelo de Uppsala 42

2.3.1.1. O Modelo Original 42

2.3.1.2. O Modelo Revisado 44

2.3.2. Outras Contribuições à Internacionalização por Redes 47

2.3.3. Redes e Mercado de Destino 51

2.4. Capital Social 53

2.4.1. Definições de Capital Social 53

2.4.2. Principais Teorias de Capital Social 56

2.4.2.1. Teoria da Força dos Laços Fracos 56

2.4.2.2. Teoria de Vazios Estruturais (Structure Holes) 57

2.4.2.3. Teoria dos Laços Fortes e Rede Fechada (Network
Closure)

2.4.2.4. Teoria de Recurso Social $\quad 59$

2.4.2.5. Teoria de Embeddedness 60

2.4.2.6. Dimensões de Capital Social 61

2.4.2.7. Modelo de Capital Social 62

2.5. Capital Social na Internacionalização 66

2.5.1. Tipos de Usos de Capital Social para a

2.5.1.1. Capital Social e Identificação de Oportunidades 68

2.5.1.2. Capital Social, Experiência e Aprendizado 75

$\begin{array}{ll}\text { 2.5.1.3. Outros Usos do Capital Social } & 79\end{array}$

2.5.2. Capital Social no Tempo e no Espaço 80

2.5.3. Capital Social e Características dos Empreendedores 85

3. Metodologia 88

3.1. Método da Pesquisa 88

3.1.1. Abordagem Abdutiva 90

3.2. Unidade de Análise e Seleção de Casos 92

3.3. Coleta de Dados 94

3.4. Análise de Dados $\quad 97$

3.4.1. Descrição dos Casos 97 
3.4.2. Codificação Teórica 98

3.4.3. Identificação de Padrões e Contrastes $\quad 99$

3.5. Limitações 100

4. Descrição dos Casos 102

4.1. CI\&T 102

4.1.1 Identificação e Breve Histórico da Empresa 102

4.1.2 Processo de Internacionalização da Ci\&T 103

4.2. Fujitec 110

4.2.1 Identificação e Breve Histórico da Empresa 110

4.2.2 Processo de Internacionalização da Fujitec 112

4.3. Ivia $\quad 115$

4.3.1 Identificação e Breve Histórico da Empresa 115

4.3.2 Processo de Internacionalização da Ivia 117

4.4. Light Infocon 121

4.4.1 Identificação e Breve Histórico da Empresa 121

4.4.2 Processo de Internacionalização da Light Infocon 123

4.5. MidiaVox 128

4.5.1 Identificação e Breve Histórico da Empresa 128

4.5.2 Processo de Internacionalização da MidiaVox 129

4.6. Totall 133

4.6.1 Identificação e Breve Histórico da Empresa 133

4.6.2 Processo de Internacionalização da Totall 135

4.7. Totvs 139

4.7.1 Identificação e Breve Histórico da Empresa 139

4.7.2 Processo de Internacionalização da Totvs 142

$\begin{array}{ll}\text { 4.8. Xseed } & 147\end{array}$

4.8.1 Identificação e Breve Histórico da Empresa 147

4.8.2 Processo de Internacionalização da Xseed 148

5. Análise dos Resultados 156

5.1. Perfil das Empresas e de seus Dirigentes 156

5.1.1 Características Gerais das Empresas 156

5.1.2 Experiência Internacional dos Empreendedores 159

5.1.3. Orientação Internacional dos Empreendedores 163

5.2. Iniciativas Internacionais das Empresas 165

5.2.1. Número de Iniciativas Internacionais 166

5.2.2. Mercados de Destino das Iniciativas Internacionais 168

5.2.3. Abordagens para Ingresso em Mercados Internacionais $\quad 170$

5.3. Uso de Capital Social e Redes na Internacionalização 173

5.3.1.Tipos de Atores $\quad 174$

5.3.2. Tipos de Laços $\quad 178$

5.3.3. Força de Laços 181

5.3.4. Origem de Laços $\quad 184$

5.4. Benefícios Associados ao Uso de Redes na

5.5. Gestão do Capital Social e Redes 189

5.6. Exploração Quantitativa de Relações entre Variáveis 190

5.7. Análise de Iniciativas Específicas 193 
5.7.1. Iniciativa A - Cl\&T e J\&J: Construindo uma Rede de Negócios

5.7.2. Iniciativa B - MidiaVox e Avaya: Internacionalizando-se por Meio da Rede de Subsidiárias de uma Multinacional

5.7.3. Iniciativa C - Fujitec e VFJ/Chris Adams: Construindo uma Relação Pessoal a Partir de uma Parceria Internacional

5.7.4. Iniciativa D - Ivia e Noesis/Marcio Braga: Construindo uma Rede de Negócios a Partir de um Relacionamento Pessoal

5.7.5. Um Processo Genérico de Evolução dos Relacionamentos

6. Conclusões

6.1. Sumário do Estudo 204

6.2. Conclusões 207

6.3. Contribuições Teóricas 210

6.4. Contribuições para Empresas e Governo 211

6.5. Recomendações para Futuras Pesquisas 212

7. Referências Bibliográficas 214

Anexos 231 


\section{Lista de figuras}

Figura 1 - Mapa temático do campo de Empreendedorismo Internacional

Figura 2 - Internacionalização e o Modelo de Rede: As situações a serem analisadas

Figura 3 - Esquema representando os passos trilhados por empresas que se internacionalizam, segundo Johanson e Vahlne

Figura 4 - Mecanismo Básico de Internacionalização no Modelo de Uppsala original

Figura 5 - O modelo do processo de internacionalização de Redes de Negócio.

Figura 6 - Comparação de quatro modelos de internacionalização por estágios

Figura 7 - Padrões de crescimento, Influências da rede e características da firma no processo de internacionalização de pequenas empresas de software

Figura 8 - Tipologia de Estudos empíricos em Capital Social

- Exemplos de redes com vazios estruturais vs. densa

Figura 10 - Modelo de Capital Social (Adler \& Kwon, 2002, p. 23) 65

Figura 11 - Receita Líquida da Totvs 141

Figura 12 - Lucro Líquido da Totvs 141

Figura 13 - Canais de distribuição da Totvs 142

Figura 14 - Evolução da receita líquida e do EBTIDA nas

operações internacionais da Totvs.

Figura 15 - Processo Genérico de Evolução do Relacionamento 201 


\section{Lista de quadros}

Quadro 2.1 - Artigos de revisões 28

Quadro 2.2 - Periódicos elencados na bibliografia de

Empreendedorismo Internacional do site ie-scholars 29

Quadro 2.3 - Lista de edições especiais sobre El (1996 a 2009) 32

Quadro 2.4 - Principais definições de Empreendedorismo

Internacional 37

Quadro 2.5 - Duas visões da internacionalização 50

Quadro 2.6 - Perspectivas teóricas e operacionalizações do
construto Capital Social

Quadro 2.7 - Definições de Capital Social 63

Quadro 2.8 - Tipologia de relacionamentos sociais e de negócios $\quad 70$

Quadro 3.1 -Casos selecionados 94

Quadro 3.2 - Resumo das fontes de dados 96

Quadro 3.3 - Descrição das principais categorias de análise $\quad 99$

Quadro 4.1 - Crescimento da IVIA de 2004 a $2007 \quad 116$

Quadro 5.1 - Características das empresas estudadas 157

Quadro 5.2 - Experiência internacional prévia dos

empreendedores $\quad 160$

Quadro 5.3 - Iniciativas de internacionalização estudadas 167

Quadro 5.4 - Mercados em que ocorreram as iniciativas de 168

Quadro 5.5 - Abordagens emergentes vs intencionais 170

Quadro 5.6 - Tipos intencionais de abordagem 171

Quadro 5.7 - Tipos emergentes de abordagem 172

Quadro 5.8 - Tipos de atores nas iniciativas internacionais $\quad 175$

$\begin{array}{ll}\text { Quadro } 5.9 \text { - Tipos de laços presentes nas iniciativas } & 179 \\ \text { internacionais }\end{array}$

Quadro 5.10 - Força dos laços presentes nas iniciativas

internacionais

Quadro 5.11 - Origem dos laços presentes nas iniciativas

internacionais

Quadro 5.12 - Benefícios obtidos nas iniciativas internacionais em

rede

Quadro 5.13 - Evolução do relacionamento entre Cl\&T e J\&J

Quadro 5.14 - Evolução do relacionamento entre MidiaVox e

Avaya

Quadro 5.15 - Evolução do relacionamento entre Fujitec e

VFJ/Chris Adams

Quadro 5.16 - Evolução do relacionamento entre Ivia e Noesis/ 


\section{Lista de tabelas}

Tabela 5.1. Coeficientes de correlação de Spearman para os construtos analisados 


\section{1 \\ Introdução}

A presente pesquisa abrange os campos de estudo do Empreendedorismo Internacional (EI) e do Capital Social, almejando aprofundar o entendimento do papel que o uso das redes de relacionamento e do capital social exerce sobre o processo de internacionalização de empresas de software brasileiras.

Este capítulo está organizado em quatro partes. A primeira seção versa sobre o contexto no qual a pesquisa está inserida. A segunda seção descreve o problema e as questões de pesquisa do presente estudo, seguida pela terceira seção, que apresenta a relevância da pesquisa em termos teóricos e práticos. Por fim a quarta seção trata da delimitação da pesquisa.

1.1.

Contexto

Após o fim da reserva de mercado de informática no início dos anos 1990, a indústria brasileira de software alcançou competência e vantagens competitivas que favoreceram a internacionalização (ROCHA \& SILVA, 2009). Tal fenômeno despontou especialmente em setores em que havia demanda específica de conhecimento do mercado brasileiro ou onde o tamanho não se apresentava suficiente para atrair os grandes players internacionais, em particular os de calçados, aviação, finanças, agronegócios, educação, energia, games, gestão, mineração e óleo e gás, que se fortaleceram nacionalmente, fazendo do Brasil um país com diversidade de competências em Tecnologia da Informação (TI) (BrasillTplus, 2015).

O mercado de software e serviços de TI no Brasil passou do décimo lugar em 2011 para o oitavo em 2013, sendo responsável por 2,4\% do total mundial, movimentando 25,9 bilhões de dólares (comparativamente com 21,4 bilhões de dólares em 2011), sendo 10,9 bilhões em software e 15 bilhões em serviços (ABES, 2014). 
Talvez por dispor de um mercado doméstico muito grande, a percentagem de exportação sobre o total do faturamento se mostra pouco significativa, sendo 1,9\% para software e $4 \%$ para serviços de TI (ABES, 2014), o que, por outro lado, sugere possíveis oportunidades.

Por ser considerado um setor estratégico, o governo brasileiro vem lançando programas de incentivo à internacionalização do setor de software. Um exemplo é o Programa TI Maior, lançado pelo governo federal em agosto de 2012 para estimular o desenvolvimento de software no Brasil, com investimento de R\$500 milhões previsto até 2015. Uma iniciativa mais recente é o programa Usinas Digitais, lançado pelo Ministério das Comunicações em agosto de 2015, que tem como objetivo estimular a criação de parques tecnológicos no país e o fomento a pesquisas para desenvolvimento de software para smartphones e computadores (Portal Brasil, 2015).

O número de exportadoras de serviços de TI no Brasil mais do que dobrou entre 2007 e 2014, segundo pesquisa realizada pela Softex (entidade que promove a internacionalização de empresas do setor), alcançando um volume de exportações de US\$ 1,62 bilhão em 2013 (BRITO, 2015). Mas, por outro lado, o Brasil é bastante atraente para empresas do setor oriundas de outros países, ameaçando a sobrevivência das empresas brasileiras que não adquirirem experiência em mercado internacionais.

No entanto, alguns programas não têm alcançado o sucesso esperado, como observado nas declarações de Benito Paret, presidente do Sindicato das Empresas de Informática do Rio de Janeiro, por ocasião do evento Rio Info em 2014, ao lamentar que, desde 2011, o Ministério da Ciência, Tecnologia e Inovação teve três ministros, com prioridades e propostas diversas: "Ficaram apenas na intenção" (Agência Brasil, 2014).

Há diversos fatores que podem atuar como motivadores para a internacionalização das empresas brasileiras de software. Em primeiro lugar, destaca-se a competição global, que embora não seja um fenômeno recente, exerce pressão expressiva sobre a indústria de software. Entre as principais características que levam o setor a sentir de forma mais acentuada a concorrência, destacam-se: (i) a distribuição digital, feita pela rede da internet, com alcance global e a cada dia mais acessível tanto em escopo quanto em custos; (ii) a gama de formas que o software pode apresentar - desde aplicativos para empresas de 
diversos setores até aqueles que miram indivíduos adultos e jovens; (iii) a quantidade e a facilidade com que jovens nerds no mundo inteiro criam soluções e as disseminam pelas redes sociais.

A segunda força motivadora surge na busca por crescimento, pois mesmo contando com amplo mercado doméstico, este representava em 2013 uma acanhada porção do global $(2,8 \%)$, levando empresários brasileiros a buscarem uma parte de seu faturamento em países estrangeiros, dado que o mercado global de software e serviços atingiu, em 2013, o valor de 1.039 bilhões (ABES, 2014).

Há também a questão de que o Brasil conta com mão de obra relativamente barata, que teve como base e incentivo o longo tempo de reserva de mercado, período que permitiu o desenvolvimento de algumas áreas de expertise em TI. Mais recentemente alguns centros de competência tecnológica vêm se destacando no país, os ditos "Vales do Silício Brasileiros", salientando-se: (i) Porto Digital (PE); (ii) San Pedro Valley (MG); (iii) PqTec (SP); (iv) Parque Tecnológico da UFRJ (RJ) e (v) Tecnopuc (RS) (Hamann, 2014).

Apesar do progresso e do visível interesse no desenvolvimento do setor que o governo brasileiro vem demonstrando por meio de programas de incentivo, as empresas brasileiras ainda enfrentam inúmeras barreiras para se destacarem internacionalmente. O programa Brasil IT Plus tem melhorado a percepção da qualidade do software brasileiro no exterior. Contudo, a imagem permanece aquém da dos concorrentes, especialmente dos países desenvolvidos, e alguns outros que conseguiram tornar-se referência em software, como Irlanda e Índia. Além disso, como a maior parte das empresas brasileiras de software são pequenas ou médias, elas dispõem de recursos limitados, afetando principalmente a capacidade de inovação, que pressupõe elevados investimentos em $P \& D$, fundamentais para a competitividade no setor.

Como forma de amenizar as barreiras e dificuldades enfrentadas para a internacionalização, alguns estudos indicaram o uso das redes de relacionamento como facilitador deste processo. O capital social pode proporcionar uma fonte para o empreendedor ou para a empresa buscar meios de suprir limitações. Acesso a conhecimento sobre mercados externos, reputação, credibilidade e confiança originadas em uma rede de relacionamento, dentre outros exemplos, são fatores capazes de diminuir o risco percebido pelo empreendedor ao se lançar em empreendimentos internacionais (ARENIUS, 2005; BARON \& TANG, 2009; DE 
CAROLIS \& SAPARITO, 2006; IRELAND, HITT, \& SIRMON, 2003; JONES, COVIELLO \& TANG, 2011; KIM \& ALDRICH, 2005; LIAO \& WELSCH, 2005; LIN, 2001; MAURER \& EBERS, 2006; MURPHY, 2011; PAYNE, MOORE, GRIFFIS, \& AUTRY, 2011; PERRY-SMITH \& SHALLEY, 2003; TSAI \& GHOSHAL, 1998).

1.2.

Formulação do problema, questões de pesquisa e objetivo do estudo

Há diversas pesquisas sobre os benefícios obtidos nas redes de relacionamento na internacionalização das empresas, procurando entender como seu uso facilita a internacionalização. Tais estudos abrangem diversos aspectos do processo de internacionalização - desde a identificação da oportunidade, passando pelo aprendizado, pela mobilização de recursos, pela escolha do modo de entrada, até a influência na expansão para outros mercados (AGNDAL, CHETTY, \& WILSON, 2008; ANDERSSON, 2000; ELLIS, 2000; ZAHRA \& GEORGE, 2002).

Diante de dificuldades tais como a "liability of foreigness" enfrentada por empreendedores, notoriamente aqueles de países emergentes, alguns estudos empíricos vêm comprovando o uso das redes de relacionamento como um dos meios de facilitação e aceleração do processo de internacionalização, especialmente das pequenas e médias empresas (PMEs) (HOLMLUND \& KOCK, 1998). Aspectos como a qualidade do ambiente institucional e as diferenças entre o país de origem e o de destino também são analisados em pesquisas de Empreendedorismo Internacional (BATJARGAL, 2003; PENG \& LUO, 2000) e têm mostrado que o uso das redes de realcionamento muitas vezes é consequência da necessidade de contornar dificuldades inerentes aos países de baixo desenvolvimento institucional (KISS \& DANIS, 2008).

As redes de relacionamento não são estáticas, podem crescer ou diminuir com o tempo, de forma proativa ou não, em situações diversas, como em decorrência de aumento do escopo geográfico ou pela mera vontade do empreendedor. Essas variações se manifestam nas estruturas, no tamanho e na importância das redes de relacionamento e, como consequência, na forma como as empresas as usam.

${ }^{1}$ Liability of foreigness pode ser traduzido como passivo decorrente de ser estrangeiro 
Por essa razão, as características das redes de relacionamento foram estudadas por meio de conceitos relacionados às estruturas da rede dos indivíduos, sua posição na rede, o tamanho da rede e a intensidade dessas relações (BURT, 1992; GRANOVETTER, 1973). As redes são formadas por laços, que podem ser fracos ou fortes. Por laços fortes, Granovetter (1973) classificou aqueles que dispendem maior quantidade de tempo, maior intensidade emocional, reciprocidade e intimidade, normalmente associados a familiares e amigos. Quanto à intensidade, o campo de empreendedorismo internacional ainda é controverso com relação aos benefícios trazidos por redes de laços fortes ou fracos nos processos de internacionalização (KISS \& DANIS, 2008).

Especificamente no Brasil, por se tratar de uma sociedade relacional, é constante o uso da rede de relacionamento para alcançar objetivos de negócios:

“...de aspectos distintivos da cultura brasileira, onde novamente 'todos' se valem de suas redes de contatos para fazer negócios ou buscam ativamente desenvolver e estabelecer estas redes para se internacionalizar" (Dib, 2008, p.268).

Porém, alguns autores advertem para a forma contingencial do uso das redes em diferentes funções de negócio, sendo a seleção de redes de estruturas fortes ou fracas, coesas ou dispersas, feita de acordo com o objetivo a alcançar (BURT, 1992; GRANOVETTER, 1973). Segundo Coleman (1990), há ocasiões em que o capital social pode ser prejudicial, por vezes até inibindo o acesso a oportunidades, especialmente quando a firma se insere em uma rede extremamente fechada (TANG, 2011). Apesar dos claros benefícios advindos de uma estrutura de rede sustentada em relacionamentos de mútua confiança e de longo prazo, também é verdade que a empresa necessita manter certa dinâmica na sua rede de relacionamentos, acrescentando novas redes e até mesmo abandonando aquelas que não mais apresentam resultados positivos (TANG, 2011).

Em resumo, muitas são as variáveis intrínsecas às redes de relacionamento que devem ser analisadas para o entendimento do papel que elas exercem nas diversas ações que as empresas realizam em seu dia a dia, ou em suas decisões mais estratégicas, como o fenômeno de interesse do presente estudo - a internacionalização. 
Portanto, torna-se importante entender como o uso das redes de relacionamento e do capital social se apresenta ao longo do processo de internacionalização da firma (YLI-RENKO, AUTIO, \& TONTTI, 2002). Em outras palavras, como são utilizados estes elementos no decorrer do processo de internacionalização da firma?

Considerando: (i) os resultados de estudos que comprovaram benefícios e vantagens obtidos pelas empresas que se inserem em redes de relacionamento e que enfrentam os desafios inerentes ao processo de internacionalização, (ii) a constatação dos diversos entraves e desafios que as pequenas empresas em países emergentes enfrentam para subsistir, mais ainda para crescer internacionalmente, e (iii) as dificuldades de empresas do setor de TI no Brasil serem reconhecidas internacionalmente, o presente estudo pretende responder à seguinte pergunta de pesquisa:

Como as redes dos empreendedores influenciam o processo de internacionalização das empresas brasileiras no setor de software ao longo do tempo?

Para obter a resposta a essa pergunta é preciso entender e detalhar o papel das redes de relacionamento e dos recursos advindos destas no processo de internacionalização de empresas de software brasileiras. Assim, formularam-se as seguintes questões associadas:

- De que modo a pertinência a redes contribui para os primeiros passos de internacionalização?

- De que forma pertinência a redes se modifica ao longo do processo de internacionalização?

- Como ocorre a gestão das redes no decorrer do processo de internacionalização?

- Quais os benefícios do uso de redes no decorrer do processo de internacionalização?

- Como evolui ao longo do tempo a construção de relacionamento? 


\section{3.}

\section{Relevância do estudo}

A relevância do estudo pode ser examinada tanto de uma perspectiva teórica quanto prática.

Do ponto de vista teórico, embora o tema Capital Social já venha sendo explorado no campo de EI (AGNDAL, CHETTY, \& WILSON, 2008; ARENIUS, 2002; HAN, 2006; KISS \& DANIS, 2008; KWON \& ARENIUS, 2010; PRASHANTHAM \& DHANARAJ, 2010; YLI-RENKO, AUTIO, \& SAPIENZA, 2001; YLI-RENKO, AUTIO, \& TONTTI, 2002), ainda há muita oportunidade de novos estudos.

A teoria de capital social tem se mostrado uma boa fundação para a perspectiva de redes nas pesquisas de EI, pois é capaz de ilustrar o entendimento sobre como os empreendedores vencem incertezas nos novos mercados. Essa temática surge quando Coviello e Munro (1995) mapearam padrões de redes que influenciam o modo de entrada em mercados externos, e foi explorada nos anos seguintes, englobando redes e relacionamentos, além do processo de criação de rede e capital social (JONES, COVIELLO, \& TANG, 2011). Pesquisas empíricas que busquem entender a relação entre os diversos tipos de recursos e informações obtidos por meio das redes e o processo de internacionalização têm sido requisitadas em artigos acadêmicos (por ex., KISS \& DANIS, 2008; KISS, DANIS, \& CAVUSGIL, 2012; ZAHRA \& GEORGE, 2002).

Apesar de reconhecerem que os empreendedores que adotam estratégias de relacionamento mais flexíveis são os que obtêm maior sucesso no processo de internacionalização, Kiss e Danis (2008) sugerem que existe espaço para explorar de que forma os empreendedores tomam decisões sobre o uso de relacionamentos na expansão internacional de seus negócios. Empreendedores utilizam suas redes para acesso a recursos críticos, adaptando-se a ambiente institucionais diversos. Mas a questão ainda não explorada é como essa adequação ocorre:

"Como atributos estruturais e relacionais das redes dos empreendedores influenciam o desenvolvimento do aprendizado e das habilidades em diferentes ambientes nacionais? O valor do capital social e do intelectual é contingente ao contexto institucional? Se afirmativo, como os empreendedores bem-sucedidos gerenciam essa complexidade? ” (Kiss, Danis, \& Cavusgil, 2012, p. 280). 
Em revisão de estudos de EI em economias emergentes Kiss, Danis e Cavusgil (2012) apontaram a necessidade de mais pesquisas sobre regiões pouco investigadas e sobre processos longitudinais, além de maior foco em perguntas do tipo "como" e por quê". Na opinião destes autores, estudos sobre o impacto das redes na internacionalização provaram sua importância nas ações de empreendedores de países emergentes, porém há ainda muito o que explorar. Algumas perguntas ainda precisam ser exploradas:

“... como empreendedores se conectam a alianças $e$ redes domésticas $e$ internacionais, o que eles aprendem de seus parceiros durante suas colaborações subsequentes, e como gerenciam suas redes de relacionamento" (Kiss, Danis, \& Cavusgil, 2012, p. 280).

Em particular no Brasil, poucos estudos foram propostos sobre o papel das redes no empreendedorismo internacional:

"Finalmente, defendemos mais estudos em países em desenvolvimento, especialmente aqueles com grandes mercados internos (como os países BRIC), a fim de melhor compreender a natureza deste fenômeno. O estudo de como Born Globals usam redes - característica importante de acordo com a literatura também precisa ser mais pesquisada no contexto de culturas relacionais” (Dib, Rocha, \& Silva, 2010, p. 248).

Outro aspecto que reforça a relevância do presente estudo é a importância do conceito de oportunidade internacional (OI) nas pesquisas de EI na tentativa de entender como o comportamento empreendedor afeta o processo de identificação da OI. Mainela, Puhakka e Servais (2014) propuseram pesquisas futuras com base em revisão de publicações em EI entre 1989 e 2012, com foco em OI. A revisão, além de apontar a importância das redes de relacionamento na identificação de oportunidade como forma de superar escassez de recursos, também identificou contradições em suas aplicações. O papel da rede por vezes é facilitador, em outras, limitador; em algumas situações as oportunidades são identificadas pelas redes pessoais dos empreendedores, em outras pela rede da firma; ou ainda quando as empresas são mais beneficiadas por laços fracos ou por laços fortes. Como conclusão, os autores reforçam a importância do estudo do contexto e das situações sociais nas quais as oportunidades surgem e como as redes participam desse processo. 
Outra temática apontada por Mainela et al. (2014) diz respeito a como as oportunidades surgem a partir de interações, discussões e interpretações entre o empreendedor e outros atores pertencentes à rede. Acredita-se que entender tais interações permitirá a compreensão do processo pelo qual atores que representam diferentes organizações criam oportunidades coletivas. Algumas perguntas são indicadas para aprimorar o entendimento sobre OIs:

"Como OIs que surgem por meio de interações se manifestam em determinadas relações de negócios internacionais? Como as dinâmicas das relações de negócios internacionais são refletidas no desenvolvimento de OIs no tempo? " (Mainela et al., 2014, p. 122).

Também Jones, Coviello, e Tang (2011) constataram em sua revisão o potencial para pesquisas de EI focadas em identificação de oportunidades, particularmente no entendimento de como esse processo acontece em relação às mudanças no aprendizado do empreendedor ou nos padrões de rede da firma.

Outra lacuna no campo de EI diz respeito aos aspectos dinâmicos do processo de internacionalização. A literatura clássica no tema centrou-se na compreensão do 'o que' e o "por quê" - ou seja, as etapas envolvidas e os fatores que explicam a mudança de uma etapa para outra - deixando a forma como o processo se desenvolve ao longo do tempo pouco explorada (CASILLAS \& ACEDO, 2013).

"Acreditamos que, assim como a internacionalização, o empreendedorismo é um processo, não é um fenômeno estático. É essencialmente um comportamento planejado que se desenvolve ao longo do tempo e interage com o seu ambiente. Isto implica que futuras investigações em EI poderiam se beneficiar de projetos de pesquisa mais longitudinais. Assim, o estudo dos estágios iniciais de internacionalização pode ser uma oportunidade para alcançar uma compreensão mais geral de como o processo empreendedor e a internacionalização interagem e evoluem ao longo do tempo" (Keupp \& Gassmann, 2009, p. 614).

Também a questão do tamanho e da idade das empresas tem sido recorrente nas revisões e sugestões de pesquisa em EI. A seleção de casos nos estudos de EI é habitualmente guiada pelo tamanho e pela idade da firma, apesar de aspectos relacionados às capacidades, orientação e capital social serem comprovadamente bons indicadores da internacionalização empreendedora, independentemente de a empresa ser jovem ou madura, grande ou pequena. Jones, Coviello e Tang (2011, p. 642) sugerem: 
“... precisamos de investigações de EI em contextos comparativos que incluam firmas menores e mais jovens e firmas maiores e/ou maduras. Tais investigações podem comparar a influência da capacidade absorvida na internacionalização empreendedora, o papel da imitação ou a influência relativa de capacidades dinâmicas relativas, ou seja, áreas onde a base de recursos das firmas jovens e menores presumivelmente têm impacto".

Revendo 323 artigos em EI, Jones, Coviello e Tang (2001) constatam que os estudos de EI vêm cada vez mais incorporando outras áreas de pesquisa e integrando teorias - marketing, estratégia, capital social, são alguns exemplos - e reiteram os diversos apelos para pesquisas multidisciplinares no campo de EI Sugerem, em particular, pesquisas que se beneficiem da teoria de capital social, explorando os riscos inerentes aos relacionamentos de redes, à natureza e ao impacto da capacidade dinâmica de geração de redes:

"No entanto, dadas as conclusões de que laços fracos são mais importantes do que laços fortes no reforço do processo de aquisição e exploração de conhecimento (Presutti et al., 2007), sugerimos uma investigação mais aprofundada sobre o impacto relativo das dimensões estruturais, relacionais e cognitivas do capital social. Isto porque outras literaturas (por exemplo, marketing de relacionamento, teoria de aprendizagem) sugerem que as duas últimas dimensões são ou deveriam ser influentes" (Jones, Coviello \& Tang, 2011, p. 643).

Por fim, estudos que avancem o conhecimento sobre os processos de internacionalização, visando responder as questões mencionadas, contribuirão para esclarecer se há diferenças nos atributos, na dinâmica das ações estratégicas das redes, no desenvolvimento e no uso do capital social por empreendedores de países emergentes em comparação aos de economias avançadas.

Do ponto de vista prático, é necessário avançar no entendimento das dificuldades enfrentadas e das formas utilizadas pelas empresas para vencê-las que fazem emergir empreendimentos bem-sucedidos na internacionalização no setor de TI. O melhor entendimento dessas questões poderá contribuir para o avanço das políticas públicas e para melhorias na gestão internacional de empresas brasileiras de software.

Em resumo, essa pesquisa espera alcançar as seguintes contribuições tanto para o avanço da pesquisa em internacionalização, como para formuladores de políticas de incentivo à internacionalização das empresas de software brasileiras e para empreendedores desse setor que desejam se expandir para outros países: 
- Contribuir para o avanço do conhecimento acadêmico, explorando as características de uso de redes de relacionamento para a internacionalização de empresas brasileiras de software. Ao analisar empiricamente a internacionalização de empresas brasileiras de software, o presente estudo buscou adicionar suas contribuições ao acervo de estudos acadêmicos sobre internacionalização, que são majoritariamente aplicados a empresas de países desenvolvidos, ou, mais recentemente, de países emergentes da Ásia, e a estudos já realizados no Brasil, em particular os de Dib (2008) e Mello (2009).

- Proporcionar aos empreendedores uma visão mais abrangente das diversas possibilidades de uso de redes de relacionamentos no processo de internacionalização de empresas brasileiras de software.

- Proporcionar subsídios a órgãos públicos e agências de fomento à exportação nas decisões dos melhores caminhos a seguir para incentivar o desenvolvimento desse setor estratégico para a economia brasileira.

\section{4. \\ Delimitação do estudo}

O presente estudo foi realizado junto a empresas de software brasileiras que se internacionalizaram. Não se pretendeu analisar a atuação de empresas de outros países, ou de empresas multinacionais atuantes no país

Por sua vez, as lentes teóricas escolhidas para a análise do fenômeno em estudo provêm dos campos de estudos de Empreendedorismo Internacional e da Teoria de Redes. Assim, o foco da análise realizada encontra-se nas redes do empreendedor e da firma utilizadas no decorrer do processo de internacionalização, não havendo preocupação em estudar outros tipos de redes de que a empresa ou o empreendedor porventura participem. 


\section{2 \\ Revisão de literatura}

A revisão de literatura está organizada em cinco seções. A primeira-descreve o método utilizado para a revisão da literatura e para a obtenção das variáveis identificadas nas entrevistas. A segunda seção inicia a revisão de literatura com uma breve descrição do campo de estudo de Empreendedorismo Internacional (EI), dentro do qual se enquadra o presente estudo. A terceira seção aborda a literatura sobre o papel das redes na internacionalização das empresas. A quarta seção revisa as teorias de Capital Social mais fortemente relacionadas à área de administração e mais especificamente inerentes aos aspectos que podem influenciar as decisões de internacionalização de uma empresa. Por fim, a quinta seção resume os resultados da revisão de literatura pertinentes ao esquema conceitual do presente estudo, com a convergência dos temas de Internacionalização e Capital Social.

\section{1.} Método de pesquisa bibliográfica

O referencial teórico adotado no presente estudo envolve dois temas principais: Empreendedorismo Internacional e Capital Social. Para realizar a busca do referencial teórico relevante ao tema de Empreendedorismo Internacional, adotou-se o seguinte procedimento:

- Primeiro, foram identificadas revisões abrangentes da literatura de EI, que serviram como guia inicial para a identificação do referencial teórico relevante;

- Segundo, recorreu-se à seção de bibliografia do site da comunidade de acadêmicos do campo de EI chamado ie-scholars (ie-scholars.net), que possui um banco extenso de artigos publicados entre 2010 e $2014 \mathrm{em}$ periódicos de relevância no tema de EI; 
- Terceiro, foram pesquisadas as bases de dados disponibilizadas pela PUC-Rio para a busca final, a partir de palavras-chave, de artigos em periódicos de 2014 em diante que pudessem não ter sido detectados pelos métodos anteriores.

No tema Capital Social, foram considerados o artigo de Payne, Moore, Griffis e Autry (2011), cobrindo o período de 1989 a 2008, e o de Carpenter, Li e Jiang (2012), que analisa as principais teorias, constructos, medidas e análises inerentes à literatura de Capital Social.

O processo de busca de literatura se iniciou, portanto, pela análise de quatro artigos recentes de revisão bibliográfica sobre os dois temas de interesse. Trabalhos contendo revisões bibliográficas permitem uma boa seleção de estudos por serem bastante abrangentes nos temas que se propõem revisar e por selecionarem os artigos em periódicos de relevância acadêmica.

No tema Empreendedorismo Internacional, as duas revisões consideradas foram a de Jones, Coviello e Tang (2011) que faz uma análise temática (de EI) e de ontologia do campo, cobrindo o período de 1989 a 2009, e a de Kiss, Danis e Cavusgil (2012) que revisa a literatura com foco em empresas de mercados emergentes. Na segunda revisão, pelas características do tema em si - mercados emergentes - poucos artigos foram encontrados em periódicos de fator de impacto alto, o que levou a uma das recomendações dos autores, de que sejam feitos mais estudos nesses países.

Alguns outros trabalhos de revisão bibliográfica também foram considerados, permitindo identificar artigos relevantes para construir o referencial teórico do presente estudo. A relação dos artigos de revisão usados pode ser vista no Quadro 2.1. 


\begin{tabular}{|c|c|c|c|c|}
\hline Autores & Periódico & Ano & $\begin{array}{l}\text { Fator de } \\
\text { Impacto }\end{array}$ & Título \\
\hline $\begin{array}{l}\text { Jones, } \\
\text { Coviello, } \\
\& \text { Tang }\end{array}$ & $\begin{array}{c}\text { Journal of } \\
\text { Business Venture }\end{array}$ & 2011 & 3,265 & $\begin{array}{l}\text { International entrepreneurship research } \\
\text { (1989-2009): A domain ontology and } \\
\text { thematic analysis }\end{array}$ \\
\hline $\begin{array}{l}\text { Kiss, } \\
\text { Danis, \& } \\
\text { Cavusgil }\end{array}$ & $\begin{array}{c}\text { Journal of } \\
\text { Business Venture }\end{array}$ & 2012 & 3,265 & $\begin{array}{l}\text { International entrepreneurship research } \\
\text { in emerging economies: A critical } \\
\text { review and research agenda }\end{array}$ \\
\hline $\begin{array}{l}\text { Peiris, } \\
\text { Akoorie, \& } \\
\text { Sinha }\end{array}$ & $\begin{array}{c}\text { Journal of } \\
\text { International } \\
\text { Entrepreneurship }\end{array}$ & 2012 & & $\begin{array}{l}\text { International entrepreneurship: A } \\
\text { critical analysis of studies in the past } \\
\text { two decades and future directions for } \\
\text { research }\end{array}$ \\
\hline $\begin{array}{l}\text { Gedajlovic } \\
\text {, Honig, } \\
\text { Moore, } \\
\text { Payne \& } \\
\text { Wright }\end{array}$ & $\begin{array}{l}\text { Entrepreneurship } \\
\text { Theory and } \\
\text { Practice }\end{array}$ & 2013 & 2,598 & $\begin{array}{l}\text { Social Capital and Entrepreneurship: A } \\
\text { Schema and Research Agenda }\end{array}$ \\
\hline $\begin{array}{l}\text { Carpenter, } \\
\text { Li \& Jiang }\end{array}$ & $\begin{array}{c}\text { Journal of } \\
\text { Management }\end{array}$ & 2012 & 6,862 & $\begin{array}{l}\text { Social Network Research in } \\
\text { Organizational Contexts: A systematic } \\
\text { review of methodological issues and } \\
\text { choices }\end{array}$ \\
\hline $\begin{array}{l}\text { Payne, } \\
\text { Moore, } \\
\text { Griffis \& } \\
\text { Autry }\end{array}$ & $\begin{array}{c}\text { Journal of } \\
\text { Management }\end{array}$ & 2011 & 6,862 & $\begin{array}{l}\text { Multilevel challenges and } \\
\text { opportunities in Social Capital } \\
\text { research. }\end{array}$ \\
\hline $\begin{array}{l}\text { Borgatti \& } \\
\text { Halgin }\end{array}$ & $\begin{array}{l}\text { Organization } \\
\text { Science }\end{array}$ & 2011 & 3,807 & On Network Theory \\
\hline $\begin{array}{l}\text { Borgatti \& } \\
\text { Foster }\end{array}$ & $\begin{array}{c}\text { Journal of } \\
\text { Management }\end{array}$ & 2003 & 6,862 & $\begin{array}{l}\text { The network paradigm in } \\
\text { organizational research: a review and } \\
\text { Typology }\end{array}$ \\
\hline $\begin{array}{l}\text { Hoang \& } \\
\text { Antonic }\end{array}$ & $\begin{array}{c}\text { Journal of } \\
\text { Business Venture }\end{array}$ & 2003 & 3,265 & $\begin{array}{l}\text { Network-based research in } \\
\text { entrepreneurship: A critical review }\end{array}$ \\
\hline $\begin{array}{l}\text { Mainela, } \\
\text { Puhakka \& } \\
\text { Servais }\end{array}$ & $\begin{array}{l}\text { International } \\
\text { Journal of } \\
\text { Management } \\
\text { Reviews } \\
\end{array}$ & 2014 & 2,673 & $\begin{array}{l}\text { The Concept of International } \\
\text { Opportunities in International } \\
\text { Entrepreneurship: A Review and a } \\
\text { Research Agenda }\end{array}$ \\
\hline
\end{tabular}

Os artigos publicados entre 2010 e 2012 listados na bibliografia do site iescholars foram selecionados utilizando os mesmo critérios usados na revisão bibliográfica realizada por Jones et al. (2011). Os critérios de exclusão adotados na busca foram:

- Estudos focados em pequenas e médias empresas (PMEs) e não em EI (onde questões e teorias sobre empreendedorismo não são endereçadas no artigo);

- Artigos cujo foco não é EI (por exemplo, quando o foco é em inovação tecnológica);

- Estudos focados em empreendedorismo doméstico;

- Estudos em empreendedorismo transnacional ou de imigração. 
Os artigos publicados em 2013 e 2014 contidos nesta lista foram obtidos a partir do Journal of International Entrepreneurship (único periódico totalmente devotado a Empreendedorismo Internacional) e em periódicos IE-friendly com fator de impacto, medido em 2013, acima de 1 (ver Quadro 2.2), também utilizando os critérios de exclusão de Jones et al. (2011).

A seleção dos artigos a partir da bibliografia anteriormente descrita foi feita com base na análise dos resumos. Todos os artigos que apresentavam as palavraschave "rede", "rede social" e "capital social" foram selecionados.

\begin{tabular}{|c|c|}
\hline \multicolumn{2}{|c|}{$\begin{array}{l}\text { Revistas Científicas com Temas de EI com Fator de Impacto em } 5 \text { Anos } \\
\qquad(2013)>=1\end{array}$} \\
\hline Academy of Management Journal & AMJ \\
\hline Academy of Management Review & AMR \\
\hline Entrepreneurship \& Regional Development & ERD \\
\hline Entrepreneurship Theory \& Practice & ETP \\
\hline Industrial Marketing Management & IMM \\
\hline International Business Review & IBR \\
\hline International Entrepreneurship Management Journal & IEMJ \\
\hline International Journal of Management Reviews & IJMR \\
\hline International Marketing Review & IMR \\
\hline International Small Business Journal & ISBJ \\
\hline Journal of Business Research & JBR \\
\hline Journal of Business Venturing & JBV \\
\hline Journal of International Entrepreneurship & JIEN \\
\hline Journal of International Business Studies & JIBS \\
\hline Journal of International Management & JIMgt \\
\hline Journal of International Marketing & JIM \\
\hline Journal of Management & JoM \\
\hline Journal of Small Business Management & JSBM \\
\hline Journal of World Business & JWB \\
\hline Management International Review & MIR \\
\hline Small Business Economics & SBE \\
\hline Strategic Entrepreneurship Journal & SEJ \\
\hline Strategic Management Journal & SMJ \\
\hline
\end{tabular}

Para a seleção dos artigos mais recentes - a partir de 2014 - foram feitas buscas nos seguintes periódicos: AMJ, AMR, ETP, IBR, IMR, JBV, JIEN, JIBS, JoM e SMJ por artigos a partir de 2014 usando "capital social", "rede social", e "empreendedorismo internacional" como palavras-chaves. 


\section{2.}

\section{O campo de empreendedorismo internacional}

\subsection{1.}

\section{Evolução do campo}

O campo de Empreendedorismo Internacional nasceu baseado no pressuposto de que algumas mudanças na economia global originaram o aparecimento de empresas, mesmo pequenas, com orientação eminentemente global (OVIATT \& MCDOUGALL, 1994). De fato, com o avanço da tecnologia, especialmente dos transportes e da comunicação global, informações sobre outros países e culturas estão a um clique de qualquer cidadão, de países emergentes a desenvolvidos. Mesmo as tradições mais "exóticas", se comparadas ao padrão ocidental, tornaram-se familiares, sendo os países pertencentes a tais culturas tão visitados quanto os destinos turísticos ocidentais mais comuns do século XX. Da mesma forma, a redução do custo de transportes e comunicações facilitou a realização de negócios internacionais por pequenas empresas. Ao mesmo tempo, assistiu-se, no início dos anos 1980, a crescente abertura dos mercados com redução de políticas protecionistas, possibilitando que pequenas empresas almejassem atingir mercados antes impensáveis.

Por tais motivos, e também pela globalização da economia, pelas mudanças tecnológicas, pelo fortalecimento dos países emergentes com grandes contingentes populacionais, Empreendedorismo Internacional tem sido um tema muito explorado nas duas últimas décadas (COVIELLO \& MUNRO, 1995, 1997; KEUPP \& GASSMANN, 2009; KISS, DANIS, \& CAVUSGIL, 2012; OVIATT \& MCDOUGALL, 1994, 1997, 2000, 2005; SCHWENS \& KABST, 2009; ZAHRA, 2005).

Apesar de Empreendedorismo e Negócios Internacionais serem temas reconhecidos tanto no meio acadêmico quanto no meio empresarial, durante muito tempo não havia convergência desses campos. Pesquisas sobre Negócios Internacionais focavam multinacionais estabelecidas e as de Empreendedorismo buscavam entender o comportamento das pequenas empresas no mercado doméstico (MCDOUGALL \& OVIATT, 2000). 
O campo de Empreendedorismo Internacional teve início com o trabalho pioneiro de McDougall (1989), em que pequenas empresas jovens e internacionalizadas, denominadas de INVs (International New Ventures) faziam contraponto às DNVs (Domestic New Ventures). Pouco depois, um artigo publicado em revista da empresa de consultoria McKinsey (RENNIE, 1993), reconheceu o novo fenômeno - alcunhado de Born Global (BG) - em que pequenas e médias empresas australianas obtinham sucesso global praticamente desde sua criação.

Nos anos seguintes, grande quantidade de trabalhos acadêmicos, muitos deles empíricos, confirmaram a presença e a importância deste tipo de empresa em diversos países, embora primordialmente nos países desenvolvidos (COVIELLO \& MUNRO, 1995, 1997; OVIATT \& MCDOUGALL, 1994, 1995, 2000). Em artigo contemplando revisão de 25 anos de trabalhos publicados no Journal of International Business Studies, Wright e Ricks (1994) chamam atenção para uma nova área de pesquisa que surgia - Empreendedorismo Internacional fruto das mudanças advindas do novo ambiente global. Edições inteiramente dedicadas à internacionalização de empresas empreendedoras começaram a surgir a partir de 1991, como, por exemplo, nos periódicos Journal of Business Venturing e Entrepreneurship Theory and Practice. Reconhecendo o crescente interesse pelo assunto, em 2000 o periódico Academy of Management Journal lançou uma edição especial devotada à interseção dos campos de Negócios Internacionais e Empreendedorismo. O Quadro 2.3 apresenta uma lista das edições especiais sobre EI em periódicos de alto impacto, entre 1996 e 2009. 


\begin{tabular}{|ll|}
\hline \multicolumn{1}{|c|}{ Edições especiais } & \multicolumn{1}{c|}{ Ano } \\
\hline Entrepreneurship Theory \& Practice & 1996 e 2002 \\
\hline McGill International Entrepreneurship Conference Series & A partir de 1998 \\
\hline Journal of International Marketing & 1999 \\
\hline Academy of Management Journal & 2000 \\
\hline Journal of International Management & 2001 \\
\hline Entrepreneurial Theory \& Practice & 2002 \\
\hline Small Business Economics & 2003 \\
\hline Journal of International Entrepreneurship & A partir de 2003 \\
\hline Canadian Journal of Administrative Studies & 2005 \\
\hline Journal of International Business Studies & 2005 \\
\hline Management International Review & 2005 \\
\hline International Business Review & 2005 \\
\hline Small Business Economics & $2005 ; 2008$ \\
\hline International Marketing Review & 2006 \\
\hline Journal of World Business & 2007 \\
\hline Strategic Entrepreneurship Journal & 2009 \\
\hline
\end{tabular}

Quadro 2.3 - Lista de edições especiais sobre El (1996 a 2009)

Fonte: Extraído de Coviello, McDougall \& Oviatt, 2011, p.626

O campo de Empreendedorismo Internacional inicialmente se ateve exclusivamente a pequenas e jovens empresas, uma recorrência que pode ser justificada pelo fato de o artigo seminal de Oviatt e McDougall (1994) concentrar claramente seu foco em firmas recém-criadas, inclusive difundindo a nomenclatura INV. No entanto, os mesmos autores trataram EI de forma mais genérica em artigo posterior, publicado em 1997, ampliando o campo para incluir também empresas empreendedoras maduras (OVIATT \& MCDOUGALL, 1997). Além disso, recentemente, alguns estudos começaram a explorar EI de forma mais abrangente, deixando de focar exclusivamente empresas pequenas e jovens (DIMITRATOS \& PLAKOYIANNAKI, 2003; MAINELA, PERNU, \& PUHAKKA, 2011; MCDONALD et al., 2003; OVIATT \& MCDOUGALL, 2005), reconhecendo que atividades empreendedoras fazem parte de um processo contínuo, com a particularidade de que, em EI, tais atividades atravessam fronteiras (ZAHRA \& GEORGE, 2002). 
Por ser um campo multidisciplinar e complexo, várias áreas de interesse vêm sendo analisadas em EI, destacando-se as diferenças culturais, modos de entrada, identificação de oportunidades internacionais (DIMITRATOS \& JONES, 2005), gerenciamento do risco, inovação, uso de redes de relacionamento ou de negócios, alianças, características, experiência internacional e motivações dos empreendedores (MAINELA et al., 2011; MCDOUGALL \& OVIATT, 2000; OVIATT \& MCDOUGALL, 1997), dentre muitas outras.

Como reforçam Dimitratos e Jones (2005), há grande concentração de estudos sobre firmas de determinado tipo e tamanho (as BGs e as INVs), esquecendo-se das firmas maduras e de médio e grande porte, que também se aventuram em mercados internacionais com atitudes empreendedoras. Os autores afirmam haver ainda bastante oportunidade de pesquisa para o avanço do campo de Empreendedorismo Internacional, abrindo os horizontes de seus modelos para outros setores e padrões de empresas, explorando as diversas facetas de empreendedorismo, como por exemplo, propriedades da organização, do empreendedor, do mercado e do ambiente internacional (ETEMAD, 2004).

Alguns estudos ressaltam a importância do capital social da liderança da empresa (WESTHEAD, WRIGHT, \& UCBASARAN, 2001), dentre outros atributos como capacitação e orientação para internacionalização, apontados na revisão de artigos feita por Jones, Coviello, e Tang (2011).

Esta revisão, compreendendo 323 artigos de EI publicados no período de 1989 a 2009 (JONES, COVIELLO, \& TANG, 2011), identificou os principais temas abordados nesses artigos, classificando-os em três tipos: (i) internacionalização de firmas empreendedoras (69\%); (ii) comparações internacionais de empreendedorismo (24\%); e (iii) comparações de internacionalizações de firmas empreendedoras (7\%). Os resultados (Figura 1) apontaram como principais tipos de pesquisa as de internacionalização de firmas empreendedoras - e, dentre estes, destacam-se os temas relativos à internacionalização, com $43 \%$, e ao tipo de empreendimento com $24 \%$. Redes e Capital Social aparecem em apenas $9 \%$ do total de 323 artigos selecionados, sendo que os primeiros artigos a tratar desse tema surgiram em 1995. Ao final desta revisão, os autores sugerem que mais estudos comparem empresas jovens e maduras, pequenas e grandes, para melhor entendimento dos aspectos relevantes de EI. 


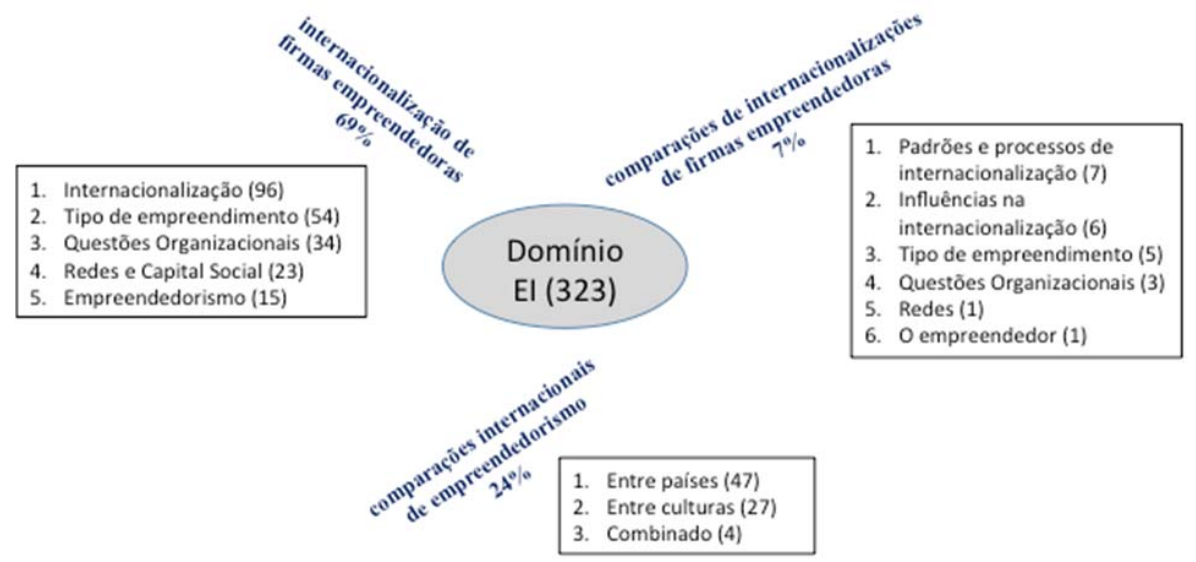

Figura 1 - Mapa temático do campo de Empreendedorismo Internacional Fonte: Adaptado de Jones, Coviello \& Tang, 2011, p. 636.

\subsection{2.}

\section{Conceitos básicos}

\subsubsection{1. \\ Empreendedorismo internacional}

Em decorrência da complexidade do campo de EI, que congrega conceitos pertinentes a diversos campos de estudos, tais como economia, marketing, negócios internacionais e empreendedorismo, dentre outros, várias definições para o fenômeno foram propostas desde as primeiras publicações. A seguir são apresentadas algumas das principais mudanças na definição do conceito de Empreendedorismo Internacional ao longo de seu desenvolvimento.

Alguns autores referenciam o artigo de McDougall (1989) como sendo o precursor em definir EI, embora critiquem a exclusão das firmas maduras do conceito (JONES \& COVIELLO, 2011; MCDOUGALL \& OVIATT, 2000). Em 1994, uma pesquisa sobre tendências no campo de Negócios Internacionais apontou pela primeira vez o quanto Empreendedorismo Internacional passaria a ser importante no cenário global. Segundo os autores,

“...até pequenas firmas estão entrando no reino dos negócios internacionais; e o sucesso, mesmo para empreendedores com orientação doméstica, é função de suas habilidades de serem competitivos internacionalmente ainda que evitem competir em muitos lugares” (Wright \& Ricks, 1994, p.688). 
Tal tentativa de definição do sucesso da internacionalização do empreendimento conflita com a visão de McDougall (1989), que identificou a intenção de internacionalizar desde a criação do empreendimento como a principal característica das empresas INVs, embora não identificando se a intenção era fruto da seleção de um setor da indústria globalmente competitivo ou se em decorrência da orientação internacional da firma.

Embasados em relatórios de estudos em vários países (UNCTAD, 1993; OECD, 1997) que apontaram o surgimento de um padrão de internacionalização menos incremental, Oviatt e McDougall (1997) desafiaram os conceitos estabelecidos nas teorias processuais de internacionalização (Johanson \& Vahlne, 1977, 1990), afirmando que mudanças nas características do mercado estavam gerando um novo comportamento nas empresas que se internacionalizavam. No entanto, e por ser um tema tão recente, várias perguntas ainda deveriam ser colocadas e verificadas. Algumas questões relativas à operacionalização do conceito foram levantadas, atreladas a possíveis soluções para a investigação do fenômeno das INVs, tais como: (i) estabelecer como uma firma pode ser considerada internacional (total de vendas geradas de países estrangeiros, em quantos países a firma opera, estruturas organizacionais, etc.) e (ii) determinar qual o tempo desde a criação até a primeira internacionalização para considerar a empresa uma INV. Para a primeira questão, os autores sugerem o uso de percentual de vendas e, para a segunda, decidem que seis anos é um prazo adequado.

Em 2000, McDougall e Oviatt, ao introduzirem o Fórum Especial de EI do Academy of Management Journal, constataram que necessitavam modificar sua definição de 1997. Suas principais conclusões foram as de que o tamanho e a idade das empresas não deveriam mais ser consideradas e que o comportamento empreendedor pode ocorrer em nível individual, em grupo ou organizacional.

Após a nova definição de McDougall e Oviatt (2000, p. 903) - "uma combinação de comportamentos inovadores, proativos e de busca pelo risco que atravessa fronteiras nacionais e tem a intenção de criar valor para as organizações" - ainda surgiram outros estudos que buscaram acrescentar novas dimensões ao conceito de Empreendedorismo Internacional. Assim, Zahra e George (2002) contribuem trazendo o foco apenas para o processo de internacionalização, ignorando o comportamento empreendedor. Outra visão 
adiciona componentes organizacionais às definições até então descritas, tais como propensão ao aprendizado, orientação à rede, orientação ao mercado estrangeiro e motivação, conferindo um caráter mais holístico às atividades empreendedoras de internacionalização da firma (DIMITRATOS \& PLAKOYIANNAKI, 2003).

$\mathrm{Na}$ busca por fundir os conceitos de empreendedorismo e internacionalização, Jones e Coviello (2005) compararam as literaturas dos dois campos, encontrando convergências, como, por exemplo, nos estudos de internacionalização que abordam o Capital Social e que focam o papel do empreendedor, ao perseguir oportunidades, e nos estudos de empreendedorismo que enfatizam o papel do empreendedor como participante de sua rede de relacionamento.

Por fim, um estudo que identifica outras dimensões no conceito de empreendedorismo (SHANE \& VENKATARAMAN, 2000) influenciou na expansão da definição de EI, que passou a abranger também os conceitos de oportunidade e criação de novas organizações, enfatizando a atividade empreendedora que atravessa fronteiras nacionais (OVIATT \& MCDOUGALL, 2005).

Um resumo com as diversas definições de Empreendedorismo Internacional é apresentado no Quadro 2.4.

\begin{tabular}{|c|c|c|c|}
\hline Ano & Autor & Definição & p. \\
\hline 1989 & McDougall & $\begin{array}{l}\text { "Desenvolvimento de INVs ou start-ups que desde sua } \\
\text { criação, se engajam em negócios internacionais. As } \\
\text { INV’s veem seus domínios operacionais como } \\
\text { internacionais desde o início da operação da firma". }\end{array}$ & 388 \\
\hline 1993 & Zahra & $\begin{array}{l}\text { "O estudo da natureza e consequências do } \\
\text { comportamento de risco de uma firma que se lança } \\
\text { em mercados internacionais". }\end{array}$ & \\
\hline 1994 & Wright \& Ricks & $\begin{array}{l}\text { "Pequenas firmas entrando no reino dos negócios } \\
\text { internacionais, como função de suas habilidades de } \\
\text { serem competitivas internacionalmente mesmo } \\
\text { evitando competir em muitos lugares". }\end{array}$ & 699 \\
\hline 1997 & $\begin{array}{l}\text { Oviatt \& } \\
\text { McDougall }\end{array}$ & $\begin{array}{l}\text { "Atividades novas e inovadoras que têm como objetivo } \\
\text { de criar valor e crescimento em organizações de } \\
\text { negócios além das fronteiras nacionais". }\end{array}$ & 293 \\
\hline 2000 & $\begin{array}{l}\text { McDougall \& } \\
\text { Oviatt }\end{array}$ & $\begin{array}{l}\text { "Uma combinação de comportamentos inovadores, } \\
\text { proativos e de busca pelo risco que atravessa } \\
\text { fronteiras nacionais e tem a intenção de criar valor } \\
\text { para as organizações". }\end{array}$ & 903 \\
\hline 2002 & $\begin{array}{l}\text { Zahra \& } \\
\text { George }\end{array}$ & $\begin{array}{l}\text { "O processo de descobrir e explorar criativamente } \\
\text { oportunidades que estejam fora do mercado } \\
\text { doméstico da firma, com objetivo de gerar vantagem } \\
\text { competitiva". }\end{array}$ & 262 \\
\hline
\end{tabular}




\begin{tabular}{|l|l|l|l|}
\hline 2003 & $\begin{array}{l}\text { Dimitratos \& } \\
\text { Plakoyiannaki }\end{array}$ & $\begin{array}{l}\text { "Processo no âmbito da organização que está inserido } \\
\text { na cultura organizacional da firma e que busca gerar } \\
\text { valor por meio da exploração de oportunidades no } \\
\text { mercado internacional". }\end{array}$ & 189 \\
\hline 2005 & $\begin{array}{l}\text { Oviatt \& } \\
\text { McDougall }\end{array}$ & $\begin{array}{l}\text { "É a descoberta, o enactment (sanção, decreto?), } \\
\text { avaliação e exploração de oportunidades - além de } \\
\text { fronteiras nacionais - para criar serviços e bens } \\
\text { futuros". }\end{array}$ & 540 \\
\hline 2009 & $\begin{array}{l}\text { Coombs, } \\
\text { Sadrieh \& } \\
\text { Annavarjula }\end{array}$ & $\begin{array}{l}\text { "Processo pelo qual mercados internacionais são } \\
\text { usados na descoberta, criação e/ou exploração de } \\
\text { bens e serviços futuros". }\end{array}$ & 26 \\
\hline
\end{tabular}

Quadro 2.4 - Principais definições de Empreendedorismo Internacional

Fonte: própria

\subsubsection{2.}

\section{Firma empreendedora}

O tema Empreendedorismo ganhou maior relevância a partir da década de 1980, especialmente em função da explosão de empresas do tipo start-ups (MCDOUGALL, 1989). Durante muitos anos, as tentativas de definir o que seria uma firma empreendedora foram se sucedendo, porém sem sucesso em obter consenso (MCDOUGALL \& OVIATT, 2000). No entanto, pode-se perceber convergência em relação a algumas dimensões características da firma empreendedora e/ou do empreendedor, como inovação, pro atividade, comportamento de risco, busca agressiva de oportunidades, dentre outras (MCDOUGALL, 1989; OVIATT \& MCDOUGALL, 2005).

Mintzberg (1973) definiu uma organização empreendedora como uma forma organizacional simples, com uma única unidade operacional, com um ou poucos indivíduos como líderes. Um estudo empírico sobre orientação empreendedora e orientação ao mercado com empresas de Ghana identificou e selecionou as firmas empreendedoras usando como critérios: (i) que a firma fosse independente - não ser parte de uma cadeia ou grupo; (ii) controlada por indivíduos (ou um time de indivíduos) empreendedores; e (iii) com entre 5 e 500 empregados em tempo integral (BOSO, STORY, \& CADOGAN, 2013).

Embora muitos estudos sobre empreendedorismo estejam voltados para empresas pequenas, nas duas últimas décadas o conceito de empreendedorismo apresentou diversos enfoques, tais como a criação e a implementação de oportunidades independentemente dos recursos atuais (TIMMONS, 1994, apud KEUPP \& GASSMANN, 2009); a renovação e a inovação dentro e fora de organizações (SHARMA \& CHRISMAN, 1999); o ato de descobrir, avaliar e explorar oportunidades (DIMITRATOS \& JONES, 2005; HITT, IRELAND, 
CAMP \& SEXTON, 2001; MAINELA et al., 2011; MATHEWS \& ZANDER, 2007; SHANE \& VENKATARAMAN, 2000); a criação de novos produtos, processos e mercados (DAILY, MCDOUGALL, COVIN \& DALTON, 2002) e o surgimento de uma nova atividade econômica (WIKLUND, DAVIDSSON, AUDRESTSCH, \& KARLSSON, 2011) .

No campo de estudos de Empreendedorismo inicialmente as pesquisas focavam as atitudes dos empreendedores. De fato, estudos sobre internacionalização mostram que as decisões sobre internacionalização adotadas pelas empresas são fortemente influenciadas pela mente de seus dirigentes e suas percepções com relação ao mundo. Líderes que apresentam características mais abertas, e que percebem suas empresas competindo em um ambiente global e não apenas doméstico, tendem a optar pela internacionalização em suas decisões estratégicas (ROCHA \& SILVA, 2009).

Abordagens "românticas" do empreendedor, como, por exemplo, aquele que tem o desejo de ser bem-sucedido, de criar uma dinastia, de se mostrar superior, de estar alerta a oportunidades foram descritas na literatura econômica (CASSON, 2005). Dessa última característica, a de estar alerta a novas oportunidades, deriva o grande interesse em examinar como tais oportunidades são descobertas, avaliadas e exploradas e eventualmente transformadas em firmas empreendedoras (VENKATARAMAN, 1997).

Shane e Venkataraman (2000, p.218) propuseram um arcabouço conceitual para as pesquisas em Empreendedorismo, que até então se voltavam apenas para empresas pequenas ou recém-criadas. Segundo os autores:

“...três questões são o foco das pesquisas sobre Empreendedorismo em Administração: (i) porque, quando e como oportunidades para a criação de bens $e$ serviços acontecem; (ii) porque, quando e como algumas pessoas e não outras descobrem e exploram as oportunidades; e (iii) porque, quando e como modos diferentes de ação são usados para explorar oportunidades empreendedoras."

Os autores afirmam que as características que diferenciam os indivíduos empreendedores de outros não são estáticas, e sim situacionais. Igualmente argumentam a favor da ideia de que o empreendedorismo também está presente dentro das organizações, ou seja, não necessariamente o ato de empreender está atrelado à criação de uma nova organização (SHANE \& VENKATARAMAN, 2000). 
Vários estudos apontaram o empreendedor como um insaciável usuário de sua rede - tanto a rede pessoal quanto a de negócios - no reconhecimento de oportunidades que eventualmente originam novas oportunidades (por exemplo, COVIELLO \& MUNRO, 1995, 1997; JOHANSON \& VAHLNE, 2009; MAINELA et al., 2011; SCHWEIZER, VAHLNE \& JOHANSON, 2010). O reconhecimento de oportunidades nos estudos de empreendedorismo tem recebido muita atenção dos acadêmicos, abarcando tanto os aspectos racionais quanto os intuitivos utilizados pelos empreendedores (JOHANSON \& VAHLNE, 2009). Um estudo abrangente sobre pesquisas em oportunidades internacionais revelou que um dos principais determinantes de identificação de oportunidades é a rede, com diversos exemplos de estudos empíricos que identificaram a importância de o empreendedor fazer parte de uma rede para o processo de reconhecimento de oportunidade (MAINELA, PUHAKKA, \& SERVAIS, 2014).

Os próprios criadores do campo Empreendedorismo Internacional (MCDOUGALL \& OVIATT, 2000) são responsáveis por acoplar as características de uma orientação empreendedora - inovadora, proativa e busca por risco (COVIN \& SLEVIN, 1989) - ao conceito de firma internacionalizada, ou seja, aquela que apresenta atividades que atravessam fronteiras. Na nova conceituação, internacionalização aparece como um processo do comportamento empreendedor e não é mais caracterizada em função do tamanho e da idade das empresas.

2.3.

Redes na internacionalização da empresa

A entrada de uma firma em mercados internacionais tende a levá-las a construir uma rede, constituída por parceiros, fornecedores, clientes, e até por novos competidores. Da mesma forma, tal empreitada coloca a firma diante de novas culturas, novos mercados, novos princípios de inovação, desafios que the permitem adquirir novos conhecimentos, expandindo horizontes e aumentando sua capacitação para lidar tanto com os mercados externos quanto com o doméstico (ZAHRA, HAYTON, MARCEL, \& O’NEILL, 2001). 
Uma pesquisa empírica buscando analisar os mais importantes relacionamentos com clientes de 85 firmas suecas com operações internacionais (BLANKENBURG \& JOHANSON, 1992) chegou à conclusão de que as firmas se inserem em redes além das suas fronteiras, enfatizando a necessidade de mais estudos sobre como as empresas gerenciam suas estruturas de rede externas (JOHANSON \& VAHLNE, 2011).

Rede de negócios pode ser definida como o conjunto de relacionamentos de negócios conectados, englobando dois conceitos principais: os relacionamentos de negócio - trocas entre firmas que interagem comercialmente - e os relacionamentos conectados - relacionamentos interdependentes entre si. (ANDERSON, HAKANSSON \& JOHANSON, 1994; JOHANSON \& VAHLNE, 2011). O processo de formação da rede de negócios se inicia por trocas sociais que se manifestam de forma gradual, gerando aprendizado recíproco e paulatinamente aumentando a confiança mútua entre os participantes, que por fim se comprometem a realizar trocas uns com os outros. (ANDERSON, HAKANSSON \& JOHANSON, 1994). Como consequência, à medida que as trocas vão se mostrando satisfatórias, cria-se uma interdependência, com laços mais fortes, trazendo segurança para futuras interações e a sensação de redução de riscos (JOHANSON \& VAHLNE, 2011).

Tal relação de interdependência, apesar de promover controle mútuo, pode também ter como consequência a perda de soberania, além do possível surgimento de unidades com poder nas organizações, já que controlam as redes internas conectadas às externas (JOHANSON \& VAHLNE, 2011). Essa visão assume que o processo de criação da rede de relacionamentos é fruto de uma ação recíproca entre conhecimento e comprometimento (JOHANSON \& VAHLNE, 2011).

Os relacionamentos também afetam o desenvolvimento de conhecimento dentro das organizações, podendo originar rotinas interdependentes nas organizações parceiras que atendam necessidades mútuas, transferir conhecimento e até mesmo gerar conhecimento novo e seu compartilhamento (COVIELLO \& MUNRO, 1997; GULATI, 1999; HOLMLUND \& KOCK, 1998; YLI-RENKO, AUTIO, \& SAPIENZA, 2001). 
Ao longo do tempo, o relacionamento se expande para outros pontos da rede, já que é pouco provável que as redes das firmas parceiras sejam exatamente as mesmas, e assim clientes e fornecedores pertencentes a uma segunda camada de relacionamentos passem a fazer parte da rede de relacionamentos da firma (JOHANSON \& MATSSON, 1987, 1988). Esse tipo de novo relacionamento pode ser estratégico, trazendo novas oportunidades em novas geografias ou países (FELZENSZTEIN, CIRAVEGNA, ROBSON \& AMORÓS, 2015), confirmando o conceito de vazio estrutural de Burt (1992). Como Johanson e Vahlne (2011, p. 487) concluíram:

"Neste contexto, é razoável considerar firmas principalmente como unidades de intercâmbio com uma estrutura de relacionamentos própria e única e não como unidades de produção, como está implícito na teoria microeconômica. Cada empresa tem também uma posição própria e única na rede com fortes implicações estratégicas”.

Como consequência da visão de rede de negócios, é presumível considerar que as redes surgem por meio das atividades de troca do dia a dia, podem ser menos ou mais fortemente estruturadas em termos de relacionamento e força do laço, como também podem ser mais ou menos estáveis ou dinâmicas. Como é difícil que as firmas de fora da rede tenham conhecimento sobre como os atores interagem, ou até mesmo quem são os atores, os autores concluem que aqueles que são membros estão em vantagem em relação àqueles que não o são em termos de conhecimento e desenvolvimento de conhecimento. Outra vantagem diz respeito à posição na rede, ou seja, os problemas de uma firma que se internacionaliza são menos relacionados com as especificidades de um país - o passivo de ser estrangeiro (liability of foreignness)- do que com as dificuldades de não pertencer a uma rede - o passivo decorrente de ser um estranho à rede (liability of outsidership) (JOHANSON \& VAHLNE, 2009, 2011).

As atividades de mercado fazem com que as empresas interajam continuamente, acumulando conhecimento, confiança e comprometimento entre si, fazendo com que surja uma rede de relacionamentos, em que cada firma estabelece sua posição. Tal posição, construída ao longo das diversas interações com as outras firmas da rede, vai definir as possibilidades e as restrições presentes e futuras da firma. Por esta perspectiva, a firma internacionalizada é aquela que estabelece e desenvolve posições em redes estrangeiras, seja por meio de extensão - quando a rede está presente em um novo país - por meio de penetração - 
quando a firma desenvolve e aumenta seu comprometimento em rede estrangeira na qual ela já faz parte - ou por meio de integração - quando aumenta a coordenação entre posições de redes de diferentes nacionalidades (Johanson \& Mattson, 1993). Os autores propõem uma classificação das empresas internacionalizadas de acordo com o modelo de redes, dependendo da situação de internacionalização do mercado comparado ao da empresa (Figura 2). Como o desenvolvimento das firmas depende de sua posição na rede, seus ativos são diferentes dependendo do grau de internacionalização, assim como as outras firmas da rede também possuem diferentes ativos, dependendo do grau de internacionalização do mercado.

\begin{tabular}{|c|c|c|c|}
\hline & & \multicolumn{2}{|c|}{$\begin{array}{l}\text { Grau de Internacionalização do mercado } \\
\text { (a rede de produção) }\end{array}$} \\
\hline & & Baixo & Alto \\
\hline \multirow{2}{*}{$\begin{array}{l}\text { Grau de } \\
\text { internacionalização } \\
\text { da firma }\end{array}$} & Baixo & The Early Starter & The Late Starter \\
\hline & Alto & The Lonely International & $\begin{array}{l}\text { The International } \\
\text { Among Others }\end{array}$ \\
\hline
\end{tabular}

Fonte: extraído de Johanson e Mattson (1993, p. 310).

\subsection{1.}

As redes no Modelo de Uppsala

\subsubsection{1.}

\section{O modelo original}

Uma das propostas mais reconhecidas sobre o fenômeno da internacionalização das empresas, o modelo de Uppsala, defende que o processo ocorre de forma gradual e dinâmica. O envolvimento da empresa que se internacionaliza no país estrangeiro escolhido vai aumentando gradualmente, geralmente iniciando-se com a simples exportação e muitas vezes finalizando com a implantação de unidades fabris no país em questão (JOHANSON \& VAHLNE, 1977). 
O processo de internacionalização descrito pelos autores engloba um caminho (Figura 3) em que o grau de comprometimento da empresa com os mercados externos aumentava gradativamente (JOHANSON \& WIEDERSHEIMPAUL, 1975; JOHANSEN \& VAHLNE, 1977, 1990).

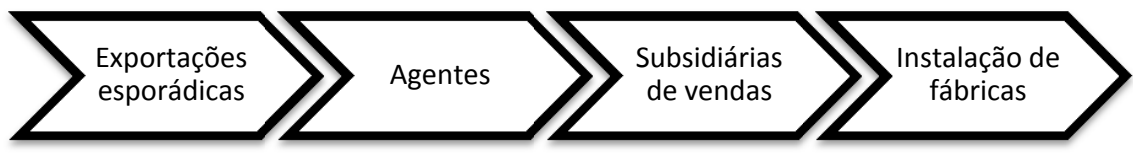

Figura 3 - Esquema representando os passos trilhados por empresas que se internacionalizam, segundo Johanson e Vahlne.

Fonte: Johanson e Vahlne (1977).

Este processo é consequência da incerteza oriunda da dificuldade de se obter informações sobre o mercado estrangeiro e encontra-se associado a mudanças que fazem com que as decisões se moldem às transformações do mercado e da empresa. As escolhas iniciais são então fruto de uma percepção de menor risco, associada à distância psíquica, definida pelos autores como o conjunto de obstáculos que dificultam a comunicação entre o vendedor, sediado no país exportador, e o comprador, no país de destino. Fatores como idioma, cultura, práticas de negócios, leis, entre outros, diminuem ou aumentam a percepção da distância psíquica ao país estrangeiro no qual a firma pretende investir (JOHANSON \& VAHLNE, 1977).

O processo gradual é justificado por Johanson e Vahlne (1977) pelo fato de que não se pode ser bem-sucedido internacionalmente sem o aprendizado sobre cada país estrangeiro em que a firma pretende operar, e que tal aprendizado só é alcançado por meio da implantação de operações nos mercados. Assim, continuamente, a cada sucesso e a cada passo no conhecimento das particularidades dos diferentes mercados, o empresário se sente melhor preparado para arriscar em outras regiões desconhecidas.

O modelo criado por Johanson e Vahlne, em 1977, apresenta um "mecanismo básico de internacionalização" (Figura 4), que se caracteriza pela simplicidade e pelo caráter dinâmico. 


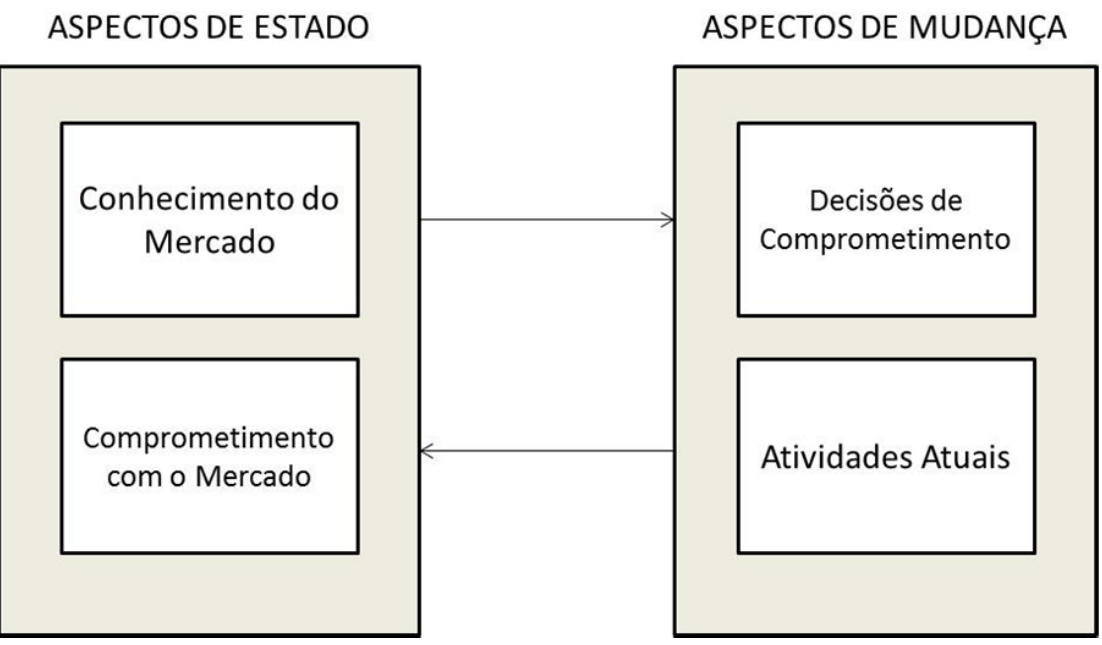

Figura 4 - Mecanismo Básico de Internacionalização no Modelo de Uppsala original Fonte: Johanson e Vahlne (1977, p. 26).

A ideia do modelo é a de um ciclo de causa e efeito, em que o comprometimento de recursos com os mercados externos e o conhecimento do mercado estrangeiro são modificados pelas decisões de comprometimento e pelos resultados das operações, ao mesmo tempo que as influenciam (JOHANSON \& VAHLNE, 1990).

\subsubsection{2.}

\section{O modelo revisado}

Em meados dos anos 1990, alguns estudos questionaram a proposta do modelo de Uppsala como o único caminho para a internacionalização, surgindo algumas evidências de que a rede de relacionamentos teria maior peso na decisão do país a ingressar do que as similaridades culturais ou linguísticas (BELL, 1995; COVIELLO \& MUNRO, 1997; JOHANSON \& VAHLNE, 2003).

Desafiando o postulado da distância psíquica, Arenius (2005) comparou a distância psíquica com a velocidade de entrada em mercados estrangeiros. Os resultados do estudo sugerem que a escolha do país pode não ser influenciada pela distância psíquica e que a velocidade de penetração em mercados externos pode ser aumentada caso a firma possua uma rede de relacionamentos relevante no mercado almejado. Supõe-se que tal rede ajude a diminuir as deficiências e vulnerabilidades decorrentes de a firma ser estrangeira, fenômeno conhecido como liability of foreignness. 
Em resposta aos questionamentos com relação à aplicabilidade do modelo de Uppsala às novas tendências de internacionalização, Johanson e Vahlne (2003) introduzem modificações substanciais no modelo original (Figura 5). Eles observam a importância das redes de relacionamento nas pesquisas de empresas que se internacionalizam cedo, mas confirmam a relevância do aprendizado através da experiência e sua relação com os resultados obtidos pela empresa, criando então um modelo unindo os dois conceitos.

No modelo revisado, as duas variáveis - conhecimento e comprometimento - não dizem mais respeito ao mercado a ser explorado (país), mas sim aos parceiros do negócio. Toda firma tem uma rede de relacionamentos de negócio, desenvolvida no longo prazo, que aumenta o conhecimento que parceiros têm sobre as necessidades, estratégias e recursos mútuos, de forma que a ampliação desse conhecimento também aumenta o comprometimento com o relacionamento (JOHANSON \& VAHLNE, 2003).

Para entender melhor o modelo desenvolvido, é necessário entender o conceito de rede de negócios usado pelos autores. Para eles, "rede de negócios é um conjunto de relacionamentos de negócios interconectados, nos quais cada troca de relações ocorre entre empresas, definidas como atores coletivos" (JOHANSON \& VAHLNE, 2003, p. 92). Todas as firmas estão conectadas a um conjunto finito de relacionamentos comerciais que, por sua vez, têm relacionamentos com outras empresas e, portanto, toda firma faz parte de uma rede de negócios sem fronteiras.

Posteriormente, Johanson e Vahlne (2009) questionam a importância da distância psíquica, colocando o conceito do "ser de fora" (outsider) em relação à rede (em contraponto ao "ser estrangeiro") como sendo fator importante com relação às incertezas que a decisão de internacionalização traz consigo. Os autores concluem que pertencer às redes consideradas relevantes é fator imprescindível para o sucesso de uma estratégia de internacionalização. Daí decorre o uso, pelos autores, do termo liability of outsidership, em contraposição a liability of foreignness. Para se tornar parte da rede, a firma deverá alavancar os relacionamentos pessoais ou de negócios já existentes ou promover a criação de parcerias (ROCHA, MELLO, DIB, \& MACULAN, 2005). 
No modelo de Uppsala revisado, a internacionalização passa a ser um resultado das diversas ações impetradas pela empresa com o objetivo de assegurar posições nas redes relevantes de seu interesse (JOHANSON \& VAHLNE, 2003, 2009). Como resultado, as relações de negócio da firma têm papel preponderante sobre a decisão de em que mercado e de que modo irão penetrar no novo ambiente.

As principais diferenças entre as duas versões do Modelo de Uppsala (o de 1977 e o de 2009) estão centradas no conceito de redes de relacionamento. O termo Oportunidade, significando a busca por oportunidades, passou a ser considerado a parte mais importante da variável Conhecimento, já presente no modelo anterior, mas que agora admite os conceitos de capacitação e recursos dos outros participantes da rede. Quanto maior o conhecimento entre os participantes da rede, mais forte é o relacionamento entre os mesmos (SCHWEIZER et al., 2010).

Ainda no conjunto de variáveis fixas, surge o atributo Posição na Rede, substituindo Comprometimento com o Mercado, fortalecendo a ideia de que o processo de internacionalização ocorre dentro de uma rede (JOHANSON \& VAHLNE, 2009) e que as empresas que se encontram bem posicionadas na estrutura da rede usufruirão dos benefícios dela oriundos (SCHWEIZER et al., 2010).

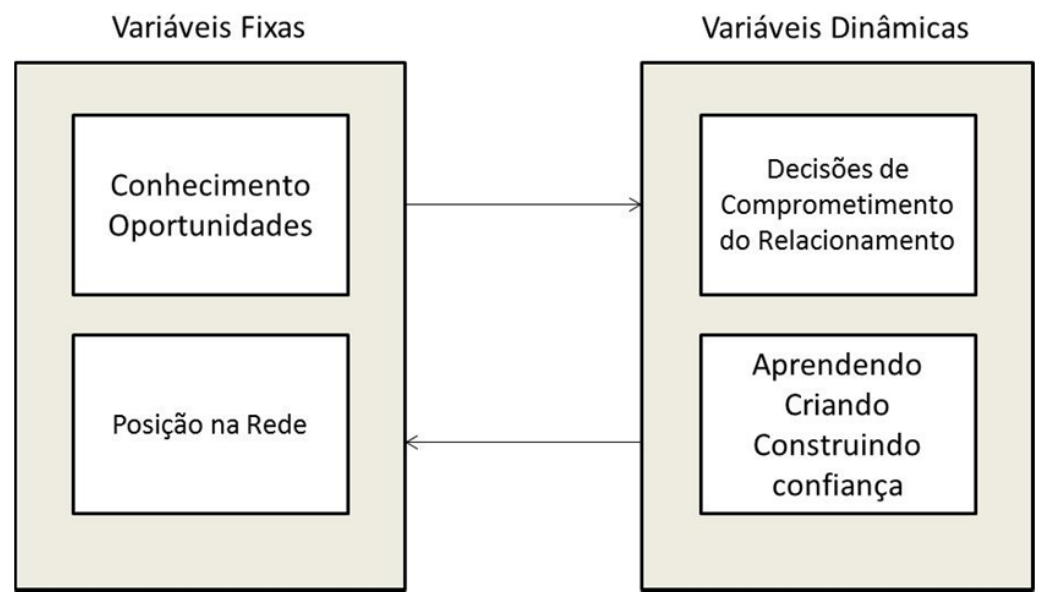

Figura 5 - O modelo do processo de internacionalização de Redes de Negócio. Fonte: Johanson e Vahlne (2009). 
No quadrante de variáveis dinâmicas, os autores enfatizaram Construção de Confiança e Criação de Oportunidades, entendendo que quanto maior o conhecimento, a confiança e o comprometimento entre as partes, mais criativo e eficaz se tornam os processos gerados na parceria. Outra adaptação do modelo foi a associação do relacionamento das redes ao comprometimento, sugerindo que o último pode influenciar as decisões de construção de novos negócios, assim como assegurar a estabilidade de relacionamentos estratégicos da empresa (JOHANSON \& VAHLNE, 2009).

\subsection{2.}

\section{Outras contribuições à internacionalização por redes}

Um dos tópicos mais estudados desde o final dos anos $1990 \mathrm{em}$ Empreendedorismo Internacional tem sido a influência das redes formais e informais no processo de internacionalização das pequenas empresas. Em 1995, Bell introduziu a questão ao desafiar a "teoria de estágios". Segundo o autor, o estudo do processo de internacionalização das empresas estava centrado no modelo proposto pela Escola de Uppsala em 1977, que postulava um processo gradual de aumento de comprometimento da empresa com o mercado internacional e que se iniciava em mercados mais próximos em termos de distância psíquica, avançando gradativamente para mercados psiquicamente mais distantes (JOHANSON \& VAHLNE, 1977; JOHANSON \& WIEDERSHEIMPAUL, 1975). Tal visão era compartilhada com diversos autores, reforçando a característica de estágios nos processos de internacionalização (Figura 6) (BELL, 1995). 


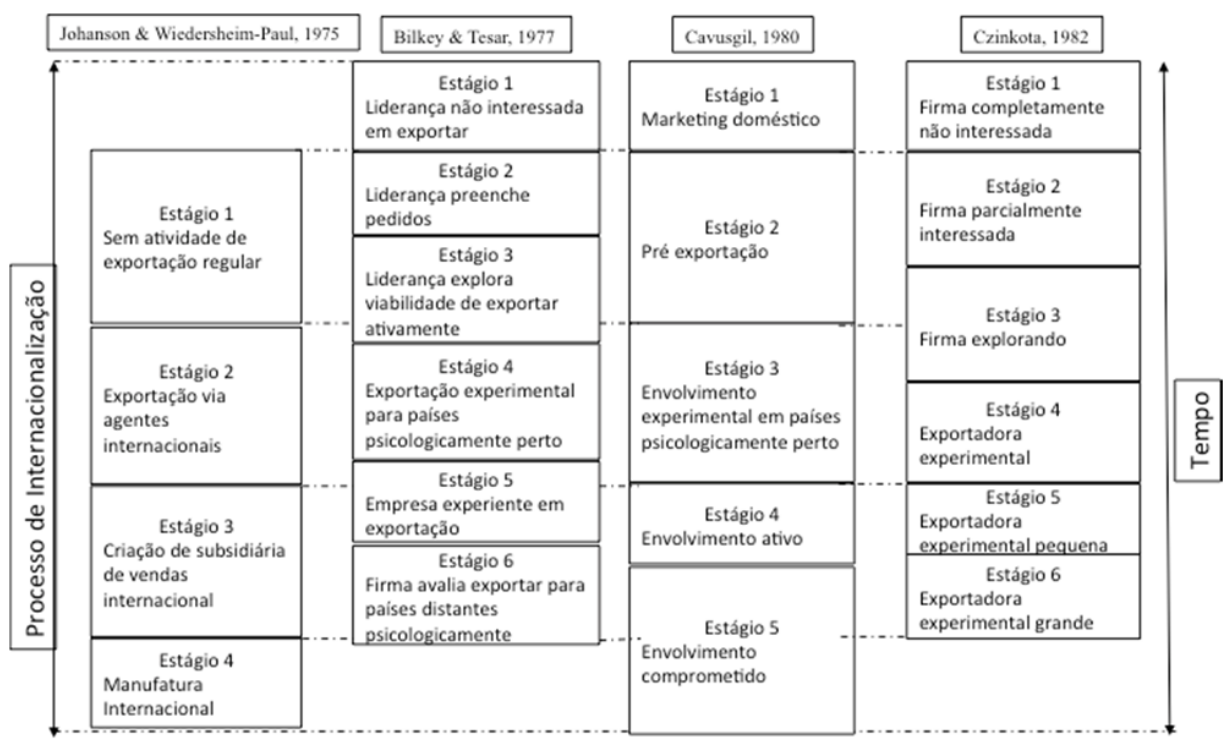

Figura 6 - Comparação de quatro modelos de internacionalização por estágios Fonte: Bell, 1995, p.61

No entanto, surgiram algumas críticas ao modelo, especialmente em relação ao fator "distância psíquica", que passou a não ser tão relevante diante do avanço da tecnologia das comunicações e dos transportes, e mais recentemente da globalização (BELL, 1995). Notadamente em relação às empresas de serviço e às de tecnologia, com seus altos custos de P\&D e curto ciclo de vida de seus produtos, a teoria de estágios não se apresentava adequada para explicar seus processos de internacionalização. $\mathrm{O}$ autor afirma que:

“...há uma grande limitação nas teorias de estágio ao usarem modelos lineares para tentarem explicar comportamentos complexos, dinâmicos, interativos $e$ frequentemente não lineares e que abordagens de redes parecem mais apropriadas" (BELL, 1995, p. 72).

Outros estudos questionaram a proposta dos modelos de estágio como o único caminho para a internacionalização. Shenkar (2001), por exemplo, argumentou que algumas vezes a distância cultural pode, inclusive, se apresentar como vantagem competitiva para a empresa que inicia negócios em outro país. Também alguns estudos mostraram situações em que a rede de relacionamentos tinha maior peso na decisão do país a ingressar do que as similaridades culturais ou linguísticas (BELL, 1995; COVIELLO \& MUNRO, 1997; CRICK \& SPENCE, 2005; JOHANSON \& VAHLNE, 2003). 
De fato, um estudo empírico conduzido por Coviello e Munro (1995), mostrou que $64 \%$ das firmas pesquisadas (pequenas firmas de software da Nova Zelândia) iniciaram atividades internacionais de maneira passiva, por meio de contatos pertencentes a redes pessoais ou de negócios. Os autores concluíram que:

“...os processos de internacionalização de pequenas empresas de software refletem uma versão acelerada do modelo de estágios, sendo guiados, facilitados e inibidos por um conjunto de relacionamentos de redes formais e informais" (COVIELLO \& MUNRO, 1997, p. 361).

No estudo, que analisou quatro firmas de software neozelandesas, os autores sugerem que, pelo menos para pequenas empresas de software, um novo quadro integrando a internacionalização por estágios com os conceitos de rede de relacionamentos poderia melhor representar seus processos de internacionalização. Com base em tais conclusões, os autores criaram um novo modelo em que os processos relativos às redes se inserem nos estágios de internacionalização (Figura 7). O modelo reflete uma visão mais ampla do processo de internacionalização de pequenas empresas (no caso, de software), pois alia o conceito de rede - onde atividades de internacionalização emergem a partir de uma rede externa de relacionamentos - ao conceito de internacionalização gradual - caracterizado pela capacidade de aprendizagem da empresa, em direta relação com a confiança e experiência adquiridas pelos executivos.

Assim, o uso de redes de relacionamento se mostra relevante no processo de internacionalização, facilitando a aquisição de conhecimento para exploração de vantagem competitiva (YLI-RENKO, AUTIO \& SAPIENZA, 2001), interferindo no aprendizado em termos de modos de entrada, dos novos mercados abarcados além dos novos relacionamentos criados ao longo dos movimentos de internacionalização da firma (COVIELLO \& MUNRO, 1997; HOLMLUND \& KOCK, 1998). CRICK E SPENCE (2005), em outro artigo empírico, encontraram quatro de 12 empresas de alta tecnologia que tiveram como estímulo para o início da internacionalização o uso de sua rede de contatos, além de outras cinco que iniciaram por meio de encontros fortuitos ou de redes de novos executivos contratados. 


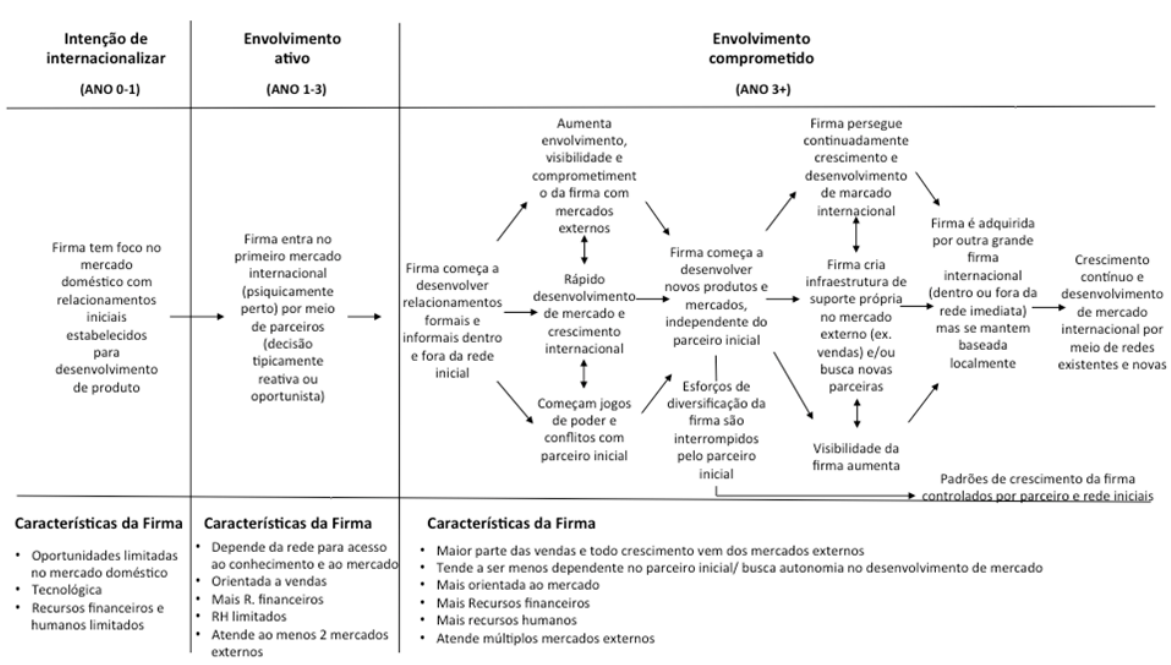

Figura 7 - Padrões de crescimento, Influências da rede e características da firma no processo de internacionalização de pequenas empresas de software Fonte: Coviello \& Munro, 1977, pág. 380.

Schwens e Kabst (2011) conduziram uma pesquisa com 248 firmas alemãs encontrando alguma convergência entre a teoria processual e a teoria de INVs, ou seja, concluíram que as empresas de tecnologia se internacionalizam de maneira proativa, porém por meio de processo sistemático e enfatizam a importância do conhecimento ou da familiaridade com o mercado externo. Os autores promovem uma análise comparativa entre as duas teorias, em que se percebem complementaridades das duas abordagens (Quadro 2.5).

\begin{tabular}{|c|c|c|}
\hline & $\begin{array}{l}\text { Teorias de Processo de } \\
\text { Internacionalização }\end{array}$ & Teoria de INVs \\
\hline Pergunta da pesquisa & $\begin{array}{l}\text { Por que a internacionalização se ocorre de } \\
\text { forma incremental? }\end{array}$ & $\begin{array}{c}\text { Como é possível que as empresas se aventurar em } \\
\text { mercados estrangeiros já desde o início? }\end{array}$ \\
\hline Origem empírica & $\begin{array}{l}\text { Firmas de manufatura suecas nos anos } \\
\qquad 1970 \text { s }\end{array}$ & $\begin{array}{l}\text { Firmas intensivas em conhecimento dos anos } \\
1990 \mathrm{~s}\end{array}$ \\
\hline Foco principal & $\begin{array}{c}\text { Enfatiza restrições à } \\
\text { internacionalização na fase pós-entrada } \\
\text { (por exemplo. distância psíquica }\end{array}$ & $\begin{array}{l}\text { Enfatiza facilitadores para } \\
\text { internacionalizar-se na fase de pré-entrada } \\
\text { (por exemplo, redes) }\end{array}$ \\
\hline Papel do conhecimento & $\begin{array}{c}\text { Conhecimento sobre Internacionalização é } \\
\text { adquirido de forma gradual e de } \\
\text { experiências próprias feitas no mercado } \\
\text { externo }\end{array}$ & $\begin{array}{l}\text { Conhecimento é enraizada no indivíduo } \\
\text { através de experiência internacional anterior } \\
\text { da equipe de gestão ou adquirido através de } \\
\text { mecanismos alternativos, como redes }\end{array}$ \\
\hline $\begin{array}{l}\text { Padrão de } \\
\text { internacionalização }\end{array}$ & $\begin{array}{l}\text { Visão processual: reativa, incrementa, } \\
\text { aumento gradual }\end{array}$ & Visão empreendedora: rápida, proativa, arriscada \\
\hline $\begin{array}{l}\text { Reguladores chave de } \\
\text { internacionalização }\end{array}$ & $\begin{array}{l}\text { Aprendizado experimental e contextual } \\
\text { vindo de experiências próprias feitas no } \\
\text { mercado externo }\end{array}$ & $\begin{array}{l}\text { Estruturas de governança alternativas como redes } \\
\text { e interação com agentes do mercado externo }\end{array}$ \\
\hline
\end{tabular}

Quadro 2.5 - Duas visões da internacionalização

Fonte: Schwens \& Kabst, 2011, p. 62. 
Existem dois tipos de estudos que investigam o papel das redes de relacionamento nas pequenas empresas: aqueles que tentam entender como a utilização das redes de relacionamento beneficia as empresas e aqueles que tentam identificar como o processo empreendedor influencia a formação das redes (HOANG \& ANTONCIC, 2003).

Em uma revisão da literatura sobre internacionalização de INVs, Evers (2011) organizou um resumo dos artigos relevantes publicados, considerando o objetivo do estudo e os fatores que influenciaram a internacionalização da firma jovem. Nele, a presença da rede ou, no mínimo, a constatação de que o empreendedor tem alguma experiência internacional, aparece em nove de 19 artigos examinados, confirmando a importância que a rede de relacionamentos exerce sobre a decisão de internacionalizar, especialmente entre empresas empreendedoras.

Verifica-se, portanto, que diversos estudos mostram o quanto a rede de contatos do empreendedor pode ajudar a superar as dificuldades encontradas. As pequenas empresas normalmente sofrem com escassez de recursos, aspecto que se agrava quando iniciam um processo de crescimento, seja doméstico, ou, mais ainda, internacional.

"As redes de relacionamento afetam as relações formais e informais e
compreendem relacionamentos que os empreendedores constroem com
profissionais de negócio e oficiais do governo, assim como aqueles que ele possui
com amigos e familiares" (KISS \& DANIS, 2008, p. 390).

\subsection{3.}

Redes e mercados de destino

É de se supor que diferenças entre os países de origem da firma e os países de destino tenham forte influência sobre a estratégia adotada para internacionalização (KISS \& DANIS, 2008), afetando a própria escolha do país, o modo de entrada, o nível de adaptação dos produtos, dentre muitos outros fatores.

Tais diferenças vêm sendo caracterizadas por meio de diferentes construtos na literatura de Negócios Internacionais, tais como o conceito de distância psíquica (JOHANSON \& VAHLNE, 1977), o estágio de desenvolvimento do mercado (emergentes, em transição ou desenvolvidos), ou ainda as condições institucionais de cada país (DANIS, DE CLERCQ, \& PETRICEVIC, 2011), entre outros. 
Um estudo empírico com 210 empresas chinesas oriundas de Hong Kong e Beijing (TANG, 2011) encontrou diferenças no uso das redes por empresas das duas cidades, apesar de grande similaridade cultural e étnica entre as duas regiões: enquanto em Beijing estabelecer relacionamento pessoais e institucionais era comum, em Hong Kong, onde tradicionalmente as PMEs têm pouco suporte do governo, não havia muito incentivo para estabelecer redes de relacionamento com canais institucionais formais. Tais variações ocorrem não apenas em decorrência de diferenças culturais, mas principalmente em razão de diferenças no ambiente institucional e de negócios (PENG, WANG, \& JIANG, 2008).

Outro estudo empírico usando uma base de dados de 637 empreendedores de quatro países diferentes concluiu que possuir uma rede maior em países com nível institucional baixo gera um efeito positivo no crescimento da receita de suas empresas (BATJARGAL, HITT, TSUI, ARREGLE, WEBB, \& MILLER, 2013).

Alguns estudos empíricos mostraram que nos países emergentes, as redes de relacionamento exercem ainda mais influência nas atividades de novos negócios das firmas, especialmente das pequenas (DANIS, DE CLERCQ \& PETRICEVIC, 2011), e em particular nos países de origem latina e asiáticos, em que predominam culturas relacionais (DIB, ROCHA, \& SILVA, 2010). Além disso, há também pesquisas que apontam para o uso de redes de relacionamento como forma de compensação para alcance de novos mercados em países com ambiente institucional de baixa eficiência (DANIS et al., 2011; KISS, DANIS, \& CAVUSGIL, 2012; PENG \& LUO, 2000).

Países com ambiente institucional pouco desenvolvido oferecem maiores desafios para empresas estrangeiras que queiram iniciar negócios em seu mercado. Leis, regulamentações e políticas governamentais podem ser um bom ou mau suporte aos negócios. Daí deriva a maior ou menor importância das relações interpessoais no comportamento dos empreendedores, ao buscarem novos mercados (KISS \& DANIS, 2008).

Ao analisar o processo de internacionalização de empresas, tanto os aspectos institucionais do país de origem quanto os dos países de destino podem ser fatores de impacto. Por exemplo, o nível de desenvolvimento institucional de um país pode sugerir que as redes de relacionamento dos pequenos empreendedores sejam formadas em sua maioria por redes de laços fortes ou fracos (KISS \& DANIS, 2008). 
É, portanto, fácil argumentar que as redes facilitam encontrar oportunidades porque países com baixa qualidade institucional não costumam ter políticas de internacionalização claras, também não geram facilidades para identificação de setores e oportunidades mais vantajosas para o país. Além disso, o fato de ser indicado por alguém que já conhece o país de destino, diminui a percepção do empreendedor quanto ao risco e aumenta o conhecimento sobre os possíveis passos burocráticos a seguir para se estabelecer no país. (KISS \& DANIS, 2008)

No entanto, como o presente estudo pretende analisar apenas empresas brasileiras, o foco de análise do impacto de diferentes níveis institucionais se refere apenas aos países de destino.

\section{4. \\ Capital social}

“A proposição central da Teoria de Capital Social é que redes de relacionamentos constituem um recurso de valor para a condução de questões sociais, disponibilizando aos membros da rede o capital 'coletivo, uma 'credencial', que dá direito a crédito, em diversos sentidos da palavra” (BOURDIEU, 1986, p. 246).

\subsection{1.}

\section{Definições de capital social}

Tem sido relativamente comum no campo de Ciências Sociais e Humanas a busca pelo entendimento de como as relações sociais podem afetar o comportamento e as instituições (GRANOVETTER, 1985). O termo Capital Social surgiu em estudos sobre comunidades geográficas, abarcou outras áreas de interesse, como por exemplo os estudos sobre a influência das relações familiares e de grupos sociais sobre os indivíduos, e se firmou nas pesquisas sobre a firma e seu desempenho (NAHAPIET \& GHOSHAL, 1998).

Em artigo de revisão de 20 anos de publicações (1989 a 2008) sobre o tema Capital Social em pesquisas de negócios, Payne et al. (2011) avaliam que o avanço do conceito de Capital Social foi inibido em decorrência das diversas conceituações e dos múltiplos níveis de análise (individual, equipe, organização e indústria) empregados. Alguns autores utilizam perspectivas macro, outros micro e ainda alguns usam ambas as abordagens (ADLER \& KWON, 2002). Como exemplos, têm-se desde as definições que abrangem os efeitos da rede na coordenação e cooperação em organizações (PUTNAM, 1995), até definições que 
buscam explicar a obtenção de oportunidades por meio de relações dos indivíduos, tais como amigos e familiares (BURT, 1992).

Payne et al. (2011) concluem que as diferenças são acentuadas tanto em relação à origem do Capital Social quanto em relação ao papel do Capital Social na influência dos resultados alcançados pelas empresas. Nos 109 artigos selecionados, sendo 80 empíricos e 29 teóricos, os autores encontraram grande diversidade de definições e de operacionalizações, além de sete diferentes perspectivas teóricas, como pode ser visto no Quadro 2.6.

Alguns estudos centram suas questões nos antecedentes enquanto outros nas implicações das redes e seu impacto nas organizações, em variáveis tais como desempenho, expansão, internacionalização e outras (CHONG \& GIBBONS, 1997; KILDUFF \& BRASS, 2010; NAHAPIET \& GHOSHAL, 1998; UZZI, 1997; WALKER, KOGUT \& SHAN, 1997).

\begin{tabular}{|c|c|c|}
\hline Perspectiva Teórica & $\begin{array}{l}\# \\
\text { artigos }\end{array}$ & Exemplos de operacionalização \\
\hline $\begin{array}{l}\text { Bridging of structure holes } \\
\text { Burt }(1982,1992,1997,2000)\end{array}$ & 30 & $\begin{array}{l}\text { Network constraint (número de conexões redundantes) } \\
\text { Betweenness centrality (menor caminho entre dois nós de uma rede) }\end{array}$ \\
\hline $\begin{array}{l}\text { Strong ties e Network closure } \\
\text { Coleman }(1988,1990)\end{array}$ & 28 & $\begin{array}{l}\text { Matriz de filiação entre atores } \\
\text { Soma de forças de laço dividido pelo total possivel }\end{array}$ \\
\hline $\begin{array}{l}\text { Embeddedness } \\
\text { Granovetter (1985); Uzzi }(1996,1997)\end{array}$ & 17 & $\begin{array}{l}\text { Agregado de laços de negócios } \\
\text { Histórico de trocas prévias }\end{array}$ \\
\hline $\begin{array}{l}\text { Teoria do recursos social } \\
\text { Lin (1999, 2001, 2002); Lin, Ensel \& Vaughn (1981); Lin, } \\
\text { Vaughn \& Ensel (1981) }\end{array}$ & 13 & $\begin{array}{l}\text { Soma de ligações pessoais e de negócio } \\
\text { Acesso a informações e recursos }\end{array}$ \\
\hline $\begin{array}{l}\text { Força dos laços fracos } \\
\text { Granovetter (1973) }\end{array}$ & 9 & $\begin{array}{l}\text { Número de laços } \\
\text { Laços fortes vs fracos }\end{array}$ \\
\hline $\begin{array}{l}\text { Múltiplas dimensões do Capital Social } \\
\text { Nahapiet \& Ghoshal (1998) }\end{array}$ & 8 & $\begin{array}{l}\text { Entrevistas abertas para avaliar extensão das redes - estrutural (frequência, } \\
\text { intensidade), relacional (normas, contratos) e cognitiva (metas, motivadores) } \\
\text { Dimensões do Capital Social } \\
\text { Itens de survey capturando dimensões estruturais, relacionais e cognitivas }\end{array}$ \\
\hline $\begin{array}{l}\text { Modelo de Capital Social } \\
\text { Adler \& Kwon (2002) }\end{array}$ & 5 & $\begin{array}{l}\text { Capital Social interno - densidade de laços, centralidade } \\
\text { Capital Social externo - laços embeddeded com stakeholders externos }\end{array}$ \\
\hline
\end{tabular}

Quadro 2.6 - Perspectivas teóricas e operacionalizações do construto Capital Social Fonte: Payne, Moore, Griffis \& Autry, 2011, p.498.

Segundo Payne et al. (2011), Capital Social refere-se aos recursos derivados de relacionamentos sociais, sendo então importante entender as estruturas das redes de relacionamentos (as ego-networks) nas quais indivíduos e organizações estão inseridos, antes de discorrer sobre as diversas conceituações de Capital Social encontradas na literatura. 
Ego-networks são redes construídas ao redor de indivíduos ou de firmas focais (ego), e todos os demais indivíduos conectados ao "ego" chamados de "alter". Existem as redes pessoais, as que têm um indivíduo na posição de "ego", e as redes de negócios, que são centradas em firmas (ARENIUS, 2002). Outras denominações também podem ser encontradas, como rede informal e formal, porém no presente estudo, usam-se os termos redes pessoais e redes de negócios.

Muitos estudos sobre Capital Social entendem que este conceito engloba tanto as redes de relacionamento quanto os recursos disponíveis nas redes (ADLER \& KWON, 2002). A rede também pode pertencer ao indivíduo ou a uma unidade social qualquer (ARENIUS, 2002), alcançando benefícios em nível individual ou tão amplos quanto uma sociedade inteira ou uma organização (LINDSTRAND, MELÉN, \& NORDMAN, 2011). As redes de relacionamento não raro são responsáveis por amenizar os riscos envolvidos, para as PMEs, em atividades tais como acesso a recursos e a oportunidades internacionais, superando as dificuldades inerentes à liability of foreignness (COVIELLO, 2006).

Para melhor classificar os artigos analisados em sua revisão, Payne et al. (2011) construíram uma tipologia, alocando as pesquisas sob a ótica de quatro perspectivas diferentes, associadas aos tipos de laços (internos ou externos) e ao Capital Social coletivo ou individual.

Seguindo tal tipologia (Figura 8), conclui-se que o foco de análise para o presente estudo melhor se enquadra no Quadrante 3, já que se pretende investigar os aspectos individuais do empreendedor ou da liderança executiva das empresas (Capital Social individual), explorando os laços externos e suas consequências no processo de internacionalização de pequenas empresas empreendedoras. 
Quadrante 1

ڤ Definição: Ativos e recursos disponíveis por meio de relações o indivíduo pode usar em seu benefício

Perspectiva dominante: Structure holes

Periódicos Dominantes: AMJ, OS

\section{Quadrante 3}

气 Definição: Ativos e recursos disponíveis por meio de relações sociais que tanto o indivíduo quanto a organização podem usar em seu benefício

త్త Perspectivas dominantes: Structure holes e Laços Fortes/ Rede Fechada

Periódico Dominante: ETP

Capital Social individual
Quadrante 2

Definição: Ativos e recursos disponíveis por meio de relacionamentos dentro da estrutura social da organização que pode ser usada pelo grupo

Perspectivas dominantes: Structure holes e Laços Fortes/ Rede Fechada

Periódico Dominante: AMJ

Quadrante 4

Definição: Ativos e recursos disponíveis para a organização por meio de laços sociais que alcançam outras organizações e por meio das quais o grupo pode se beneficiar.

Perspectivas dominantes: Laços Fortes/ Rede Fechada

Periódico Dominante: SMJ

Capital Social coletivo

Figura 8 - Tipologia de Estudos empíricos em Capital Social Fonte: adaptado de Payne et al., 2011, p.497.

Por ser um tema tão amplamente estudado em diversas áreas, também são encontradas várias teorias relacionadas a Capital Social, sendo as mais relevantes para o presente estudo descritas nas seções a seguir. Alguns conceitos importantes a respeito das redes foram desenvolvidos por diferentes escolas (e tratados em diversas teorias), a destacar os conceitos de "embeddedness", "closure", força dos laços e vazios estruturais (structure holes), como se descreve adiante.

\subsection{2.}

\section{Principais teorias de capital social}

\subsubsection{1.}

\section{Teoria da Força dos Laços Fracos}

A criação de Capital Social pode ser analisada pelo viés das forças dos laços que compõem a rede. A Teoria da Força dos Laços Fracos (ou rede aberta), de Granovetter (1973), advoga que firmas com maior concentração de laços fracos têm vantagem sobre aquelas que mantêm relações fortes. Laços fracos permitem aumentar o escopo da rede, podendo trazer novas informações e recursos, pois executam o papel de pontes entre os diversos atores da rede. Além disso, requerem menos esforço e custo para serem mantidas, já que não exigem trocas e interações frequentes. A força dos laços reside na combinação de características 
como intimidade, quantidade de interações, tempo da relação e intensidade emocional. Laços fracos, aqueles que têm as características anteriormente descritas em menor grau, são normalmente oriundos de meros conhecidos, ou de firmas desconectadas (SHARMA \& BLOMSTERMO, 2003), enquanto que os laços fortes são os que primordialmente se constituem de amigos e familiares.

Portanto, uma das principais vantagens associadas aos laços fracos é a capacidade de transferência de conhecimento, já que é comum observar empresas muito interrelacionadas apresentarem base de conhecimento similar, ou seja, a troca entre as firmas normalmente é de pequena relevância. Em contrapartida, firmas que apresentam grande número de laços fracos em sua rede de relacionamentos têm mais facilidade de adaptação e são mais propensas a buscar novos conhecimentos, comona obtenção de informações sobre mercados externos durante seu processo de internacionalização ou na capacidade de avaliar novas oportunidades de forma mais frequente (SHARMA \& BLOMSTERMO, 2003).

\subsubsection{2. \\ Teoria de Vazios Estruturais (Structure Holes)}

A Teoria de vazios estruturais de Burt (1992) analisa o Capital Social com ênfase na estrutura da rede, ou seja, pela posição que componentes da rede têm uns em relação aos outros, ou para a relatividade da posição do "ego" em relação a seus "alters". Os espaços estruturais existem quando dois atores de uma rede não estão conectados. Apesar do indiscutível benefício usufruído por meio de redes que possuem grande número de laços, Burt argumentou que mais valioso ainda seria participar em redes mais abertas (aquelas que possuem vazios estruturais), pois permitiria acesso a informações não redundantes. Em outras palavras, uma firma focal ("ego") obtém mais benefício quanto maior o número de "alters" não interrelacionados encontrados em sua rede. Nesse caso, ter acesso ao que ele chamou de "brokers", ou seja, atores da rede que se encontram entre outros atores, permitiria maior acesso a informações que circulam entre tais espaços. Os brokers teriam a vantagem de construir pontes entre elos não conectados. A teoria enaltece o papel do broker como possuidor de Capital Social de valor, uma vez que conecta atores que não estariam conectados na rede, obtendo vantagens por meio de informação diversificada (BURT, 1992). 
Para esclarecer o conceito de vazios estruturais a Figura 9 ressalta as diferenças entre uma rede repleta de vazios estruturais e outra densa.

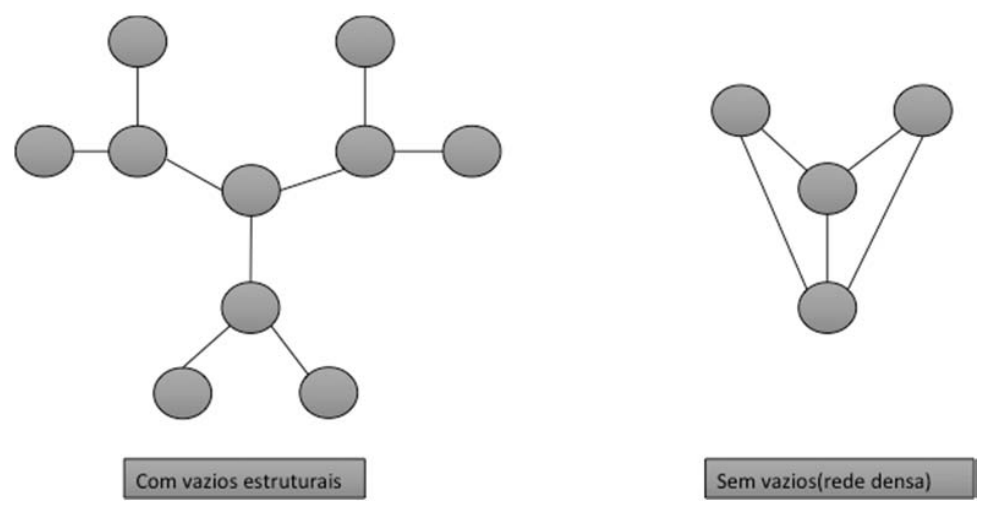

Figura 9 - Exemplos de rede com vazios estruturais vs. densa Fonte: Singh, 1998,p.70

\subsubsection{3.}

Teoria dos Laços Fortes e Rede Fechada (Network Closure)

Para Coleman (1990, p. 302), o Capital Social é "algum aspecto da estrutura social que facilita certas ações de indivíduos dentro da estrutura”. Capital Social pode ser entendido como uma variedade de diferentes entidades que têm duas características em comum: todas versam sobre algum aspecto de uma estrutura social e facilitam algumas ações de indivíduos que pertencem à estrutura. Portanto, um indivíduo pode mobilizar um relacionamento da estrutura social transformando em ações, tornando possível o alcance de determinados resultados que não seriam alcançados de outra forma.

Segundo Coleman (1990), são poucos os casos em que o Capital Social pode ser interpretado como um recurso criado como resultado direto de investimento com o objetivo de obter retorno. Para ele, algumas formas de Capital Social, como, por exemplo, a confiança, podem advir de experiências fortuitas sobre as quais o indivíduo teve pouco controle ou intenção.

No entanto, alguns autores entendem que o Capital Social não deve ser pensado como algo que surge de forma fortuita, como subproduto de outras atividades, e sim deve ser um recurso ativamente gerenciado e responsavelmente empregado (ARENIUS, 2002). 
O conceito de closure destaca uma importante característica das redes: quando o ego e seus alters se relacionam todos entre si, a rede é considerada coesa (COLEMAN, 1990). A rede coesa parece implicar na criação de normas e confiança, já que cada ator está ligado a outro por meio de laços fortes. Tal força faz gerar um alto nível de Capital Social relacional e cognitivo (COLEMAN, 1990; NAHAPIET \& GHOSHAL, 1998), incorporando a vantagem de relações menos oportunistas, mas também apresentando desvantagens como redução de inovação e aumento de redundância de informações (BON, 2015).

\subsubsection{4.}

\section{Teoria de recurso social}

Capital Social, aquele capturado por meio de relações sociais, é visto por Lin (2001, p. 19) como "um bem social, em virtude das ligações dos atores e do acesso aos recursos da rede ou do grupo dos quais são membros".

Recursos inseridos em redes de relacionamento trazem benefícios para os participantes de quatro diferentes formas, que explicam porque Capital Social pode aprimorar resultados: informações, influência, credenciais sociais e reforço de identidade (LIN, 2001). Informações podem ser estratégicas, por exemplo, na identificação de oportunidades, especialmente se o indivíduo ou firma possui laços sociais bem posicionados no mercado. Os laços sociais também podem exercer influência sobre atores que exerçam papeis críticos em decisões (em nível individual ou da empresa). As credenciais sociais permitem que indivíduos que tenham acesso a relações estratégicas sejam percebidos pelas organizações como uma provável fonte de obtenção de vantagens, além das que normalmente estariam acessíveis. E por fim, o reconhecimento e reforço de identidade, alcançado por aqueles que mantêm relações sociais, são benefícios que trazem apoio emocional (LIN, 2001).

Lin (2001) utiliza o conceito de Capital Social como parte do contexto da rede de relacionamento, ou seja, como um recurso acessível por meio de laços sociais a atores que ocupam locais estratégicos na rede ou posições importantes na organização. 


\subsubsection{5.}

\section{Teoria de Embeddedness}

Granovetter (1985) fez uma ampla crítica aos teóricos da época por tratarem a questão das relações sociais diante das ações econômicas humanas de duas formas antagônicas e extremas: enquanto os economistas argumentavam com conceitos "subsocializados" (p. 483), cientistas sociais usavam argumentos "supersocializados" (p. 483). Em sua visão, os atores econômicos não se comportam ou decidem fora de um contexto social (visão dos socialistas), tampouco aderem a um roteiro vinculado apenas à sua categoria social (visão dos economistas), porém a maioria das ações econômicas de tais atores (comportamentos e decisões, por exemplo) está inserida (embedded) em redes de relacionamentos interpessoais. Segundo Granoveter (1985) atores em contextos organizacionais estão fortemente inseridos em redes de relacionamentos interpessoais e, portanto, suas ações são inevitavelmente sujeitas às consequências de embeddedness da rede. Para o autor, embeddedness pode ser definida como as influências contextuais dos laços e redes de relacionamento nas ações dos participantes das redes.

Uzzi (1999, p. 482) definiu embeddedness como "o grau com que transações comerciais acontecem por meio de relações sociais e redes de relacionamento que usam protocolos de troca associados a acessórios sociais (não comerciais) para conduzir negócios". Segundo Uzzi (1999), laços embedded estão associados a relacionamentos pessoais, enquanto laços arm-length estão associados a relações de mercado. Aqui há um antagonismo entre os laços originados de relações pessoais, definidos como embedded, versus os originados de relações de trabalho (arm-length).

Um estudo etnográfico com 23 empresas empreendedoras (UZZI, 1997) concluiu que a rede embedded promove benefícios tais como economia de tempo e eficiência na alocação de recursos, porém tais benefícios crescem até um determinado patamar, a partir do qual os laços começam a impactar o desempenho econômico, à medida que, por exemplo, isolam as empresas de informações que residem fora de sua rede, reduzindo a capacidade inovadora da organização.

Carpenter, Li, e Jiang (2012) concluíram que Capital Social diz respeito às consequências das redes para os participantes e embeddedness refere-se aos mecanismos pelos quais tais consequências são concretizadas. 


\subsubsection{6.}

\section{Dimensões de capital social}

Nahapiet e Ghoshal (1998, p. 243) definiram Capital Social como "a soma dos recursos reais e potenciais inseridos, disponíveis e derivados de redes de relacionamento possuídas por um indivíduo ou por uma unidade social". Para os autores, há três diferentes dimensões que caracterizam o Capital Social: (i) relacional, (ii) cognitiva e (iii) estrutural.

A dimensão relacional faz referência aos ativos criados e alavancados por meio de relacionamentos baseados em confiança, normas, obrigações e identificação. Tal dimensão permite avaliar as relações que os diversos atores mantêm entre si, como amizade e respeito, diferenciando-os dos demais mesmo quando apresentam posição similar na estrutura da rede. A dimensão relacional é pautada nas características inerentes aos relacionamentos, como, por exemplo, quando duas partes confiam entre si e se permitem compartilhamento de informações ou recursos. A dimensão relacional envolve obrigações e expectativas assim como identificação entre os atores.

A dimensão cognitiva é representada por códigos, línguas e narrativas compartilhadas pelos diversos atores da rede. O Capital Social cognitivo facilita a comunicação entre os atores, ajudando a diminuir barreiras entre culturas diferentes reduzindo, por exemplo, os riscos inerentes aos avanços internacionais.

Por fim, a dimensão estrutural abrange o entendimento das conexões entre os atores da rede, ou seja, dos laços e como se organizam. Aspectos como a densidade dos laços, ou a hierarquia entre eles são avaliados nessa dimensão, permitindo análises sobre que tipos de laços trazem mais ou menos benefícios para as empresas e indivíduos.

Como conclusão, os autores sugerem que as firmas podem ter desempenhos diferentes causados por suas diferenças nas habilidades de criar e explorar Capital Social. Indo mais além, afirmam que, pelo menos em termos de capital intelectual, as firmas que desenvolvem melhor suas configurações de Capital Social são mais propensas ao sucesso (NAHAPIET \& GHOSHAL, 1998). 
2.4.2.7.

Modelo de capital social

Adler e Kwon (2002) identificaram diversas aplicações do conceito de Capital Social em estudos sobre organizações, surgindo como um poderoso fator para explicar o sucesso tanto dos indivíduos quanto das empresas em diferentes temas, tais como carreira, compensação, recrutamento, inovação, eficiência de equipes, empreendedorismo, aprendizado e formação de start-ups, dentre muitos outros.

Segundo os autores, a principal linha que norteia os estudos de Capital Social é a de que a boa vontade - que pode ser definida como simpatia, confiança e poder de perdão - que outros têm com terceiros pode ser considerada um recurso de valor, gerando alguns possíveis efeitos, como a disponibilidade de informação, a influência e a solidariedade. Em decorrência, o Capital Social depende da estrutura social em que os atores estão inseridos, sendo disponível em função da localização que o ator tem na estrutura de suas relações sociais (centralidade), por meio das quais favores e presentes são trocados.

Adler e Kwon (2002) constataram, em sua extensa revisão, que as várias definições de Capital Social se assemelhavam de forma ampla, porém com pequenas diferenças importantes. O Quadro 2.7 apresenta um subconjunto das definições enumeradas no referido artigo, contendo as mais compatíveis com o problema de pesquisa do presente estudo: a influência que o Capital Social de indivíduos exerce sobre o processo de internacionalização das empresas que lideram, e suas principais manifestações. 


\begin{tabular}{|c|c|c|}
\hline $\begin{array}{l}\text { Visão } \\
\text { externa ou } \\
\text { interna }\end{array}$ & Autores e ano & Definição \\
\hline \multirow[t]{3}{*}{ Externa } & $\begin{array}{l}\text { Belliveau, O’Reily \& } \\
\text { Wade 1985, p. } 248\end{array}$ & $\begin{array}{l}\text { "Afiliações institucionais de elite e rede pessoal } \\
\text { de um indivíduo" }\end{array}$ \\
\hline & Bordieu 1985, p. 243 & $\begin{array}{l}\text { "Feito de obrigações sociais (conexões) que são } \\
\text { conversíveis, sob certas condições, em capital } \\
\text { econômico e podem ser institucionalizados na } \\
\text { forma de um título de nobreza" }\end{array}$ \\
\hline & Burt, 1992, p. 9 & $\begin{array}{l}\text { "Amigos, colegas, e contatos mais genéricos, } \\
\text { por meio dos quais você recebe oportunidades } \\
\text { de usar seu capital humano e financeiro" }\end{array}$ \\
\hline Interna & $\begin{array}{c}\text { Coleman, 1990, p. } \\
302\end{array}$ & $\begin{array}{l}\text { "Capital Social é definido por sua função. Não é } \\
\text { apenas uma entidade única, mas uma variedade } \\
\text { de entidades que têm duas características em } \\
\text { comum: todos consistem de algum aspecto de } \\
\text { estrutura social e facilitam certas ações de } \\
\text { indivíduos que pertencem à estrutura" }\end{array}$ \\
\hline \multirow[t]{4}{*}{ Ambas } & Loury, 1992, p. 100 & $\begin{array}{l}\text { "Relacionamentos sociais que ocorrem de forma } \\
\text { natural entre pessoas que promovem ou assistem } \\
\text { na aquisição de competências e habilidades com } \\
\text { valor de mercado...um ativo que pode ser tão } \\
\text { significante quanto legados financeiros para a } \\
\text { manutenção da desigualdade na nossa } \\
\text { sociedade" }\end{array}$ \\
\hline & $\begin{array}{c}\text { Nahapiet \& Ghoshal, } \\
1998, \text { p. } 243\end{array}$ & $\begin{array}{l}\text { "A soma de recursos atuais e potenciais } \\
\text { inseridos, disponíveis e derivados da rede de } \\
\text { relacionamentos possuída por um indivíduo ou } \\
\text { por uma unidade social. Portanto, Capital Social } \\
\text { engloba tanto a rede quanto os ativos que podem } \\
\text { ser mobilizados por meio desta rede" }\end{array}$ \\
\hline & Pennar, 1997, p. 154 & $\begin{array}{l}\text { "A rede de relacionamentos sociais que } \\
\text { influenciam o comportamento individual entre } \\
\text { pessoas e, portanto, afetam o crescimento } \\
\text { econômico" }\end{array}$ \\
\hline & $\begin{array}{l}\text { Woolcock, 1998, p. } \\
153\end{array}$ & $\begin{array}{l}\text { "A informação, confiança e normas de } \\
\text { reciprocidade inerentes em uma rede social" }\end{array}$ \\
\hline
\end{tabular}

Dentre as diferenças ressaltadas pelos autores, a primeira a ser considerada diz respeito ao foco, que se apresenta de duas formas: (i) centrado nas fontes, nos efeitos, ou no conteúdo das redes; e (ii) centrado nas relações internas dentro de uma coletividade (bonding) ou em relações externas entre atores (bridging) (ADLER \& KWON, 2002). Nos estudos que exploram as relações externas,

“...o Capital Social explica o sucesso de indivíduos e firmas em sua rivalidade: os atos de indivíduos e grupos podem ser grandemente facilitados por suas ligações diretas $e$ indiretas a outros atores na rede social. " (ADLER \& KWON, 2002, p. 19). 
Nos estudos que exploram as relações internas, o foco recai nas características internas de atores coletivos,

“...o Capital Social de uma coletividade (organização, comunidade, nação, etc.) está menos nos laços externos coletivos a outros atores externos e mais nas estruturas internas - nas ligações entre indivíduos ou grupos dentro da coletividade, e especificamente naquelas que facilitam a busca por metas coletivas. " (ADLER \& KWON, 2002, p. 21).

Há ainda um terceiro grupo de definições, que se caracteriza pela neutralidade com relação à dimensão interna/externa, e que se justifica por duas principais razões:

“i) a distinção depende do referencial - as relações entre um empregado e colegas dentro de uma firma são externas em relação ao empregado e internas com relação à firma; ii) as dimensões não são mutuamente exclusivas - o comportamento de uma firma, por exemplo, é influenciado tanto pelas ligações externas com outras firmas quanto pelo tecido de suas ligações internas." (ADLER \& KWON, 2002, p. 21).

Por último, destaca-se a definição criada por Adler e Kwon (2002, p. 23), que se apresenta compatível com a visão interna e com a externa, permitindo que o Capital Social seja atribuído tanto ao ator individual quanto ao coletivo:

"Capital Social é a boa vontade disponível a indivíduos ou grupos. Suas fontes advêm da estrutura e do conteúdo das relações sociais do ator. Seus efeitos se manifestam na forma de informação, influência e solidariedade que se tornam disponíveis para o ator."

Apesar do consenso de que Capital Social deriva das relações sociais, os autores consideravam que ainda havia espaço para pesquisas que procurassem entender quais as fontes de Capital Social: quais os aspectos específicos das relações sociais que criam Capital Social? (Adler \& Kwon, 2002). Nas pesquisas que focam no entendimento de tais fontes e de seus papeis relativos, há duas linhas predominantes: i) quando a fonte do Capital Social está localizada na estrutura formal dos laços que constroem a rede de relacionamento, expondo a importância das características da estrutura tais como closure e vazios estruturais; e ii) quando a fonte de Capital Social está localizada no conteúdo dos laços, ou seja, nas normas e crenças compartilhadas, habilidades, amizade ou relação profissional. Diferentes tipos de laços, por exemplo, amizade versus laços de trabalho, produzem diferentes efeitos em seus usos. 
Os estudos empíricos que buscam entender o papel de tais estruturas e laços em diversas questões relacionadas às organizações se baseiam no conceito de apropriação dos laços sociais, ou seja, na constatação de que laços de um tipo podem ser usados com diferentes propósitos e que seus conteúdos podem ser conectados (ADLER \& KWON, 2002). Baseados em tal conceito, os autores propuseram um modelo onde evidenciam que oportunidade, motivação e habilidade são necessários para que um ator consiga acesso e use Capital Social, conforme visto na Figura 10.

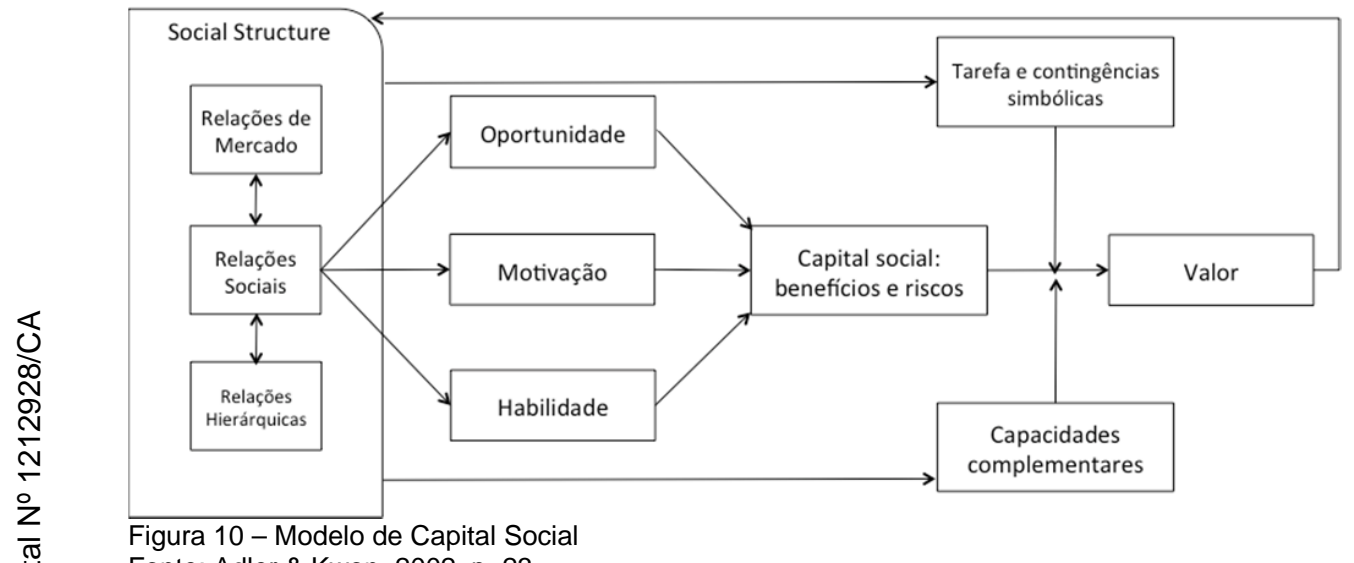

Fonte: Adler \& Kwon, 2002, p. 23.

Resumindo a discussão sobre as diversas definições, dimensões e aplicações do conceito de Capital Social, o presente estudo usa o conceito de Capital Social de Nahapiet e Ghoshal (1998, p. 243) que o definem como "a soma de recursos atuais e potenciais inseridos, disponíveis e derivados da rede de relacionamentos possuída por um indivíduo ou por uma unidade social. Portanto, Capital Social engloba tanto a rede quanto os ativos que podem ser mobilizados por meio desta rede".

Tal definição é feita em termos dos recursos e dos benefícios advindos das redes. Como o presente estudo pretende analisar o impacto do uso do Capital Social na internacionalização das empresas, a busca do entendimento sobre os benefícios advindos da rede parece ser a abordagem mais adequada.

Em síntese, as características das redes de relacionamento estudadas pelos teóricos de Capital Social dão as bases para a avaliação das manifestações deste capital nos processos de internacionalização das empresas de software brasileiras, objeto do presente estudo. 


\section{5 .}

\section{Capital social na internacionalização}

Diversos resultados positivos em relação ao processo de internacionalização de empresas foram encontrados na literatura relacionados ao uso do Capital Social, como, por exemplo, a velocidade da internacionalização (ARENIUS, 2005), a identificação de oportunidades (ARENIUS, 2002), a aceleração do aprendizado (JOHANSON \& VAHLNE, 2003; YLI-RENKO, AUTIO \& TONTTI, 2002), a busca por capital (BATJARGAL \& LIU, 2004) e como compensação pela "liability of foreignness" ou por deficiências institucionais (KISS \& DANIS, 2008; YLI-RENKO et al., 2001).

No Brasil, um país da América Latina, com uma sociedade com fortes características relacionais, alguns estudos afirmaram a importância do uso das redes no processo de internacionalização (veja por exemplo ROCHA, MELLO, DIB, \& MACULAN, 2005). Kiss et al. (2012) identificaram diversas lacunas em estudos sobre internacionalização na América Latina, contudo encontraram vários estudos sobre países da região onde as redes exerciam forte influência nas atividades iniciais de internacionalização. Como recomendação de pesquisas futuras, os autores destacam a importância de estudos empíricos que busquem entender como empreendedores usam as diversas formas de rede como forma de responder às mudanças rápidas típicas de países emergentes.

$\mathrm{Na}$ extensa exploração da literatura feita no presente estudo não foram encontradas evidências de pesquisas, especialmente no Brasil ou na América Latina, que identifiquem as diferentes manifestações das redes e seu emprego no início e no prosseguimento do processo de internacionalização.

\subsection{1.}

\section{Tipos de usos de capital social para a internacionalização}

Na literatura sobre Capital Social e Empreendedorismo é farta a relação de benefícios identificados empiricamente, tais como acesso a novas fontes de conhecimento, conhecimento de novas oportunidades internacionais, conhecimento pela experiência ou pelo aconselhamento, solidariedade e referência por terceiros, influência, recursos financeiros, recursos humanos, melhora de desempenho (INKPEN \& TSANG, 2005; SASI \& ARENIUS, 2008; SCHWENS \& KABST, 2011; SINGH, 1998; ZHOU, WU, \& LUO, 2007). 
As PMEs sofrem com escassez de recursos e uma das formas para sobrepujar tal limitação é o uso das redes (pessoais ou de negócios). De fato, Johannisson (1990, p. 41) descreve "as redes pessoais do empreendedor como o recurso mais importante da firma".

As redes de relacionamento facilitam o enfrentamento dos desafios no processo de internacionalização de pequenas empresas porque permitem acesso a diferentes recursos críticos, tais como conhecimento do mercado (SCHWENS \& KABST, 2011), recursos financeiros (CRICK \& SPENCE, 2005; FREEMAN, EDWARDS, \& SCHRODER, 2006) ou identificação de oportunidades internacionais (EVERS \& O'GORMAN, 2011; MCDOUGALL, SHANE, \& OVIATT, 1994), mesmo aquelas pertencentes a setores diferentes daquele em que a empresa atua (VOUDOURIS, DIMITRATOS, \& SALAVOU, 2011). Dentre as estratégias utilizadas pelas firmas para sobrepujar as dificuldades, o uso de redes parece ter papel relevante, tanto na forma de contatos pessoais, quanto de relacionamentos com clientes e fornecedores e até mesmo quando seguem o cliente como forma de expansão (FREEMAN et al., 2006). Não só as redes são usadas nos caminhos iniciais da internacionalização, como constantemente encontram-se empresas que se esmeram em nutrir e acrescentar relacionamentos como forma de manter o ritmo de crescimento (COVIELLO \& MUNRO, 1997; FREEMAN et al., 2006; HOLMLUND \& KOCK, 1998; MUSTEEN, FRANCIS, \& DATTA, 2010; BUCIUNI E MOLA, 2014).

Há na literatura diversos estudos que apontam o uso da rede pessoal de relacionamentos dos executivos e fundadores das pequenas empresas como uma das principais forças a minimizar os desafios inerentes às firmas, não importando se tais empresas são manufatureiras, de serviço, de tecnologia ou familiares (AUTIO et al., 1997; COVIELLO \& MARTIN, 1999; CRICK \& SPENCE, 2005; ELLIS, 2000; KONTINEN \& OJALA, 2010; ZAHRA et al., 2000a).

Apesar de muitos estudos terem destacado o papel relevante que as redes de relacionamento exercem sobre empreendedores nas diversas etapas do seu empreendimento (por ex., COVIELLO \& MUNRO, 1995), o entendimento sobre o impacto que diferentes formas e conteúdos das redes exercem sobre o processo de internacionalização da empresa ainda é escasso (YU, GILBERT, \& OVIATT, 2011). Em pesquisa com 118 empresas norte-americanas no setor de biotecnologia, Yu et al. (2011) descobriram que tipos diferentes de informações 
trocadas entre as PMEs e seus parceiros afetam diferentemente os padrões de internacionalização das firmas

A estrutura da rede também exerce influência sobre o processo de internacionalização, tornando importante identificar a quantos pontos da rede possivelmente úteis à internacionalização o empreendedor tem acesso e se estes são valiosos ou repetitivos, à luz do conceito de vazios estruturais (BURT, 1992). Yu et al. (2011) descobriram que o impacto que a coesão de uma rede exerce sobre a internacionalização pode ser contingencial, dependendo da complexidade tecnológica envolvida, do conhecimento do mercado e do tempo (longo ou curto prazo), mostrando que as teorias de vazios estruturais e de closure da rede são complementares.

\subsubsection{1.}

\section{Capital social e identificação de oportunidades}

Muitos autores que estudaram as redes de relacionamento e as pequenas empresas alertaram para o fato de que as redes de relacionamento geram Capital Social, facilitando o acesso aos recursos e às oportunidades internacionais (ZAHRA \& GEORGE, 2002; ZHOU, WU, \& LUO, 2007).

Dentre as principais barreiras encontradas pelas PMEs para sua expansão, especialmente para fora do país de origem, pode-se citar a falta de recursos, sejam financeiros, humanos, conhecimento de mercado, tecnologia e oportunidades (KISS, DANIS, \& CAVUSGIL, 2012; LINDSTRAND, MELÉN, \& NORDMAN, 2011; ZHOU, WU, \& LUO, 2007). No entanto, alguns estudos sobre as PMEs encontraram padrões mais ousados de expansão, com movimento de internacionalização muitas vezes acontecendo desde o surgimento do empreendimento (KNIGHT \& CAVUSGIL, 1996; OVIATT \& MCDOUGALL, 1994). As incursões arrojadas muitas vezes são originadas pelo uso das redes (COVIELLO \& MUNRO, 1997), que substituem a falta de recursos das empresas (CRICK \& SPENCE, 2005; EVERS \& O'GORMAN, 2011; FREEMAN et al., 2006; MCDOUGALL et al., 1994). 
Singh (1998), pesquisando 303 empresas de Tecnologia da Informação, observou que diversas características da rede influenciaram o processo de reconhecimento de oportunidade das firmas, como força dos laços fracos e os benefícios de uma rede heterogênea ou de vazios estruturais. Os resultados apontaram que $42 \%$ dos empreendedores identificaram os amigos e a família como a fonte de ideias para seus empreendimentos e $75 \%$ utilizaram as redes de relacionamento para transformar ideias em oportunidades.

Zhou et al. (2007) investigaram o papel mediador das redes de relacionamento no desempenho da internacionalização de empresas Born Global pequenas e médias, sugerindo que empreendedores deveriam considerar as redes de relacionamento como um meio eficiente de PMEs se internacionalizarem. Tal conclusão é fundamentada por três benefícios relacionados a informações das redes de relacionamento: (i) reconhecimento de oportunidades; (ii) aprendizado pela experiência e pelo aconselhamento; e (iii) referência baseada em confiança e solidariedade.

Outro estudo verificou uma preferência pelo uso de contatos da rede pessoal (como família e amigos) por empreendedores do que pelo uso da rede de negócios (como bancos e advogados) para identificação de oportunidades (SINGH, 1998).

Pertencer a uma rede formada por especialistas da mesma área de conhecimento também pode trazer benefícios ao processo de internacionalização. Um estudo envolvendo dez empresas da África do Sul - seis firmas de software e quatro de biotecnologia - encontrou evidências de que as redes baseadas em conhecimento do empresário existentes antes da fundação da empresa têm papel relevante no processo inicial de internacionalização. Tais redes são definidas pelos autores como sendo aquelas formadas por indivíduos que compartilham o mesmo conhecimento especializado, como entre profissionais de TI. (MASANGO \& MARINOVA, 2014).

Empresas podem manter ligações com diversos tipos de atores em mercados internacionais, tais como clientes, distribuidores, fornecedores, competidores, ONGs e funcionários públicos. Das diversas formas de manifestação das redes de relacionamento, duas dimensões principais afloram: os laços de negócio e os laços sociais. Nas redes de negócio, há trocas comerciais, o que não ocorre nas redes de relacionamento. Um exemplo de classificação é encontrado no artigo de Evers e O'Gorman (2011), onde, além das duas dimensões mencionadas, os autores 
também diferenciam as manifestações em termos do relacionamento da firma vertical ou horizontal (Quadro 2.8). Os autores propõem que os empreendedores se beneficiam de suas redes de relacionamento e de negócio para identificar oportunidades em mercados estrangeiros. Por meio do estudo de casos de três empresas, observaram que a seleção do mercado estrangeiro efetivamente ocorreu pela interação entre o empreendedor e diversos membros de suas redes (tanto social quanto de negócios).

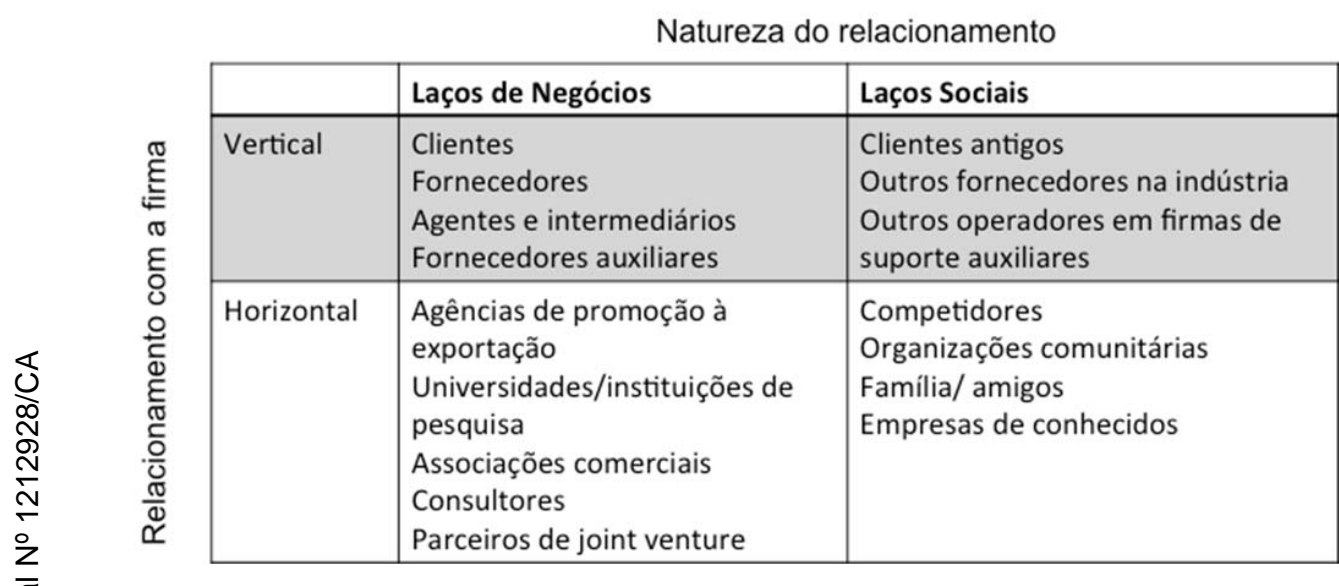

Quadro 2.8 - Tipologia de relacionamentos sociais e de negócios. Fonte: Evers \& O'Gorman, 2011, p.553

Redes de negócios e sociais são importantes fontes de informação relacionadas ao encontro de oportunidade internacionais (COVIELLO, 2006; KONTINEN \& OJALA, 2011). As redes de relacionamento podem acelerar os movimentos para fora do mercado doméstico de diversas formas: por meio de laços individuais dos fundadores e executivos, laços profissionais com firmas parceiras ou não, consultores, organizações de fomento à exportação, congressos, feiras e exposições internacionais (CRICK \& SPENCE, 2005; BOEHE, 2013). Laços familiares e de amigos também se manifestam, embora alguns estudos empíricos tenham revelado que estes são minoria (KONTINEN \& OJALA, 2011). 
Zahra e George (2002) vêm o EI como um processo que busca descobrir e explorar novas oportunidades além do mercado doméstico de forma criativa. Baseado em tal entendimento, o Capital Social (que se manifesta por meio de conexões, contatos, experiência internacional, redes de relacionamentos) pode ser considerado uma das fontes de busca criativa de oportunidades internacionais (ARENIUS, 2002; CRICK \& SPENCE, 2005).

Considerando-se as três dimensões do Capital Social de Nahapiet e Ghoshal (1998) (relacional, cognitiva e estrutural), observa-se como cada uma pode representar um benefício no processo de internacionalização de uma pequena firma. A dimensão relacional fortalece o aspecto de confiança entre os atores da rede, comoquando um membro da rede aponta uma oportunidade para uma empresa, ou disponibiliza informações que levam a novos negócios. A dimensão cognitiva facilita a comunicação entre os atores, ajudando a diminuir barreiras entre culturas diferentes, reduzindo os riscos inerentes aos avanços internacionais, além de permitir a criação de objetivos comuns, o que pode levar a maior criação de oportunidades ou troca de conhecimento.

Por fim, a dimensão estrutural pode indicar o tamanho do alcance geográfico da rede, que se traduz na capacidade de a firma vislumbrar oportunidades em maior ou menor número de mercados externos: quanto mais dispersa a rede (geograficamente), menor a redundância de informações e maiores as chances de expansão (GRANOVETTER, 1973; MUSTEEN, FRANCIS, \& DATTA, 2010; FELZENSZTEIN, CIRAVEGNA, ROBSON, \& AMORÓS, 2015).

As dimensões estrutural e relacional mencionadas, têm sido de grande interesse em estudos de empreendedorismo, que tipicamente buscam analisar o impacto que o tamanho das redes exerce na compensação pela falta de recursos, os tipos de redes mais acessados e as forças dos laços que compõem a rede dos empreendedores (KISS \& DANIS, 2008).

Diversas formas (manifestações ou tipos) de Capital Social são encontradas em estudos empíricos que facilitaram ou viabilizaram a expansão internacional de pequenas empresas. Por exemplo, o estudo de O'Gorman e Evers (2011) mostrou que organizações de promoção à exportação exerceram papel preponderante como intermediárias na construção de redes, ajudando no desenvolvimento da capacidade exportadora de firmas irlandesas do setor de frutos do mar, em 
processos que iam desde a identificação da oportunidade até a indicação de novos clientes.

Há diversos tipos de laços - fornecedor-cliente, contatos pessoais, contatos adquiridos ao acaso, e contatos adquiridos por estratégias propositais. Cada tipo de laço desses pode trazer diferentes recursos para a pequena firma que se internacionaliza, e o impacto pode variar se a empresa pertence a um país emergente ou não. Ciravegna, Lopez e Kundu (2014) compararam firmas da Costa Rica e da Itália, buscando identificar padrões e diferenças na forma de desenvolver e usar suas redes para entrar em seu primeiro mercado externo. Suas principais conclusões indicam que as empresas da América Latina se utilizam mais de suas redes criadas nas escolas do que em associações do setor e são mais propensos a contratar consultores externos para ajuda-los.

Há indícios de que, entre os empreendedores, é mais comum adquirir conhecimento e recursos (HOANG \& ANTONCIC, 2003) de mercados internacionais por meio de suas redes de relacionamento do que por meio de práticas formais de coleta de informação (ELLIS, 2000). Pesquisas empíricas identificaram como fator influenciador no processo de internacionalização de empresas o uso das redes de relacionamento domésticas e de relacionamentos pessoais de jovens empreendedores (HARRIS \& WHEELER, 2005; HOLMLUND \& KOCK, 1998). Também Manolova et al. (2010) identificaram efeitos positivos de laços pessoais fortes na internacionalização de PMEs da Bulgária, mostrando que também em economias consideradas de transição são encontrados efeitos positivos das redes, especialmente na forma de obtenção de informação sobre mercados externos e identificação de oportunidades.

A composição das redes é outra importante dimensão analisada nos estudos de Capital Social, identificando se a mesma é formada por laços sociais (embedded) ou de negócios (de mercado), e as consequências dessas estruturas em diversas dimensões, como desempenho, internacionalização, obtenção de recursos etc. (UZZI, 1999).

Embora alguns estudos de empreendedorismo trabalhem com os conceitos de laços fortes e laços fracos, ainda não há claro entendimento de como os empreendedores efetivamente decidem contar com um ou outro tipo (KISS \& DANIS, 2008). 
Kiss e Danis (2008) propuseram que a relevância de laços fortes vs. fracos seria dependente do contexto institucional do país de destino do empreendedor. Os países com ambiente institucional mais desenvolvido permitem que os empreendedores tenham amplo acesso a recursos, como informação, pessoal e finanças. Tal acesso facilita a entrada de empresas estrangeiras em seu mercado, sem tanta necessidade de contar com indicação de outros. Portanto, nesses casos, o uso de Capital Social não dependeria tanto de relações mais duradouras (GRANOVETTER, 1973; OVIATT \& MCDOUGALL, 2005). O simples fato de ter tido uma experiência professional positiva anterior pode originar uma indicação para uma oportunidade internacional.

Alguns autores no campo do EI encontraram suporte empírico para a Teoria da Força dos Laços Fracos (GRANOVETTER, 1973), mostrando que tais ligações trazem maior benefício para empreendedores, servindo como pontes para obtenção de informações não disponíveis em suas redes mais fortes (HOANG \& ANTONCIC, 2003; KONTINEN \& OJALA, 2011; TANG, 2011). Singh (1998) exemplifica diversos tipo de laços fracos (colegas de escola, conhecidos de clube, encontros esporádicos) que, mesmo requerendo pouco esforço de manutenção, podem transformar informações em oportunidades. No entanto, relações fortes também são valiosas, já que são baseadas em confiança, o que facilita a troca de favores entre os atores (SINGH, 1998). Uma abordagem contingencial na análise do uso de redes fracas ou fortes foi sugerida por Hoang e Antoncic (2003), argumentando que, no início do processo de crescimento, o uso de laços fortes é mais útil, já que pressupõe confiança entre os atores. No entanto, para permitir crescimento sustentável, as relações de laços fracos se mostram mais benéficas, e portanto, são alvo dos empreendedores, pois oferecem maior contorno, agindo como "pontes locais" que alcançam oportunidades não inseridas nas redes mais fechadas (KISS \& DANIS, 2008).

Além disso, experiências acumuladas pelo uso de redes facilitam o desenvolvimento de novas conexões, tornando a empresa mais central, aumentando sua visibilidade e reputação, permitindo acesso a parceiros de renome, ampliando assim as chances de obter informações valiosas sobre novas oportunidades (TANG, 2011). 
Alguns autores identificaram que o tamanho da rede pode significar vantagem para o empreendedor, já que cada elo da rede pode representar fonte de informação, e ainda mais se forem redes menos coesas, onde há maior diversidade de informações fluindo (ANDERSON, 2008; BURT, 1992; FELZENSZTEIN, CIRAVEGNA, ROBSON, \& AMORÓS, 2015).

Empreendedores possuem comportamentos intuitivos e racionais quando estão no processo de identificar oportunidades, se utilizam de experiência, mas também buscam conhecimento, pesquisam e agem com ajuda de seus relacionamentos, familiares ou de negócios, que muitas vezes são os grandes incentivadores que impulsionam o negócio (MAINELA et al., 2011; SINGH, 1998). "Na essência, um empreendedor é um usuário da rede que atua sobre a realidade com outras pessoas para criar novas maneiras de fazer negócio" (MAINELA et al., 2011, p. 435).

$\mathrm{O}$ presente estudo enfatiza o uso das redes de relacionamento como facilitador na busca de oportunidades internacionais, ou seja, o que se pretende entender melhor é o quanto o uso das redes de relacionamento facilita a descoberta e o consequente avanço para mercados internacionais. Interessa aqui identificar as características dessas redes, tais como a força dos laços (COLEMAN, 1990; GRANOVETTER, 1973), os vazios estruturais (BURT, 1992), os tipos de redes (familiar, profissional, parceiros etc.) e como as mesmas influenciam as decisões sobre as oportunidades de expansão, especificamente as internacionais (SINGH, 1998).

Outra característica do processo de internacionalização discutida nos estudos de Empreendedorismo Internacional é o comportamento proativo na busca de oportunidades. Proatividade é uma característica amplamente aceita em estudos focados nos empreendedores, porém, alguns estudos encontraram PMEs que se internacionalizam inicialmente por um "feliz acaso" (serendipity) (CRICK \& SPENCE, 2005; TANG, 2011), em situações não planejadas nem determinadas por decisões estratégicas (VASILCHENKO \& MORRISH, 2011). 
Tais situações de "feliz acaso", muitas vezes são fruto de uma rede de relacionamentos ou de estar no lugar certo na hora certa, e a seleção de mercados se inicia de forma não planejada, por meio da rede ou de referências, facilitada pela capacidade e rapidez de ação do empreendedor (CRICK \& SPENCE, 2005; SIGMUND, SEMRAU, \& WEGNER, 2015). Processos de internacionalização oriundos de uso da rede de relacionamentos se mostram sem padrões, as vezes por meio de contatos ocasionais, mostrando a importância de que estudos sobre internacionalização de empresas considerem fatores aleatórios e não previsíveis como possíveis influenciadores do uso das redes (VASILCHENKO \& MORRISH, 2011).

No entanto, outros pesquisadores mostraram empiricamente que as INVs formam e utilizam suas redes de forma intencional (COVIELLO, 2006) e que suas estratégias de internacionalização são construídas de maneira proativa (SCHWENS \& KABST, 2011).

Em um estudo empírico com PMEs chinesas, Tang (2011) identificou relação positiva entre a atitude proativa de criar redes e o uso de redes no processo de internacionalização. Outro estudo com 109 empresas chinesas confirmou a hipótese de que empresas que buscaram pro ativamente sua primeira oportunidade internacional alcançaram maior escopo geográfico, porém não confirmaram a hipótese de que o uso da rede na identificação da oportunidade seria mais provável de acontecer quando há mais experiência internacional por parte dos dirigentes da empresa (CIRAVEGNA, MAJANO, \& ZHAN, 2014).

\subsubsection{2.}

Capital social, experiência e aprendizado

Quando revisaram seu modelo de internacionalização, conhecido como o Modelo de Uppsala, Johanson e Vahlne (2003) consideraram que a rede também tinha papel preponderante sobre a variável conhecimento. Segundo os autores, a firma desenvolve a longo prazo uma rede de negócios que aumenta o conhecimento que parceiros têm sobre as necessidades, estratégias e recursos mútuos (JOHANSON \& VAHLNE, 2003). 
Firmas inseridas em redes de empresas com presença internacional têm acesso à base de conhecimento dos parceiros e se beneficiam do aprendizado pela rede para, por exemplo, entender melhor os diversos aspectos do mercado estrangeiro em que pretendem atuar (LEVITT \& MARCH, 1988). Mainela et al. (2011) afirmam que o processo empreendedor é a combinação de experiência e uso de rede na busca pelos conhecimentos necessários no desenvolvimento da estratégia. Também são percebidos outros benefícios do uso da rede de relacionamento, como o aumento da confiança entre os atores, fortalecido pelo compartilhamento de experiências anteriores (MANOLOVA, MANEV, \& GYOSHEV, 2010).

Empresas inseridas em redes apropriadas são mais capazes de aprender a partir da experiência de outros participantes das redes (COVIELLO \& MUNRO, 1997), ajudando-as a avaliar potenciais mercados ou a identificar e se inserir em outras redes relevantes para seu processo de internacionalização (AL-LAHAM \& SOUITAIRS, 2008).

Em contraposição aos processos formais encontrados nas grandes empresas, as PMEs contam mais com as preferências pessoais dos empresários. Essas decisões podem ser tomadas de forma causal ou sob o processo identificado como effectuation por Sarasvathy (2001). Na dinâmica causal, a decisão é norteada por objetivos e por seus meios para alcançá-los; na dinâmica effectuation, parte dos meios e recursos disponíveis para o alcance de resultados, mais em linha com uma estratégia emergente. As redes exercem influência nos modos de decisão dos empresários, inclusive aquelas relacionadas à internacionalização, uma vez que podem abastecê-los com informações e aprendizado tornando seus processos de decisão mais estruturados, em linha com a dinâmica causal (CHILD \& HSIEH, 2014). 
As redes das empresas podem acelerar o processo de internacionalização, não apenas ao dar acesso a recursos externos, como também por permitir aprendizado organizacional, conhecimento experiencial internacional, dentre outros benefícios (ZHOU et al., 2007). Para adquirir informações de marketing e conhecimento experiencial, as PMEs se utilizam das redes formais e informais e, para tal, muitas delas utilizam estratégias para desenvolverem redes relevantes para seu processo de internacionalização (TANG, 2011).

Schwens e Kabst (2011) identificaram que firmas de tecnologia usam suas redes para alavancar o aprendizado sobre mercados estrangeiros sem requerer o processo experimental, permitindo mais rapidez para superar o liability of foreignness.

Muitos autores identificaram um padrão, em que as PMEs utilizam redes no início do processo de internacionalização para adquirir conhecimento experiencial sobre os mercados que selecionam, além de buscarem complementar seus recursos por meio de relações sinérgicas com outras empresas (CRICK \& SPENCE, 2005; JONES, 1999; SCHWENS \& KABST, 2011).

Um estudo empírico sobre a influência das redes realizado com PMEs em seu estágio inicial de internacionalização, desenvolvido por Sharma e Blomstermo (2003), mostrou o impacto positivo de laços fracos no processo de internacionalização, permitindo maior conhecimento dos mercados e dos clientes previamente, a um custo menor, já que os laços fracos dispendem menos recursos para se manter.

Zhou et al. (2007) também identificaram que as redes de relacionamento na China têm papel fundamental no desempenho internacional das empresas, trazendo informações que favorecem o aprendizado e a experiência no novo mercado.

Um estudo de pequenas e médias firmas da Nova Zelândia, Suécia e Dinamarca concluiu que executivos com experiência internacional e aqueles que adquiriram experiência por meio de sua rede internacional são mais criteriosos na escolha de seus laços e buscam novos clientes ao criarem as relações (HOHENTHAL, JOHANSON, \& JOHANSON, 2014). 
Outro estudo empírico, nos EUA, evidenciou que o tamanho da rede de relacionamento de um gerente está positivamente relacionado à quantidade e à diversidade de informação disponível, facilitando tomadas de decisão, aprendizado, dentre outros benefícios (ANDERSON, 2008).

Khanin, Ogilvie e Leibsohn (2012) estudaram as decisões de reinvestimento de risco em economias emergentes e suas relações com a densidade das redes, concluindo que tais decisões teriam melhores resultados se as empresas soubessem explorar o conhecimento advindo das redes densas. As empresas que são capazes de criar ou de se inserir em redes de conhecimento, adquirem mais competência ao gradualmente aprenderem como operar em ambientes institucionais menos desenvolvidos.

Outro estudo empírico sobre o impacto de redes, diferenciando os resultados de redes densas ou esparsas (BURT, 1992) em relação ao ambiente institucional do mercado de destino, foi analisado por Khanin, Ogilve, e Leibsohn (2012). Os autores avaliam que, apesar de perderem o fluxo de novas informações - mais comuns nas redes esparsas (segundo a teoria dos vazios estruturais) - as empresas de capital de risco que usam redes mais densas são mais beneficiadas, já que encontram um ambiente de alto nível de confiança. Portanto, quanto maior a densidade das redes internacionais que uma empresa de capital de risco possui, menor o número de rodadas de investimento (ou seja, melhor seriam as decisões de reinvestimento) oferecidas às empresas do portfolio no mercado de destino, corroborando os benefícios do uso de redes densas (KHANIN, OGILVE, \& LEIBSOHN, 2012).

Mais benefícios foram encontrados em estudos empíricos que analisam o papel das redes de relacionamento para empresas que buscam a internacionalização, como, por exemplo, na identificação de parcerias (ELLIS, 2000); na obtenção de conhecimento sobre práticas de negócios internacionais (SHARMA \& BLOMSTERMO, 2003); e alargando a visão internacional do empreendedor (CHEN, 2003). 


\subsubsection{3.}

\section{Outros usos do capital social}

Outro efeito importante que uma rede de relacionamentos pode prover a uma empresa é a melhoria em sua reputação, estabelecendo legitimidade e credibilidade, características que podem trazer vantagem competitiva à empresa ao perseguir o crescimento internacional (ZAHRA \& GEORGE, 2002; ZHOU et al., 2007).

Uma manifestação de Capital Social identificada como valiosa para empreendedores é o aconselhamento, disponível normalmente como um dos laços diádicos que formam a rede (HITE \& HESTERLY, 2001; ZHOU et al., 2007). Aconselhamentos normalmente se manifestam em redes embasadas em confiança, construídas com base em experiências compartilhadas com intensidade no passado, como por exemplo os laços étnicos (PRASHANTHAM, DHANARAJ \& KUMAR, 2015). Esse benefício obtido da rede permite redução de custos de transação como por exemplo, busca por informação, negociação, estabelecimento de contratos. Um bom exemplo seria quando em uma negociação o uso de boas referências de um conhecido permite economia de tempo e dinheiro que seriam gastos com práticas de salvaguarda para potenciais malfeitos (MANOLOVA, MANEV, \& GYOSHEV, 2010)

Há também estudos controversos sobre os benefícios do uso da rede de relacionamentos das empresas. Kenny e Fahy (2011) fizeram uma pesquisa para avaliar o impacto das redes no desempenho de empresas irlandesas de alta tecnologia. Eles conceituaram os tipos de redes por meio de três dimensões: capital humano, informação e combinação de recursos. Capital humano foi definido como o conjunto de habilidades e experiências adquiridas pelos executivos da empresa, seja por meio de atividade acadêmicas ou de trabalho, que lhes dão acesso a redes de relacionamento e informações mais valiosas, aumentando sua capacidade de entrever boas oportunidades. Os resultados apontaram apenas o capital humano como tendo impacto positivo no desempenho, e que as empresas investigadas, contrariando vários estudos de PMEs, não utilizaram suas redes externas para conduzir seus processos de internacionalização (KENNY \& FAHY, 2011). 
Um estudo empírico com dez empresas de tecnologia da informação finlandesas revelou que os fundadores de algumas das empresas utilizaram seu capital social para atrair novos membros para cargos executivos, enquanto outras, que já possuíam estrangeiros em cargos gerenciais, criaram redes amplas em mercados-chave (SASI \& ARENIUS, 2008).

Há estudos que vão além, concluindo que as pequenas empresas empreendedoras, na maior parte das investidas internacionais não utilizam qualquer processo estratégico, mas são seus contatos da rede de relacionamentos que orientam as decisões de seleção de mercado e modo de entrada (TORKKELI, PUUMALAINEN, SAARENKETO, \& KUIVALAINEN, 2012).

\subsection{2.}

\section{Capital social no tempo e no espaço}

Pode haver diferença na forma de uso do capital social pelos diversos tipos de empresa ou pela situação na qual a empresa se encontra em determinado momento de seu ciclo de vida. Empresas em diferentes estágios de internacionalização, com diferentes estratégias de internacionalização, podem sofrer impacto de forma diferente ou por variáveis distintas (INKPEN \& TSANG, 2005), dependendo de sua estratégia (BAUM, SCHWENS, \& KABST, 2011). Portanto, pode-se supor que, em casos em que a descoberta da oportunidade internacional se deu por meio da rede de relacionamento do empreendedor ou de algum de seus executivos, a natureza dos laços ou a frequência de uso podem variar conforme o estágio em que a empresa se encontra em seu processo de internacionalização.

Há um consenso geral de que as empresas possuem redes desde sua concepção, mas há algumas discussões sobre como as redes se apresentam ao longo da vida de uma empresa e de que forma extrair benefícios delas nos diversos estágios do processo de internacionalização (BAUM, MCEVILY, \& ROWLEY, 2012; SEPULVEDA \& GABRIELSSON, 2013).

Alguns estudos identificaram que, em sua fase inicial de crescimento, as empresas fazem uso de redes constituídas por vínculos pessoais arraigados (por exemplo, família e amigos), fundamentados em conexões densas e coesas (BELL, 1995; COLEMAN, 1990; COVIELLO, 2006; CRICK \& SPENCE, 2005; HITE \& HESTERLY, 2001; SINGH, 1998; MASANGO \& MARINOVA, 2014) e maior 
uso de redes pessoais em estágios iniciais e com redes de negócios mais dominantes em estágios subsequentes (IBEH \& KASEM, 2011; VASILCHENKO \& MORRISH, 2011).

Han (2006) propôs um modelo que estabelece que o número, a força e o conteúdo dos laços variam no tempo, por meio das diversas interações no processo de internacionalização. A autora argumenta que mudanças acontecem de forma passiva - pela erosão natural das relações no decorrer do tempo - ou de forma ativa, por meio de filtros e seleções promovidos pela empresa em decorrência do gradativo ganho de experiência que ocorre ao longo do processo de internacionalização.

Há também estudos que apontam que a rede utilizada na primeira internacionalização normalmente não é útil para futuras investidas internacionais, fazendo com que as empresas se sintam compelidas a expandir a rede - como, por exemplo, ao contratar novos executivos que possuam rede de contatos diferente (CRICK \& SPENCE, 2005).

Em estudo empírico com bancos de investimento canadenses, Baum et al. (2012) concluíram que o desempenho oriundo de redes de laços coesos aumentaria com a idade dessas relações. Em contrapartida, os benefícios de desempenho oriundos de redes de laços de ponte (bridging ties) diminuiriam com o tempo. Os autores alertam então para a importância de se analisarem os efeitos das redes em conjunto com os aspectos relacionais e temporais associados.

Sepulveda e Gabrielsson (2013) argumentam que as redes são fonte de recursos que suportam as empresas ao longo dos diversos estágios, incluindo o processo de internacionalização. No entanto, com a maturidade, as empresas adquirem diversidade de recursos, tornando-se mais autônomas, e supostamente diminuem o acesso às suas redes de contato. Embora haja diversos estudos sobre o impacto das redes em Empreendedorismo Internacional (COVIELLO, 2006; OVIATT \& MCDOUGALL, 1994, 2005; ZHOU et al., 2007), poucos investigam o uso das redes ao longo do tempo.

Estudando firmas de tecnologia de informação indianas, Prashantham e Birkinshaw (2015) analisam a eficiência das redes domésticas no processo de internacionalização de tais firmas. Suas conclusões apontam para a pouca efetividade de redes domésticas de laços fortes, a menos das relações inseridas nos grupos de indústria. 
Um fenômeno cultural muito estudado da sociedade chinesa tem reforçado tal argumento: o "guanxi", que exerce um papel mediador entre a internacionalização e o desempenho de PMEs, ao reduzir custos de transação e facilitar a troca de recursos, informações e conhecimento (ZHOU, WU, \& LUO, 2007). Porém, com o crescimento da empresa, os laços iniciais se mostram insuficientes, levando a firma a acrescentar aos laços mais antigos - definidos por Hite e Hesterly (2001) como laços que foram adquiridos no modelo de dependência de trajetória (path-dependence) - outros vínculos para obtenção de benefícios para a empresa. Os novos vínculos são menos densos (arm-length) e a empresa os acessa na busca por explorar os vazios estruturais de redes mais abertas, além de adotar uma abordagem mais ativa de gerenciamento da rede (HITE \& HESTERLY, 2001; HOANG \& ANTONCIC, 2003; MUSTEEN et al., 2010). Tal raciocínio está em linha com a ideia defendida por Burt (1992) de que a empresa obtém mais benefícios participando de redes de menor densidade, ou seja, daquelas em que é possível fazer a ponte entre os espaços estruturais. De fato, um estudo empírico feito com 84 pequenas empresas de software indianas, revelou que quanto mais vazios estruturais existem na rede externa dos empreendedores, melhor o desempenho da empresa (VISSA \& CHACAR, 2009).

Outro ponto interessante com relação ao uso das redes ao longo das etapas do processo de internacionalização de uma empresa diz respeito ao seu desenvolvimento ao longo do tempo. O próprio processo de internacionalização expande o alcance da rede da firma, fazendo com que as relações com determinados agentes (como, por exemplo, clientes e fornecedores) se estreitem, nos primeiros países onde iniciam seus negócios. A nova rede facilita não só novas entradas, como também o sucesso nos novos mercados (COEURDEROY, COWLING, LICHT, \& MURRAY, 2012).

Schwens e Kabst (2011) reconheceram a importância das redes para as PMEs de tecnologia durante os estágios pré-entrada em mercados estrangeiros. Porém, os autores argumentam que o uso da rede não está restrito à fase inicial, e que vários outros estudos mostraram o papel da manutenção e até da expansão da rede nas empresas bem-sucedidas internacionalmente (BUCIUNI \& MOLA, 2014; COVIELLO, 2006; COVIELLO \& MUNRO, 1997; YLI-RENKO, AUTIO \& TONTTI, 2002). Além disso, as relações se desenvolvem por meio de um 
processo contínuo, especialmente aquelas com clientes e fornecedores, permitindo que as partes aprendam entre si.

Há ainda a constatação de que pequenas empresas (especificamente, empresas familiares) são pouco amparadas pelas redes mais densas e antigas, porém muito apoiadas por redes fracas e recentes como, por exemplo, aquelas criadas em feiras internacionais (KONTINEN \& OJALA, 2011). Em uma revisão de artigos sobre empreendedorismo e redes, Hoang e Antoncic (2003, p. 166) observaram que :

"a dependência das redes não se restringe aos estágios iniciais. Empreendedores continuam a usar as redes para obter informações de negócios, conselhos $e$ soluções de problemas, sendo que alguns contatos provêm múltiplos recursos”.

Vasilchenko e Morrish (2011) perceberam em um estudo qualitativo com empresas neozelandesas que o uso das redes não era de forma acidental. Além disso, embora houvesse evidência de maior uso das redes de relacionamento nos estágios iniciais, ao longo do tempo a internacionalização da empresa, por si mesma, propiciava a formação de uma rede de negócios, que por sua vez, ajudava no avanço para outras geografias.

Outro conceito importante para o entendimento do papel das redes nas empresas é o de centralidade. Gulati (1999) argumentou que a firma que possui uma posição central na rede aumenta sua capacidade de formar alianças, já que se permite utilizar uma grande teia de relações para obter informações de valor sobre mercado, parceiros ou oportunidades. Normalmente são os fundadores e sua rede externa de relacionamentos que disponibilizam acesso a recursos, clientes, fornecedores e consultores. Alguns estudos empíricos confirmam que no início do processo de internacionalização relações diádicas, principalmente o Capital Social dos fundadores, são suficientes para inserir a empresa no mercado, porém se mostram insuficientes para uma expansão internacional significativa (SASI \& ARENIUS, 2008).

Poucos estudos consideram uma abordagem de processo quando analisam as redes de relacionamento (HOANG \& ANTONCIC, 2003), embora Klyver e Grant (2010) tenham argumentado que os empreendedores têm redes de relacionamento que mudam ao longo da vida da firma, tornando importante analisar a forma de uso e os benefícios advindos das redes de relacionamento ao longo do tempo. Com seu comportamento inovador como característica, é natural que 
empreendedores busquem a expansão de suas redes se tal expansão trouxer benefícios para seu negócio.

Alguns estudos identificaram o uso das redes como um meio facilitador para o aumento de escopo internacional em PMEs (como, por exemplo, CANNONE \& UGHETTO, 2014), e outros poucos analisaram o impacto do tamanho da rede no escopo geográfico internacional da firma (YLI-RENKO et al., 2002). Cannone e Ughetto (2014) identificaram por meio de uma pesquisa com 445 empresas startups de alta tecnologia internacionalizadas (sendo aproximadamente um terço empresas de software) um efeito positivo e significativo do uso das relações da rede como incentivo à internacionalização rápida e à expansão do escopo internacional. Dimitratos, Amorós, Etchebarne e Felzensztein (2014) estudaram 116 PME's chilenas, e encontraram evidências de que estabelecer relacionamentos com parceiros domésticos e internacionais aumenta a probabilidade da firma se tornar micro multinacional.

No entanto, não foram identificados estudos sobre o aumento ou não da necessidade de uso das redes quando a empresa já se encontra mais fortalecida nos mercados internacionais (alcançando maior número de países ou com significativo percentual de faturamento originado em negócios internacionais). Se por um lado, alguns autores apontam para a posse de maior rede quanto maior o escopo geográfico, já que o avanço por outros mercados vai naturalmente aumentando o número de laços (HOANG \& ANTONCIC, 2003; TANG, 2011), por outro lado empresas mais consolidadas buscam novos mercados de forma mais estratégica e utilizando os meios formais e estruturados de identificação de oportunidades, como pesquisas de mercado, governos e agências de comércio exterior (ELLIS, 2000).

Outra variável importante a se analisar é a transformação da rede ao longo do tempo em cada mercado atingido pela empresa. Firmas tendem a se estabelecer de forma mais comprometida quanto mais experiente em mercados internacionais, como por exemplo aquelas que iniciam associadas a um parceiro local e só após algum tempo se arriscam a criar presença local (JOHANSON \& WIEDERSHEIM-PAUL, 1975). 
Sandberg (2014), entretanto, não confirmou essa dinâmica quando analisou o modo de entrada em mercados emergentes de 203 PMEs da Suécia, já que a maior parte dessas firmas usou nós indiretos (como distribuidores ou revendedores) dentro do mercado de destino. Sendo mercados emergentes, as empresas podem ter optado por esse tipo de entrada com receio dos problemas institucionais normalmente encontrados em tais países. No entanto, o mesmo estudo encontrou uma correlação entre o tempo de permanência da firma em determinado mercado como facilitador para o modo mais comprometido de se estabelecer.

Em resumo, os estudos sobre as implicações do uso do Capital Social em PMEs que se internacionalizam mostram que os diversos atores e estruturas das redes afetam as decisões de internacionalização de forma contingencial. Fatores como o tempo decorrido desde a primeira entrada em mercado externo, ou o grau de internacionalização alcançado pela empresa, podem influenciar a forma como os empreendedores identificam oportunidades em novos mercados. Além disso, os laços fortes ou fracos empregados na busca de oportunidade também podem ser contingenciais em relação ao tempo de internacionalização da firma. À medida que a empresa se torna mais madura em seu processo de internacionalização, e mesmo em seu ciclo de vida, além do aprendizado obtido durante as internacionalizações anteriores, a rede de relacionamentos naturalmente se expande (mais clientes, fornecedores, empregados), aumentando a chance de ter acesso a pontos mais distantes da rede. Os resultados até agora identificados se mostram pouco conclusivos, levando à consideração de que aspectos como o amadurecimento da empresa, ou o porte da empresa podem levar a diferentes usos das redes de relacionamento no alcance de novos mercados internacionais.

\subsection{3.}

\section{Capital social e características dos empreendedores}

As pesquisas sugerem que o comportamento empreendedor é fator determinante para entender o processo de empreendedorismo internacional. Muito frequentemente as redes de relacionamento usadas para internacionalização são oriundas de determinadas características dos fundadores ou altos executivos da empresa, tais como experiência prévia internacional de trabalho e educação no exterior (CANNONE \& UGHETTO, 2014; MASANGO \& MARINOVA, 2014; 
OVIATT \& MCDOUGALL, 1997). Alguns estudos confirmam que tais características influenciam o processo de internacionalização das empresas (CRICK \& SPENCE, 2005; FREEMAN et al., 2006; ZAHRA et al., 2000; ZAHRA \& GEORGE, 2002), e que experiência internacional e a proporção de laços pessoais da alta gerência efetivamente melhoram o desempenho internacional das empresas (CARPENTER, SANDERS \& GREGERSEN, 2001; DAILY, CERTO, \& DALTON, 2000; MAIS, CARVALHO \& AMAL, 2014). Muitas empresas empreendedoras que se internacionalizaram o fizeram por meio dos contatos oriundos da experiência anterior de seus fundadores e executivos, como estudar fora ou ter trabalhado em multinacionais (CRICK \& SPENCE, 2005; DIB et al., 2010; EVERS \& O'GORMAN, 2011). Além da experiência prévia, o empreendedor que pro ativamente cria uma rede de relacionamentos, como, por exemplo, se engajando em associações da indústria, têm maiores possibilidades de obter sucesso na identificação de oportunidades em mercados externos, mesmo que essas associações sejam domésticas.

Em uma revisão da literatura sobre internacionalização de INVs, Evers (2011) destacou o papel dos empreendedores como pivôs no processo de tomada de decisão, argumentando que fatores como experiência, contatos e conhecimento prévio dos mercados externos os tornam arrojados na busca por oportunidades em outros países. No entanto, muitos estudos percebem os laços internacionais formados anteriormente à fundação da empresa como associados a dimensões de experiência gerencial ou do setor e menos em relação aos laços sociais, como família e amigos (ANDERSSON, EVERS, \& GRIOT, 2013; EVERS, 2011). A percepção das oportunidades, muitas vezes, acontece por meio dos laços sociais do empreendedor (ELLIS, 2000; HOLMLUND \& KOCK, 1998), permitindo acelerar o processo entre aquisição da informação e decisão de internacionalizar a firma (EVERS \& O'GORMAN, 2011).

Sasi e Arenius (2008) revelam que, embora tenham sido as firmas que obtiveram acesso a recursos originados de relacionamentos, estes pertenciam às redes dos fundadores da empresa e não à rede da empresa (clientes, fornecedores etc.). Também identificaram que os laços eram de longo prazo, fortemente baseados em confiança e comprometimento. Em decorrência, as PMEs com maior quantidade de sócios fundadores podem ter mais acesso ao Capital Social útil para internacionalização, exceto quando os sócios têm histórias de vida muito 
entrelaçadas. Em tal caso, suas redes muito provavelmente serão sobrepostas, o que diminui a variedade de laços. Portanto, quanto menos redundantes são os laços entre os participantes, mais Capital Social estará inserido na rede. 


\section{3 \\ Metodologia}

Neste capítulo são apresentados os aspectos relacionados à escolha do método de pesquisa utilizado no presente estudo. O capítulo compreende cinco seções. A primeira seção explica o método adotado - o estudo de caso com abordagem abdutiva. Na segunda seção são apresentados os casos escolhidos e as justificativas para tais escolhas. A terceira seção descreve os processos de coleta, e a quarta seção abrange a descrição da análise dos dados. Por fim, a quinta seção apresenta as limitações do estudo.

\section{1.}

Método da pesquisa

O presente estudo adota uma abordagem qualitativa e abdutiva, com uso da metodologia de estudo de caso. Além disso, trata-se de um estudo longitudinal e retrospectivo.

Empreendedorismo Internacional (EI) é um tema amplo, interdisciplinar, que envolve teorias de estratégia de negócios, cultura, internacionalização, dentre outras. Tradicionalmente, seguindo o padrão de periódicos de língua inglesa, boa parte das pesquisas publicadas neste campo utiliza métodos quantitativos (ANDERSEN \& SKAATES, 2004; BIRKINSHAW, BRANNEN, \& TUNG, 2011; VAARA \& TIENARI, 2004,).

Entretanto, no campo de EI, alguns autores, e até um número especial lançado em 2011 pelo Journal of International Business Studies, apontaram a lacuna de estudos qualitativos e a potencial contribuição que esses estudos podem trazer para os meios acadêmico e empresarial. Estudos qualitativos em pesquisas de negócios internacionais têm sido considerados um caminho a ser explorado (PAUWELS \& MATTHYSSENS, 2004). Entre as características consideradas relevantes em tais estudos, que poderiam trazer benefícios ao campo de EI, foram mencionados a ênfase exploratória, a obtenção de descrições mais profundas e os estudos de caso (BIRKINSHAW, BRANNEN \& TUNG, 2011), sendo múltiplos 
estudos de caso considerados mais importantes (ANDERSEN \& SAKAATES, 2004).

Estudos qualitativos podem oferecer uma visão complementar e, por vezes, mais adequada para determinadas perguntas de pesquisa, mas questionamentos em relação aos fatores que levam uma pesquisa a estar mais adequada ao método qualitativo ou ao quantitativo ainda são bastante presentes na literatura de EI.

Especificamente em relação ao método de estudo de caso, e particularmente nas Ciências Sociais, Yin (2010) identificou algumas condições que favoreceriam seu uso em pesquisas acadêmicas. Pesquisas que proponham questões iniciadas em "como" ou "por que", nas quais o investigador não tenha controle sobre os acontecimentos e cujo enfoque seja sobre fenômeno contemporâneo, seriam as mais adequadas ao método.

Ao comparar o estudo de caso com outros métodos, Yin (1989) afirma que há muitos pontos comuns com dois outros métodos - o histórico e o experimental, que também se pautam em "comos" e "por quês". Entretanto, o estudo de caso é mais indicado do que o método histórico quando a pesquisa apresenta possibilidade de observação prática e de entrevistas, e também quando não está voltada apenas para eventos passados, o que está alinhado com o presente estudo, cujos fatos são, em boa parte, contemporâneos. Da mesma forma, o método experimental não é apropriado ao presente estudo, já que não é possível manejar o comportamento das variáveis inerentes aos fenômenos estudados (YIN, 1989).

Em pesquisas de negócios é frequente o uso do método de estudo de caso quando se quer entender um processo complexo, para otimizar o entendimento de um problema (GHAURI, 2004), para o qual não exista um formato ou padrão definido e que apresente certo grau de complexidade. Para Woodside (2010), projetos cujo propósito seja uma combinação de descrição, entendimento, predição e controle podem se basear em estudos de caso. Estudos de caso são excelentes métodos para quando se necessita aprofundar o conhecimento de determinado fenômeno e, em especial, quando se pretende realizar uma análise longitudinal (GHAURI, 2004).

O principal objetivo de um estudo de caso deve residir em entender profundamente atores, interações, sentimentos e comportamentos que ocorram em um processo em determinado espaço de tempo (YIN, 1989). Tal é a natureza do presente estudo. 
O presente estudo é longitudinal, ou seja, atende ao requisito de que os dados tenham sido "colhidos para cada unidade de análise em dois ou mais momentos distintos do tempo" (HASSETT \& PAAVILAINEN-MÄNTYMÄKI, 2013). Para tal, utiliza dados disponíveis no Núcleo de Pesquisas em Negócios Internacionais da PUC-Rio, referentes a entrevistas e dados secundários coletados em cada empresa selecionada ao longo de seu processo de internacionalização, além de dados colhidos recentemente para a presente pesquisa. No entanto, apesar da característica essencialmente longitudinal, há também um enfoque retrospectivo, já que, em cada entrevista realizada ao longo do tempo, há elementos que são recordados.

Portanto, a escolha do método se justifica:

- por abranger um período de tempo extenso;

- pela necessidade de entender a lógica subjacente às decisões dos empreendedores entrevistados no uso de suas redes no processo de internacionalização;

- pela pequena quantidade de casos de empresas no setor de software com características adequadas à presente pesquisa (ou seja, que tenham se internacionalizado para mais de um país e que em pelo menos uma ocasião tenham se beneficiado do uso de sua rede de relacionamento para este fim); e

- pela quantidade restrita de estudos empíricos e teóricos que tratam do uso de redes de relacionamento no processo de internacionalização de empresas brasileiras.

\subsection{2.}

\section{Abordagem abdutiva}

O presente estudo utiliza uma abordagem abdutiva que pode ser definida como um processo contínuo de evolução (path-dependent), não-linear, caracterizada por idas e vindas entre teoria e dados empíricos e que tem como objetivo alinhar teoria e realidade (DUBOIS \& GADDE, 2002).

A abordagem abdutiva está presente desde o início da pesquisa, combinando indução e dedução. Segue-se uma descrição do processo abdutivo seguido durante a realização da pesquisa: 
(i) Foi realizada uma revisão de literatura preliminar, cobrindo de forma ampla a temática de capital social e redes, e suas aplicações a negócios internacionais.

(ii) Tendo-se optado por realizar um estudo longitudinal com empresas brasileiras de software internacionalizadas, realizou-se uma busca na base de dados do NUPIN - Núcleo de Pesquisas em Negócios Internacionais da PUC-Rio, para identificar casos de empresas brasileiras de software para os quais se dispusesse de várias entrevistas realizadas ao longo dos anos. O resultado dessa busca levou à escolha de oito empresas. Os critérios de seleção são apresentados mais adiante.

(iii) Foi então realizada uma primeira análise de transcrições das entrevistas já realizadas com as empresas selecionadas. Em seguida, aprofundou-se a revisão de literatura, para melhor entendimento de lacunas, divergências e oportunidades de pesquisas relacionadas às situações identificadas.

(iv) Seis dentre as oito empresas foram novamente entrevistadas, cada qual com um roteiro de entrevista customizado, baseado nas lacunas identificadas. Duas empresas não concederam nova entrevista. Uma delas (Fujitec) havia sido entrevistada em 2015. Já a última entrevista com a Totvs ocorreu em 2012. Como se trata de empresa de capital aberto, informações adicionais foram obtidas de relatórios da empresa disponibilizados ao público.

(v) Ao longo de todo o processo de análise dos dados, consultou-se continuamente a literatura, confrontando-se os dados empíricos com a teoria e os resultados de outros estudos. Esse enfoque de idas e vindas do campo à literatura e de volta ao campo foi caracterizado como um "movimento contínuo entre o mundo empírico e o mundo modelado, permitindo que questões da pesquisa e o enquadramento teórico sejam sucessivamente reorientados quando confrontados com o mundo empírico" (DUBOIS \& GADDE, 2002). 
$\mathrm{O}$ enfoque abdutivo tem maior potencial em pesquisas que buscam refinar teorias existentes, identificar novos padrões e analogias. Tal abordagem permite que a confrontação com descobertas empíricas e intuições sobre a teoria ocorridas ao longo do processo do estudo desencadeiem mudanças nas estruturas teóricas correntes (DUBOIS \& GADDE, 2002).

\section{2 .}

Unidade de análise e seleção de casos

Uma característica importante e normalmente confundida em relação ao estudo de caso é que este não professa a lógica de representatividade, em que se utilizam amostras de uma população e se pretende chegar a generalizações empíricas. Yin (1989) observa que o método de estudo de caso engendra resultados "que são generalizáveis para proposições teóricas e não para universos ou populações" e que "o propósito do pesquisador é expandir e generalizar teorias (generalização analítica) e não enumerar frequências (generalização estatística) ”.

Optou-se por realizar um estudo de casos múltiplos, estratégia que pareceu mais adequada considerando-se a pergunta de pesquisa do presente estudo e o interesse em identificar e comparar processos longitudinais que podem ser distintos entre empresas. Tal orientação é dada por Ghauri (2004) e Yin (1989), para guiar a decisão de quantos casos utilizar.

A unidade de análise utilizada no presente estudo é a empresa. Além disso, dentro de cada caso foram identificadas subunidades de análise, que são as diversas iniciativas de entrada em mercados externos pelas empresas. Um total de 87 iniciativas de internacionalização foi identificado e analisado nas oito empresas brasileiras de software selecionadas para o presente estudo. Esta estratégia é recomendada por Ghauri (2004), como forma de "examinar múltiplas instâncias do fenômeno em estudo". O interesse em utilizar uma perspectiva longitudinal para entender o uso de redes no processo de internacionalização de empresas de software brasileiras também deu suporte à decisão de trabalhar com essas subunidades de análise.

O processo de seleção dos casos levou em conta os seguintes critérios:

(i) Empresas brasileiras desenvolvedoras de software, de capital nacional. 
(ii) Empresas de diversos tamanhos, como recomendado na literatura (JONES, COVIELLO, \& TANG, 2011; DIMITRATOS \& JONES, 2005), sendo selecionadas duas empresas de grande porte, uma de médio porte e seis pequenas.

(iii) Empresas internacionalizadas, ou seja, que atuassem em pelo menos um mercado estrangeiro.

(iv) Uso de redes de relacionamento em pelo menos uma iniciativa de internacionalização.

(v) Empresas maduras no processo de internacionalização, ou seja, que já existiam há pelo menos 15 anos e que haviam se internacionalizado há pelo menos 10 anos, por se tratar de uma lacuna na literatura (JONES, COVIELLO, \& TANG, 2011) e por ser necessária essa longevidade para examinar a evolução dos relacionamentos em rede ao longo do tempo.

(vi) Empresas para as quais se dispunha de entrevistas anteriores na base de dados do NUPIN.

(vii) Empresas que ainda pertencessem aos mesmos empreendedores.

(viii) Concordância, por parte da empresa, em fornecer as informações solicitadas.

Embora não se tratasse de um pré-requisito, a seleção das empresas buscou também alcançar certa dispersão geográfica, já que há variações econômicas e mesmo culturais entre as várias regiões brasileiras.

Cabe salientar ainda que duas das oito empresas selecionadas relataram na última entrevista não ter obtido nenhum faturamento internacional em 2015. Como essas empresas pretendiam prosseguir em suas atividades internacionais, considerou-se que se tratava de uma situação conjuntural e que seria interessante prosseguir também com esses dois estudos de caso.

O Quadro 3.1 apresenta os casos (unidade de análise) selecionados para o estudo, assim como o número de iniciativas de entrada em mercados externos em cada empresa (subunidade de análise). 


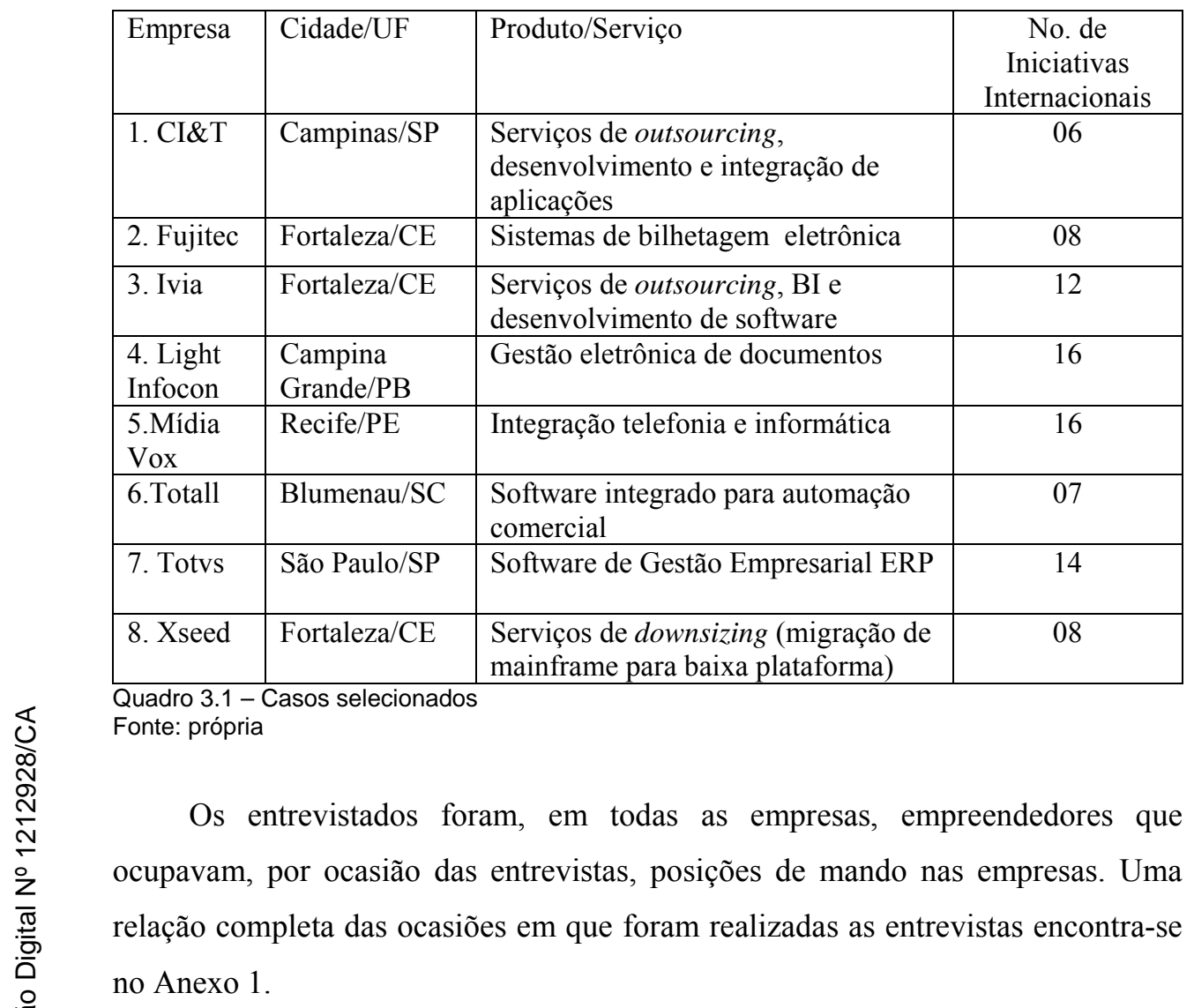

3.3.

\section{Coleta de dados}

O método de estudo de caso se utiliza com frequência de múltiplas formas de coleta de dados, visando aumentar a profundidade da pesquisa, que normalmente se caracteriza como de conteúdo complexo. Em estudos de caso, os casos escolhidos - indivíduo, grupo, organização, dentre outros - passam por uma análise minuciosa, onde são colhidos dados de distintas fontes.

No intuito de obter validação, o presente estudo adotou o cruzamento dos dados por meio de uso de diversas fontes:

- Entrevistas realizadas no passado com as oito empresas, pertencentes ao banco de dados do NUPIN em mais de uma ocorrência e quando possível com mais de um dirigente da empresa (Anexo 1); 
- Entrevistas pessoais da autora do presente estudo com dirigentes das empresas selecionadas, além de diversas consultas telefônicas, por e-mail e por Skype para elucidar dúvidas que surgiam à medida que se progredia na análise;

- Publicações em jornais, revistas e na internet;

- Casos acadêmicos publicados em revistas e anais de congressos sobre as empresas selecionadas;

- Documentos internos e sites das empresas.

Dessa forma, as fontes de informação iniciais do presente estudo foram entrevistas em profundidade realizadas com as oito empresas de software brasileiras selecionadas para o estudo. Todas as empresas, com exceção de uma, já haviam sido previamente entrevistadas em mais de uma ocasião, com intervalo mínimo de um a dois anos entre cada entrevista. Em um caso, havia uma entrevista e uma palestra dada pelo empreendedor em congresso realizado pelo NUPIN.

Foram efetuadas novas entrevistas com cada uma das oito empresas selecionadas, com o intuito de aprofundar o entendimento sobre a influência do capital social nas ações de internacionalização. As entrevistas foram realizadas preferencialmente com um ou mais empreendedores (ou co-empreendedores) de cada firma. Foi utilizado um roteiro individual de entrevista para cada empresa, o que se fez necessário, uma vez que já se partiu de um conjunto inicial amplo de informações, mas que requeriam maior aprofundamento, detalhamento e confirmação, além de se levantar novas iniciativas de entrada em mercados externos porventura ocorridas após a última entrevista disponível no NUPIN. As novas entrevistas realizadas, assim como as anteriores, foram gravadas e transcritas.

No Quadro 3.2 são listadas as fontes de dados usadas. 


\begin{tabular}{|c|c|c|c|c|c|c|}
\hline Empresas & 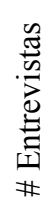 & 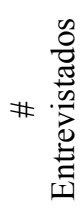 & 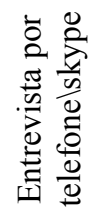 & Site & $\begin{array}{l}\frac{0}{0} \\
\frac{0}{0} \\
0 \\
Z\end{array}$ & 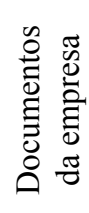 \\
\hline CI\&T & 3 & 2 & 3 & SIM & SIM & NÃO \\
\hline Fujitec & 4 & 2 & 1 & SIM & SIM & NÃO \\
\hline Ivia & 5 & 2 & 2 & SIM & SIM & SIM \\
\hline Light Infocon & 3 & 1 & 2 & SIM & SIM & SIM \\
\hline Midia Vox & 4 & 2 & 2 & SIM & SIM & NÃO \\
\hline Totvs & 2 & 2 & 1 & SIM & SIM & SIM \\
\hline Totall.com & 4 & 1 & 4 & SIM & SIM & NÃO \\
\hline Xseed & 5 & 1 & 1 & SIM & SIM & NÃO \\
\hline Total & 30 & 13 & 16 & & & \\
\hline
\end{tabular}

Quadro 3.2 - Resumo das fontes de dados

Fonte: própria

O uso de entrevistas em estudos de EI confere realismo a estudos empíricos, balanceando e complementando as ações de "sentar e pensar" típicas de pesquisas acadêmicas (MACDONALD \& HELLGREN, 2004). No entanto, é preciso ter cuidados na análise dessas entrevistas, devido à diversidade, à quantidade e, às vezes, até mesmo às contradições encontradas nas informações coletadas (MACDONALD \& HELLGREN, 2004). Com esse propósito, foram utilizadas diversas fontes secundárias (informações nos sites das empresas, artigos em revistas e jornais de negócios, outras informações disponíveis na internet, artigos acadêmicos, teses e dissertações etc.). Foram realizadas ainda consultas posteriores aos entrevistados, por telefone, Skype, ou e-mail, para confirmar ou esclarecer dúvidas, ou para solicitar informações adicionais que se fizeram necessárias.

O uso de mais de uma entrevista por empresa (em alguns casos com pessoas diferentes), combinada ao uso de fontes secundárias, permitiu realizar a triangulação, indispensável à validade da pesquisa baseada em estudos de casos (PAUWELS \& MATTHYSSENS, 2004).

Em resumo, o procedimento de coleta de dados implementado permitiu análise retrospectiva e longitudinal de cada caso, contribuindo para o melhor entendimento do uso das redes ao longo do processo de internacionalização. 
3.4 .

Análise de dados

Análise de dados em estudos de casos é provavelmente a etapa mais difícil da pesquisa, já que além de entender os pontos de vista dos indivíduos entrevistados, é necessário interpretar os dados à luz do contexto em que estão inseridos (GHAURI, 2004). No presente estudo, a escolha por usar múltiplos casos foi motivada pelo desejo de se obter uma avaliação cruzada de empresas de diferentes tamanhos e características, tentando apontar de que forma conjunturas diferentes influenciam as decisões e os resultados concernentes ao uso de capital social e das redes.

Ghauri (2004) recomenda que a análise de estudos de caso, especialmente longitudinais, utilize determinadas técnicas e que aconteça em estágios. As etapas da análise de dados foram conduzidas seguindo os passos delineados a seguir:

(i) Descrição dos casos

(ii) Codificação teórica, incluindo a descrição das principais categorias de análise.

(iii) Identificação de padrões e contrastes.

\subsection{1.}

Descrição dos casos

O primeiro passo da descrição dos casos consistiu, para cada empresa selecionada, de uma narrativa sobre a empresa e seu processo de internacionalização, em ordem cronológica. As informações apresentadas são originadas das diversas entrevistas e demais fontes de evidência, tais como notícias de revistas especializadas, documentos encontrados nos sites das empresas, dentre outros.

Cada descrição de caso incluiu:

- Breve apresentação da empresa, em relação a suas principais características como área de atuação, características de seus dirigentes, ano de fundação, tamanho e percentual de internacionalização.

- Descrição do processo de internacionalização, de forma cronológica, salientando os aspectos inerentes ao tema pesquisado, qual seja, a utilização das redes de relacionamento da empresa e de seus dirigentes. 
Além disso, foram selecionadas quatro iniciativas de internacionalização entre as 87 analisadas que, pela sua longevidade, especificidade e disponibilidade de dados permitiram uma análise mais detalhada. Essas iniciativas são descritas no contexto do caso, mas são objeto de análise separada.

3.4.2.

Codificação teórica

Foram agrupados os dados coletados de acordo com conceitos teóricos, codificando-os e apresentando-os de forma clara. Segundo Ghauri (2004), essa codificação ajuda na interpretação dos resultados.

As principais categorias de análise são apresentadas no Quadro 3.3.

\begin{tabular}{|c|c|}
\hline Categorias & Descrição \\
\hline $\begin{array}{l}\text { Iniciativa } \\
\text { Internacional }\end{array}$ & $\begin{array}{l}\text { Entrada em novo mercado com qualquer modo de entrada; mudança de modo } \\
\text { de entrada em mercado onde já atua; entrada em rede de multinacional. }\end{array}$ \\
\hline $\begin{array}{l}\text { Origem da } \\
\text { Iniciativa } \\
\text { Internacional }\end{array}$ & $\begin{array}{l}\text { Emergente - quando a iniciativa não foi da empresa estudada. } \\
\text { Intencional - quando a iniciativa foi da empresa estudada }\end{array}$ \\
\hline $\begin{array}{l}\text { Tipo de Ator } \\
\text { (Contato) }\end{array}$ & $\begin{array}{l}\text { Ponto de contato entre a empresa foco e a empresa envolvida na iniciativa } \\
\text { internacional } \\
\text { Cliente e ex-cliente } \\
\text { Cliente do cliente } \\
\text { Fornecedor e ex-fornecedor } \\
\text { Parceiro e ex-parceiro } \\
\text { Empregado e ex-empregado } \\
\text { Ex-colega (de universidade ou de trabalho) } \\
\text { Funcionário de órgão governamental } \\
\text { Consultor } \\
\text { Prospect (Futuro cliente) } \\
\text { Concorrente } \\
\text { Ex-professor } \\
\text { Família } \\
\text { Amigo } \\
\text { Conhecido } \\
\text { Empresa adquirida (Subsidiária ou filial) }\end{array}$ \\
\hline Tipo de Laço & $\begin{array}{l}\text { Negócios - laços criados a partir de interações entre empresas } \\
\text { Governo - laços criados entre a empresa foco e indivíduos pertencentes a } \\
\text { órgão governamental } \\
\text { Pessoal - todos os outros tipos de laços (familiares, amigos, colegas de escola } \\
\text { etc.) }\end{array}$ \\
\hline Força do Laço & $\begin{array}{l}\text { Laço fraco = laço superficial, ainda não baseado em confiança forte e onde as } \\
\text { partes não se conhecem bem } \\
\text { Laço forte = quando o entrevistado usou termos que identificam relações de } \\
\text { amizade, confiança, comprometimento entre as partes }\end{array}$ \\
\hline $\begin{array}{l}\text { Origem do } \\
\text { Laço }\end{array}$ & $\begin{array}{l}\text { Doméstico - quando o relacionamento estre indivíduos ou empresas se } \\
\text { estabeleceu originalmente no Brasil. } \\
\text { Internacional - quando o relacionamento entre indivíduos ou empresas se } \\
\text { estabeleceu originalmente no exterior. }\end{array}$ \\
\hline Benefícios & $\begin{array}{l}\text { - Identificação de oportunidade }- \text { quando o relacionamento trouxe } \\
\text { oportunidade de negócio para a empresa, tendo se concretizado ou não. }\end{array}$ \\
\hline
\end{tabular}




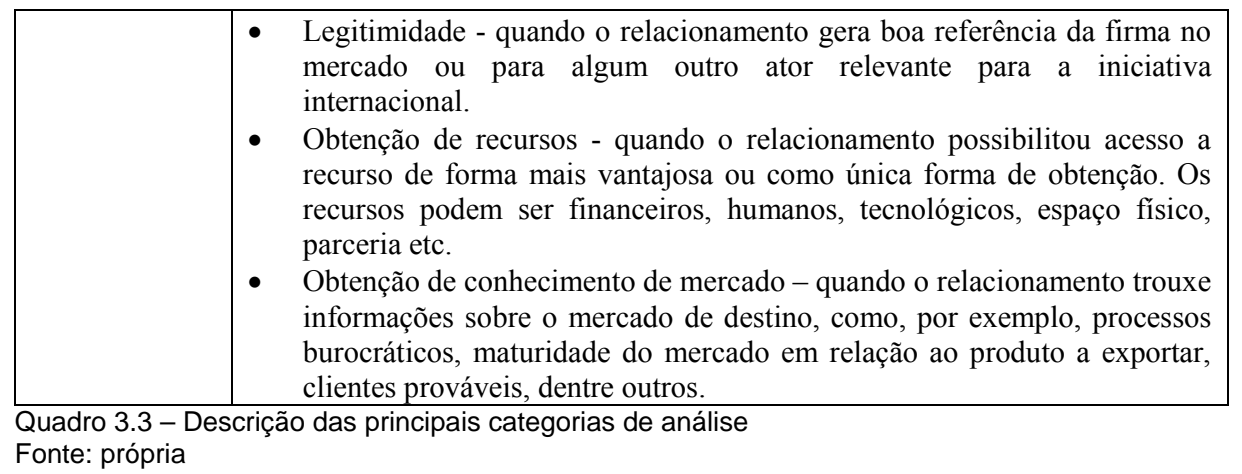

3.4.3.

Identificação de padrões e contrastes

O terceiro passo da análise consistiu na organização e classificação dos elementos relevantes identificados nas entrevistas, de acordo com as perguntas da pesquisa e com as categorias de análise. Como o presente estudo pretendeu examinar de forma abrangente o papel das redes e do capital social no processo de internacionalização das empresas selecionadas, houve o cuidado de destacar não só os aspectos já descritos na literatura, como também novos elementos que porventura houvessem surgido.

O objetivo dessa etapa foi obter, de forma condensada, um retrato das empresas e de suas estratégias de uso das redes, de forma a permitir a comparação com a literatura existente.

A análise foi feita de duas formas: comparação de padrões com a teoria e comparação entre casos e iniciativas internacionais. A comparação de padrões (pattern-matching) com a teoria buscou determinar a existência de padrões e conflitos nos dados, com vistas a identificar relações ou lacunas entre dados e perguntas de pesquisa (GHAURI, 2004; PAUWELS \& MATTHYSSENS, 2004). Já a análise cruzada de casos (cross-case analysis) buscou identificar diversidade de manifestações do fenômeno em estudo, tanto entre os oito casos como entre as 87 iniciativas de internacionalização. Complementarmente à análise qualitativa utilizou-se a análise de correlação para identificar relações entre variáveis inerentes às iniciativas. 
3.5.

\section{Limitações}

Todo método de pesquisa apresenta certo número de limitações: algumas podem ser inerentes ao método em si, outras estão relacionadas ao contexto em que a pesquisa está inserida.

A generalização é uma questão apontada como limitação típica de estudos de casos, embora não se devam confundir generalizações estatísticas com generalização teórica. Embora os resultados obtidos em um estudo de casos não possam ser estendidos para a população da qual foram extraídos os casos (empresas brasileiras de software internacionalizadas), os resultados permitiram chegar a generalizações teóricas, sob a forma de proposições, que poderão vir a ser testadas futuramente na população.

Há ainda as limitações decorrentes do uso de entrevistas em profundidade realizadas por outros pesquisadores, que não tinham em mente os propósitos do presente estudo e que, portanto, trazem algumas das limitações inerentes ao uso de dados secundários. No entanto, como todas as entrevistas disponíveis foram realizadas com um propósito comum - o de identificar o processo de internacionalização das empresas - seu conteúdo aproxima-se em muito dos interesses do presente estudo.

Em estudos de casos, as percepções individuais têm papel importante, tanto do lado do entrevistador quanto do entrevistado. $O$ entrevistador pode introduzir um viés analítico, influenciado por suas próprias conjeturas acerca do estudo, tanto na etapa de preparação da coleta de dados quanto na execução em si. Já o entrevistado oferece uma visão própria dos fatos, ou pode responder o que acha que o entrevistador quer ouvir (fenômeno conhecido como viés de aprovação social).

Há ainda o chamado "viés retrospectivo", que ocorre quando é solicitado ao entrevistado que narre eventos passados (HASSETT \& PAAVILAINENMÄNTYMÄKI, 2013). Aquilo que se relata "é a representação da experiência, não a experiência em si” (TOURANGEAU, RIPS, \& KASINSKI, 2000), ou seja, a acurácia do relato é prejudicada pelo fato de que as experiências relatadas foram percebidas, organizadas, interpretadas e armazenadas na memória previamente e, portanto, são passíveis de distorção. Entre as possíveis distorções encontram-se esquecimento, relato parcial, ou mesmo informações errôneas. Verificou-se ainda 
que as taxas de esquecimento aumentam à medida que os fatos relatados se distanciam no tempo (TOURANGEAU, RIPS, \& KASINSKI, 2000).

No entanto, a triangulação de dados por meio de entrevistas realizadas em diferentes momentos do tempo, em alguns casos com diferentes entrevistados na empresa, inclusive retomando e esclarecendo questões já abordadas em entrevistas anteriores, a realização de novas entrevistas voltadas para as questões específicas de interesse do presente estudo e o uso de dados publicados de diversas fontes contribuíram para minorar os potenciais vieses previamente indicados.

Há ainda limitações que podem provir da empresas selecionadas para o estudo. Em primeiro lugar, a distribuição geográfica das empresas não reflete a distribuição nacional, mais adensada no Sudeste, o oposto do que ocorre na seleção de casos para a presente pesquisa. Esse fato ocorreu em decorrência da disponibilidade de casos que se enquadrassem nos critérios de seleção relevantes ao tema da pesquisa. Em segundo lugar, embora todas as empresas pertençam ao setor de software, há certa variedade de produtos e serviços oferecidos pelas empresas que estão associados a diferentes formas de prestar o serviço em termos de negociação, preços, comprometimento e necessidade de presença física, dentre outros. 


\section{4 \\ Descrição dos casos}

Este capítulo descreve os oito casos selecionados para a presente pesquisa. A descrição de cada caso busca contextualizar a empresa e seu processo de internacionalização. $O$ texto também expõe citações dos entrevistados, permitindo melhor entendimento das questões abordadas sob a ótica daqueles que viveram as situações pesquisadas. As empresas são descritas, neste capítulo, em ordem alfabética.

\section{1.}

$\mathrm{CI} \& \mathrm{~T}$

\subsection{1}

Identificação e breve histórico da empresa

A CI\&T é uma empresa de TI baseada em Campinas, que oferece serviços especializados em outsourcing, desenvolvimento e integração de aplicações. Dentre os serviços oferecidos, destacam-se: Desenvolvimento de aplicações, Gerenciamento de aplicações, Inteligência de Negócios (Business Intelligence), Consultoria em Tecnologia e Arquitetura de TI, Serviços de Computação em Nuvem (Cloud Computing), Serviços móveis, Quality Assurance e Consultoria SAP. Em 2015, a CI\&T está fisicamente presente no Brasil e em mais três países, com escritórios nos EUA (New York e Los Angeles), China (Ningbo), Japão (Tokyo) e Brasil (Campinas, São Paulo, Rio de Janeiro e Belo Horizonte).

A empresa foi considerada a $68^{\mathrm{a}}$ classificada no ranking "The Global Outsourcing 100" da International Association of Outsourcing Professionals (IAOP) de melhores provedoras de serviços em 2012 e a 72ª em 2013. Em 2015, obteve o quinto lugar no ranking geral $100+$ Inovadoras no Uso da TI e o $1^{\circ}$. lugar na categoria "Fornecedores de Tecnologia" prêmio anual oferecido pela IT Midia em parceria com a PWC. A empresa também tem conquistado posições no ranking Melhor Empresa para Trabalhar por nove anos consecutivos, além de ter seu trabalho reconhecido como parceira de grandes multinacionais como Google 
(parceira do ano de 2015 para serviços em nuvem) e Instituto Gartner (nominada “Cool Vendor").

Fundada em 1995 por Cesar Gon (atual Diretor Geral Executivo) e Fernando Matt (Diretor Financeiro), a empresa contava, em 2015, com aproximadamente 2.000 empregados, sendo cerca de 200 sediados no exterior. Bruno Guiçardi, que foi o primeiro funcionário contratado, se tornou o terceiro sócio em 1997.

Em 2013, a direção da empresa decidiu intensificar sua presença no exterior e modificar sua estrutura global com intenção de aumentar a autonomia de cada uma das quatro regiões onde atuava: América Latina, América do Norte, Europa e Ásia.

Em 2015, a CI\&T se posicionava em $31^{\circ}$ lugar entre as empresas brasileiras mais internacionalizadas, segundo o ranking FDC de Multinacionais Brasileiras, sendo a sétima colocada dentre as empresas com até um bilhão de reais de faturamento. No mesmo ano, a empresa gerou receita de 330 milhões de reais, sendo cerca de $40 \%$ originada das operações internacionais, com meta de dobrar de tamanho a cada três anos até 2020 .

\subsection{2.}

\section{Processo de internacionalização da Ci\&T}

A CI\&T já nasceu internacional. O primeiro contrato, que motivou a própria criação da empresa, atendia um cliente multinacional - IBM - participando de um projeto tecnologicamente sofisticado, que abrangia laboratórios da IBM no Brasil, na França e nos Estados Unidos.

Seus sócios eram jovens recém-saídos da faculdade de engenharia, um dos quais trabalhava na IBM como terceirizado. Ao tomar conhecimento de uma concorrência para o desenvolvimento de um projeto, abriu uma empresa junto com o colega de faculdade, participaram e ganharam. Nas palavras de Bruno Guiçardi:

"A CI\&T foi fundada graças a uma oportunidade que surgiu na IBM, de competir em um projeto em que dois sócios tinham competência na área. Um dos sócios já estava trabalhando lá, como terceirizado, e ficou sabendo dessa oportunidade. E então ele perguntou para o gestor se podia abrir uma empresa para competir pelo projeto. Ele nos consideraria? Ele disse que sim. Então abrimos a empresa e ganhamos. Foi assim que começou a CI\&T, começou com o projeto. ” 
O contrato com a IBM, segundo Cesar Gon (Loturco, 2015), "criou um DNA internacional ao nosso negócio". Aliado ao fato de estarem inseridos numa multinacional, outro fator que permeou o processo de internacionalização da empresa foi a orientação internacional que, desde o início, se via nos jovens empreendedores. Segundo Cesar Gon, desde a fundação os sócios tinham em mente dois objetivos claros: "ser uma empresa global e alcançar uma receita de 100 milhões de reais".

A busca pela internacionalização era fruto de um espírito ambicioso dos sócios, conforme relatou Bruno Guiçardi:

"Somos uma empresa com uma ambição muito grande. [...]. Não é brincadeira não: acreditamos que podemos ser uma das melhores empresas do mundo no que fazemos. Então temos um desejo de mostrar essa competência, de provar essa missão, de conseguir ganhar o jogo aqui, ganhar o jogo nos Estados Unidos, ganhar o jogo na Europa... onde o jogo estiver sendo jogado."

Com os bons resultados alcançados no projeto, a CI\&T foi crescendo dentro da IBM, chegando a ter 30 funcionários em 1998. Então aconteceu o que os entrevistados classificaram como o "renascimento" da CI\&T. O Centro de Desenvolvimento da IBM, uma operação sediada em Hortolândia, Campinas, que era o maior cliente da CI\&T, fechou, como reflexo de uma crise da IBM no mundo, demitindo seus funcionários e cancelando os contratos com fornecedores. Àquela época, $80 \%$ da receita da CI\&T provinham dos contratos com a IBM, e a empresa teve que se reinventar.

Os sócios constataram o crescimento do uso da internet e decidiram explorar e desenvolver projetos que utilizassem tal tecnologia, que começava a despontar como promissora. Segundo Bruno Guiçardi:

"Isso já era novo na época, em 98. Bem novo, falar em sistemas de internet. E então, a empresa se especializou, criou um DNA de estar sempre olhando coisa novas do ponto de vista de tecnologia, que serão as novas trends tecnológicas e estar à frente do mercado. E fazemos isso desde então.”

O contato com a IBM, uma empresa de referência mundial, vista como a mais cobiçada pelos melhores profissionais de TI no mundo, fez com que os empresários percebessem que tinham potencial para fazer desenvolvimento de software com padrão de qualidade ainda melhor do que o da IBM. Isso reforçou o desejo de disputar o mercado global e não se restringir ao mercado doméstico. Como descreve Bruni Guiçardi: 
“Então acabou crescendo em nós a ideia de que 'Poxa, dá pra fazer muito melhor do que a IBM...' Fazer desenvolvimento de software de um jeito muito melhor. E o que nos inspirou foi esse aprendizado nos primeiros três anos. Foi o que criou esse 'viruszinho' lá dentro, de que 'podemos ser uma empresa melhor até do que a IBM, melhor até do que a empresa que é considerada a melhor do mundo'. Então, acho que foram esses primeiros anos que criaram essa perspectiva de que o mercado é uma terra de cego... [...] E estamos buscando realizar essa missão: a de ser uma das melhores empresas do mundo em desenvolvimento de software. "

No período de 1998 a 2003, a empresa cresceu apenas no mercado doméstico, e quando houve a primeira grande valorização do dólar, os sócios perceberam que poderiam ser mais competitivos internacionalmente. Eles entendiam que uniam bom diferencial técnico e custos baixos, cenário perfeito para a competição internacional.

O primeiro contrato internacional surgiu por meio de uma empresa na Califórnia na qual um dos sócios era brasileiro, além de um empregado dessa empresa ser ex-funcionário da CI\&T. Somado a isso, a CI\&T obteve boas referências do Brasil, gerando um clima de confiança. O contrato foi fechado por telefone em 2004, para desenvolvimento de um projeto a partir do Brasil, com valor em torno de 30 a 40 mil dólares. Mais seis ou oito projetos foram fechados em sequência, criando um portfólio de referências em experiência internacional, fundamental para a continuidade da exploração do mercado norte-americano. Assim relatou Bruno Guiçardi:

"E eles tinham um funcionário que já tinha trabalhado na CI\&T. Era uma pessoa que saiu da CI\&T e foi para os Estados Unidos, e trabalhava no time dessa empresa. E era muito bom, como todos os profissionais da CI\&T são muito bons. E esse cliente ficou impressionado, conheceu a CI\&T por ali, começou a acompanhar as atividades da CI\&T, os cases, e se sentiu confiante para fazer esse primeiro contrato."

O segundo cliente internacional foi a Johnson \& Johnson (J\&J). Embora o projeto fosse realizado no Brasil, a escolha da CI\&T foi viabilizada pelo fato de a empresa ter casos de sucesso no exterior, condição para permitir que fosse considerada para participar da seleção. Apesar de naquele momento, ainda não haver negócios entre as duas empresas, uma participação anterior da CI\&T em uma concorrência da $J \& J$, ganha por um concorrente, gerara boa impressão em termos de qualificação técnica e pioneirismo tecnológico. Os sócios nutriram os relacionamentos que obtiveram durante essa interação, por meio de convites para eventos, como explica Bruno Guiçardi: 
"Nós mantivemos ativo [o relacionamento com um diretor e um VP da J\&J], chamávamos para eventos, mandávamos newsletter, quando estavam nos mesmos eventos, batíamos papo, víamos como estava a situação...”

Essa interação no passado, aliada à boa impressão que a empresa causou nos dois executivos da J\&J, levou à indicação da CI\&T para a Johnson \& Johnson dos EUA, que estava buscando parceiros no país para diversificar seus centros de competência, que já existiam na Índia e nos EUA. Por fim, em 2004, foi fechado o negócio com a $J \& J$, ainda em pequena monta, mas que foi um embrião que cresceu ao longo dos anos, chegando em 2013 a contar com 300 participantes. Segundo relatou Bruno Guiçardi: "Fechamos o primeiro [contrato] e depois foi uma cadeia. A Johnson era um conjunto de 84 empresas diferentes, e nós fomos navegando entre essas diferentes empresas."

O contrato com a $J \& J$, além de estreitar as relações e aumentar a rede de relacionamentos da empresa, firmava a reputação da CI\&T como boa fornecedora, o que permitiu abrir as portas para a entrada em outros continentes, como a Europa. No relato de outro sócio, Leonardo Mattiazzi:

"Só que quando começamos lá eles eram bastante descentralizados. Então, no fundo, o que que eu fiz foi ir viajando... ir percorrendo essas empresas irmãs, digamos, $e$ ir vendendo os nossos serviços lá. Então a VisionCare é em Jacksonville, na Flórida. Eu fui lá pra Jacksonville, conseguimos o contrato, o primeiro contrato com a Vistakon. Já a LifeScan é na Califórnia, assim como a Neutrogena. Eu fui para lá, começamos o contrato com eles. E aí conseguimos. Com a LifeScan já começamos com um contrato na Europa, isso em 2007. ’”

Em 2006, a C\&IT abriu uma filial na Filadélfia para prospectar clientes, conseguindo aumentar sua presença nos Estados Unidos, não só em outras organizações da J\&J, mas também em outras empresas como Pfizer, Bayer, Roche, Yahoo, dentre outras. Como relatou Bruno Guiçardi:

“Conforme fomos crescendo na Johnson e vimos que podia ser uma oportunidade importante, fizemos alguns movimentos importantes. Mandamos o nosso melhor homem de vendas para cá, para os Estados Unidos. Abrimos uma filial aqui nos Estados Unidos. Até então estávamos operando a partir do Brasil, não tinha um ser humano aqui. "

Além de aprofundar a estratégia de seguir o cliente (J\&J), Leonardo Mattiazzi, no comando dessa filial à época, começou a prospectar outros clientes, ao mesmo tempo que recebia algumas solicitações, como, por exemplo, de um startup que conheceu a CI\&T pelo site da internet: 
“Eu comecei a expandir [os contatos] para outras empresas, em geral empresas pequenas. Então teve uma startup em Nova Iorque... Fechamos contrato com eles em 2008, se não me engano. E depois tivemos mais algumas startups, uma delas no Colorado. Elas estão em lugares diferentes, então eu vivia viajando pelos Estados Unidos.... Geramos uma referência tão forte que depois nos levou pra Pfizer, que é a maior empresa de farma do mundo."

Nos Estados Unidos, segundo Bruno Guiçardi, um elemento fundamental para as novas oportunidades de negócios é o boca-a-boca, a partir de uma rede de relacionamentos de negócios estabelecida pela empresa no decorrer dos anos:

\begin{abstract}
"A nossa mais recente conclusão sobre o que funciona aqui nos Estados Unidos é que não é diferente de como funcionam os negócios de serviços de TI no Brasil. Vendemos os nossos serviços dentro de uma esfera de influência que conseguimos estabelecer. Ou seja, não conseguimos vender para quem não nos conhece. E aí as referências são fundamentais.... Então, para quem conseguimos vender aqui nos Estados Unidos? Para organizações em que tem alguém que veio de uma empresa que nós já atendemos, ou alguém que está precisando de certo tipo de serviço e conhece alguém que trabalhou conosco. É uma rede de referências. E é assim que funciona a venda. É muito difícil - acontece, mas é exceção - vender para alguém que não recebeu uma referência a nosso respeito."
\end{abstract}

O mesmo executivo ressalvou, porém, que nos países mais desenvolvidos institucionalmente a rede usada é sempre a de negócios, para obtenção de referência do serviço. Os serviços de tecnologia do Brasil necessitam ser legitimados por quem já conhece o trabalho da empresa. Os norte-americanos, por exemplo, não se importam de serem abordados por desconhecidos, não precisam de alguém conhecido para abrir as portas, o foco deles é a proposta de valor que se oferece. Bruno reconheceu, no entanto, que em países como Brasil, Argentina, ou México, a rede de relacionamentos pessoal pode fazer diferença:

"Na Argentina foi tão complicado quanto no Brasil. Lá nós já tínhamos alguns relacionamentos, usamos gente conhecida para nos ajudar. Quem nos ajudou foi outro brasileiro que já tinha um call center lá, e ele nos deu alguns direcionamentos. A empresa dele nos ajudou também."

Em 2009, a CI\&T fez uma joint venture com uma empresa japonesa de TI Rococo Global Technologies - estabelecendo, em operação conjunta, um escritório em Tóquio e um centro de desenvolvimento na China em Ningbo, onde há 15 universidades de TI. O centro de desenvolvimento tem a função de atender os clientes da Ásia. A ideia de abrir as fronteiras para a Ásia foi baseada na percepção de que os grandes clientes àquela época, com presença na Ásia, recomendariam a CI\&T para prestar serviços na região. Segundo Bruno Guiçardi: 
"Nós achamos que havia uma oportunidade de expandir nossa presença na Ásia, por meio de alguns clientes, principalmente a Johnson. Então validamos a ideia com executivos da J\&J e eles nos garantiram que tinham interesse, nós já éramos um vendor global para eles... Nós achamos que, se fossemos para lá, seria possível conseguir negócios com os mesmos clientes, seria simples assim. Aumentar o número de negócios com os clientes atuais naquela nova geografia. Então, fomos numa missão comercial [...] para buscar parceiros, porque sem um parceiro local não iríamos conseguir entrar no mercado japonês. Achamos uma empresa que se interessou e ficamos uns dois anos 'namorando'. Visitas de parte a parte. E então fechamos uma joint venture com essa empresa japonesa. [...] Eles colocariam gente deles, japoneses. E nós ficaríamos responsáveis pela operação."

Em retrospectiva, Bruno Guiçardi observou que a decisão foi acertada:

"Depois vimos que nossa avaliação estava correta. Sem a parceria com os japoneses nós não teríamos conseguido entrar no Japão. Então, não teria funcionado, a filial não ia vender nem um amendoim. O pessoal local não teria aceitado fazer negócio se não soubesse que tinha uma parceria com uma empresa japonesa estabelecida.”

Em 2011, a CI\&T fechou contrato com a Pfizer por indicação de um executivo que saíra de uma empresa que fora atendida pela CI\&T, mas que mantinha um relacionamento com um dos sócios via redes sociais (LinkedIn). Ao ingressar na Pfizer, o executivo verificou a necessidade de troca de fornecedor no setor em que atuava, convidando a CI\&T que, após apresentar três propostas, se tornou fornecedora da Pfizer.

Em 2012, a CI\&T abriu seu segundo centro de desenvolvimento fora do Brasil, em Buenos Aires, Argentina, com a finalidade de atender o mercado dos Estados Unidos, porém a crise na Argentina fez com que esse centro fosse desativado em dois anos.

Em 2013, a CI\&T decidiu intensificar sua estratégia internacional, designando líderes para quatro grandes regiões do planeta - América Latina, América do Norte, Europa e Ásia - com o objetivo de ganhar conhecimento das particularidades de cada uma. Segundo Cesar Gon em entrevista ao site Convergência Digital, é necessário manter presença local nesses mercados, o que está alinhado com o modelo de negócios da empresa que entrega seus serviços a partir de centros de desenvolvimento localizados em regiões estratégicas de alta competência e baixo custo. O executivo explicou: "Estes mercados pedem uma presença local e o modelo de negócio da CI\&T garante uma estrutura global de entrega com foco na excelência, competitividade e escala dos nossos serviços" (Convergência Digital, 2012). 
A estratégia que havia impulsionado a empresa de se associar à rede de uma grande multinacional foi replicada, e a empresa prestava serviços na Europa e na Ásia, na maior parte dos casos associada a grandes multinacionais norteamericanas e japonesas, como explicou Bruno Guiçardi: "Na Europa, nós vendemos para as empresas internacionais, para as subsidiárias das norteamericanas, Coca-Cola, Pfizer, Johnson \& Johnson”. Essa forma de penetração permitia à CI\&T vencer a falta de legitimidade das empresas de tecnologia brasileiras na Europa e na Ásia:

"Chegar num lugar desenvolvido e tentar estabelecer relação, é dificílimo, porque falta legitimidade, 'que história você tem para contar, que referência você tem para dar?’ Se a sua referência for só no Brasil, não serve para nada”.

Em 2014, tendo conquistado importantes clientes na Ásia, como Lush, MTI e Kose, a empresa comprou a parte da Rococo na joint venture, tornando-se CI\&T Japão, em Tokyo. Foi contratado um brasileiro, para dirigir a filial, com 25 anos de experiência no Japão, com quem mantinham relacionamento constante. Em 2015, a empresa continuava investindo no mercado internacional, que já respondia por $40 \%$ do faturamento total.

Em 2015 foi inaugurada a filial de Londres, para facilitar o relacionamento com os executivos das subsidiárias locais de multinacionais norte-americanas, para as quais a CI\&T prestava serviços.

\section{Linha do Tempo de Internacionalização da CI\&T}

\begin{tabular}{ll}
\hline ANO & Evento \\
\hline 1995 & Fundação da CI\&T \\
2004 & Contrato com empresa da Califórnia \\
2004 & Contrato com a Johnson \& Johnson \\
2005 & Abertura de filial na Filadélfia \\
2009 & $\begin{array}{l}\text { Joint Venture com Rococo Global Technologies no Japão e } \\
\text { abertura de centro de competência em Ningbo na China }\end{array}$ \\
2011 & Abertura de escritório em New Jersey \\
2012 & $\begin{array}{l}\text { Abertura do centro de competência em Buenos Aires } \\
\text { Abertura de escritórios em Atlanta e Califórnia }\end{array}$ \\
2013 & Abertura de escritório em Houston \\
2014 & $\begin{array}{l}\text { Abertura de filial no Canadá } \\
\text { Cenpra da participação da Rococo na joint venture; nova }\end{array}$ \\
2015 & Abertura de filial em Londres \\
\hline
\end{tabular}




\section{2.}

\section{FUJITEC}

\subsection{1.}

\section{Identificação e breve histórico da empresa}

A Fujitec é uma empresa de TI baseada em Fortaleza, que oferece primordialmente serviços especializados em sistemas de bilhetagem eletrônica, além de sistemas de videomonitoramento eletrônico embarcado, sistemas de administração de cartões, sistemas de avanço de sinal e controle de velocidade. Em 2016, a Fujitec está fisicamente presente no Brasil, e atende com suas soluções alguns países como Estados Unidos, Itália, Colômbia e Nigéria.

Fundada em 1991 por quatro sócios, três deles engenheiros formados em diferentes universidades brasileiras, mas que estudaram juntos na infância e adolescência em Fortaleza, a empresa provia inicialmente soluções inteligentes nas áreas de automação comercial e projetos envolvendo uso de cartões eletrônicos.

A escolha do nome da empresa já demonstrava a vocação de se internacionalizar, conforme um dos sócios, Wicca Neves relata: "E ficou Fujitec, de tecnologia. Só que nós vimos que é um nome, lá fora, que agrada e, principalmente, por ser japonês, entre aspas, é tido como ligado a tecnologia".

A inserção no mercado de bilhetagem eletrônica aconteceu de forma acidental. Em decorrência de um trabalho desenvolvido para a Assembleia Legislativa do Ceará, a Fujitec foi chamada para desenvolver um software de controle eletrônico do transporte gratuito de estudantes em Fortaleza. Nessa ocasião, os sócios perceberam a oportunidade de associar hardware e software por meio do uso de smartcards, no transporte público. A solução incluía equipamento, tipo catraca, e o software da Fujitec, que fazia a leitura dos cartões.

Para ter a solução completa foi necessário fazer parcerias com outras empresas que fabricavam o equipamento (hardware). No Brasil, a Fujitec se associou a uma empresa de São Paulo, mas como os sócios já percebiam o avanço dessa tecnologia na Europa em relação ao Brasil, foram à Suiça buscar soluções mais inovadoras. Wicca Neves explicou: "Nós fizemos uma viagem para a Europa e uma das empresas a serem visitadas era essa empresa suíça." 
Nos anos seguintes, a empresa cresceu no Brasil, chegando a ter, em 2008, mais de um milhão de cartões em uso em suas aplicações e mais de 4.000 equipamentos e leitoras de validação instalados e operando. Seus sistemas processavam mais de dez milhões de transações por mês, com uma carteira de clientes diversificada, que abrangia empresas de transportes públicos, bancos, colégios, clubes, ou outros setores que fizessem uso de cartões eletrônicos. Nesse mesmo ano, a Fujitec contava com cerca de 30 funcionários, tendo apresentado crescimento elevado em receita no período de 2000 a 2007, quando seu resultado alcançou cerca de quatro milhões de reais, sendo aproximadamente 30\% proveniente de atividades internacionais.

Tendo como carro-chefe da empresa o sistema de bilhetagem eletrônica, a Fujitec sofreu perdas em seus negócios entre 2013 e 2015, fortemente influenciadas por questões políticas, já que a grande maioria de seus clientes era proveniente da esfera pública, e pelo avanço tecnológico, como esclareceu um dos empreendedores, Danilo Reis: "Com o surgimento de aplicação móvel, muitas das utilidades que eram previstas para smartcards foram absorvidas pelos smartphones".

Em 2015, a empresa contava com dez funcionários e suas incursões internacionais não mais aconteciam, embora ainda mantivesse sistemas na Itália, na Colômbia e nos EUA. Os sócios entendiam que seus produtos não necessitavam de mais investimentos e que atenderiam à demanda ainda por alguns anos.

Em 2014 a empresa redirecionou sua estratégia, desenvolvendo um produto novo que atendia diferentes mercados, saindo da dependência do governo como cliente principal. A Fujitec se associou à Universidade de Fortaleza para dar continuidade às pesquisas. Como afirmou Danilo Reis: "Então hoje levamos nosso P\&D para dentro da universidade. Assim, você baixa o custo de mão de obra." 
Os planos da empresa para 2016 eram de iniciar a comercialização, no mercado doméstico e no mercado internacional, de produtos com tecnologia de geolocalização, atrelados ao conceito de internet das coisas. Também planejavam usar a rede de contatos adquirida em suas empreitadas internacionais para buscar parceiros na produção dos artefatos, já que seria um produto sensível a custos, mas sem perda de qualidade. Segundo Danilo Reis, a busca de um parceiro internacional era necessária pela não viabilidade de produzir o hardware no Brasil:

"Você não consegue viver em um mundo competitivo, com as regras que temos aqui no Brasil. Infelizmente.[...] Porque é um trade off qualidade - preço. Então vamos ver se na China conseguimos um prȩ̧o [bom] com uma qualidade mínima aceitável. Ou se nos Estados Unidos o preço que eles vão fazer ainda é competitivo. Porque esse produto, se ele for muito caro, perde um pouco a função.”

\subsection{2.}

\section{Processo de internacionalização da Fujitec}

Em busca de fornecedor de tecnologia smartcard na Europa, os sócios resolveram viajar para a Suíça no ano de 1994, para conhecerem algumas empresas. Na Cardintel, do grupo Siemens, estabeleceram um contato mais próximo, que gerou visita dos suíços ao Brasil, crescimento da rede com outras empresas relevantes do mercado e possibilidades de novos negócios, tanto na Europa quanto no Brasil, envolvendo os agora parceiros. Segundo Wicca Neves:

“... Nessa ocasião, nós trouxemos esse fornecedor aqui em Fortaleza, ele nos conheceu e ficou impressionado por já termos desenvolvido o produto. Logo em seguida, ele nos convidou para irmos à Suíça dar um treinamento para seus funcionários".

A Cardintel produzia os chips dos cartões magnéticos e foi um parceiro importante, pois percebeu que a tecnologia desenvolvida pela Fujitec disporia de um grande mercado para ser explorado e, por consequência, as vendas dos seus chips também aumentariam, passando então a indicar a Fujitec na Europa.

Em contrapartida, a Fujitec também oferecia a possibilidade de a empresa suíça penetrar no mercado brasileiro. Uma das oportunidades em conjunto foi a participação em uma concorrência para o governo suíço. A Fujitec perdeu, mas rendeu-lhes experiência e despertou os sócios para o potencial da internacionalização. Como relatou Danilo Reis: 
“... Eles nos forneceram alguns contatos, ou seja, foi muito importante o networking deles para que nós pudéssemos começar a ter acesso ao pessoal que tinha a tecnologia... os provedores, realmente, a Siemens, a Thompson, ou seja, eles tinham já um networking formado na área”.

Com o tempo, os sócios foram percebendo que possuíam um produto de alta tecnologia a preços bastante competitivos o que os incentivou a buscar oportunidades tanto em mercados desenvolvidos, como Europa e Estados Unidos, quanto na América Latina.

A segunda oportunidade internacional ocorreu de forma emergente. Havia em 1996 uma licitação internacional para bilhetagem de ônibus no Rio de Janeiro, da qual a Fujitec não pretendia participar. No entanto, uma empresa australiana, a VFJ, procurou-os para que formassem uma parceira. Criaram um consórcio que, mesmo não tendo fechado negócios naquela oportunidade - o projeto no Rio parou por motivos políticos - fomentou uma relação duradoura.

A empresa australiana decidiu então se estabelecer no Brasil e buscar mais negócios em conjunto com a Fujitec. No decorrer do processo da licitação no Rio de Janeiro, a VFJ, primordialmente na figura de seu diretor de Marketing, Chris Adams, ficou impressionada com a qualidade e com o comprometimento dos profissionais da Fujitec, surgindo daí uma relação estreita de confiança mútua, que abriu outras portas no mercado internacional para a empresa brasileira.

No Brasil as duas empresas participaram de mais alguns projetos levando a VFJ a abrir um escritório no Rio de Janeiro, fechado em um ano em decorrência da falta de negócios, que esbarravam nos entraves burocráticos do órgãos públicos brasileiros.

A saída da VFJ do Brasil acabou por acelerar o processo de internacionalização da Fujitec, muito em função do forte laço criado entre os sócios da Fujitec e Chris Adams, que passou a envolvê-los nas oportunidades que surgiam nos mercados por onde navegava. Nas palavras de Danilo Reis: "Então, por um lado foi ruim, porque a gente tinha uma proximidade maior, e por outro lado foi bom, porque até quando ele foi pra lá, ele nos levou junto."

Dessa aliança surgiram mais dois negócios: um contrato de consultoria e venda de licença do software para a TSF, empresa de transporte da Itália e um projeto no Havaí. 
O projeto no Havaí também envolveu uma empresa de consultoria internacional, que, por sua vez, indicou a Fujitec para outra oportunidade em Denver, com uma das maiores empresas de transporte dos EUA, a RTD.

“Aí a Booz Allen nos levou para lá... Eu acho também que, de certa maneira, eles sabiam que o nosso custo era baixo. Porque, para você ter uma ideia, o projeto lá de Honolulu são dois milhões e quatrocentos mil dólares. A nossa parte ficou em oitocentos mil dólares”. (Danilo Reis)

Porém esses projetos não conseguiram render o que os sócios esperavam. No projeto de Denver, em razão de garantia e seguros que a empresa norteamericana exigia para cobrir o risco de insucesso. Para a Fujitec conseguir esses seguros teria que expor até recursos pessoais dos sócios, pois o projeto girava em torno de valores altos, incompatíveis com o tamanho da empresa. Como explicou Danilo Reis:

"Hoje, no mercado americano, eu só não estou indo porque eu aprendi um negócio: ir sem dinheiro, sem bala para gastar lá é meio perda de tempo. Até oportunidades surgem, tenho alguns contatos feitos na época, que, aqui e acolá, ainda consulto.”

No Havaí, a empresa conseguiu implantar o sistema, mas teve que entrar na Justiça contra uma parceira chinesa que deixou de pagar 400 mil dólares após a entrega.

Incentivados pela frequência com que oportunidades internacionais estavam surgindo e desmotivados pelas dificuldades que surgiam no mercado norteamericano, os sócios começaram a frequentar feiras especializadas em transporte no Brasil. Buscavam eventos que atraíssem principalmente clientes da América Latina, onde consideravam que a imagem do Brasil era forte. Foi assim que oportunidades no Equador e na Colômbia surgiram, segundo Danilo Reis:

“Tem esse projeto de Quito, que surgiu através de uma feira em São Paulo, que é até outra estratégia... Querendo ou não, nós [o Brasil] somos os Estados Unidos dos pobres. As feiras nacionais, em muitas delas você tem uma atuação a nível de América Latina."

A tal altura, a Fujitec já possuía boa reputação e era procurada nas feiras por potenciais clientes que vinham com referências de outros clientes brasileiros. No entanto, o projeto na Colômbia, que despontava como promissor, envolvendo uma alta quantidade de ônibus, em um mercado praticamente virgem, também trouxe prejuízo para a empresa, mas, dessa vez, o motivo foi político. 
As novas investidas internacionais, a partir de 2015, estavam focadas no novo produto, baseado na internet das coisas. A expectativa dos sócios era de que a experiência obtida e o networking desenvolvido nos projetos nos EUA, Itália e Colômbia viabilizariam novos negócios. Os sócios planejavam ter a produção nos EUA ou na China e a comercialização global. Nas palavras de Danilo Reis:

"Então, é complicado, nos Estados Unidos criamos um networking bom. Assim, se eu quiser produzir na Califórnia, eu tenho como chegar lá, tem fulano e tem sicrano. Eu sei onde comprar, eu sei onde fazer."

\section{Linha do Tempo de Internacionalização da FUJITEC}

\begin{tabular}{ll}
\hline ANO & Evento \\
\hline 1991 & Fundação da Fujitec \\
1994 & Parceira com Cardintel na Suíça \\
1995 & Participação em licitação para o governo suíço \\
1996 & Parceria com a VFJ da Austrália \\
2001 & $\begin{array}{l}\text { Parceria com a VFJ para venda de licenças do software para } \\
\text { empresa de ônibus na Itália (TSF) }\end{array}$ \\
2003 & Projeto no Havaí \\
2004 & Projeto em Denver (empresa RTD) \\
2004 & Participação em projetos no Equador e na Colômbia \\
2006 & Implantação do sistema no Havaí \\
2008 & Implantação do sistema na Colômbia \\
\hline
\end{tabular}

4.3.

IVIA

4.3.1.

Identificação e breve histórico da empresa

A Ivia é uma empresa brasileira, situada em Fortaleza, no Ceará, fundada em 1996 por dois sócios oriundos da IBM, com formação em informática: Alexandre Menezes e Edgy Paiva. Mais um sócio integrou a Ivia a partir de 2005, Márcio Braga, ex-colega da IBM, que havia trabalhado em Portugal por sete anos, trazendo experiência internacional à empresa. 
A Ivia atuou no início como provedora de serviços de internet, alcançando o primeiro lugar como provedor corporativo do Ceará. Porém, em pouco tempo a empresa redirecionou sua estratégia, ao perceber que esse setor rapidamente se esgotaria. Por volta do ano 2000, os dois sócios venderam o provedor e decidiram produzir software para a internet. Os principais produtos da empresa eram webdesign, desenvolvimento de aplicações, suporte e administração de sistemas e configurações de redes e bancos de dados.

A Ivia vem apresentando excelentes resultados desde os anos 2000, como mostra o Quadro 4.1.

\begin{tabular}{|l|c|c|c|c|c|}
\hline & 2004 & 2005 & 2006 & 2007 & 2016 \\
\hline Número de empregados & 35 & 117 & 258 & 320 & 450 \\
\hline Faturamento (R\$ milhões) & 1,5 & 3,7 & 7,1 & 16 & 35 \\
\hline
\end{tabular}
Quadro 4.1 - Crescimento da IVIA de 2004 a 2007
Fonte: Rocha, Mello, Maculan e Pacheco (2010), entrevistas e notícias no site da empresa

Com o redirecionamento estratégico, a Ivia passou a ser uma empresa desenvolvedora de software, comercializando dois tipos de produtos: o software por encomenda e o software produto, ou seja, padronizado, com pequenas adaptações ao cliente.

Os sócios entendiam que o padrão de seus produtos e serviços deveria ser comparável ao padrão internacional, por se tratar de setor extremamente competitivo e os grandes players multinacionais estarem presentes no Brasil. Essa visão permitiu o sucesso doméstico e também a entrada em mercados externos. Segundo o sócio Edgy Paiva, as empresas nacionais do setor de software, por disporem de um grande mercado doméstico, pouco se arriscavam lá fora, mas as multinacionais estrangeiras também disputavam o mercado brasileiro (Empresa Cearense..., 2008).

Em 2002, a Ivia iniciou suas incursões internacionais, por meio de uma parceria com uma empresa portuguesa, Noesis. Com a crise em Portugal, em 2008, os Estados Unidos passaram a ser o maior mercado externo da Ivia, embora em 2015 ainda não contassem com escritório no país. Como explicou o sócio Alexandre Menezes, a vantagem do setor de software é que a exportação é simples, e migrar de um país europeu para um americano não representa grandes custos. 
Em 2009, 2012, 2013, 2014 e 2015, a Ivia ocupou posições no ranking da Revista PME Exame das 200 empresas que mais crescem no Brasil. Em 2012, a empresa ficou, pelo terceiro ano consecutivo, entre as melhores empresas para trabalhar no Brasil, pelo ranking GPTW, ocupando o primeiro lugar no Nordeste, feiro repetido em 2014 e 2015.

Em 2016, a empresa estava fisicamente presente nos estados do Ceará, Pernambuco e Rio Grande do Norte, no Brasil, e em Portugal, com aproximadamente 450 funcionários, faturando na ordem de 35 milhões de reais, sendo 5\% originados de negócios internacionais. Essa proporção se alterava muito em função da variação cambial e do comportamento do mercado doméstico, como explicou Alexandre Menezes em março de 2016:

"Nos últimos quatro, cinco anos talvez. Havia uma aceleração do Brasil e o mercado interno contratou bastante. Então, embora os nossos serviços de exportação crescessem, o crescimento interno era mais expressivo... Mas, há um ano, desde a desvalorização do real... Então pode ser que, daqui a 10, 12 meses, quando você for me perguntar de novo, o que era $5 \%$ já tenha voltado a ser $25 \%$."

\subsection{2.}

Processo de internacionalização da Ivia

O início do processo de internacionalização da Ivia se deu em 2002, de forma não intencional. Um ex-colega da IBM, Márcio Braga, na época diretor de uma empresa portuguesa (Noesis) e que, mais tarde, viria a se juntar aos dois sócios fundadores na Ivia, ofereceu uma oportunidade de prestação de serviços de treinamento no Banco Espírito Santo em Portugal. Alexandre Menezes assim relatou:

\footnotetext{
"No momento da criação [da Ivia] não estávamos vislumbrando nada internacional, não. O mercado brasileiro é muito grande. É muito grande ainda hoje, não é?[...] Neste caso específico, um contemporâneo nosso da época de IBM trabalhava lá e nos chamou para ajudá-lo nesse aspecto."
}

O mercado cearense estava começando a se esgotar para a Ivia, sendo o caminho natural explorar outras cidades do Brasil, como Brasília e São Paulo. No entanto, esses mercados já estavam muito explorados, inclusive por grandes empresas multinacionais, e a experiência em Portugal fez com que os sócios percebessem que tinham produtos e serviços competitivos também na Europa, decidindo assim pela expansão na região. Alexandre Menezes descreveu como se deu o despertar para a oportunidade: 
"A primeira venda, foi bem pontual. [...] Percebemos que o mercado de lá é tão receptivo quanto o daqui e nós tínhamos alguns valores agregados, em termos de melhor especialização na área de tecnologia. Nós estamos mais próximos [do que os europeus] da grande fonte de tecnologia de software que é a americana. [...] Seguimos bastante essa cultura americana e por isso estamos um pouco à frente das questões tecnológicas da Europa.”

O modo de entrada escolhido foi o de buscar parcerias com empresas com produtos e serviços complementares, e a busca levou cerca de um ano, com idas e vindas, trocas de e-mail e telefonemas. No início, a opção era por empresas similares, mas logo os sócios perceberam que estas os viam como concorrentes e a solução encontrada então foi a escolha de uma empresa que não oferecesse serviços idênticos, mas que tivesse boa reputação e carteira de clientes significativa na Europa, além de predisposição para diversificar seu portfolio. Nas palavras de Alexandre Menezes:

"Passamos então a definir, em parte, a forma como a Ivia agiria, se uma abertura de escritório, uma subsidiária, uma representação, ou uma parceria. Acabamos concluindo que a melhor opção era uma parceria com uma empresa. E aí veio a pesquisa nessa dúzia de empresas pra saber qual era a melhor e que também aceitasse e visse com bons olhos a parceria."

Em 2003, a Ivia selou um contrato de parceria com a Noesis, tanto por se enquadrar nas características definidas, quanto pelo fato de ter em seus quadros o ex-colega da IBM. Márcio Braga, então diretor da Noesis, explicou como se dava a divisão de trabalho entre os parceiros:

“Nosso foco, na Noesis, era toda a parte de consultoria na área de tecnologia da informação. Mas nós não tínhamos produtos. Então, houve um link com a oferta da Ivia. A Ivia tinha produtos prontos e fazia projetos fechados, sob encomenda. E a Noesis só fazia consultoria. Reunimos as ofertas... [...] Mas a chancela de conhecermos no passado o Márcio, de termos trabalhado na IBM, era muito forte, tão forte que, quando ele quis voltar ao Brasil, ele se tornou nosso sócio.”

Logo no ano seguinte a Ivia abriu um escritório em Lisboa, pois havia necessidade de transferência de conhecimento, já que o que a Ivia comercializava era totalmente diferente das ofertas da Noesis. Como descreveu Alexandre Menezes:

“Em 2003 nós assinamos a parceria e iniciamos uma parte da operação. Como esse parceiro era complementar, não fazia nada do que fazíamos, tivemos até que manter uma estrutura comercial, com funcionários nossos lá.” 
A forma de trabalho escolhida pela Ivia em mercados externos é a de ter um parceiro local, responsável principalmente pela parte comercial, diminuindo os riscos de não conhecer a burocracia e os costumes de negócios locais, ao mesmo tempo que aumenta o grau de confiança dos clientes, ao lidar com locais. Como explicou Márcio Braga: "O nosso foco é que nós não temos uma ação direta com o cliente final, ou seja, não vendemos diretamente. A minha intenção é que um parceiro meu trabalhe cada conta."

Além disso, ao escolher a Noesis como parceira, a Ivia passou a pertencer a uma extensa rede de fornecedores e clientes, não só em Portugal, como em outros países da Europa. Alguns clientes da Noesis eram grandes empresas, como a Portugal Telecom, Sonae e Vodafone. Márcio Braga relatou:

\begin{abstract}
"Porque a Noesis trabalhava com grandes contas, só com empresas grandes. Foi ótimo. Fizemos várias viagens, tanto para a Espanha, como para a Bélgica. Então, foi muito bom em termos de network. Tanto, que quando eu voltei para cá, estruturamos essa área - Portugal e Espanha - e o foco é tentar um parceiro na Espanha, em um processo que está em andamento. Naturalmente isso ficou comigo porque eu detinha o network, a cultura, o falar, porque é diferente..."
\end{abstract}

Após algum tempo, os sócios perceberam a necessidade de contratar um gerente de território, sem deixar de usar o parceiro, mas para garantir a continuidade das prospecções que até então exigiam diversas idas e vindas do gerente da área internacional. A empresa selecionou um brasileiro que trabalhava há 16 anos em Portugal e que pode unir o conhecimento dos dois países, além de já ter trabalhado em parceria em um cliente da Ivia.

O gerente de território também tinha a função de aumentar a rede de parcerias, atendendo à estratégia da Ivia, que buscava empresas com diferentes características, que comercializassem outros produtos e serviços, sempre complementares. Márcio Braga descreveu em 2006:

"Ele já foi também Diretor de várias empresas lá [em Portugal]. Hoje, é um consultor que nós convidamos a fazer parte da Ivia. Porque pra nós é importante; levar daqui pra lá, não funciona, ou seja, ele não tem [contatos], vai bater na parede de gelo. Se chega um gerente lá, que nunca trabalhou em Lisboa, não sabe andar em Portugal, não fala espanhol, não conhece os costumes, não vai dar muita força."

A vinda de Márcio Braga para a Ivia permitiu à empresa utilizar a rede de relacionamentos que o novo sócio havia constituído na Europa e, em particular, em Portugal. A esse respeito, Márcio Braga observou: 
“A rede fornece as referências locais. É como uma certificação de profissionais. Porque, por mais que você seja bom, tem que ter algum tipo de selo, com referências locais. O mais difícil é quebrar a barreira da desconfiança, conseguir chegar na pessoa certa. Então, isso ajuda, se você já trabalhou lá, se você conhece as pessoas."

Em 2008, em decorrência da grave crise econômica em Portugal, o foco internacional da Ivia voltou-se para os Estados Unidos. A empresa já havia feito alguns movimentos anteriores de prospecção nos mercados da América do Norte: o primeiro, quando um dos sócios passou três meses nos Estados Unidos; o segundo, quando a Ivia participou de duas feiras nos Estados Unidos, em 2005; e, por fim, quando a empresa contratou um consultor brasileiro, residente no Canadá, para um mapeamento inicial de oportunidades nesses dois grandes mercados da América do Norte.

Alguns contratos aconteceram por indicação de ex- funcionários. Foi assim no contrato com a Liberty Power, na Flórida, que se mantem desde 2008, indicada por um ex-funcionário, que conhecia o diretor de tecnologia dessa empresa e, posteriormente, outro contrato no Canadá, que aconteceu por indicação de uma ex-funcionária radicada nesse país.

Os dirigentes da Ivia prosseguiram com a estratégia de buscar parceiros, pois entendiam que a presença de uma empresa local madura trazia confiança aos clientes. Dentro dessa filosofia, a Ivia fez parceria com duas empresas na Flórida, a SWCS e a Concepta, que atuam como agentes nos EUA. A última foi inserida na rede da Ivia de uma forma peculiar. Um funcionário da Ivia foi abordado por uma empresa da Flórida, para ir trabalhar lá. O empregado comunicou ao sócio, que ligou para o empresário da Flórida e propôs que ele contratasse a Ivia. Como Alexandre Menezes detalhou:

"Em vez de você contratar um funcionário, um a um, por que não contrata a Ivia? E aí pode ter debaixo da Ivia 400 pessoas à sua disposição. E assim eu cheguei a essa outra empresa, que é a Concepta. Fizemos alguns negócios com eles, mantemos relações com eles, e é provável até que realizemos alguns investimentos juntos."

A empresa mantem a rede ativa por meio de participação em eventos e, principalmente, por uso das redes sociais. Alexandre e seus sócios estão permanentemente ligados às redes sociais, e acreditam na importância dessa manutenção para futuros negócios, aliada a bons serviços, gerando referência e legitimidade. 
A empresa pretendia investir mais no mercado internacional a partir de 2016, impulsionada pela desvalorização do real e pela situação econômica brasileira, como ressaltou Alexandre Menezes:

"Isso vai aumentar [o percentual de receita internacional] por causa da nossa vontade, agora, de crescer mais. Nosso mercado interno é enorme, crescemos lá fora, mas crescemos muito mais dentro, porque as demandas aqui, a precariedade, as necessidades são maiores. Então, crescemos com uma velocidade grande aqui no Brasil. Mas com essa questão do dólar e o momento de bastante preocupação nacional, a Ivia vai direcionar a mira para o mercado externo."

\section{Linha do Tempo de Internacionalização da Ivia}

\begin{tabular}{ll}
\hline ANO & Evento \\
\hline 1996 & Fundação da Ivia \\
2003 & Início da parceira com a Noesis de Portugal \\
2004 & Contratação de Gerente de Território em Portugal \\
2006 & Estabelecimento de filial em Lisboa \\
2006 & Início da parceira com a Visionway de Portugal \\
2008 & Projeto na Inglaterra \\
2009 & Início dos negócios na Florida - EUA \\
2010 & Parceria com empresa norte-americana - SWCS \\
2014 & Parceria com empresa norte-americana - Concepta \\
\hline
\end{tabular}

4.4.

Light Infocon

4.4.1.

Identificação e breve histórico da empresa

A Light Infocon foi fundada em 1995, como resultado da fusão de outras duas empresas: a Infocon Tecnologia de Campina Grande, e a Light Software, de Brasília, fundadas em 1983 e 1990, respectivamente. A Infocon Tecnologia foi fundada por Alexandre Moura, seu irmão Antão Moura e Jacques Sauvé, um professor da Universidade Federal de Campina Grande, canadense. Antão Moura e Jacques Sauvé haviam acabado de chegar do Canadá, onde fizeram seus cursos de doutorado em engenharia elétrica e trouxeram para o Brasil o licenciamento de um produto chamado Unix System File da AT\&T. 
Os sócios perceberam, com o fim da reserva do mercado de informática no Brasil, no início da década de 1990, e a entrada de grandes players internacionais, que a sobrevivência da empresa dependeria de crescimento mais acelerado, maior amplitude de ofertas e maior alcance geográfico. Decidiram, então, pela fusão com a empresa de Brasília, a Light Software, com a qual já haviam trabalhado, além de seus executivos terem um relacionamento de longo tempo. $\mathrm{O}$ fundador da Light Software era Jairo Fonseca, que permaneceu na direção da filial de Brasília, onde dispunha de importante rede de conexões na esfera governamental. Alexandre Moura afirmou que os empresários haviam desenvolvido o hábito de "olhar sempre um pouco para a frente", de modo a identificar tendências cujos indícios estivessem começando a se manifestar:

“... em meados da década de 1990, ficou claro que, se não aumentássemos o tamanho da empresa, não fizéssemos fusões e juntássemos com novas tecnologias de terceiros, não iríamos muito longe. Então, como já havia uma parceria com a Light Software, uma empresa de Brasília, e já tínhamos alguns produtos desenvolvidos de forma conjunta, fizemos uma fusão com a mesma, dando origem, em 1995, à Light Infocon S.A.”.

O principal produto comercializado pela empresa é a gestão eletrônica de documentos e workflow, viabilizado por tecnologia de banco de dados textual multimídia orientado a objeto.

Para garantir a qualidade técnica, a Light Infocon investiu em parcerias com universidades e centros de tecnologia, como a Universidade Federal de Campina Grande, a Fundação Parque Tecnológico da Paraíba e o Institute of Software of China Academy of Sciences (Iscas) (Moura, 2007). Em 2008, cerca de 20\% dos gastos totais da empresa eram dedicados a P\&D.

A empresa colecionou diversos reconhecimentos ao longo de sua história, em resposta ao investimento em pesquisa. Dentre eles, destacam-se: duas vezes o Prêmio Assespro, na categoria Suporte à Documentação e ao Planejamento; o prêmio Editor's Choice, da revista PC-World da Espanha; e o Top of the World, da revista Unix Magazine, dos Estados Unidos. Em 2006, a Light Infocon foi indicada para o Prêmio Finep de Inovação Tecnológica, região Nordeste, na categoria produto. 
Em 2015, a empresa apresentava um total de 59 funcionários no Brasil, distribuídos entre a matriz em Campina Grande e a filial em Brasília, além de dois funcionários no exterior, locados em seu escritório na cidade do Porto, em Portugal. O faturamento da empresa girava em torno de 11 milhões de reais com $23,5 \%$ originados em mercados externos.

\subsection{2.}

\section{Processo de internacionalização da Light Infocon}

Os sócios da Light Infocon sempre tiveram em mente que a empresa deveria se expandir internacionalmente. Mesmo não havendo um plano de negócios formal planejando o passo a passo, havia um acordo tácito de conquistar um novo mercado por ano. Como observou Alexandre Moura: "Na realidade, tínhamos definido o seguinte: a partir do momento que botarmos o primeiro pé fora, vamos montar pelo menos uma expansão anual. "

O mercado brasileiro, especialmente na região Nordeste do Brasil, era muito restrito, e para os sócios, que já contavam com experiência e vivência nos EUA, foi um movimento natural, como esclareceu Alexandre Moura: “Nós já vendíamos para fora do Estado, de Campina Grande, porque a dificuldade de vender para São Paulo ou para os EUA é a mesma, principalmente com esses contatos, com essa network que tínhamos".

A primeira oportunidade, assim como muitas outras adiante, se deu por meio de relacionamentos, quando a empresa ainda era apenas a Infocon. Com a intenção de buscar o mercado externo, os sócios mapearam sua rede de contatos em busca de pessoas que pudessem ajudar a alcançar clientes de perfil adequado ao que pretendiam comercializar. Dessa análise, identificaram na Califórnia amigos dos sócios que haviam feito doutorado no Canadá, e surgiu a primeira oportunidade de trabalhar com exportação. Segundo Alexandre Moura, a empresa possuía uma rede relacionamentos gerada ao longo do doutorado na Universidade de Waterloo, sendo que grande parte dos membros dessa rede havia se instalado na Califórnia e no Vale do Silício:

"Fizemos uma lista do que desejávamos fazer. O nosso checklist dizia: 'temos que montar um escritório, temos que buscar parceiros locais'. E dentre esses parceiros locais, que tipo de parceiros queremos? E dentro desse tipo de parceiro desejado, temos contato antecedente com algum que tenha esse perfil? Então fizemos aquele trabalho de casa de mapear o que queríamos. E então nós fomos atrás. Tínhamos uns contatos com pessoas que tinham feito doutorado lá, com pessoas que eu conhecia de outros negócios, ou seja, existia um network.” 
A empresa começou exportando, mas em um ano os sócios perceberam que, para a empresa se manter e crescer nesse mercado seria necessário estabelecer um escritório. Assim, inauguraram o primeiro escritório internacional, em San Jose, Califórnia. Esse escritório foi mantido por muito tempo, ganhando muitos clientes, o que atraiu a atenção de candidatos a parceria. Como ilustrado por Alexandre Moura:

"Mantivemos o escritório por muito tempo até que a coisa andou e chegou a um certo tamanho. Deixa eu fazer uma comparação aqui; é como se você montasse o seu escritório mas com o objetivo de o seu negócio ser atrativo pra alguém local querer ser seu parceiro. Então você começa a mostrar para o pessoal local que tem negócio e você está ganhando cliente, está aparecendo e isso serve de ímã. Quando o parceiro chega, você tem condições, ele já está suficientemente interessado para realmente gerar um negócio. Um negócio, que eu digo, é a parceria. E aí você mostra o seu modelo de negócio que é exatamente não estar presente, a não ser em apoio."

O modelo de criar um pequeno escritório, conseguir algumas vendas, para depois se associar a algum parceiro local e fechar o escritório tornou-se recorrente nas futuras expansões da empresa. Como descreveu Alexandre Moura: "Então, chegamos a montar a empresa nos Estados Unidos. [...] Mas quando a coisa começou a ficar mais azeitada, não precisávamos mais [de escritório]."

Logo em seguida a Light Infocon exportou para o Canadá, em função das relações que o sócio canadense tinha no país. No entanto, nesse país não houve volume considerável, o que fez com que não tivesse necessidade de abrir escritório.

Outra forma eficiente que a empresa usou para internacionalizar foi a participação em feiras e eventos, que aliada à referência de clientes norteamericanos e canadenses, produziu negócios na França e na Itália. Relações com canadenses que trabalhavam com empresas francesas e norte-americanos descendentes de italianos trouxeram as indicações e a legitimidade necessárias para a expansão nesses dois países. Como observou Alexandre Moura:

"Essa é a questão. Por exemplo, Canadá tem a parte francesa e, com isso, fica mais fácil conversar com o pessoal da França. Aí, você conhecia uma empresa da França que usa o seu produto e que tem negócios com canadenses. Você trabalha com empresas nos Estados Unidos em que há muitos descendentes de italianos, que apresentam sua empresa a uma coligada lá na Itália, que está precisando do mesmo produto. E por aí, vai." 
Na China, o processo de entrada teve a ajuda da Softex, que abriu um escritório privado, com recursos da Finep, para abrigar empresas brasileiras e ajudá-las a penetrar no mercado chinês. A Light Infocon liderou a abertura desse escritório compartilhado - o China Office - dentro do Instituto de Tecnologia de Software Chinês (ISCAS), que atuava como uma espécie de incubadora, com a participação de várias universidades, fornecendo financiamento, incubação, apoio de joint venture, dentre outros benefícios. Nessa ocasião, para superarem as dificuldades burocráticas da China de 1997, os sócios acionaram contatos pessoais da Alemanha, que trabalhavam na Lufthansa na China, as redes criadas nos cursos no exterior dos sócios e do responsável pelo escritório na China. Além disso, buscaram ajuda com dirigentes de outras empresas brasileiras de outros setores que já atuavam no país, como a Embraer, algumas churrascarias, e a Weg, que ajudaram a conhecer mais as nuances do mercado e a chegar nas pessoas certas. Como ilustrou Alexandre Moura:

"Os contatos eram do tipo: precisamos tirar tal documento, com quem falamos na prefeitura de Beijing? Se você for entrar na burocracia maluca, leva meses. Tinha um brasileiro que morava na China, falava chinês e servia de consultor genérico para qualquer empresário brasileiro que chegava lá. E nós o conhecemos através de quem já estava lá.”

Seguindo o modelo de estabelecer parceria quando já tivessem alguns negócios, escolheram uma empresa local, que foi indicada por chineses, colegas de doutorado dos sócios, e que era ligada a uma universidade. O parceiro local dispunha de rede de contatos no país, a que se combinou a rede estabelecida pela Light Infocon no período em que dispunha de escritório compartilhado.

Na Austrália, a incursão, iniciada em 2001, se deu por meio de um funcionário casado com uma australiana, que se mudou para o país e fundou uma subsidiária, em que a Light Infocon tinha $70 \%$ de participação. Depois de alguns anos, as vendas passaram a ser feitas por uma empresa parceira, onde esse australiano foi trabalhar, liderando a equipe que cuidava do produto da Light Infocon. 
Em 2004, a Light Infocon abriu um escritório em Aveiro, Portugal, junto com um parceiro local. Ao contrário dos outros países onde atua ou já atuou, o escritório em Portugal permanece até os dias atuais por "uma questão estratégica", embora tenha migrado para a cidade de Porto. À época em que foi instalado pela primeira vez em terras lusitanas, Aveiro foi escolhida por ser uma cidade universitária, com concentração de empresas de tecnologia.

A atuação em Angola se deu inicialmente de forma pontual, por exportação, em parceria do escritório de Portugal com clientes portugueses. Só em 2011, por meio de uma parceria com uma empresa do interior de São Paulo que já tinha um ponto de apoio em Angola, a Light Infocon estabeleceu presença no país africano. Angola, Estados Unidos e Portugal (incluindo Espanha) eram, em 2015, os três grandes centros internacionais da Light Infocon em termos de faturamento. Como descreveu Alexandre Moura:

"Basicamente temos um parceiro aqui do Brasil que já tinha negócios lá. Fomos complementar o que essa outra empresa faz. E surgiu a oportunidade para as duas empresas atuarem em Angola. Então foi isso que nos levou a fazer os primeiros negócios em Angola. Depois a coisa andou e se tornou um mercado interessante."

Há também o caso de uso de fornecedor como ponte para comercializar em outros países. A Light Infocon usa os serviços de uma fábrica de software na Índia, em Goa (cuja língua é o português). Algumas vezes, os parceiros em Goa revendem os produtos, como relatou Alexandre Moura:

"Eles fazem esse serviço para o mundo todo, China, Austrália, Nova Zelândia Ele diz: 'Eu tenho um cliente lá que está precisando de um software que vocês têm. Posso vender?' Eu digo, 'claro'. Eles me indicam e fecham o negócio. [...]Tem país que eu nem sei nem onde é. Eu adapto para a língua que ele pede e mando.”

Outra forma de atuar utilizada recentemente, muito em função dos custos, é de prover os serviços apenas a distância, especialmente para empresas que possuam filiais no Brasil. Quando há necessidade de interações mais presenciais, a Light Infocon utiliza videoconferências ou atua junto aos escritórios do cliente no Brasil, como explicou Alexandre Moura:

"Um exemplo é a Inglaterra. Mas na Inglaterra, por incrível que pareça, conseguimos fazer isso a distância mesmo, sem ter um escritório lá...Qualquer problema que demande uma presença, uma visita, resolvemos com uma videoconferência, ou até através do próprio escritório dos clientes da Inglaterra que têm escritórios aqui no Brasil." 
Em 2015, a Light Infocon buscava "estreitar mais as relações" com a empresa parceira, em busca de novas oportunidades na Austrália e Nova Zelândia. Porém a empresa teve dificuldades e a parceria não teve continuidade.

A ênfase em redes e parcerias é considerada uma característica-chave da estratégia internacional da empresa. Em apresentação feita em encontro da Academy of International Business, no Rio de Janeiro, em 2010, Alexandre Moura destacou: "O desenvolvimento de networks e parcerias é nossa principal estratégia para alcançar os mercados internacionais." Em uma das entrevistas, ele já havia salientado: "É aquela questão, nesse ramo - eu não sei como é nos outros, eu não posso falar - mas, em tecnologia, é ponto pacífico a questão de você ter seu network. Sem isso, não se consegue fazer nada".

Alexandre Moura entende que as experiências anteriores dos sócios no exterior trouxeram, além da rede, uma atitude importante para lidar com o mercado internacional.

"Se você ver minha história de vida, eu fiz intercâmbio de jogos quando era adolescente. Meus pais sempre nos mandaram para fora, desde quando éramos pequenos. Então, eu não olho para o estrangeiro de baixo para cima, eu olho no mesmo nível."

\section{Linha do Tempo de Internacionalização da Light Infocon}

\begin{tabular}{ll}
\hline ANO & \multicolumn{1}{c}{ Evento } \\
\hline 1983 & Fundação da Infocon em Campina Grande \\
1988 & Primeira exportação para EUA \\
$1989 \begin{array}{l}\text { Primeiro Escritório Internacional - San Jose, Califórnia } \\
\text { (EUA) }\end{array}$ \\
1989 Exportação para o Canadá \\
1993 Exportação para França, Itália, Espanha \\
$1995 \begin{array}{l}\text { Aquisição da Light Software de Brasília e fundação da } \\
\text { Light Infocon }\end{array}$ \\
1995 Parceria com empresa em Madri \\
$1996 \begin{array}{l}\text { Estabelecimento de escritório em Pembroke Pines, Flórida } \\
\text { (EUA) na incubadora da Softex }\end{array}$ \\
$1997 \begin{array}{l}\text { Estabelecimento do China Office (China) e estabelecimento } \\
\text { de parceria com empresa local }\end{array}$ \\
$2001 \begin{array}{l}\text { Estabelecimento de escritório na Austrália em parceria com } \\
\text { brasileiro }\end{array}$ \\
2003 Exportações para Chile, Argentina, Inglaterra \\
2004 Estabelecimento de escritório em Aveiro, Portugal \\
\hline 2008 Mudança do escritório de Aveiro para a cidade do Porto \\
\hline 2011 & $\begin{array}{l}\text { Estabelecimento de escritório compartilhado com parceiro } \\
\text { brasileiro em Angola }\end{array}$ \\
\hline
\end{tabular}




\section{5.}

\section{MidiaVox}

\subsection{1.}

Identificação e breve histórico da empresa

A MidiaVox é uma empresa de Recife, Pernambuco, fundada em 1994. A empresa foi fundada por cinco sócios, dos quais apenas três permaneceram na sociedade: Alcides Niceas Pires, com formação em análise de sistemas, Garibaldi Galvão Rocha, engenheiro de telecomunicações, e Tuca Paes de Andrade, administrador de empresas.

A principal área de atuação da MidiaVox é o desenvolvimento de software de integração entre tecnologias de telefonia e informática (CTI - Computer Telephone Integration). Dentre os produtos e serviços oferecidos, estão os sistemas de resposta audível (URA), centrais de atendimento, call centers, atendimento automático de ligações, correio de voz, servidor de fax, teleconferências, reconhecimento de fala e portais de voz. Integrando-se com a internet, a MidiaVox tem sistemas de telefonia sobre protocolo IP. A empresa também desenvolve aplicativos para a plataforma Android. Inerente às características de seus produtos - que integram telefonia e informática - a empresa atua constantemente associada a empresas de telefonia. Foi assim no Brasil, onde se associou à Siemens, empresa alemã com significativa presença no Nordeste, e no exterior, em parceria com a Avaya, empresa norte-americana que atua no mundo todo.

A inovação tem sido uma presença constante na MidiaVox desde sua fundação. No site da empresa, em comemoração aos seus 20 anos, os sócios assim descreveram o início do empreendimento: "Após o período de gestação da tecnologia, com muito trabalho nas madrugadas pós expediente nas empresas nas quais trabalhávamos, o nascimento foi quase um ato burocrático." Em 2005, a MidiaVox recebeu o prêmio Finep de Inovação Tecnológica na categoria Pequena Empresa. Em 2011 e 2015, recebeu da Avaya Communication o "Key Supplier Avaya", um reconhecimento dado a poucos parceiros, como explica o sócio Alcides Pires: 
“Os prêmios são concedidos aos fornecedores nas mais diversas áreas. Tem fornecedor de software, fornecedor de hardware, fornecedor de serviços de instalação. Enfim, tem diversas classificações. O nosso prêmio, especificamente, é na parte de serviços profissionais. Foram dois fornecedores do mundo todo que receberam esse prêmio na nossa categoria."

Em 2015, a MidiaVox tinha escritórios em Recife e em São Paulo, embora tivesse, em seu portfolio, clientes espalhados pelo mundo. Nesse ano, a empresa obteve faturamento em torno de três milhões de reais, com 25 funcionários, todos alocados em Recife. Os negócios internacionais, que se iniciaram em 2000, com a ida para o Chile, mantinham-se ao longo dos 15 anos, muito em função de uma única parceria, com a Avaya, atuando junto a sua rede de subsidiárias, em mais de 150 locais. A receita proveniente do mercado externo variava em função do câmbio, mas, ao final de 2015, estava entre 35 e 40 \%, como previu Alcides Pires em entrevista realizada naquele ano:

\footnotetext{
"No ano passado [2014] foi em torno de 30\%. Esse ano [2015] deve ser mais. Há a questão cambial em si e a questão da economia mais parada no Brasil. Ou seja, a quantidade de novos projetos no Brasil fatalmente vai diminuir. Já começamos a sentir que a demanda por projetos novos está caindo, enquanto na Colômbia, por exemplo, não está havendo nenhuma queda. Então, naturalmente, vamos terminar alocando mais a equipe para projetos internacionais do que para projetos nacionais."
}

\subsection{2.}

\section{Processo de internacionalização da MidiaVox}

A primeira oportunidade fora do Brasil aconteceu de forma não planejada, já que os sócios nunca tiveram a intenção de internacionalizar a empresa. A MidiaVox prestou serviços no Brasil para a Avaya, uma empresa multinacional de soluções de call center, tendo sido bem avaliados pelo gerente à época. Quando esse gerente foi transferido para o Chile, solicitou que a MidiaVox executasse o mesmo serviço no país. O sócio Alcides Pires detalhou como ocorreu essa primeira oportunidade internacional:

"Eu tenho uma visão talvez muito simplista dos negócios internacionais. Os negócios internacionais são negócios como outros quaisquer. Como é um negócio interestadual, é a mesma coisa, com alguns complicadores. Então como é que acontece um negócio interestadual? Você faz o trabalho, alguém vê, ou então você faz propaganda daquele trabalho que você fez, alguém lá fora vê o que você fez e aí quer que você faça o trabalho lá. Nós fizemos um trabalho para esse cliente, que tem presença global, aqui no Recife e fomos muito bem sucedidos. Então o que aconteceu? Com essa experiência bem sucedida no Brasil, eles começaram a solicitar que replicássemos a solução em outros lugares”. 
Diante de mais um projeto bem sucedido e tendo alcançado o mais alto posto de direção na Avaya na América Latina, o executivo decidiu implantar o modelo de parceria em diversos países da região. Essa parceria dura há 15 anos, mesmo com esse executivo brasileiro atuando em 2016 em New York:

"Quanto ao Chile, o trabalho que fizemos para esta empresa no Brasil foi iniciado por um executivo da filial da empresa em São Paulo, que visualizou o modelo baseado em um mix de trabalho interno da Avaya com trabalho de parceiros externos, como nós. Este modelo foi muito bem sucedido e o executivo foi promovido para um cargo de nível regional - América Latina. Hoje ele é um Diretor Global da Avaya e consegue ver as oportunidades em que nos encaixamos. [...] É aquela historia, nós criamos uma reputação, que tem dois aspectos: um aspecto é a companhia, a MidiaVox, como empresa, e outro, o pessoal, principalmente o meu sócio, que conhece a fundo a tecnologia”.

O modelo de trabalho envolvendo parceiros foi implantado pela Avaya com a MidiaVox e mais alguns concorrentes, porém com o passar do tempo, a confiança entre as duas empresas se tornou forte. "No início eram uns dois ou três concorrentes que prestavam serviços para a Avaya. Hoje em dia, os outros dois acabaram e só estamos nós", revelou Alcides Pires.

A partir daí, a MidiaVox passou a fazer parte de uma rede de relacionamentos com diversos executivos espalhados pelo mundo, gerando negócios nos mais diferentes países, como Alemanha, Argentina, Bahamas, Bermudas, Canadá, Colômbia, Costa Rica, EUA, Guatemala, Itália, Japão, México, Porto Rico, Rússia e Venezuela. Alcides Pires ilustrou com diversos exemplos como essa rede beneficiou a MidiaVox:

"No caso da Rússia, o gerente de serviços da Avaya é um brasileiro que já nos conhecia daqui. [...] Esse modelo funcionou muito bem na Colômbia. Então, os executivos colombianos da Avaya estão assumindo posições importantes em outros países e confiam em nosso trabalho."

Apesar de a grande maioria dos serviços internacionais da MidiaVox atender a Avaya, a rede de relacionamentos criada também permite alcançar outros clientes, como exemplificou Alcides Pires:

"A Avaya tem unidades que funcionam, de certa forma, autônomas. Então isso é como um mercado novo para nós, ou seja, o trabalho bem feito em um deles faz com que outros venham a nos conhecer. E vamos ganhando novos mercados à medida que entra uma nova unidade da Avaya como contratante nosso. [...] A parceria está em vigor até hoje [2015], fortalecida pela entrada de novos clientes da própria Avaya. Eles vão conquistando novos mercados, nós acompanhamos essa conquista junto com eles. Por exemplo, fizemos alguns serviços para os clientes da Avaya no Canadá.” 
Algumas oportunidades também surgiram fora da parceria com a Avaya, em decorrência de executivos que iam trabalhar em outras empresas. Alcides Pires ilustrou esse caso:

"Nós não trabalhamos só com equipamento Avaya ou software Avaya. Então, se aparecer alguém, como já apareceu, por exemplo, no Chile, nós chegamos muito perto de vender o nosso software de URA para lá. [...] Nós temos equipamentos que concorrem com equipamentos da Avaya. Então, o executivo do Chile, que tinha sido cliente da Avaya, saiu, montou uma empresa etc. E nos chamou para participar de uma concorrência lá. Infelizmente ele perdeu a concorrência, mas se tivesse ganhado, o nosso software estaria rodando no Chile por um caminho desses, do executivo sair da empresa, conhecer a qualidade do nosso trabalho e poder ter nos contratado."

No entanto, nem sempre a expansão da rede além dos limites da Avaya produzia negócios. A parceria com a Avaya restringia a MidiaVox em algumas situações, como exemplifica Alcides Pires:

"Veja, eu acredito que existe uma dificuldade natural em ter uma empresa, com o grau de envolvimento que temos nos projetos, trabalhando com duas concorrentes diferentes. É como se fôssemos uma empresa de preparação física $e$ trabalhássemos ao mesmo tempo para o Vasco e para o Fluminense, ou para o Vasco e para o Flamengo ${ }^{2}$. Então, é muito difícil, porque naturalmente seríamos vistos com desconfiança pelo outro."

Os sócios passaram a ver o mercado externo como uma fonte de diversificação estratégica, o que foi apontado nas entrevistas concedidas em 2008 e 2015 por Alcides Pires:

"Hoje, com o valor do dólar como está pra nós é melhor trabalhar para o Brasil do que pra o exterior. No entanto, percebemos com uma visão estratégica de diversificação de mercados. E nós vemos muito isso. Por exemplo, no México, depois que passou a privatização da telefonia, os negócios rarearam. Em compensação, com o crescimento econômico da Colômbia e da Venezuela, os negócios esquentaram. Com a crise econômica da Argentina, os negócios acabaram lá, simplesmente acabaram. E só recentemente é que voltamos a fazer negócios lá. Então, assim, enquanto um mercado está bom, o outro está ruim."

Embora não houvesse, no início, planos de internacionalização, os sócios entendiam que a partir do primeiro evento, passaram a fazer parte de uma grande rede de relacionamentos que gerava negócios internacionais. O sócio Garibaldi Rocha deixou clara a importância percebida na constituição dessa rede para a expansão internacional da MidiaVox:

\footnotetext{
${ }^{2}$ Times de futebol do Rio de Janeiro.
} 
“Na verdade a internacionalização não foi uma decisão assim pensada $e$ planejada. Vamos para o exterior... não foi assim. Foi: 'Você está a fim de fazer um trabalho no exterior?' 'Estou'. 'E quanto você cobra?' 'Tanto'. 'Tá bom eu pago'. E então, quando você faz um trabalho, aquilo chama outro, e outro, que chama outro, que chama outro... E hoje nós temos um fluxo mais ou menos constante de projetos no exterior... Nós criamos uma rede de contatos, o que é mais difícil de ser feito em negócios internacionais do que em nacionais. Pessoas que você conhece que estão ali num outro país e chamando a empresa. Isso nós conseguimos criar."

No entender dos sócios, nutrir os relacionamentos da rede da Avaya é importante para a MidiaVox e, por isso, mantêm contato frequente com os dirigentes das unidades regionais da Avaya, especialmente na América Latina. Ao longo do tempo, alguns desses relacionamentos se fortaleceram, mas não perdurariam se, em sua visão, não houvesse dois componentes cruciais, a competência e a ética:

"Como prezamos os aspectos éticos, os aspectos mercadológicos são consequência. Mesmo que tivéssemos uma enorme vantagem mercadológica, não iríamos buscar outro parceiro que ferisse os aspectos éticos com a Avaya. O preço desse bom relacionamento é que precisamos cuidar para continuarmos sendo vistos como parceiro confiável. [...] Normalmente começamos nos conhecendo por Skype. Com o tempo, ao longo do projeto, criamos uma relação mais pessoal." (Alcides Pires)

Recentemente, a empresa tem mantido contatos com outra grande parceira, a Oracle, e pretende seguir o mesmo modelo de aderir à rede da multinacional. Os serviços que irão oferecer não concorrem com os da Avaya, o que deixa os sócios muito à vontade. Mais uma vez, essa oportunidade surgiu da rede da Avaya, já que um ex-funcionário da mesma, que passou a trabalhar na Oracle, iniciou as negociações com a MidiaVox: "O Sr. X, que foi da Avaya, e hoje está trabalhando na Oracle, identificou umas oportunidades que são de natureza diferente do que fazemos na Avaya. E ele é uma pessoa com quem temos relacionamento de longo tempo e que confia bastante em nós."

Ter a oportunidade de entrar na rede de uma empresa como a Avaya teve papel relevante no processo de internacionalização da empresa. Na opinião de Alcides, esse é o processo mais eficiente, embora necessite de tempo e paciência: 
"Eu diria que a maioria dos projetos de internacionalização que eu vejo ignoram isso [a rede]. Eu vejo muitas vezes esse aspecto ser ignorado, ou relegado. Como se fosse possível pegar uma malinha, passar 15 dias numa cidade e estabelecer uma parceria com alguém lá que vai vender seu produto. A nossa experiência é no sentido oposto. Fizemos algo positivo aqui em Recife, essa experiência se replicou pelo Brasil. Essa rede, ao longo do tempo, vagarosamente, foi assumindo posições mais estratégicas na companhia [Avaya] e graças a isso fomos sendo indicados para outros negócios no exterior. Foi o crescimento basicamente em decorrência da rede e não por uma ação direta, como, por exemplo, por meio de participação em feiras."

\section{Linha do Tempo de Internacionalização da MidiaVox}

\begin{tabular}{cl}
\hline ANO & \multicolumn{1}{c}{ Evento } \\
\hline 1994 & Fundação da MidiaVox em Pernambuco \\
2000 & Chile - parceria com a Avaya \\
2001 a & América Latina - Argentina, Bahamas, Bermudas, \\
2004 & Caribe, Colômbia, Costa Rica, México, Venezuela, \\
2004 & Jorto Rico,- parceria com a Avaya \\
2006 & Itália, Alemanha - parceria com a Avaya \\
2007 & EUA - parceria com a Avaya \\
2012 & Canadá - cliente Avaya \\
2014 & Guatemala, Panamá - parceria com a Avaya \\
\hline
\end{tabular}

\section{6.}

\section{Totall Sistemas}

\subsection{1.}

\section{Identificação e breve histórico da empresa}

A Totall Sistemas Ltda é uma empresa originada da Oficina Software, inaugurada em 1991 por dois sócios, ambos analistas de sistemas: Murilo Machado e Edilson Paterno. O produto inicialmente criado e comercializado era o software de automação comercial Totall, lançado na Fenasoft de 1991, maior feira brasileira de software. Este software adquiriu força de marca suficiente para levar os sócios a decidirem, em 2001, fundar uma nova empresa batizada de Totall.com S.A. Ao longo dos anos, a empresa desenvolveu outros aplicativos de automação comercial, primordialmente focando os pequenos lojistas. Mais tarde, em decorrência de uma parceria com a Fuji, desenvolveu produtos direcionados aos revendedores Fuji do Brasil. 
No início dos anos 2000, a empresa investiu no desenvolvimento de aplicativos de apoio à decisão, atualmente conhecidos como BI (do inglês, Business Intelligence, ou Inteligência de Negócios), lançando na Fenasoft de 2011 o Totall Netdata, que mais tarde passou a se chamar Totall BI.

Até 2002, a Totall comercializava seus produtos por meio de revendedores, com bom alcance geográfico, chegando a ter 47 revendas no Brasil, vendendo principalmente para empresas pequenas. Os sócios perceberam que esse segmento de mercado além de mais arriscado em ternos de sonegação, era muito influenciado por preço, e não pela qualidade do produto. Edilson explica como decidiram mudar de foco:

"Porque, por exemplo, até 2001 ou 2002, nós éramos totalmente dependentes da venda de parceiros locais aqui no Brasil, que chamamos de revenda e distribuidor. Então percebemos que tínhamos que sair do mercado do pequeno e ir para o de médio porte, porque cada vez mais o mercado do pequeno estava complicado. [...] Nós tínhamos que sair desse mercado e ir para um mercado onde o cliente não comprasse por preço e sim por qualidade, por serviço. Chegamos a ter 47 revendas no Brasil todo, só que nós percebemos que esses parceiros não estavam preparados porque eram empresas regionais que faziam tudo. Eles vendiam o meu produto, mas vendiam micro, davam treinamento, davam assistência técnica, vendiam um sistema de contabilidade, vendiam sistema."

Em 2016, a Totall tinha a matriz em Blumenau e mais três escritórios comerciais em São Paulo, Belo Horizonte e Rio de Janeiro. Além destes, a empresa contava com diversos parceiros no Brasil que revendiam os produtos Totall BI, já que os mesmos podem ser ofertados diretamente aos clientes. A empresa dispunha de aproximadamente 20 revendas, 3.900 clientes (100 no Chile) e 11.9000 licenças. No mercado internacional, até 2010, a Totall mantinha dois funcionários em Portugal, mas posteriormente passou a ter só uma empresa representante, a ASSEC, fechando o escritório de Covilhã.

A Totall obteve receita de 2,1 milhões de reais em 2014, contando com 36 funcionários e previa receita de 2,5 milhões para 2015. Em 2008, com a mesma receita de 2,5 milhões de reais, $10 \%$ eram originados do mercado externo, enquanto que, em 2014, apenas 2\%. Em 2015, esse percentual baixou para $0 \%$. 


\subsection{2.}

\section{Processo de internacionalização da Totall}

O primeiro movimento para fora do Brasil aconteceu de forma emergente, ao participar da Fenasoft em 1993, onde a empresa buscava expor seus produtos visando clientes nacionais. Na ocasião, foi procurada por executivos de uma empresa de Moçambique, a NCL. Edilson Paterno faz uma retrospectiva positiva da experiência:

"Moçambique era uma coisa muito inicial. Foi um: 'vamos lá, vamos vender'. Foi uma venda como se fosse para alguém em Manaus ou em Belém. Quer dizer, era uma oportunidade, poderia dar dinheiro ou não, mas era um negócio que, felizmente, naquelas primeiras licenças, nós ganhamos, faturamos.”

Em 1996, novamente na Fenasoft, tiveram início negociações com a Fuji do Brasil para implantação do software de automação comercial em suas lojas. A Totall desenvolveu versões específicas direcionadas exclusivamente para lojistas Fuji Photo Film do Brasil, implantando-as em todas as lojas da empresa no território nacional. Diante do sucesso desse projeto, a Fuji solicitou a instalação do software em suas lojas no Chile.

Foi a partir dessa segunda experiência internacional que os sócios despertaram para a possibilidade de expansão no exterior, buscando de forma intencional outras oportunidades. A começar pela Fuji, que tinha presença global, e que propiciou contato com outras subsidiárias na América Latina. Também usaram a parceria com a Unisys para explorar o mercado colombiano:

"Tinha a Fuji na Venezuela e eu fui lá umas duas ou três vezes. Chegamos a fazer contato e já estávamos elaborando a minuta de contrato, mas houve uma reviravolta política naquele país e eles suspenderam o investimento. Tanto na Venezuela, quanto na Colômbia, estávamos prospectando o mercado em parceria com a Unisys. Tínhamos uma boa parceria com a Unisys Brasil”.

Somente em 2006, em função da participação de um dos sócios - Edilson Paterno - em grupo de fomento ao desenvolvimento e internacionalização de empresas de software de Blumenau, aconteceu novo movimento de internacionalização. O grupo reunia dez empresas locais, com o apoio do Sebrae de Santa Catarina, da Prefeitura de Blumenau e do Departamento de Sistemas e Computação da Fundação Universidade Regional de Blumenau. 
Uma das iniciativas desse projeto foi enviar uma equipe para avaliar o potencial dos produtos das dez empresas em Portugal. Nessa missão identificou-se uma ação da prefeitura de Covilhã, que culminou com um acordo de cooperação com a prefeitura de Blumenau. Para as empresas brasileiras foi disponibilizado um espaço físico com excelente estrutura, dentro do Parque Tecnológico de Covilhã.

Uma vantagem obtida do relacionamento entre os participantes do grupo que trabalhou junto no projeto de Covilhã foi o fato de ter-sido criada uma rede de negócios, gerando até mesmo algumas vendas no Brasil por meio dessas parcerias. Edilson Paterno esclarece como percebeu os benefícios originados desse consórcio:

"A ideia de formar aquele consórcio das dez empresas foi interessante, não só nós, como outras empresas acabaram se conhecendo mais, fizeram negócios. Fiz negócios com empresas que estavam aqui no grupo. Então, isso também ajudou internamente a vender um pouco mais."

$\mathrm{Na}$ avaliação feita pela primeira equipe enviada a Portugal, os produtos da Totall teriam boa aceitação pelo mercado local, especialmente o Totall BI, um produto voltado para pequenas empresas, o que ainda não era comum. Para confirmar o estudo, Edilson Paterno decidiu ir pessoalmente a Portugal. As constatações feitas na viagem foram assim descritas pelo empresário:

"Quando eu fui lá, em fevereiro de 2007, aí sim, percebi que automação comercial não dava, não valia a pena. Era melhor ficar focado no Business Intelligence. [...] A maioria das empresas de médio porte não tem Business Intelligence (BI). Só as grandes corporações e os bancos. E é até novidade para algumas coisas... Eu vi que tinha mercado.”

A estratégia usada para penetrar em Portugal era a de encontrar um parceiro similar, fornecedor de software, disposto a comercializar o Totall BI, com as vantagens de uma empresa local. Além de dispor de uma revendedora, a Totall manteria dois funcionários no Parque Tecnológico de Covilhã, como explicou Edilson Paterno: "Então resolvemos centrar nosso foco no Business Intelligence e procurar boas software houses que tivessem produtos de alguns segmentos e quisessem dispor de um produto novo sem investir nele".

A Totall firmou parceria com a Assec, sediada em Covilhã, que já possuía em sua carteira 150 clientes. Na visão dos sócios, eram claros os benefícios que ambas as empresas obteriam com essa parceria: 
"Eles são uma software house de médio porte e têm produtos para várias áreas, não são focados. Mas eles têm um número de clientes bastante grande na indústria panificadora. Um número grande de padarias em Portugal, que são contas médias, o que é uma vantagem para nós, porque o nosso Business Intelligence também não é para o grande cliente. E é uma vantagem para a Assec, porque eles não dispunham deste tipo de software. Então, o que eles vão nos dar? Conhecimento do mercado, pelo menos, e principalmente naquela região, em alguns segmentos, a facilidade de chegar nos clientes. [...] Eles ganharam dinheiro e tempo, porque o nosso problema de informática é muito isso. Às vezes, não adianta você fazer o melhor produto, o problema é ter o produto no tempo certo".

A partir de Covilhã, a Totall fez algumas tentativas de expansão na Europa: (i) entre 2008 e 2009, na Espanha e na França, e (ii) entre 2010 e 2011, em Angola e Moçambique, todas não concretizadas. Além da Assec, que prospectava em nome da Totall, a experiência do consórcio também havia deixado uma rede de relacionamentos que indicavam oportunidades para a empresa. Edilson Paterno explica esse fato: "Quem trabalha mesmo é o distribuidor. Os outros são empresas com que temos contato, que fazem a indicação, mas não têm foco, ou não têm estrutura."

$\mathrm{Na}$ Espanha, os sócios perceberam que a crise econômica iniciada em 2008 aumentaria muito os riscos, e decidiram não investir. Na França, havia a oportunidade de usar a rede de relacionamentos pessoal de um parceiro em Portugal e que havia morado na França. Iniciaram negociações com uma empresa de software francesa, mas perceberam que era um mercado que exigiria presença local, o que também implicava investimento de risco.

Já a iniciativa em Angola não evoluiu porque o modelo considerado adequado para entrar no país seria o de estabelecer parcerias, principalmente por se tratar de um país com burocracia pouco ortodoxa, o que exigia conhecimento local. O temor de enfrentar problemas éticos e, até mesmo, comportamento oportunista por parte de um parceiro desconhecido fez com que a empresa desistisse de investir no país. Edilson assim descreve como se deu a tomada de decisão em relação à entrada em Angola:

"Em Angola teríamos que montar a estrutura lá. E teria que ter um sócio local. Pelo menos as pessoas que fizeram negócios que ainda estão lá, comentam a mesma coisa, que é preciso ter alguém local que conheça como funciona. [...]É ruim você investir em sociedade com alguém que você não conhece. E se der um problema, você vai processar o parceiro como? Ele está no país dele! Então, nós resolvemos não evoluir.” 
Continuaram, portanto, com a estratégia de manter a prospecção em Portugal e na África nas mãos do parceiro português, comunicando-se por videoconferências a partir do Brasil, quando necessário.

Os sócios achavam que, se investissem mais em Portugal, teriam conseguido mais negócios, apesar da crise. A decisão de recuar foi tomada em função do pouco lastro financeiro à época:

"O grande problema acho que foi não termos confiança e não investirmos para ter mais frente de atuação. Daria tranquilamente para manter o parceiro e ter um escritório em Lisboa e outro na cidade de Porto, por exemplo. Teríamos investido uma boa grana, mas eu acho que, apesar de toda a crise, teríamos um retorno muito melhor.[...] [E também contou] o fato de não termos disponibilidade e dinheiro à época para fazer esses investimentos...”

A estratégia de internacionalização em 2015 estava centrada na tentativa de estabelecer sociedade com uma grande multinacional, parceira antiga no mercado brasileiro, que comercializaria o produto da Totall na América Latina. Esse formato era considerado interessante, dado que um parceiro desse porte já possui presença em diversos países, permitindo uma expansão rápida e segura. A forma e os benefícios advindos dessa parceria são explicados pelo sócio Edilson Paterno:

"Pensar, nós pensamos [em continuar a internacionalizar], mas ou estamos em joint venture com alguém, ou fazemos como estamos já há alguns meses, conversando com uma empresa multinacional americana. E a ideia é ter um produto de automação comercial para a América Latina. E o que nós estamos tentando é fazer com que esse produto seja o nosso. Estamos conversando para que eles encampem esse produto, para ser vendido com o nome deles, com a marca deles. Seria produzido por nós e vendido por eles. Eu acho que é muito mais fácil, porque eles já têm escritórios na Colômbia, na Argentina, acho que no Equador... Então, é muito mais fácil desse jeito porque você vai chegar nesses países, ter alguém local e vender o seu produto. Não vai ter a sua marca, mas vai estar vendendo o seu produto. Esse, pra nós, acho que é o melhor caminho."

Dentre as maiores dificuldades para internacionalização relatadas estão a falta de financiamento a juros baixos e a marca Brasil para produtos e serviços de TI, que, mesmo na América Latina, não é unanimemente reconhecida, na opinião de Edilson Paterno. Essas barreiras induzem os empresários a buscar parcerias com empresas multinacionais estabelecidas globalmente, mesmo que para isso tenham que abrir mão de suas marcas. 
"Apesar de ter alguma iniciativa do governo, a marca software brasileiro ainda não é algo reconhecido. Então, eu acho que é muito mais fácil crescer primeiro internamente do que externamente. Porque a marca software brasileiro não é uma coisa forte. Eu estive agora em 2012, 2013 na Colômbia e percebi isso. [...] E nós temos produtos de qualidade em várias áreas. Mas eu acho que uma dificuldade que a maioria das empresas enfrenta, quando quer vender lá fora, é que nós somos desconhecidos. [...] É diferente quando você fala de um produto de Israel, um produto americano, indiano, russo, que já têm um certo reconhecimento como qualidade."

Linha do Tempo de Internacionalização da Totall

\begin{tabular}{cl}
\hline ANO & \multicolumn{1}{c}{ Evento } \\
\hline 1991 & Fundação da Oficina Software em Blumenau \\
1993 & Exportação para Moçambique \\
1996 & Parceria com a Fuji no Chile \\
2001 & Fundação da Totall.Com \\
2007 & $\begin{array}{l}\text { Acordo de distribuição em Portugal com a empresa } \\
\text { Assec }\end{array}$ \\
\hline
\end{tabular}

4.7.

TOTVS

4.7.1.

Identificação e breve histórico da empresa

A Totvs foi fundada originariamente como Microsiga, no ano de 1983, por dois sócios: Laércio Cosentino e Ernesto Haberkom. Ernesto era o dono da Siga, uma empresa de informática que desenvolvia sistemas para os grandes computadores (mainframes) e Cosentino era um de seus mais jovens e competentes diretores, que estava certo de que, no futuro, as empresas migrariam para a microinformática. Tanto assim que convenceu seu chefe a criarem em sociedade uma nova empresa, que foi batizada à época de Microsiga (COSENTINO, HABERKORN E CÍCERO, 2001). Apenas em 2005, após uma sucessão de aquisições que visavam diversificar seu portfolio de ofertas, a empresa mudou o nome para Totvs, que, em latim, significa "tudo", ou "todos". A nova marca era uma alusão à capacidade de a empresa prover soluções completas a seus clientes. 
A Totvs apresentou um desempenho excelente em toda sua história, crescendo no Brasil, primeiramente por meio de franquias, e mais tarde, a partir de 2003, empregando a estratégia de aquisições de diversas concorrentes no mercado doméstico-

Em 2006, a Totvs abriu o capital lançando ações na Bovespa, destacando-se como a primeira empresa no setor de software a abrir seu capital no Brasil.

Em 2015, a Totvs era a sexta maior desenvolvedora de sistemas de gestão integrada (ERP) do mundo e a primeira de países emergentes, sendo a líder absoluta no Brasil e na América Latina. As soluções da Totvs incluem softwares de gestão empresarial integrada (ERP), gerenciamento de relacionamento com clientes (CRM), Business Intelligence (BI) e Supply Chain Management (SCM).

A empresa está presente nos três segmentos de clientes: grandes, pequenas e médias e microempresas, sendo líder de mercado no Brasil e na América Latina no segmento das PMEs. Sua estrutura no Brasil é formada por cinco filiais, 52 franquias e nove centros de desenvolvimento (fábricas de software) com mais de três mil funcionários alocados em desenvolvimento de software e suporte. Ao todo a empresa conta com mais de sete mil empregados diretos.

Em 2014, a Totvs alcançou 1,8 bilhão de reais em receita, com mais de $50 \%$ de participação de mercado de ERP no Brasil, com investimento de mais de um bilhão de reais em $P \& D$ nos últimos cinco anos, sendo considerada a $21^{\mathrm{a}}$. marca mais valiosa do Brasil no ranking da Interbrand. Em termos de desempenho financeiro, a empresa vem apresentando bons resultados (ver figuras 11, 12). 


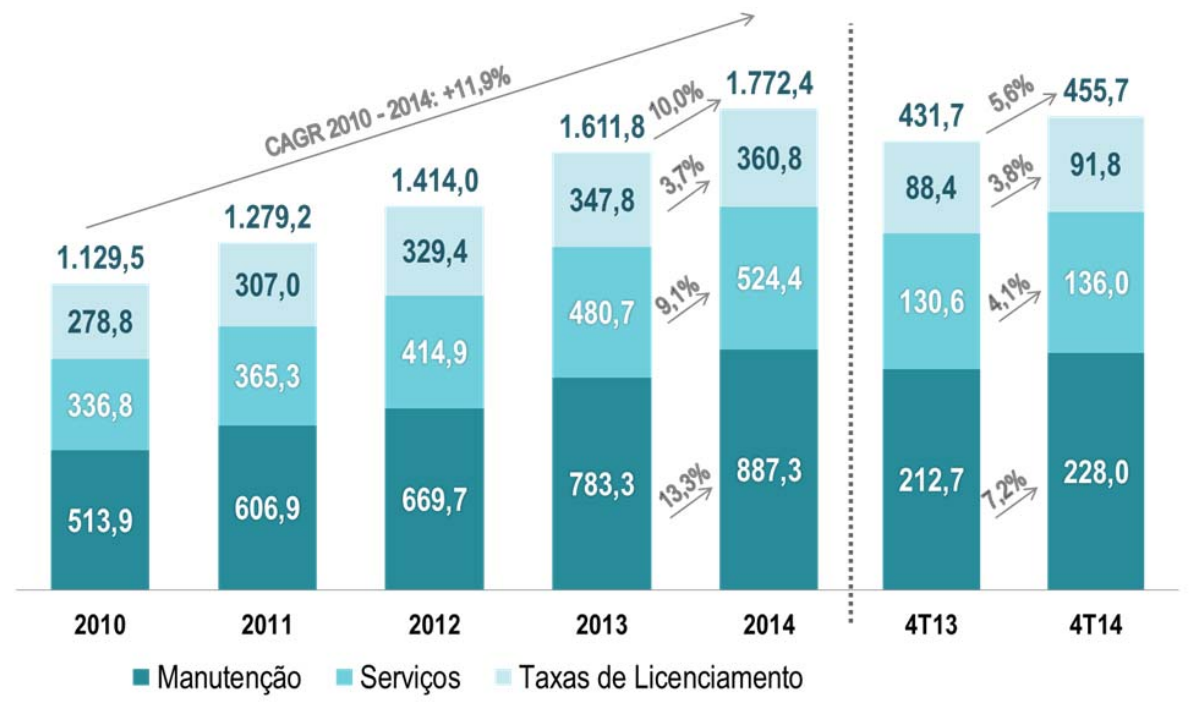

Figura 11 - Receita Líquida da Totvs em 2014 (R\$ MM)

Fonte: Apresentação dos Resultados $-4^{\circ}$. Trimestre de 2014 - (www.totvs.com.br, acessado em 21/02/2016)

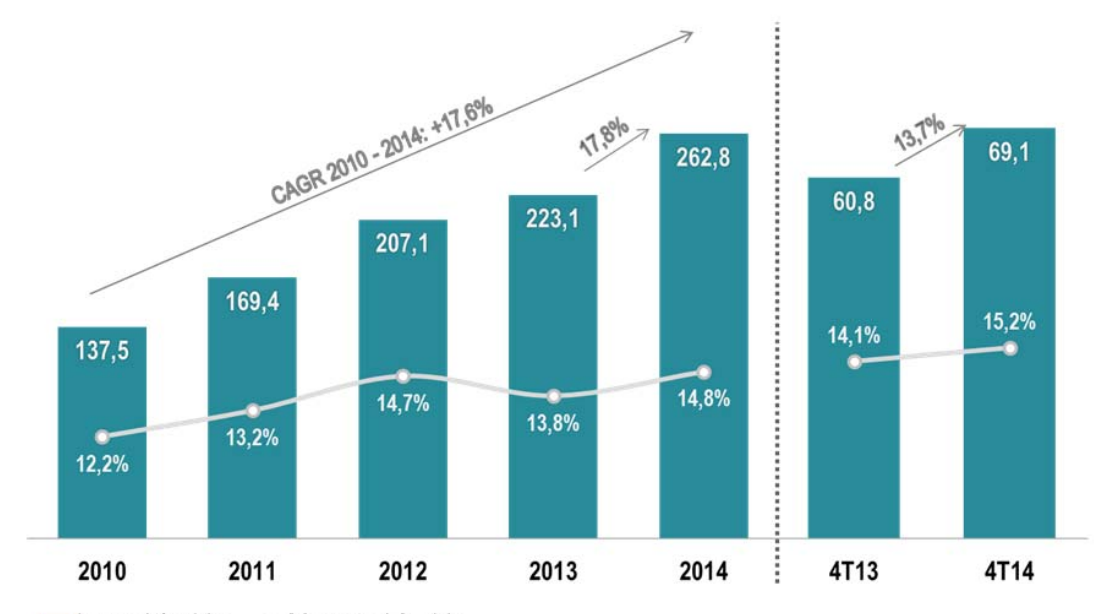

- Lucro Líquido -Margem Líquida

Figura 12 - Lucro Líquido da Totvs em 2014 (R\$ MM)

Fonte: Apresentação dos Resultados $-4^{\circ}$. Trimestre de 2014 - (www.totvs.com.br, acessado em 21/02/2016)

Internacionalmente, em 2016, a Totvs está presente em 41 países, dispondo de seis filiais (Argentina, México, Colômbia, EUA, Portugal e China), e quatro centros de desenvolvimento (EUA, México, China e Taiwan). Também mantém clientes ativos em outros países da América do Sul, Europa, Ásia e África em que não dispõe de filiais. As operações internacionais somam mais de 500 funcionários, entre diretos e indiretos, e contam com ampla rede de canais de distribuição e franquias de suas soluções de negócios, como visto na Figura 13. 


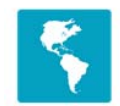

AMÉRICAS

In Clientes ativos

Canais

Filiais

(ARG e MEX)

- Centros de Desenvolvimento

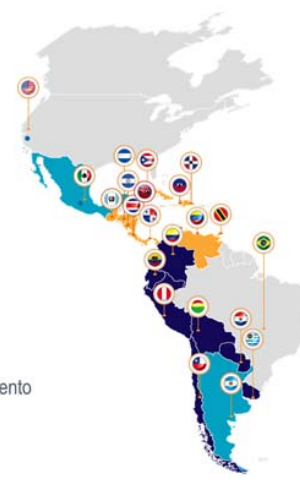

Figura 13 - Canais de distribuição da Totvs Fonte: Totvs, 2015a

Segundo o relatório de apresentação de resultados da empresa, a receita líquida das operações no mercado internacional cresceu $20 \%$ em 2014, passando de 27,8 milhões de reais para 33,4 milhões, correspondente a $1,9 \%$ da receita líquida consolidada. Uma visão dos resultados no período de 2011 a 2014 pode ser vista na Figura 14.
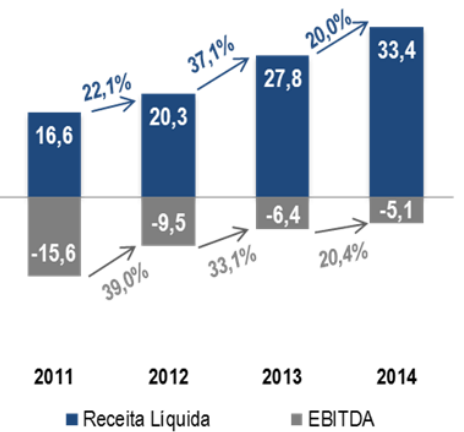
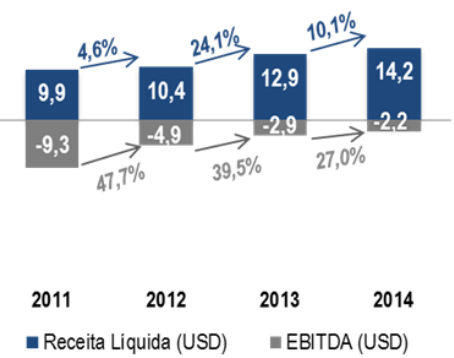

Figura 14 - Evolução da receita líquida e do EBTIDA nas operações internacionais da Totvs. Fonte: Totvs, 2014.

\subsection{2.}

\section{Processo de internacionalização da Totvs}

A primeira experiência internacional da Totvs foi para acompanhar clientes brasileiros que possuíam operações na Espanha e nos EUA, e para tal apenas foi feita uma adaptação do software para o mercado de destino, mas não houve interesse em a empresa se estabelecer nessas regiões. O vice-presidente da Totvs, Wilson Godoy, detalhou: 
“A Totvs localizou seus softwares para o mercado norte-americano, fez a manutenção dos softwares, mas não tem operação comercial nem de entrega. As atividades são somente para manter os clientes brasileiros com operações nos EUA (que não são poucas). Uma operação própria da Totvs nesse país seria muito custosa."

Em 1997, iniciou-se o processo de expansão para fora do país, com a abertura de uma filial em Buenos Aires, Argentina. A motivação estava ligada à percepção de que a concorrência de empresas internacionais aumentaria no mercado brasileiro, como descreveu Godoy:

"Eu mesmo fui até a Dinamarca fazer essa avaliação [...] Mas isso de fato acendeu as nossas luzes amarelas: 'Precisamos fazer alguma coisa, não adianta ficar aqui, sentado em berço esplêndido, porque a concorrência vai aumentar de lá para cá. Então, tínhamos que fazer a concorrência aumentar também daqui para lá.”

Decidiu-se explorar o mercado argentino como primeiro passo, já que a Argentina atravessava um período econômico favorável, além de ter proximidade cultural e geográfica com o Brasil. Um dos executivos foi designado para explorar o mercado argentino, inicialmente buscando entender que adaptações o produto ERP deveria sofrer. Wilson Godoy conta como foi essa exploração:

"No começo de 97 fomos para a Argentina, numa forma absolutamente amadora, inicialmente. Eu pessoalmente fui lá conversar com alguns escritórios contábeis para começar a entender um pouquinho o que seria uma eventual localização de software para a Argentina. [...] A empresa era muito menor, os processos eram muito menos formais, e a metodologia que usávamos era uma metodologia baseada em heróis. Daí, começamos a localizar o software, abrimos nossa filial e começamos a trabalhar efetivamente o mercado argentino."

A filial da Argentina se mantem como o hub para o Cone Sul, porém em todas as outras incursões na América do Sul, o modelo adotado foi o de franquia, como aconteceu no Chile, Colômbia, Porto Rico, Paraguai e Uruguai, logo em seguida:

"A primeira filial foi a Argentina, e a partir daí criamos franquias. Nós sempre vamos ter o que chamamos de hubs. A operação que cuida de Angola é a de Portugal, até em função da língua, e da própria legislação, que é muito próxima à de Angola. Vamos imaginar que nós vamos abrir uma operação na Ásia, muito provavelmente vamos ter uma filial na Ásia e os países em volta vão ser franquias. Nós costumamos irradiar através de um hub. Hoje os hubs são Argentina (Cone Sul), México, Portugal e Brasil." 
A empresa decide então explorar a América Latina, onde entende que a marca Brasil tem relevância, além da proximidade cultural e geográfica, conforme comenta Godoy:

"A marca Brasil, na indústria de software, é uma dificuldade nos países de Primeiro Mundo, por isso uma das razões de querer partir para a América Latina é que o Brasil é um ícone nessa região. É importante usarmos a força onde já temos."

Conforme a empresa aumenta sua presença na região, cresce a rede de relacionamentos, uma vez que o modo de entrada, via franquia, leva a parcerias estreitas com outras empresas em cada país em que a Totvs passa a operar. Wilson Godoy esclareceu que os franqueados são vistos como sócios:

"Na escolha dos parceiros/clientes, há uma busca por empresas de determinadas características - culturas bastante próprias e marcantes, selfmade man, e que precisem de software que se adapte a realidade deles com alguma facilidade $e$ poucos investimentos. [...] Primeiro, tem o procedimento de hunting, que é técnico, procuramos um empresário com skill técnico e comercial, procuramos ter sócios com esse perfil. [...] Não tenha dúvida de que ter empatia é importante, o nosso franqueado acaba sendo sócio da nossa operação fora do país, então a empatia é importante e tem que haver convergência de valores forte para poder fazer com que isso funcione."

No entanto, nas próprias palavras do Vice-Presidente, a rede formada por esses parceiros não gera identificação de oportunidades, já que todas as decisões de entrada em novos mercados são decididas a partir da matriz no Brasil:

"Não [os franqueados não levaram a contatos que facilitaram encontrar outros parceiros em outros países]. Normalmente a estrutura de gerenciamento internacional está aqui no Brasil, principalmente para a abertura de novos negócios."

Contudo, a rede criada pelos clientes ajuda a entrada em novos países, à medida que estes se expandem, como exemplificou Álvaro Cysneiros:

"Mas já percebemos, por exemplo, o cliente originariamente mexicano, levando a Totvs para a Colômbia, um português nos levando para Angola, um chileno nos levando para o Peru, nas expansões deles. [...] É um cliente de um país nos levando para outro país. Isso é um exemplo que eu acho que nós começamos a construir, uma referência, pode não ser global, mas pelo menos dentro da América Latina, que extrapola o Brasil.”

Além da América do Sul, a estratégia de expansão por aquisições-gerou as operações no México e em Portugal. A Sipros, adquirida em 2003, era mexicana e a RM Sistemas, adquirida em 2006, contava com escritórios em Portugal. Em 2008 foi criada a operação de Angola, subordinada à de Portugal. 
Em 2012, a empresa decidiu fazer uma reestruturação das operações internacionais, com o objetivo de estabelecer bases para um crescimento sustentável. Algumas das medidas implantadas foram: (i) alteração das principais lideranças e revisão dos processos e estruturas e das operações; (ii) adequação de escopo do portfólio de soluções, dando foco em verticais com bom potencial de crescimento e menor esforço de localização; (iii) criação de um hub de localização de soluções no México; (iv) redução do número de unidades próprias; e (v) expansão do número de canais de distribuição na região, ampliando o papel dos empreendedores locais como franqueados (TOTVS, 2014a).

Em 2013, a empresa tinha planos de investir mais agressivamente na expansão internacional, e traçava uma estratégia de fortalecer a marca Totvs, criando referência global que permitisse maior sustentação no crescimento externo. Álvaro Cysneiros explicou de que maneira a empresa planejava alcançar a meta:

“A Totvs quer ser uma referência global. Nós somos hoje o sexto player no mercado, queremos ser o terceiro até 2016. Só [crescimento] orgânico não vai dar. Temos que expandir fronteiras. Então, ser uma referência global, que está no nosso mote agora, é ter mais unidades em outros países."

Como parte das ações para criar uma marca global, a Totvs abriu um centro de desenvolvimento na Califórnia, no Vale do Silício, o TotvsLabs. Esse centro, além de contar com profissionais de diversas regiões do mundo, firmou parceira com duas universidades da região, com a função de deixar as pesquisas da Totvs alinhadas com o estado da arte da indústria de software. Álvaro Cysneiros esclareceu:

"Uma coisa interessante é que temos [na Califórnia] chinês, tailandês, russo, indiano, um monte de gente trabalhando, até para ajudar nessa cultura de internacionalização. O TotvsLab é um braço do nosso time de tecnologia do Brasil. [...] E nós contratamos Stanford para validar o nosso roadmap, ou seja, aquilo que nós pensamos hoje e no futuro em termos de tecnologia e de aplicações, tem um time de doutores de Stanford que recebe uma apresentação, acho que semestral, e eles validam. Eles e Santa Fé também. [...] E trazem notícias do front do que há de mais moderno, para nos criticar." 
Apesar da decisão de restruturação internacional, a empresa continuava a ter resultados modestos nesse segmento. Em 2014, a companhia inclusive informou a investidores que havia desistido de duas metas relativas à estratégia de expansão internacional: a primeira, de alcançar entre $3 \%$ e $5 \%$ da receita até o final de 2016 nas vendas fora do país; e a segunda, de alcançar ponto de equilíbrio das operações internacionais, correspondente a EBITDA igual a zero, no segundo semestre de 2014 (TOTVS, 2014b)

Em 2016 a Totvs criou o hub Região Andina, localizado em Bogotá, com o objetivo de melhor atender Colômbia, Equador e Peru, somando-se às duas outras estruturas: Norte, no México e Sul, na Argentina. A intenção da empresa é a de atuar mais fortemente na região, implementando novos canais e parceiros de negócios. Marcelo Souccar, responsável pela área internacional da Totvs desde fevereiro de 2016, afirmou: "Reestruturamos a nossa operação para aprimorar o atendimento às empresas locais e reforçar, ainda mais, a nossa estratégia nas Américas" (BRIGATTO, 2016).

Linha do Tempo de Internacionalização da TOTVS

\begin{tabular}{|c|c|}
\hline ANO & Evento \\
\hline 1983 & Fundação da Microsiga em São Paulo \\
\hline 1997 & Abertura de Filial na Argentina \\
\hline $\begin{array}{l}1997 a \\
2003\end{array}$ & Abertura de franquias no Chile, Paraguai, Uruguai \\
\hline 2003 & $\begin{array}{l}\text { Aquisição da Sipros no México e criação da Microsiga } \\
\text { México (estabelecendo centro de desenvolvimento em } \\
\text { Querétaro) }\end{array}$ \\
\hline $\begin{array}{l}2004 \text { a } \\
2006\end{array}$ & Abertura de franquias em Porto Rico e Colômbia \\
\hline $\begin{array}{l}2006 \text { a } \\
2007\end{array}$ & $\begin{array}{l}\text { Aquisição da RM Sistemas e criação da EuroTotvs, } \\
\text { com base em Portugal }\end{array}$ \\
\hline $\begin{array}{l}2008 \mathrm{a} \\
2009\end{array}$ & $\begin{array}{l}\text { Abertura de oito novas franquias, localizadas em } \\
\text { Bolívia, Uruguai, Norte de Portugal, Angola } \\
\text { (subordinada à subsidiária de Portugal), Argentina } \\
\text { (Córdoba e Mendoza) e Paraguai (duas unidades em } \\
\text { Assunção). }\end{array}$ \\
\hline 2010 & $\begin{array}{l}\text { Estabelecimento de centro de desenvolvimento nos } \\
\text { EUA (Totvs Labs, no Vale do Silício) }\end{array}$ \\
\hline 2011 & Abertura de franquia no Peru \\
\hline 2013 & Abertura de franquias na Venezuela e Equador \\
\hline 2015 & $\begin{array}{l}\text { Aquisição da Bematech, agregando centros de } \\
\text { desenvolvimento na China e Taiwan. }\end{array}$ \\
\hline 2016 & Criação do hub Região Andina, em Bogotá, Colômbia \\
\hline
\end{tabular}


4.8.

Xseed

\subsection{1.}

Identificação e breve histórico da empresa

A Xseed foi fundada em 1991, na cidade de Fortaleza, por três sócios. Ronaldo Brandão e Luis Miranda eram ex-funcionários da Unisys, com experiência na área técnica, e o terceiro um empresário da região, que participava como financiador do início do empreendimento. A motivação desse empresário em investir na Xseed estava relacionada ao produto que planejavam criar e comercializar. Dono de vários escritórios, cada qual com seu mainframe, precisava migrar seus sistemas para a plataforma baixa e assim reduzir seus custos com os mainframes.

Além de já contarem com esse primeiro cliente - o sócio financiador - os empresários percebiam que havia um nicho de mercado interessante. Muitas empresas de grande e médio porte estavam no processo de implantar o que se chamou de downsizing, ou seja, migrar os sistemas de uma plataforma mainframe para a plataforma descentralizada. Decidiram, então, criar uma ferramenta que auxiliasse a fazer a migração com segurança, e alcançaram um bom resultado, como explicou o sócio Ronaldo Brandão:

"Nós desenvolvemos uma solução de software única no mundo. Voltada para o ambiente da Unisys, nós criamos uma ferramenta, em tecnologia e metodologia de trabalho, que só depois de cinco anos começou a aparecer concorrente."

Ao longo dos anos, a Xseed passou a atuar como uma espécie de fábrica de software, especializada em converter código de uma plataforma mainframe para outra descentralizada. Com essa forma de prestar serviço, a empresa conseguiu maior flexibilidade para atender clientes distantes geograficamente, e mesmo internacionais, contando com o custo mais baixo da mão de obra e da infraestrutura do Nordeste do Brasil. Ronaldo Brandão explicou como funciona trabalhar com o conceito de fábrica, e como, mais recentemente, tem buscado trabalhar nos mercados internacionais com empresas parceiras, usando esse modelo: 
"Nesse conceito de fábrica de software que temos, o normal é integrar o sistema do cliente, trazer para cá para a transformação e voltar para implantar lá [no cliente]. Então aqui, em algum momento, tínhamos entre 12 e 15 pessoas trabalhando nesse projeto e lá só tinha uma ou duas pessoas. [...] Para nós isso é interessante também, é um modelo que estamos tentando perseguir para ficar como uma fábrica de software de conversão, de modo que não tenhamos desgaste viajando tanto e que os parceiros possam executar [a integração] e ficando com 30, $40 \%$ do contrato."

Além do foco em projetos de migração, a empresa também provê serviços de desenvolvimento de sistemas sob medida, usando o mesmo conceito de fábrica de software, porém esse serviço só é prestado no Brasil. "Nós temos outros trabalhos como fábrica de software e desenvolvimento de sistema sob medida. Mas isso é mais no Brasil."

Em 2015, a empresa mantinha 16 funcionários fixos, todos sediados no Brasil, mas essa quantidade flutuava de acordo com as necessidades de projetos. As receitas originadas do mercado externo variavam de $15 \%$ a $70 \%$, em função do número de negócios, ficando em torno de $40 \%$ no ano de 2015 . Um dos motivos para tal variação é o ciclo de vendas do principal produto da Xseed, que é muito alto, como observou Ronaldo Brandão:

"Nós vendemos projetos de serviços, principalmente serviços acompanhados de software. Temos um ciclo de vendas extremamente longo. Às vezes, acontece um milagre de um negócio acontecer em quatro meses, cinco meses. Mas, o normal é doze, dezoito meses.”

\subsection{2.}

\section{Processo de internacionalização da Xseed}

Como o produto criado e comercializado pela Xseed é tipicamente um produto de nicho de mercado, voltado para grandes corporações, os sócios, desde o início, visavam clientes no mundo todo. Por essa razão, o nome da empresa já foi definido para ser global. Ronaldo Brandão assim justificou:

"Para você ver nossa vontade de ir pra fora, o nome da empresa hoje, que não foi sempre esse, mas que sempre foi o nome do produto, já foi criado pensando no mercado externo. Nós, desde o início, sempre pensamos em ir perturbar os outros no quintal deles, porque em outro momento eles iriam nos perturbar. [...]. Por exemplo, quando ganhamos esse contrato da Colômbia, todo o pessoal aqui passou por um treinamento de espanhol, por quase um ano com aula dentro da empresa pra poder lidar com as pessoas de lá, na língua deles. Então, é uma preocupação de internacionalização. A ferramenta é toda em inglês, ou seja, desde que nascemos, olhamos para o mercado como um todo, não só Brasil.” 
A primeira experiência internacional não envolvia serviços de downsizing, mas um produto empacotado. Para comercializar esse aplicativo, os sócios decidiram abrir uma filial nos EUA, na Flórida. Porém, muito cedo surgiu um concorrente de peso, quando a Microsoft lançou um produto similar. No entanto, os sócios encararam essa experiência como importante no aprendizado para internacionalização. Mesmo após encerrar a empresa, os sócios sonhavam em voltar para o mercado norte-americano, não apenas pelo que representaria financeiramente, mas também pela possibilidade de se manter no estado da arte em termos de avanços tecnológicos, como destacou Ronaldo Brandão:

"Nós sentimos muito não termos mais essa conta lá [nos EUA], porque estaríamos sugando a tecnologia que está acontecendo no momento. Nós procurávamos, na época, repassar tudo o que estava acontecendo em termos de tecnologia, de evolução de produto, caminhos, de perspectivas tecnológicas, por isso nos ressentimos um pouco, apesar de a internet dar algum subsídio.[...] Mas a nossa perspectiva, acho que é por aí.."

Uma das formas que os sócios encontram de não perderem totalmente o contato com os Estados Unidos foi a manutenção da rede de relacionamentos. Ronaldo Brandão exemplificou a importância da manutenção da rede de relacionamentos:

"Eu fiz algumas amizades [do tempo em que teve a filial nos EUA] que perduram até hoje. Até hoje, temos indicações de serviços, que, às vezes, não se concretizam, $e$, às vezes, evoluem em alguma conversa por conta desse contatos.[...] Nós ficamos em contato com um parceiro, que é muito amigo nosso e que ainda hoje nós conversamos uma coisa ou outra: ‘Ah tem uma oportunidade aqui..'. Mas não é um trabalho efetivo, se surge alguma oportunidade ele faz contato conosco. Ele é ex-Unisys, e também trabalha nesse setor."

A Xseed contou com a ajuda de órgãos do governo, como a Softex, para participar em feiras internacionais. Foi por esse meio que a empresa obteve o primeiro contrato na América Latina, na Colômbia, em 1998. Na opinião dos sócios, nessas feiras ocorreram os contatos mais importantes em termos de geração de negócios e parcerias no exterior, como observado Ronaldo Brandão:

“Mas até 2000, todo ano nós estivemos em feira nos Estados Unidos e algumas vezes na Alemanha. E havia duas feiras nos Estados Unidos, a Condex, que é geral, e uma feira setorial. Todo ano."

"Nossos negócios internacionais, tanto parceiros quanto contratos, foram conseguidos nessas feiras.[...] O projeto na Colômbia iniciou na feira nos Estados Unidos, fizemos uma parceria na Alemanha, e outra nos Estados Unidos.” 
Depois de prestar serviços por algum tempo na Colômbia, os sócios decidiram prospectar clientes naquele país, embora reconhecessem que essa ação não traria resultados rápidos:

"Nós estamos na Colômbia batendo na porta de alguns clientes que ainda existem
lá e disso resultou um contrato com o Banco Central. Nós temos perspectiva de vir
a fechar outros negócios por lá, mas nosso negócio é um nicho, muito específico,
requer investimento grande, não é um projeto barato, não é um projeto de decisão
fácil.

Também prospectaram na Costa Rica, buscando fechar acordo com empresa local, como esclareceu Ronaldo Brandão: "Na Costa Rica temos uma parceria, já ficamos perto de fechar uma licitação. Temos feito visita a clientes lá pelo menos uma vez, duas vezes por ano junto com o representante que temos no país.”

Por ter um mercado alvo bastante específico e pontual, a empresa prefere trabalhar com parceiros em mercados externos. Esse modelo já foi aplicado na Colômbia, Costa Rica, Espanha, Nova Zelândia, dentre outros. A Xseed tem dois papeis dentro da parceria: o primeiro é o de suportar as vendas, que necessitam de muitas horas de entendimento dos sistemas do cliente e de preparação de uma proposta detalhada; e o segundo, o de codificar a migração dos sistemas, o que é feito em Fortaleza, na fábrica de software. A empresa parceira tem a responsabilidade de prospectar em seu país e de implantar a migração no ambiente do cliente. Como bem exemplifica Ronaldo Brandão:

"Na realidade nós temos uma tecnologia que permite com que uma empresa parceira consiga um contrato, nós fazemos uma parte desse contrato, que é a transformação do código, e ela executa a parte de serviços associada a esse contrato, então é uma parceria interessante. Aonde ela vende a nossa solução fazemos um núcleo do negócio aqui, em Fortaleza, e eles concluem o trabalho lá."

O processo de identificação do parceiro varia de caso para caso. Na Costa Rica, o processo foi emergente, já que o empresário local procurou na internet uma solução e acabou encontrando a Xseed. Na Colômbia, onde já atuavam junto ao Banco Central, um VP do banco indicou a empresa com a qual fecharam parceria. Conforme Ronaldo Brandão: "Estabelecemos um relacionamento. Como são projetos longos e poucos clientes, nós desenvolvemos um relacionamento de amizade e isso continua até hoje, continuam nos indicando. Nosso negócio é muito baseado em indicação." 
Por perceberem a importância da manutenção de suas redes, os sócios procuram visitar os clientes externos pelo menos uma vez por ano, mantendo a relação em situações menos formais, como jantares. Ronaldo Brandão relatou:

"Normalmente temos visitado esse cliente [Banco Central da Colômbia]. Como é distante, uma vez por ano passamos por lá, fazemos uma visita, conversamos, jantamos, levamos algum presente. Costumo levar DVDs brasileiros, ou seja, mantendo algum contato fora do esquema normal de trabalho. E com outros [executivos] fazemos amizade mesmo, mesmo que tenham saído do banco, saímos para jantar, nos atualizamos nas conversas. Então, gera alguma amizade fora do projeto. Não tanto quanto gostaríamos, porque há uma dispersão geográfica grande. Mas o respeito profissional continua, independente dessa amizade. Às vezes acontece de visitar um cliente dez anos depois e ele nos recomendar: "pode confiar que esse pessoal é sério, se diz que faz, faz'."

Os sócios são criteriosos na escolha dos parceiros, pois entendem que o ciclo de vendas e pós-venda é crucial para o tipo de serviço que prestam. O processo todo envolve desde a confecção da proposta, que abrange muitas horas de entendimento da situação do cliente e a entrega de um extenso documento, passando pela execução da codificação e terminando na implantação, que é executada pelo sócio local. A parceria é fortemente influenciada pela identificação pessoal entre os parceiros.

"Nós somos extremamente conservadores no que diz respeito a relacionamentos com parceiros. Não temos tido muitas parcerias, até porque, ou nós nos identificamos pessoalmente com um executivo da empresa, ou essa parceria não evolui. Nosso negócio requer mais aproximação, requer mais confiança, uma série de coisas. Então, nós temos um parceiro na Colômbia - já vão aí cinco ou seis anos - que é amigo nosso. No nosso caso, estamos vendendo um serviço que não tem um valor definido, depende da dificuldade, depende de uma série de coisas. Nós estamos vendendo a credibilidade do nosso nome. E como é um negócio muito específico, de muita tecnologia, se o parceiro não estiver muito conectado conosco, não tiver muita confiança, ele pode, por exemplo, para fechar o negócio, fazer afirmativas de solução que nós não temos e que queimaria nossa solução."

As parcerias com empresas de tecnologia (como IBM ou Oracle) são vistas como muito voláteis. No Brasil e no exterior, a Xseed teve alguns negócios em parceria com essas multinacionais, mas tais empresas mudam muito internamente, não havendo espaço para criação de vínculos mais duradouros. Como explica Ronaldo Brandão: "Se surge [oportunidade], vamos junto, senão, até logo." 
Para os executivos da Xseed, a referência obtida de um cliente era considerada fundamental para perseguir novas oportunidades. Nos mercados externos, essa referência se mostrava ainda mais crucial. No Brasil, a empresa já contava com muitos casos de sucesso, mas no exterior, o nome do Brasil no setor de TI não ajudava, como relata Ronaldo Brandão:

"Eu diria que [consequência positiva das parcerias] é mais a visibilidade como referência. Porque nos novos mercados internacionais eu posso mencionar que eu tenho o cliente A, B, C e D e estou dando suporte a partir daqui [Brasil], porque essa é uma questão. [...] Mas no circuito software corporativo há muitas restrições contra software brasileiro. Então, por exemplo, há dois anos atrás perdemos um negócio com um banco da Croácia. Chegamos, andamos, andamos, andamos, nitidamente perdemos esse negócio por uma questão de desconfiança do cliente na nossa capacidade técnica de execução e, principalmente, de suporte. Então é importante ter essas referências."

Os sócios tiveram experiências reais que confirmavam a necessidade de obter legitimidade para concorrerem em mercados externos, tanto por clientes brasileiros quanto pelos novos clientes internacionais que iam formando a rede. Ronaldo Brandão cita o exemplo da importância desse benefício no mercado financeiro:

"Como empresa de serviços, temos duas barreiras principais: credibilidade e garantia. A questão da credibilidade, nós praticamente já vencemos essa etapa, porque temos anos de estrada e temos cases de sucesso para mostrar. Os clientes vinham no Brasil, visitavam uma empresa, visitavam outra empresa, viam que o nosso é um serviço de qualidade e garantido. E então voltavam e assinavam o contrato. E depois dão referência para terceiros. Você vê a referência que nós temos do Banco Central da Colômbia. Os clientes disseram assim: 'eles são bons, cumprem, são excepcionais'. Rasgaram elogios mesmo em uma carta de referência para terceiros. E esse universo é muito fechado, esse universo financeiro."

Algumas parcerias acontecem de forma emergente, originadas de referências dadas por clientes, como aconteceu com a empresa espanhola IT Deusto, que procurou a Xseed a partir da indicação do Banco da República na Colômbia. A visão dos sócios em parcerias com grandes empresas era a de aproveitar o alcance geográfico e penetrar em novos mercados juntos. A parceria na Espanha pretendia alcançar clientes na América Latina, onde a empresa espanhola estava investindo à época (2004), porém não evoluiu. No entanto, é um bom exemplo do uso da rede para expansão internacional :

“Exatamente por conta das nossas referências na Colômbia, essa pessoa nos procurou e disse 'Olha, eu estou com um negócio, alguns negócios em perspectiva'. Então começamos a tabelar, fazer viagens e contatos. E estamos com perspectivas no México, e ano que vem com a possibilidade de ir para a Espanha, junto com essa empresa.” 
Por alguns anos, em decorrência das origens dos sócios (ex-funcionários da Unisys) e da solução criada, o mercado alvo se restringia a corporações que utilizavam mainframes Unisys. Mas esse universo era finito e bem menos expressivo que o "mundo" IBM. Após alguns anos, a Xseed fez uma parceria com a IBM no Brasil, em busca de estender seu público-alvo no mercado doméstico, e procurou também por meio dessa parceria alcançar o mercado latino-americano. Ronaldo Brandão esclarece sobre as dificuldades enfrentadas nesse movimento:

"Nós estamos com uma parceria relativamente forte hoje no Brasil, com a IBM, e essa parceria deve se estender para as Américas. Estamos negociando e, aí sim, eu acho que temos acesso a uma expansão muito grande. É uma parceria que estamos fazendo com alguns executivos da IBM, porque é difícil domar um touro desse tamanho... Então nós estabelecemos uma parceria com uma empresa constituída por ex-funcionários IBM e essa parceira está trabalhando a IBM juntamente conosco. É uma parceria de confiança, são amigos nossos de longa data. [...] Então, essa parceria depende muito desse relacionamento pessoal, e é com isso que nós temos tratado o negócio, nós não sabemos tratar de forma diferente.”

Além das parcerias com empresas de alcance geográfico significativo, outra forma menos relevante de internacionalização da Xseed ocorre por meio de contatos pela internet. A empresa se empenha em manter o site atualizado e com informações sobre seus casos de sucesso para garantir mais esse canal.

Em 2006, a empresa fechou mais um contrato de downsizing com uma empresa de software da Nova Zelândia. O negócio aconteceu em função da boa referência originada do sucesso do projeto com o Banco da República na Colômbia. Várias oportunidades nas Américas do Sul e Central surgiram pela indicação que o banco colombiano oferecia com relação à Xseed. A empresa neozelandesa tinha clientes espalhados pelo mundo, que usavam a aplicação convertida pela Xseed. Consequentemente, esses clientes precisariam converter seus sistemas pelo mesmo processo, o que abriria uma rede de possíveis clientes para a empresa:

"E uma derivação interessante, é que, por exemplo, a aplicação na qual estamos fazendo a conversão tem usuários na Rússia, na Grécia, na Jordânia, na Malásia, na América Central, do Sul, nos Estados Unidos. E como esse processo de migração leva uma peça de software nossa, então, necessariamente, à medida que eles forem fazendo a evolução desses clientes, nós vamos ter esses clientes como nossos também." 
As duas empresas fizeram uma parceria de tal forma que o produto da Xseed fosse distribuído para os clientes da empresa neozelandesa, que acabara de ter um significativo aporte financeiro, com o intuito de promover tal expansão.

"E essa empresa tem também um aspecto interessante, eles estão em um processo de evolução da solução deles, houve injeção de capital e eles devem agredir o mercado, nesse caso internacional, mais fortemente, e a ideia é pegarmos uma carona neles. [...] Existe um quase acordo de distribuição do nosso produto por eles, para os clientes deles."

Por meio dessa implantação, a Xseed teve oportunidade de trabalhar em clientes no Vietnã, Filipinas, Austrália, Estados Unidos e Venezuela. Os projetos eram pequenos, como treinamento, mas traziam aprendizado e referência, como destaca Ronaldo Brandão:

"E aí nós damos suporte e eventualmente algum treinamento à nossa ferramenta. Já estivemos no Vietnã, nas Filipinas dando treinamento sobre a ferramenta. Isso aí não implica dizer em faturamento e coisas expressivas não, mas em experiência e referência. [...] Podemos dizer que temos esses clientes desse lugar."

Em 2007, um executivo que os sócios haviam conhecido em 2002, em uma licitação, que se tornou amigo pessoal, indicou uma oportunidade na Costa Rica, que se concretizou.

Em 2015 a empresa estava empenhada em novamente tentar expandir seus negócios para o "mundo IBM". A Xseed estabeleceu um consórcio com a 4BearsTech, de SP, uma empresa jovem com fortes intenções de se inserir no mercado internacional, que provê soluções de migração para o ambiente IBM. As duas empresas oferecem a junção da tecnologia IBM com a experiência da Xseed em processos e metodologia de migrações. Fecharam contratos no Brasil e estavam em 2015 em negociações para firmar parceria com uma grande multinacional norte-americana. Ronaldo Brandão acreditava que esse seria um ano de "reinvenção" da Xseed:

"A nossa empresa está voltando a 20 anos atrás, migrando para o mercado IBM. [...] Essa aproximação com o pessoal de São Paulo, que é uma empresa jovem, como a Xseed era há vinte anos atrás, com gás no mercado... [...] Estamos pegando carona na rede deles - contatos na Europa, França, Holanda, EUA unindo as forças e dividindo tarefas. Nós usamos referências de outros clientes para os projetos de migração, nossa metodologia, usamos nossas referências da Colômbia, da empresa da Nova Zelândia. E isso reforça essa parceria, só que os contatos novos, essas aberturas de novas frentes, está mais sendo feito pela empresa de São Paulo.” 
Linha do Tempo de Internacionalização da Xseed

\begin{tabular}{|c|c|}
\hline ANO & Evento \\
\hline 1991 & Fundação da Xseed \\
\hline 1996 & Criação de Filial na Florida - EUA \\
\hline 1998 & $\begin{array}{l}\text { Colômbia - projeto de downsizing empresa de telefonia } \\
\text { e energia }\end{array}$ \\
\hline 2003 & Colômbia - projeto no Banco da República \\
\hline 2004 & Parceria com empresa na Espanha (IT-Deusto) \\
\hline 2006 & Porto Rico (parceria com a HP) \\
\hline 2006 & $\begin{array}{l}\text { Nova Zelândia (GFG Globo) - projeto de downsizing e } \\
\text { parceria }\end{array}$ \\
\hline $\begin{array}{l}2006 \\
2015\end{array}$ & $\begin{array}{l}\text { Vietnã, Filipinas, Austrália, Estados Unidos, Caribe, } \\
\text { Venezuela (parceria GFG Globo) }\end{array}$ \\
\hline 2007 & Costa Rica (parceiro local) \\
\hline 2007 & $\begin{array}{l}\text { República Dominicana (Ban Reserva em parceria com } \\
\text { a HP) }\end{array}$ \\
\hline 2015 & $\begin{array}{l}\text { Parceria com empresa paulista com intuito de maior } \\
\text { penetração internacional }\end{array}$ \\
\hline
\end{tabular}

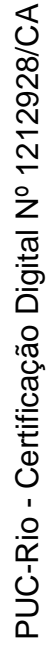




\section{5 \\ Análise dos resultados}

Este capítulo apresenta os resultados das análises efetuadas com base nos oito casos selecionados para a presente pesquisa. A primeira etapa da análise consiste em uma comparação entre as características gerais de cada empresa e de seus empresários. A seguir analisam-se as iniciativas de ação internacional à luz do uso das redes, buscando-se similaridades e contrastes e relacionando os resultados com a literatura apresentada. Por fim são descritas e analisadas algumas iniciativas de internacionalização que ilustram de forma mais completa o uso de redes

\section{1 .}

Perfil das empresas e de seus dirigentes

A literatura de empreendedorismo internacional enfatiza a importância das características da firma e de seus dirigentes em moldar o processo de internacionalização (p. ex., KEUPP \& GASSMANN, 2009). Assim sendo, faz-se a seguir uma breve descrição de características das empresas estudadas e de seus dirigentes consideradas relevantes.

\subsection{1.}

\section{Características gerais das empresas}

O Quadro 5.1 mostra as principais características das empresas estudadas.

As empresas apresentam forte variação com relação ao tamanho, tanto em termos de faturamento, quanto em número de funcionários. Considerando-se o número de empregados, duas entre as empresas estudadas são de grande porte (CI\&T e Totvs), uma é de médio porte (Ivia) e as demais são de pequeno porte, uma característica predominante no setor de software no Brasil.

Quatro entre as empresas estudadas apresentam percentual significativo de receita internacional ao longo dos anos, sendo uma de grande porte (CI\&T) e as outras três de pequeno porte. Duas empresas apresentam baixo percentual de negócios internacionais e duas delas, por ocasião da última entrevista, já não 
tinham atividades no exterior (Fujitec e Totall). Essas empresas foram fortemente afetadas pela valorização do real até o início de 2015, que dificultou os negócios no exterior, além de terem voltado suas atenções, ao mesmo tempo, para o crescimento no mercado doméstico, que viveu, até 2014, um período de forte expansão. Para facilitar a análise, sempre que possível e relevante, os resultados são apresentados destacando-se as empresas segundo seu tamanho.

\begin{tabular}{|c|c|c|c|c|c|c|c|c|}
\hline 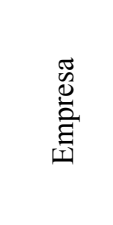 & Produto ou Serviço & Cidade & UF & 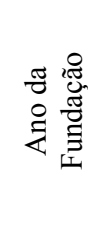 & 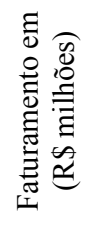 & 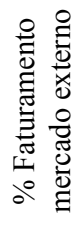 & 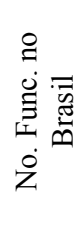 & 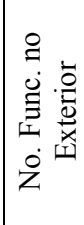 \\
\hline \multicolumn{9}{|l|}{ Grandes } \\
\hline CI\&T & $\begin{array}{c}\text { Serviços de } \\
\text { outsourcing, } \\
\text { desenvolvimento e } \\
\text { integração de } \\
\text { aplicações }\end{array}$ & Campinas & SP & 1995 & 330 & 40 & 2000 & 200 \\
\hline Totvs & $\begin{array}{l}\text { Software de Gestão } \\
\text { Empresarial ERP }\end{array}$ & $\begin{array}{l}\text { São } \\
\text { Paulo }\end{array}$ & SP & $\begin{array}{c}1983 \\
(2005) \\
* *\end{array}$ & 1.800 & 2 & 7000 & 500 \\
\hline \multicolumn{9}{|l|}{ Média } \\
\hline Ivia & $\begin{array}{c}\text { Serviços de } \\
\text { outsourcing, BI e } \\
\text { desenvolvimento de } \\
\text { software } \\
\end{array}$ & Fortaleza & $\mathrm{CE}$ & 1996 & 35 & 5 & 450 & 0 \\
\hline \multicolumn{9}{|c|}{ Pequenas } \\
\hline Fujitec & $\begin{array}{c}\text { Sistemas de } \\
\text { bilhetagem eletrônica }\end{array}$ & Fortaleza & $\mathrm{CE}$ & 1991 & n.d. & 0 & 10 & 0 \\
\hline $\begin{array}{l}\text { Light } \\
\text { Infocon }\end{array}$ & $\begin{array}{l}\text { Gestão eletrônica de } \\
\text { documentos }\end{array}$ & $\begin{array}{l}\text { Campina } \\
\text { Grande }\end{array}$ & $\mathrm{PB}$ & $\begin{array}{c}1983 \\
(1995) \\
*\end{array}$ & 11 & 24 & 59 & 2 \\
\hline $\begin{array}{l}\text { Midia } \\
\text { Vox } \\
\end{array}$ & $\begin{array}{l}\text { Integração telefonia } \\
\text { e informática }\end{array}$ & Recife & $\mathrm{PE}$ & 1994 & 3 & $\begin{array}{c}35 \mathrm{a} \\
40 \\
\end{array}$ & 25 & 0 \\
\hline Totall & $\begin{array}{c}\text { Software Integrado } \\
\text { de Automação } \\
\text { Comercial }\end{array}$ & Blumenau & $\mathrm{SC}$ & 1991 & 2,5 & 0 & 36 & 2 \\
\hline Xseed & $\begin{array}{c}\text { Serviços de } \\
\text { downsizing } \\
\text { (migração de } \\
\text { mainframe para baixa } \\
\text { plataforma) }\end{array}$ & Fortaleza & $\mathrm{CE}$ & 1991 & n.d. & 40 & 16 & 0 \\
\hline $\begin{array}{l}\text { Quadro } \\
\text { Fonte: pr } \\
* \text { O prim } \\
\text { Infocon } 1 \\
* * \text { O prin } \\
\text { nome ap } \\
* * * \text { Totv } \\
\text { n.d. = nã }\end{array}$ & $\begin{array}{l}\text { - Características das e } \\
\text { ria } \\
\text { o ano é a data de fundas } \\
\text { a fusão de duas empres } \\
\text { ro ano é a data de fund } \\
\text { a fusão com diversas ol } \\
\text { - resultados de } 2014, \text { o } \\
\text { disponível }\end{array}$ & $\begin{array}{l}\text { npresas est } \\
\text { ão da Infoco } \\
\text { s. } \\
\text { ção da Micr } \\
\text { tras empresa } \\
\text { estante são r }\end{array}$ & $\begin{array}{l}\text { dadas } \\
\text { Tecn } \\
\text { siga; } \\
\text { s. } \\
\text { esultac }\end{array}$ & $\begin{array}{l}\operatorname{logia} ; 19 \\
05 \text { é a di } \\
\text { s de } 201\end{array}$ & 5 é a da & de cria & ão da $\mathrm{L}$ & seu \\
\hline
\end{tabular}


No que se refere à localização geográfica, as duas maiores empresas encontram-se em São Paulo, a empresa de médio porte está localizada na região Nordeste, assim como cinco entre as empresas de pequeno porte, além de uma empresa em Santa Catarina, região Sul do Brasil. As localizações dessas empresas não refletem a distribuição nacional do setor de software brasileiro, mas resultam apenas da disponibilidade de empresas que se adequavam aos critérios da pesquisa e com informações suficientemente ricas na base de dados utilizada.

Os produtos e serviços, embora relacionados ao desenvolvimento de software, um dos critérios de seleção dos casos, apresentam variações que devem ser destacadas. As empresas CI\&T e Ivia têm como principal serviço o desenvolvimento de aplicações, podendo atuar em diversas indústrias e setores, pois seus sistemas são desenvolvidos de acordo com as necessidades de seus clientes. A Totall e a Totvs têm como carro-chefe softwares de automação gerencial, embora a Totvs ao longo do tempo tenha também investido em fábricas de software, que ainda representam uma fatia pequena do negócio. Além disso, a Totvs possui soluções que atendem a quase todos os setores, enquanto o produto da Totall atende apenas ao setor de varejo. A Light Infocon oferece soluções de gerenciamento eletrônico de documentos, inclusive textos multimídia, atendendo a um mercado relativamente amplo. Já as demais empresas - Fujitec, MidiaVox e Xseed - têm produtos que atingem nichos de mercado específico. A Fujitec oferece sistemas de bilhetagem eletrônica, portanto seu mercado é fortemente centrado em empresas de transporte e setores públicos (primordialmente prefeituras). A MidiaVox desenvolve soluções que integram TI $\mathrm{e}$ telecomunicações, atendendo sobretudo empresas de telecomunicações. A Xseed é provedora de solução de migração de plataforma mainframe para plataforma descentralizada, tendo um mercado alvo finito, pois quase todas as grandes corporações vêm realizando essa migração desde o final dos anos 1990.

A coincidência nas datas de fundação das empresas, fortemente concentradas na década de 1990, tem explicação na história da indústria de TI no Brasil, marcada por anos de reserva de mercado, que se encerrou em 1991. Apenas duas empresas foram criadas previamente ao fim da reserva de mercado: Microsiga, que após uma série de aquisições viria a se tornar futuramente Totvs, e a Infocon Tecnologia, antecessora da Light Infocon. Cabe mencionar ainda que o processo de crescimento dessas duas empresas só ocorreu a partir da década de 
1990, década marcada por forte expansão do setor (Mello, 2009). Por fim, deve-se notar que o tempo decorrido desde a fundação das empresas estudadas proporciona uma perspectiva histórica relevante para o trabalho que se pretendeu realizar.

\subsection{2.}

Experiência internacional dos empreendedores

A literatura mostra que experiências internacionais anteriores podem influenciar o processo de internacionalização (CANNONE \& UGHETTO, 2014; OVIATT \& MCDOUGALL, 1997). Dirigentes de empresas com história de vida mais cosmopolitas tendem a se inserir em mercados estrangeiros, enquanto aqueles empresários com experiências centradas no seu país de origem tendem a permanecer limitados ao mercado doméstico (ROCHA \& SILVA, 2009). Por exemplo, em uma revisão da literatura sobre internacionalização de INVs, Evers (2011) destacou o papel dos empreendedores como pivôs no processo de internacionalização, argumentando que fatores como experiência, contatos e conhecimento prévio dos mercados externos os tornariam mais arrojados na busca por oportunidades em outros países. Experiências internacionais de intercâmbio, estudo ou profissionais mudam percepções, derrubam mitos com relação a dificuldades e mesmo com relação a suas capacidades e competências.

Seguindo esta lógica, considerou-se relevante identificar aspectos da experiência internacional dos empreendedores nas empresas estudadas. O Quadro 5.2 mostra a experiência anterior à fundação das empresas de cada empreendedor. 


\begin{tabular}{|c|c|c|c|c|}
\hline 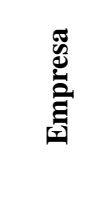 & Sócio & 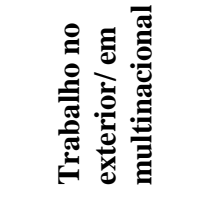 & $\begin{array}{c}\text { Educação } \\
\text { Internacional }\end{array}$ & 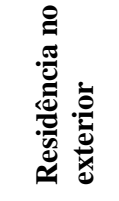 \\
\hline \multicolumn{5}{|c|}{ Grandes } \\
\hline \multirow{3}{*}{ CI\&T } & Bruno Guiçardi & Argentina & Não & Não \\
\hline & Fernando Matt & Não & Não & Não \\
\hline & Cesar Gon & Ex-IBM & Não & Não \\
\hline Totvs & LaércioCosentino & Não & Não & Não \\
\hline \multicolumn{5}{|l|}{ Média } \\
\hline \multirow{3}{*}{ Ivia } & $\begin{array}{l}\text { Alexandre } \\
\text { Menezes } \\
\end{array}$ & Ex-IBM & $\begin{array}{c}\text { Curso de francês no } \\
\text { Canadá }\end{array}$ & Não \\
\hline & Edgy Paiva & Ex-IBM & Não & Não \\
\hline & Marcio Braga & $\begin{array}{l}\text { EX-IBM } \\
\text { Portugal }\end{array}$ & Não & Portugal \\
\hline \multicolumn{5}{|c|}{ Pequenas } \\
\hline \multirow{3}{*}{ Fujitec } & Wicca Neves & Não & Não & Não \\
\hline & Adalberto Pessoa & Não & Não & Não \\
\hline & Danilo Reis & EUA & Não & EUA \\
\hline \multirow{4}{*}{$\begin{array}{l}\text { Light } \\
\text { Infocon }\end{array}$} & Alexandre Moura & Não & Intercâmbio nos EUA & EUA \\
\hline & Jacques Sauvé & Sim & Doutorado no Canadá & Canadá \\
\hline & Antão Moura & Não & Doutorado no Canadá & Canadá \\
\hline & Jairo Fonseca & Não & Não & Não \\
\hline \multirow{3}{*}{$\begin{array}{l}\text { Midia } \\
\text { Vox }\end{array}$} & Alcides Pires & Não & Não & Não \\
\hline & Garibaldi Rocha & $\begin{array}{c}\text { Ex- Sulamerica } \\
\text { Telecom }\end{array}$ & Não & Holanda \\
\hline & Tuca Paes & Não & Não & Não \\
\hline \multirow{2}{*}{ Totall } & Edilson Paterno & Não & Não & Não \\
\hline & Murilo Machado & Não & Não & Não \\
\hline \multirow{2}{*}{ Xseed } & Ronaldo Brandão & Ex-Unisys & Não & Não \\
\hline & Luis Miranda & Ex-Unisys & Não & Não \\
\hline
\end{tabular}

Quadro 5.2 - Experiência internacional prévia dos empreendedores

Fonte: própria

De forma geral, observa-se que é bastante limitada a experiência internacional desses empreendedores, particularmente no que se refere a estudar ou residir no exterior. A forma mais comum de experiência internacional encontrada nos casos estudados foi o fato de haverem trabalhado em uma empresa multinacional do setor de TI (particularmente IBM e Unysis), o que facilitou os contatos com indivíduos provenientes de variados países, mesmo estando sediados no Brasil. Na verdade, essas duas multinacionais realizaram amplos processos de downsizing, com a passagem do mercado de computadores de grande porte para os de menor porte, o que liberou para o mercado um bom número de profissionais experientes e muito bem treinados, que acabaram por fundar suas próprias empresas, como no caso de alguns empreendedores estudados. 
Embora seja comum encontrar na literatura diversos casos de empresas internacionalizadas de países emergentes cujos dirigentes se utilizaram de suas redes formadas em universidades, notoriamente na China e na Índia, esse fenômeno não parece se repetir para empresas brasileiras. No Brasil, não há ainda grandes estímulos ou mesmo a cultura de se enviar alunos para o exterior, embora esse movimento venha crescendo em anos recentes. Além do surgimento de empresas especializadas em intercâmbio, também foram criados recentemente alguns programas do governo de incentivo a ida de estudantes ao exterior, como o Ciência sem Fronteiras e o Intercâmbio Gratuito 2016. Em 2015, segundo o Relatório Open Doors do Institute of International Education, 31,2\% dos estudantes internacionais nos Estados Unidos eram originados da China, 13,6\% da Índia e 2,4\% do Brasil, embora no ano anterior o Brasil contasse com apenas $1,5 \%$.

Apesar da experiência internacional limitada, em particular quando se compara com os casos recentes de China e Índia, os empreendedores das empresas estudadas valorizam a experiência internacional adquirida, com alguns deles reconhecendo que experiências internacionais passadas proporcionam conforto e segurança para negociar e atuar em mercados externos. É possível perceber arrojo e autoconfiança nos dirigentes da Light Infocon, originariamente formada por dois irmãos que tiveram parte de sua educação nos EUA, o que, nas palavras de um deles, os tornou mais confiantes em negociações internacionais, mesmo aquelas envolvendo mercados mais desenvolvidos:

"Eu gosto de passar a experiência para o pessoal que está começando e está querendo ir para lá [mercado externo]. Quando estou em eventos, muita gente me procura, e eu não tenho problema, gosto de passar minha experiência. Usa quem quiser. É a tal da história, [brasileiro] acha que, porque é nordestino, porque é do interior da Paraíba... Mas se você vê minha história de vida, eu fiz intercâmbio de jogos quando eu era adolescente, meus pais sempre nos mandaram para fora, desde pequenos, então eu não olho estrangeiro de baixo para cima, olho no mesmo nível." (Alexandre Moura, fundador, Light Infocon)

A experiência internacional abre os olhos a oportunidades e proporciona uma nova perspectiva. Um dos sócios da CI\&T atribuiu a sua curta experiência na Argentina o entendimento de que avançar em mercados internacionais seria possível para a empresa: 
"Por seis meses eu estive em um projeto na Argentina. [...] Então, foi bacana ver que não tinha muito segredo por aí não. Eu era recém formado, mas... o mundo é sem fronteiras para quem for mais competente.” (Bruno Guiçardi, sócio, CI\&T)

Diversas empresas empreendedoras que se internacionalizaram o fizeram por meio de redes de relacionamento criadas a partir de experiência anterior de seus fundadores e executivos, como, por exemplo, quando atuavam em multinacionais (Crick \& Spence, 2005; Dib et al., 2010; Evers \& O'Gorman, 2011). De forma geral, a condição de experiência internacional mais recorrente nas empresas analisadas foi a de ter pertencido a alguma empresa multinacional, embora atuando no Brasil. Nos casos analisados, quatro empresas têm como sócios ex-empregados de multinacionais, e, ainda que de formas diferentes, essas experiências tiveram influência em seu processo de internacionalização. Ronaldo Brandão, da Xseed, enfatizou esse aspecto:

"Tem a ver [com ter participado de uma corporação global], saber lidar com valores altos. Nós falamos de contratos como se fôssemos uma multinacional, sem sermos... Não temos receio de falar em valores de projeto. E isso é importante." (Ronaldo Brandão, fundador, Xseed)

Outro caso marcante em que a experiência em uma multinacional criou a oportunidade de internacionalização foi o da Ivia, em que um ex-colega da multinacional, atuando em uma empresa portuguesa, convidou os sócios da Ivia para um treinamento em Portugal, passo inicial da internacionalização e de futura parceria, que culminou com o ingresso do ex-colega como sócio na Ivia.

Um exemplo um pouco distinto é o da CI\&T. Um dos futuros sócios prestava serviços à IBM. Tendo tomado conhecimento de uma concorrência a ser aberta pela multinacional para um projeto, os jovens empreendedores abriram a empresa e venceram a concorrência. O projeto com a IBM inseriu o novo empreendimento, desde sua fundação, em um ambiente internacional:

"Dentro da IBM já era um projeto bem sofisticado do ponto de vista técnico. Feito pelo laboratório da IBM com outros laboratórios da França e dos Estados Unidos. Já era um plano internacional, bem sofisticado. E aí a CI\&T nasceu nesse ambiente de projetos já internacionais.” (Bruno Guiçardi, sócio, CI\&T)

Na MidiaVox, o único dos três sócios com alguma experiência internacional era o fundador Garibaldi Rocha: 


\begin{abstract}
"Garibaldi tinha [experiência internacional prévia]. Ele trabalhou na Philips na área de desenvolvimento de software, na área de PABX. E a Philips tinha uma fábrica aqui em Recife e em função daquela reserva de mercado, a Philips tinha que vender um equipamento feito no Brasil. Então, ele teve que aprender a fazer software aqui no Brasil e passou um tempo na Holanda, fazendo treinamento e desenvolvimento. Ficou uns seis meses mais ou menos. " (Alcides Pires, fundador, MidiaVox)".
\end{abstract}

Das oito empresas analisadas, apenas uma, a Totall, não apresentou nenhum tipo de experiência internacional prévia à fundação por parte de seus dirigentes. Talvez em função disso, a Totall iniciou seu processo de internacionalização de forma reativa, ao participar de uma feira no Brasil e ser abordada por executivos de uma empresa de consultoria brasileira que representava um cliente de Moçambique.

\title{
5.1.3.
}

\section{Orientação internacional dos empreendedores}

Outra característica examinada é a orientação internacional dos empreendedores. A globalização tornou primordial que os empresários tenham a percepção de que suas empresas estão inseridas em ambiente de competição global. Aqueles que não possuem modelo mental global tendem a encontrar maiores dificuldades em flexibilizar suas estratégias e adaptar-se a ambientes distintos (MACHADO-DA-SILVA, CASALI, \& FERNANDES, 2000). Estudos comprovam que decisões sobre internacionalização adotadas pelas empresas são fortemente influenciadas pelo modelo mental de seus dirigentes e suas percepções com relação ao mundo (ROCHA \& SILVA, 2009). Empreendedores que buscam a internacionalização, via de regra, apresentam o que alguns autores chamam de "orientação internacional" (OVIATT e MCDOUGALL, 1995; JONES e COVIELLO, 2005; GABRIELSSON e KIRPALANI, 2012). McDougall (1989) identificou a intenção de internacionalizar desde a criação do empreendimento como a principal característica das INVs.

No caso da CI\&T, os depoimentos sugerem a existência de uma orientação internacional desde a fundação, como observou um executivo de topo entrevistado:

"Eu acho que, primeiro, foi uma motivação que existia desde sempre, construir uma empresa global, uma ambição dos sócios-fundadores mesmo, de criarem algo admirável, uma empresa para ser admirada, e uma empresa com essa característica global.” (Leonardo Mattiazzi, Vice Presidente, CI\&T). 
A Light Infocon, além de ter seus dirigentes com a maior experiência internacional dentre as empresas analisadas, também dispunha de sócios que tinham, desde o início, orientação internacional:

“ $O$ nosso business plan não focava determinados mercados. Focava que a empresa tinha que exportar. [...]. Porque as concorrentes estão aqui dentro, então nós temos que entender isso. Uma maneira de ganhar experiência, é ir no mercado externo. [...] Os Estados Unidos foi escolhido porque identificamos qual seria o mais eficiente e o custo/benefício melhor. E naquele momento, era os Estados Unidos. Agora, o business plannig da empresa dizia, nós temos que exportar, senão não sobrevivemos.(Alexandre Moura, Fundador, Light Infocon)

Da mesma forma, os sócios da Xseed já pensavam em se tornar globais desde a criação da empresa:

"Para você ver nossa vontade de ir pra fora, o nome da empresa já foi criado pensando no mercado exterior. Nós, desde o início, sempre pensamos em ir perturbar os outros no quintal deles, porque em outro momento eles iriam nos perturbar. Quando a empresa foi formada, ela já foi formada pensando no mercado mundial, não no Brasil somente." (Ronaldo Brandão, fundador, Xseed).

Observe-se que a Ivia e a Totvs, embora não tivessem sido fundadas por empreendedores que tivessem, desde o início, uma orientação internacional, passaram a ter essa orientação posteriormente.

$\mathrm{Na}$ Ivia, que também era formada por sócios egressos da IBM, forjou-se muito cedo um modelo mental de que a competição no setor de TI é global:

"Então, falando da questão pessoal: uma questão profissional, uma visão profissional de que se não formos lá pra fora, os lá de fora vêm para cá. Então nós procuramos fazer esse caminho inverso." (Alexandre Menezes, fundador, Ivia).

Esse mesmo raciocínio foi o que motivou a primeira investida da Totvs em mercados externos, e mesmo não logrando resultados percentuais expressivos, sua penetração geográfica e a iniciativa de criar um centro de desenvolvimento no Vale do Silício mostram que seus executivos se consideram inseridos em um ambiente global:

"A Totvs quer ser uma referência global. Nós somos hoje o sexto player no mercado, queremos ser o terceiro até 2016. Só [o crescimento] orgânico não vai dar. Temos que expandir fronteiras." (Álvaro Cysneiros, Diretor - Mercados Internacionais, Totvs) 
Os entrevistados da Fujitec, MidiaVox e Totall declararam não pretender se internacionalizar ao criar a empresa. Mesmo assim, há indícios de uma orientação internacional desde o início das atividades da empresa. Wicca Neves, da Fujitec, proporcionou evidências de orientação internacional desde a fundação da firma, na própria escolha do nome:

"E ficou Fujitec, de tecnologia. Só que nós vimos que é um nome, lá fora, que agrada e, principalmente, por ser japonês, entre aspas, é tido como ligado a tecnologia”. (Wicca Neves, fundador, Fujitec)

Em linhas gerais, as sementes da internacionalização dos empresários brasileiros das empresas de software estudadas parecem estar mais presentes em atitudes do que em experiências internacionais passadas. Poucos tiveram experiências internacionais anteriores significativas, sendo que a maior parte se caracterizava por ter pertencido aos quadros de alguma multinacional ou estudado em escolas internacionais por período curto. Mesmo assim, alguns mostram orientação internacional prévia à fundação, ou adquirida nos primeiros anos da empresa.

5.2 .

\section{Iniciativas internacionais das empresas}

Identificou-se um conjunto de 87 iniciativas internacionais realizadas pelas empresas estudadas. Como as entrevistas foram realizadas no decorrer de um longo período de tempo, acredita-se que tenha sido possível identificar a maior parte das iniciativas de internacionalização dessas empresas, mas, certamente, nem todas as iniciativas realizadas foram incluídas. Isso se deve ao fato de que restou pouca memória de algumas iniciativas, provavelmente por não terem tido sequência, ou sucesso, ou ainda por algumas iniciativas serem basicamente repetitivas, seguindo o mesmo processo. Além disso, na maior parte das empresas não há registros escritos de sua história, dependendo-se dos relatos dos fundadores ou de executivos que permaneceram nas empresas por longo período de tempo. Assim, observam-se diferenças em relatos sobre iniciativas de internacionalização colhidos em diferentes momentos, com eventuais diferenças de datas, ou ainda datas que são estimadas, mas sobre as quais não há certeza quanto a sua exatidão. Por fim, cabe salientar que, em algumas empresas, houve mais oportunidade de se obterem os dados desejados, quer por se contar com o testemunho de um ou mais 
empreendedores-fundadores, quer por se haver realizado maior número de entrevistas ao longo do tempo.

\subsection{1.}

\section{Número de iniciativas internacionais}

O Quadro 5.3 mostra o número de iniciativas por empresa estudada e alguns dados a elas relacionados. Observe-se que embora haja razoável segurança quanto à data da primeira iniciativa internacional em cada empresa, não há segurança quanto à data da última, devido a ocasiões diferentes referentes à última entrevista realizada em cada empresa, ou dados não disponíveis sobre a última iniciativa, como no caso da Totvs.

As empresas iniciaram suas atividades internacionais em diferentes décadas e em fases diferentes de sua trajetória. À exceção das duas empresas de grande porte (CI\&T e Totvs), as demais podem ser caracterizadas como INVs, ou novos empreendimentos internacionais, já que se internacionalizaram poucos anos após sua fundação. 


\begin{tabular}{|c|c|c|c|c|c|c|c|}
\hline \multirow[t]{2}{*}{ Empresas } & \multicolumn{3}{|c|}{ Ano de } & \multirow[b]{2}{*}{$\begin{array}{c}\text { No. } \\
\text { de } \\
\text { iniciativas }\end{array}$} & \multirow{2}{*}{$\begin{array}{c}\text { Anos } \\
\text { entre } \\
\text { fundação } \\
\text { e } 1^{\mathrm{a}} \\
\text { iniciativa }\end{array}$} & \multicolumn{2}{|c|}{$\begin{array}{c}\% \text { do faturamento } \\
\text { internacional }\end{array}$} \\
\hline & $\begin{array}{l}\text { Funda- } \\
\text { ção }\end{array}$ & $\begin{array}{c}1^{\mathrm{a}} \\
\text { iniciativa } \\
\text { internac. }\end{array}$ & $\begin{array}{c}\text { Última } \\
\text { iniciativa } \\
\text { internac. } \\
\text { estudada }\end{array}$ & & & $\begin{array}{c}\mathrm{em} \\
2008\end{array}$ & $\begin{array}{c}\text { em } \\
2015\end{array}$ \\
\hline \multicolumn{8}{|l|}{ Grandes } \\
\hline CI\&T & 1995 & 2004 & 2015 & 6 & 9 & $35 \%$ & $40 \%$ \\
\hline Totvs & 1983 & 1997 & 2013 & 14 & 14 & $8 \%$ & $2 \%$ \\
\hline \multicolumn{8}{|l|}{ Média } \\
\hline Ivia & 1996 & 2003 & 2016 & 12 & 7 & $5-8 \%$ & $5 \%$ \\
\hline \multicolumn{8}{|l|}{ Pequenas } \\
\hline Fujitec & 1991 & 1994 & 2008 & 8 & 3 & $30 \%$ & $0 \%$ \\
\hline $\begin{array}{l}\text { Light } \\
\text { Infocon }\end{array}$ & 1983 & 1988 & 2011 & 16 & 5 & $14 \%$ & $24 \%$ \\
\hline MidiaVox & 1994 & 2000 & 2014 & 16 & 6 & $12 \%$ & $35-40 \%$ \\
\hline Totall & 1991 & 1993 & 2008 & 7 & 2 & $10 \%$ & $0 \%$ \\
\hline Xseed & 1991 & 1997 & 2007 & 8 & 6 & $\begin{array}{c}15-20 \% \\
(*)\end{array}$ & $40 \%$ \\
\hline
\end{tabular}

(*) Informação referente ao ano de 2006

Quadro 5.3 - Iniciativas de internacionalização estudadas

Fonte: própria

Chama a atenção o fato de que a última iniciativa de internacionalização estudada, no caso das empresas Fujitec, Totall e Xseed, data de 2007-2008. Entre essas, a Fujitec e a Totall já não obtiveram faturamento proveniente de negócios internacionais em 2015, embora não tenha sido sempre assim. De fato, na tese de doutorado de Mello (2009), que também estudou essas empresas, a Totall registra $10 \%$ de faturamento proveniente do mercado internacional em 2008 e a Fujitec $30 \%$, naquele mesmo ano. Claramente, a redução do faturamento proveniente de operações internacionais nos últimos anos está associada a um abandono do mercado internacional pelas próprias empresas, que não se perceberam interessadas, ou competitivas, para atuar internacionalmente.

O número de iniciativas internacionais estudadas variou bastante de empresa para empresa, mas não se observa qualquer relação entre o número de iniciativas e a percentagem do faturamento proveniente dos negócios internacionais em 20152016. Faz-se novamente a ressalva de que o número de iniciativas internacionais analisadas em cada empresa não corresponde necessariamente ao número total de iniciativas executadas por aquela empresa, pelos motivos anteriormente mencionados. 
Por sua vez, a Light Infocon tem a maioria de iniciativas em mercados desenvolvidos, mas também ingresso em mercados emergentes. Sua trajetória de internacionalização mostra uma presença inicial em mercados desenvolvidos (EUA, França, Itália, Espanha), seguida pela entrada em um mercado emergente bastante competitivo, a China, e depois revezando-se os ingressos entre mercados emergentes (India, Chile e Argentina) e desenvolvidos (Austrália, Inglaterra e Portugal). O último ingresso estudado foi em Angola, por meio da conexão doméstica, uma empresa parceira de São Paulo. A trajetória da Light Infocon ao longo do tempo é bastante peculiar, e como se viu na descrição de seu histórico de internacionalização, marcada pela abertura de escritórios temporários visando criar redes de relacionamento. Apesar de ainda pequena, a empresa obtém parcela relevante de seus negócios no mercado internacional e essa parcela aumentou de 2008 a 2015 , de $14 \%$ para $24 \%$.

A Fujitec entrou em maior número de mercados desenvolvidos do que não desenvolvidos, mas sua trajetória internacional é marcada pela passagem do primeiro grupo (desenvolvidos) para o segundo (não desenvolvidos), o que pode estar associado ao esgotamento das vendas internacionais.

As outras empresas (Totvs, MidiaVox, Totall e Xseed) apresentam predominância de mercados não desenvolvidos.

A Totvs realizou uma escolha estratégica ao escolher a América Latina como foco de expansão internacional, o que se justifica pelo fato de disputar o mercado global com multinacionais poderosas, atuantes em todo o mundo. Não obstante, como analisado no caso relatado no capítulo anterior, ainda não conseguiu firmar presença significativa no mercado regional latino-americano, de tal modo que o faturamento obtido no exterior se reduziu nos últimos anos, correspondendo, em 2015, a apenas $2 \%$ de seu faturamento total.

A MidiaVox atua internacionalmente por meio de uma parceria com a multinacional Avaya. Inicialmente, conquistou posição na parceira como fornecedora para a América Latina e depois alcançou indicação como fornecedora global, aumentando seu faturamento de $12 \%$ para $35-40 \%$. É essa lógica que explica sua trajetória de mercado a mercado. A Totall seguiu de mercados não desenvolvidos para desenvolvidos, mas tem tido dificuldade em manter suas vendas internacionais, que eram de 10\% do faturamento em 2008 (MELLO, 2009) e caíram para $0 \%$ em 2015. Por fim, a Xseed tem mantido uma percentagem 
elevada de faturamento internacional e, apesar da predominância de entrada em mercados não desenvolvidos, não apresenta nenhum padrão na ordem de ingresso em mercados externos.

Em síntese, há indícios de que a presença continuada em mercados desenvolvidos pode ser vista como indicador de competitividade e sucesso na internacionalização. É possível que, face a concorrência mais acirrada e consumidores mais exigentes, as empresas sejam forçadas a serem mais competitivas, ou a se retirar do mercado.

\subsection{3.}

\section{Abordagens para ingresso em mercados internacionais}

Considerando-se as 87 iniciativas de internacionalização estudadas, 48 se deram por iniciativa das empresas e 39 decorreram de situações emergentes (Quadro 5.5). Observa-se que, à exceção da Totvs, em que as iniciativas estudadas foram em sua totalidade intencionais, e da MidiaVox, em que foram exclusivamente emergentes, nas demais empresas encontra-se uma combinação de iniciativas próprias com situações emergentes.

\begin{tabular}{|c|c|c|c|c|c|c|}
\hline \multirow[t]{2}{*}{ Empresas } & \multirow{2}{*}{$\begin{array}{c}\% \text { do } \\
\text { faturam. } \\
\text { internac. } \\
2015\end{array}$} & \multirow{2}{*}{$\begin{array}{l}\text { No. de } \\
\text { iniciat. } \\
\text { internac. }\end{array}$} & \multicolumn{3}{|c|}{ Abordagem inicial } & \multirow{2}{*}{$\begin{array}{l}\text { Sequência temporal } \\
\text { das abordagens }\end{array}$} \\
\hline & & & $\begin{array}{l}\text { Emer- } \\
\text { gente } \\
\text { (E) }\end{array}$ & $\begin{array}{l}\text { Inten- } \\
\text { cional } \\
\text { (I) }\end{array}$ & $\begin{array}{c}\text { \% abordag. } \\
\text { emergentes } \\
\text { sobre total }\end{array}$ & \\
\hline \multicolumn{7}{|l|}{ Grandes } \\
\hline CI\&T & $40 \%$ & 6 & 3 & 3 & $50 \%$ & $2 \mathrm{E} \rightarrow 2 \mathrm{I} \rightarrow 1 \mathrm{E} \rightarrow 1 \mathrm{I}$ \\
\hline Totvs & $2 \%$ & 14 & 0 & 14 & $0 \%$ & 14I \\
\hline \multicolumn{7}{|l|}{ Média } \\
\hline Ivia & $5 \%$ & 12 & 5 & 7 & $42 \%$ & $1 \mathrm{E} \rightarrow 4 \mathrm{I} \rightarrow 2 \mathrm{E} \rightarrow 3 \mathrm{I} \rightarrow 2 \mathrm{E}$ \\
\hline \multicolumn{7}{|l|}{ Pequenas } \\
\hline Fujitec & $0 \%$ & 8 & 5 & 3 & $63 \%$ & $1 \mathrm{I} \rightarrow 5 \mathrm{E} \rightarrow 2 \mathrm{I}$ \\
\hline $\begin{array}{l}\text { Light } \\
\text { Infocon }\end{array}$ & $24 \%$ & 16 & 3 & 13 & $19 \%$ & $\begin{aligned} 9 \mathrm{I} \rightarrow 1 \mathrm{E} & \rightarrow 2 \mathrm{I} \rightarrow 1 \mathrm{E} \rightarrow 2 \mathrm{I} \\
& \rightarrow 1 \mathrm{E}\end{aligned}$ \\
\hline MidiaVox & 35 a $40 \%$ & 16 & 16 & 0 & $100 \%$ & $16 \mathrm{E}$ \\
\hline Totall & $0 \%$ & 7 & 3 & 4 & $43 \%$ & $3 \mathrm{E} \rightarrow 4 \mathrm{I}$ \\
\hline Xseed & $40 \%$ & 8 & 4 & 4 & $50 \%$ & $3 \mathrm{I} \rightarrow 1 \mathrm{E} \rightarrow 1 \mathrm{I} \rightarrow 3 \mathrm{E}$ \\
\hline Total & -- & 87 & 39 & 48 & $45 \%$ & -- \\
\hline
\end{tabular}

Quadro 5.5 - Abordagens emergentes vs intencionais

Fonte: própria 
Observe-se que as abordagens emergentes são similares ao que, na literatura de exportação é chamado de "pedidos inesperados vindos do exterior". Nestes casos, as empresas são procuradas e isso abre oportunidades de negócios no exterior, o que pode ser um indicativo de que essas empresas dispõem de um produto ou serviço que pode ser competitivo em outro país, ou, provavelmente, não seriam procuradas. No entanto, essa consideração não parece se impor na interpretação dos resultados obtidos, pois a Fujitec, empresa com predomínio de abordagens emergentes, encontra-se, ao menos momentaneamente, fora do mercado internacional.

Dentre as formas intencionais de inserção internacional, a presente pesquisa identificou oito tipos: visitas a fornecedores e complementadores no exterior; participação em eventos, feiras internacionais e rodadas de negócios (como as promovidas pela Apex-Brasil e pela Softex); contratação de consultoria externa; contratação de executivo estrangeiro; uso de rede pessoal; uso de rede de negócios; associação com outras empresas; participação em projetos internacionais em conjunto com órgãos governamentais. No Quadro 5.6 são apresentadas os diversos tipos intencionais de abordagem identificados.

\begin{tabular}{|c|c|c|c|c|c|c|c|c|}
\hline $\begin{array}{l}\text { Tipos } \\
\text { intencionais }\end{array}$ & CI\&T & Totvs & Ivia & Fujitec & $\begin{array}{c}\text { Light } \\
\text { Infocon }\end{array}$ & $\begin{array}{l}\text { Midia } \\
\text { Vox }\end{array}$ & Totall & Xseed \\
\hline $\begin{array}{l}\text { Viagem c/ } \\
\text { visitas a } \\
\text { empresas }\end{array}$ & $\mathrm{X}$ & $\mathrm{X}$ & $\mathrm{x}$ & $\mathrm{x}$ & $\mathrm{x}$ & & $\mathrm{X}$ & \\
\hline $\begin{array}{l}\text { Feiras/eventos/ } \\
\text { rodadas negócio }\end{array}$ & $\mathrm{X}$ & & $\mathrm{x}$ & $\mathrm{x}$ & $\mathrm{X}$ & & & $\mathrm{x}$ \\
\hline $\begin{array}{l}\text { Contratação de } \\
\text { consultoria }\end{array}$ & $\mathrm{x}$ & & & $\mathrm{x}$ & & & & \\
\hline $\begin{array}{l}\text { Contratação de } \\
\text { executivo } \\
\text { estrangeiro }\end{array}$ & $\mathrm{x}$ & & $\mathrm{x}$ & & & & & \\
\hline $\begin{array}{l}\text { Uso de rede } \\
\text { pessoal }\end{array}$ & & & & & $x$ & & & \\
\hline $\begin{array}{l}\text { Uso de rede de } \\
\text { negócios }\end{array}$ & & & & & $\mathrm{x}$ & & $x$ & $\mathrm{x}$ \\
\hline $\begin{array}{l}\text { Associação } \\
\text { com outras } \\
\text { empresas }\end{array}$ & $\mathrm{x}$ & $\mathrm{x}$ & & & & & & \\
\hline $\begin{array}{l}\text { Projeto intl. com } \\
\text { órgãos govern. }\end{array}$ & & & $\mathrm{x}$ & & $\mathrm{x}$ & & $\mathrm{x}$ & $\mathrm{x}$ \\
\hline
\end{tabular}

Quadro 5.6 - Tipos intencionais de abordagem

Fonte: própria

Nota: " $\mathrm{x}$ " indica o uso do tipo de abordagem relatado em pelo menos uma iniciativa. 
Alguns empreendedores relataram buscar oportunidades internacionais por uso de suas redes de negócios ou pessoais, mas também há incidência de iniciativas arrojadas, denominadas cold call, em que o empresário busca parcerias ou conhecimento de negócio ou vendas diretamente, sem utilizar qualquer intermediário. No caso do uso intencional de redes pelas empresas estudadas para dar início a novas iniciativas internacionais, há relatos de apenas três empresas fazendo uso ativo da rede: Light Infocon, Ivia e Xseed.

Dentre as iniciativas emergentes, ou seja, aquelas que ocorreram fortuitamente, foram mencionadas como origem da oportunidade a visita de executivos estrangeiros, a indicação de membro da rede e o acesso à empresa por meio do site (Quadro 5.7).

\begin{tabular}{|c|c|c|c|c|c|c|c|c|}
\hline $\begin{array}{l}\text { Tipos } \\
\text { emergentes }\end{array}$ & CI\&T & Totvs & Ivia & Fujitec & $\begin{array}{l}\text { Light } \\
\text { Infocon }\end{array}$ & $\begin{array}{l}\text { Midia } \\
\text { Vox }\end{array}$ & Totall & Xseed \\
\hline $\begin{array}{l}\text { Visita de } \\
\text { executivos } \\
\text { estrangeiros }\end{array}$ & & & $\mathrm{x}$ & $\mathrm{x}$ & & & $\mathrm{x}$ & \\
\hline $\begin{array}{l}\text { Acesso ao site } \\
\text { por estrangeiros }\end{array}$ & & & & $\mathrm{x}$ & & & & $\mathrm{x}$ \\
\hline $\begin{array}{l}\text { Indicação de } \\
\text { membro da rede }\end{array}$ & $\mathrm{x}$ & $\mathrm{x}$ & $\mathrm{x}$ & $\mathrm{x}$ & $\mathrm{x}$ & $\mathrm{x}$ & $\mathrm{x}$ & $\mathrm{x}$ \\
\hline
\end{tabular}

Quadro 5.7 - Tipos emergentes de abordagem

Fonte: própria

Nota: "x" indica o uso do tipo de abordagem relatado em pelo menos uma iniciativa.

Há na literatura evidências de geração de capital social por meio de experiências fortuitas sobre as quais o indivíduo teve pouco controle ou intenção (COLEMAN, 1990). Em um episódio no processo de internacionalização da Fujitec, uma empresa australiana - a VFJ - a procurou, propondo uma parceria para participação em licitação no Brasil. Embora essa empresa fosse concorrente, oferecia benefícios para a Fujitec, como financiamento a juros mais baixos. A licitação no Brasil não foi ganha, mas a curta interação entre um executivo da empresa australiana e os sócios da Fujitec trouxe outro benefício inesperado: o executivo se tornou amigo dos sócios e um divulgador dos bons serviços que a Fujitec entregava: 
“Então, nós fechamos essa parceria com a empresa australiana, e o diretor de marketing deles, Chris Adams, tem uma experiência fantástica, é assim um cidadão do mundo. [...]. É fantástico em termos de networking, de experiência. E eu acredito que, quando fechamos esse elo, ele gostou muito da nossa competência técnica, da nossa agilidade, da nossa flexibilidade, do nosso software... Então ele ficou impressionado e quis levar essa solução pra agregar ao equipamento dele. [...] Ele disse: 'Quero agora vocês como parceiros no resto do mundo'." (Danilo Reis, fundador, Fujitec)

$\mathrm{O}$ acesso a site da empresa por potenciais compradores ou parceiros estrangeiros é um formato que parece estar se tornando mais comum recentemente, como destacou Ronaldo Brandão, da Xseed: "A nossa exposição é por meio de internet ou feiras. Tem essa plataforma de clientes mais ampliada. [...] Vem tendo mais facilidade pela internet." Algumas empresas de software podem ter mais aderência a esse tipo de abordagem, em razão do produto ou serviço que oferece. No caso da Xseed, como existem poucas ofertas de soluções de downsizing no mundo, empresas que necessitam de tal ferramenta podem se beneficiar dessa forma de busca.

\section{3.}

\section{Uso de capital social e redes na internacionalização}

As firmas estão conectadas a um conjunto finito de relacionamentos comerciais que, por sua vez, têm relacionamentos com outras empresas e, portanto, cada uma delas pode estar conectada a uma rede de negócios internacional (JOHANSON \& VAHLNE, 2003). Em particular, a literatura aponta que, dentre as estratégias utilizadas pelas pequenas firmas para sobrepujar as dificuldades e a escassez de recursos, o uso de redes parece ter papel relevante, tanto na forma de contatos pessoais, quanto de relacionamentos com clientes e fornecedores e, até mesmo, quando essas empresas seguem o cliente a outros mercados. O empreendedor é forte usuário da sua rede de relacionamentos, tanto pessoal quanto de negócios. (COVIELLO \& MUNRO, 1995, 1997; FREEMAN et al., 2006; JOHANSON \& VAHLNE, 2009; SCHWEIZER, VAHLNE, \& JOHANSON, 2010; MAINELA et al., 2011). 
Coleman (1988) e Nahapiet e Goshal (1998) sugerem que as redes de relacionamento, proporcionam acesso a recursos que não estariam disponíveis por outro meio. Sob essa ótica, a rede oferece conexões-chave que atendem aos interesses dos atores (nesse caso, os dirigentes das empresas) comoacesso a novos clientes, conhecimento e recursos financeiros ou humanos. (RODRIGUES e CHILD, 2012).

Para superar o liability of outsidership, ou seja, o fato de não pertencerem a redes internacionais, as firmas alavancam os relacionamentos pessoais ou de negócios já existentes, ou promovem a criação de parcerias (ROCHA, MELLO, DIB, \& MACULAN, 2005).

\subsection{1.}

\section{Tipos de atores}

A rede é formada por atores que podem ser de diversos tipos, como clientes, fornecedores, concorrentes, agências privadas ou governamentais, família, ou amigos (COVIELLO \& MUNRO, 1995; EVERS \& KNIGHT, 2008; ZAIN \& NG, 2006; HOHENTHAL, JOHANSON, \& JOHANSON, 2014).

$\mathrm{Na}$ literatura, diversos atores de redes foram identificados como relevantes para pequenas empresas, como distribuidores, multinacionais, clientes, profissionais pertencentes a instituições da indústria ou setores do governo. Para efeitos da presente pesquisa, o ator, em uma rede, é definido como o indivíduo identificado como ponto de contato entre a empresa estudada e a organização envolvida na iniciativa internacional. A análise das entrevistas permitiu identificar diferentes tipos de atores utilizados pelas firmas em cada iniciativa internacional. No Quadro 5.8 estão apresentados os tipos de atores usados como contatos em cada iniciativa internacional analisada na pesquisa. 


\begin{tabular}{|c|c|c|c|c|c|c|c|c|}
\hline Tipos de atores & CI\&T & Totvs & Ivia & Fujitec & $\begin{array}{l}\text { Light } \\
\text { Infocon }\end{array}$ & $\begin{array}{l}\text { Midia } \\
\text { Vox }\end{array}$ & Totall & Xseed \\
\hline $\begin{array}{l}\text { Cliente e ex- } \\
\text { cliente }\end{array}$ & $\mathrm{x}$ & & & & $\mathrm{x}$ & $\mathrm{x}$ & $\mathrm{x}$ & $\mathrm{x}$ \\
\hline $\begin{array}{l}\text { Fornecedor e ex- } \\
\text { fornecedor }\end{array}$ & & & & $\mathrm{x}$ & $\mathrm{x}$ & & & \\
\hline $\begin{array}{l}\text { Parceiro e ex- } \\
\text { parceiro }\end{array}$ & $\mathrm{x}$ & $\mathrm{x}$ & $\mathrm{x}$ & $\mathrm{x}$ & $\mathrm{x}$ & & $\mathrm{x}$ & $\mathrm{x}$ \\
\hline $\begin{array}{l}\text { Empregado e ex- } \\
\text { empregado }\end{array}$ & $\mathrm{x}$ & & $\mathrm{x}$ & & & & & \\
\hline $\begin{array}{l}\text { Ex-colega de } \\
\text { escola/ trabalho }\end{array}$ & & & $\mathrm{x}$ & & $\mathrm{x}$ & & & \\
\hline $\begin{array}{l}\text { Funcionário de } \\
\text { órgão governam. }\end{array}$ & & & $\mathrm{x}$ & & $\mathrm{x}$ & & $\mathrm{x}$ & $\mathrm{x}$ \\
\hline Prospect & & $\mathrm{x}^{*}$ & $\mathrm{x}$ & $\mathrm{x}$ & $\mathrm{x}$ & & $\mathrm{x}$ & $\mathrm{x}$ \\
\hline Concorrente & & $\mathrm{x}$ & & $\mathrm{x}$ & & & & \\
\hline Ex-professor & & & & & $\mathrm{x}$ & & & \\
\hline Amigo & & & & & $\mathrm{x}$ & & & \\
\hline Conhecido & & & $\mathrm{x}$ & & $\mathrm{x}$ & & & \\
\hline Tipos de atores & 3 & 3 & 6 & 4 & 9 & 1 & 4 & 4 \\
\hline
\end{tabular}

Quadro 5.8 - Tipos de atores nas iniciativas internacionais

Fonte: própria

Nota: "x" indica o uso do tipo de ator relatado em pelo menos uma iniciativa.

(*) Trata-se de um prospect candidato a franqueado.

Ao analisar o Quadro 5.8, pode-se notar que clientes, ex-clientes, parceiros e ex-parceiros são os grandes protagonistas das iniciativas internacionais das empresas analisadas. Há poucos casos de uso de laços informais, como família ou amigos, o que está em linha com alguns trabalhos empíricos, que mostram o menor uso de tais laços nas iniciativas internacionais de empresas empreendedoras (KONTINEN \& OJALA, 2011; SINGH et al., 1999).

A CI\&T, a MidiaVox e a Totall associaram-se a empresas multinacionais e a partir dessa parceria estreita, conseguiram penetração em diversos mercados no mundo. Essa forma de atingir mercados externos - denominada na literatura "seguir o cliente" (client following) ou ainda "dançando com gorilas" (dancing with gorilas ${ }^{3}$ ), em alusão ao poder das MNCs - é encontrada em alguns estudos empíricos (ETEMAD, WRIGHT, \& DANA, 2001; MELLO \& ROCHA, 2009; PRASHANTHAM \& BALACHANDRAN, 2009).

No entanto, há também estudos que identificaram relacionamentos de empresas com multinacionais como não sendo úteis à internacionalização (PRASHANTHAM \& BIRKINSHAW, 2015), ao constatarem que o locus da atividade conjunta esteve firmemente embutido no país de origem da empresa. Esse é o caso da Xseed, que conquanto mantenha parcerias com multinacionais

\footnotetext{
${ }^{3}$ Termo utilizado por Prashantham (2016).
} 
em negócios no Brasil, não realiza avanços de forma consistente com essas empresas em mercados externos. Como ilustrou um entrevistado:

"Quando falamos de parcerias com as grandes multinacionais nós brincamos que é a parceria da dança do urso, porque o urso te tira para dançar e dança até quando ele quer, depois ele te joga fora. Parceria com essas empresas é muito em cima do interesse delas.” (Ronaldo Brandão, fundador, Xseed).

Pode-se atribuir esses diferentes resultados com relação ao uso de redes de multinacionais ao tipo de parceria da empresa. No caso da Xseed, as multinacionais com as quais trabalha no Brasil também são empresas do setor de Tecnologia da Informação, portanto concorrentes em algumas circunstâncias. A parceria da MidiaVox é com uma empresa complementar e as da CI\&T e da Totall são de setores completamente distintos: na verdade, clientes que conferem legitimidade e indicam para outras subsidiárias ou empresas do grupo.

Segundo Prashantham (2016), as multinacionais também obtêm benefícios ao se associarem a pequenas empresas inovadoras em países emergentes. A Totall mantém parceria com a Unisys por mais de 15 anos, e a multinacional atua como distribuidora de seu produto de automação comercial, que apresenta características específicas para o mercado latinoamericano.

Em termos de diversidade de tipos de contato, a Ivia e a Light Infocon apresentam a maior heterogeneidade de tipos de atores dentre as oito empresas estudadas. Essas firmas têm como dirigentes indivíduos que atribuem grande importância ao desenvolvimento e manutenção de suas redes de relacionamento. A posse de uma rede diversificada e balanceada, formada por laços fracos e laços fortes, pode ser muito valiosa, por permitir um fluxo mais completo de informações e conhecimento (HOANG \& ANTONCIC, 2003; UZZI, 1996).

No modelo de Uppsala revisado, a internacionalização passa a ser um resultado das diversas ações impetradas pela empresa no contexto das redes de relacionamento. $\mathrm{O}$ empreendedor tem papel ativo na busca por se inserir e se manter dentro de redes relevantes ao processo de internacionalização. (JOHANSON \& VAHLNE, 2003, 2009), sendo tal pro atividade uma característica desses empreendedores (MCDOUGALL \& OVIATT, 2000). Adler e Kwon (2002) desenvolveram um modelo que mostra o trinômio oportunidade, motivação e habilidade como sendo o conjunto de eventos que permite a aquisição dos benefícios que o capital social pode trazer. O empreendedor precisa ter 
habilidade e motivação para conseguir acessar e usar, em benefício da empresa, o capital social.

Não só as redes são usadas nos caminhos iniciais da internacionalização, como constantemente encontram-se empresas que se esmeram em manter e acrescentar relacionamentos como forma de manter o ritmo de crescimento (COVIELLO \& MUNRO, 1997; FREEMAN et al., 2006; HOLMLUND \& KOCK, 1998; MUSTEEN, FRANCIS \& DATTA, 2010).

Nesse aspecto, a análise das entrevistas trouxe diversos depoimentos de empresários que se esmeram em manter a rede de contatos internacionais ativa. Algumas delas, como a Ivia, a Light Infocon e a CI\&T relataram formas diferentes de manutenção de suas redes. Enquanto a Ivia e a Light Infocon aplicam uma abordagem mais pessoal, por e-mail, telefonando, ou mesmo viajando com frequência para manter a empresa na mente de seus clientes, a CI\&T utiliza um enfoque mais de negócios, enviando artigos interessantes ou newsletters com frequência para seus clientes. É importante que os empreendedores mantenham suas redes vivas, como destaca Alexandre Menezes, da Ivia:

"Mas eu diria que hoje tem sido mais atuante. Não é a resposta, não é o passivo, é $o$ ativo mesmo, $e$ o ativo tem se dado através da nossa rede de relacionamentos. A pessoa, ou é cliente, ou é amigo, ou é parceiro. Hoje em dia, os negócios são feitos através desse networking, por exemplo, uma rede social profissional, como Linkedin. Alguns dos contatos chegam através dessa rede. Essa manutenção [da rede] é inerente ao nosso negócio, estamos em todas as redes sociais, eu, meus sócios, diretores. Quem sai mantém o contato conosco, por conta desse método nosso." (Alexandre Menezes, fundador, Ivia)

Da mesma forma, Alexandre Moura, da Light Infocon, relata o esforço para manter sua rede de relacionamentos, tanto de contatos da indústria, por meio de participação em eventos no mundo de negócios, quanto de contatos pessoais:

"Mantenho minha rede por meio de troca de e-mail. Não deixo de pelo menos uma vez por mês mandar alguma coisa interessante, alguma notícia, que é do interesse da pessoa. [...] Tenho essa preocupação de manter a rede, prezo muito o relacionamento com as pessoas, conheço muita gente. E nesse tipo de coisa é até mais fácil [manter a rede no exterior], porque no exterior o número de pessoas é menor, fica fácil de lembrar. E certamente, no final do ano, eu sempre falo, alguns dias antes do Natal, pelo menos ligo, uso Skype, redes sociais." (Alexandre Moura, fundador, Light Infocon) 
No outro extremo em relação à heterogeneidade de contatos estão duas empresas: a MidiaVox e a Totvs, a primeira utilizando o cliente (uma multinacional) como ponto de contato, e a última realizando contatos com candidatos a franqueados. A Totvs usa como estratégia a abertura de franquias nos países em que ingressa e, portanto, sua rede passa a ser constituída primordialmente por parceiros. Em um único caso identificado nas entrevistas, houve indicação de um parceiro já existente e em outros dois casos a iniciativa internacional se originou da aquisição de empresas concorrentes que já tinham operações no exterior, ou seja, as operações foram adquiridas (nesses três casos, os laços foram considerados fracos). Já a MidiaVox se associou a uma empresa cujos serviços são complementares aos seus (e em alguns casos, concorrentes, mas, quando isso ocorre, a MidiaVox vende apenas no Brasil).

Alguns autores avaliam que pertencer a uma rede muito fechada gera uma relação de interdependência que pode ter como consequência a perda de independência, além do possível surgimento de unidades com poder nas organizações, já que controlam as redes internas conectadas às externas (por exemplo, JOHANSON \& VAHLNE, 2011). A MidiaVox teve sua trajetória internacional totalmente ligada à empresa Avaya, e com isso teve dificuldades para desenvolver outras iniciativas. Oportunidades de negócios com outras empresas (concorrentes da Avaya) surgiram, mas os sócios perceberam que poriam a parceria em risco e decidiram não dar continuidade.

A grande incidência de prospects como ponto de contato das iniciativas está relacionada em quase todos os eventos emergentes, em que a empresa focal é procurada pelo possível cliente. As iniciativas intencionais em que o ponto de contato foi um prospect foram as chamadas investidas cold call, quando a empresa busca por clientes sem nenhuma indicação.

\subsection{2.}

Tipos de laços

Outra característica de rede analisada em estudos sobre empresas empreendedoras diz respeito aos tipos de laços utilizados nas iniciativas internacionais. Os processos de internacionalização de pequenas empresas são diretamente influenciados por suas redes formais e informais, pessoais e de negócios (COVIELLO \& MUNRO, 1997). Um estudo empírico conduzido por 
Coviello e Munro (1995) mostrou que 64\% das firmas pesquisadas (pequenas firmas de software da Nova Zelândia) iniciaram atividades internacionais por meio de contatos pertencentes a redes pessoais ou de negócios. No Quadro 5.9 apresentam-se o número absoluto e percentual de iniciativas internacionais com laços e os tipos de laços utilizados pelas empresas analisadas, classificados em laços pessoais, de negócios, ou com o governo.

Três empresas, sendo duas empresas de grande porte e uma de pequeno porte apresentaram iniciativas que, de alguma forma, não estiveram ligadas a laços, sendo esta situação bastante marcante na Totvs

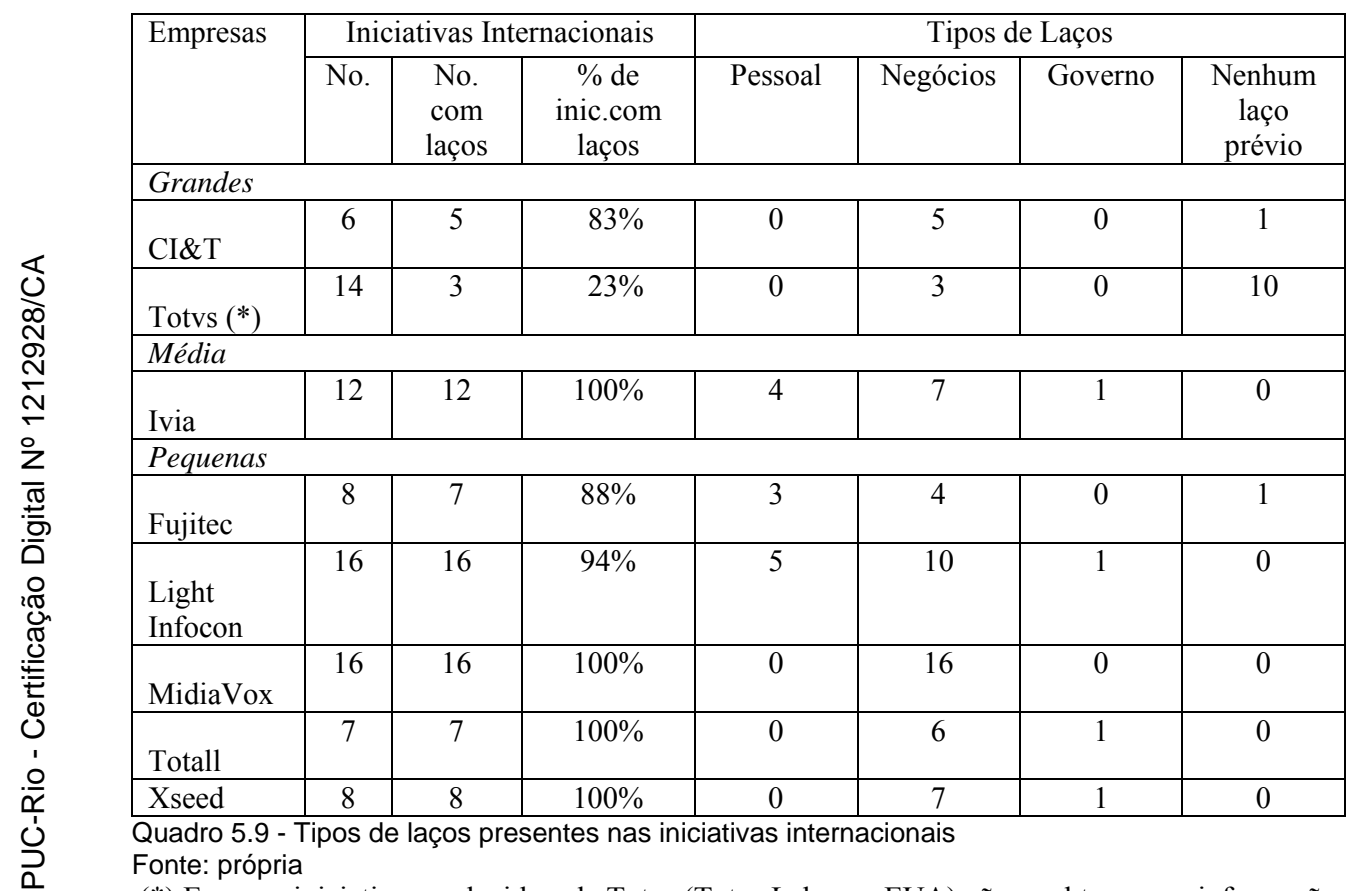

(*) Em uma iniciativa conduzida pela Totvs (Totvs Lab, nos EUA) não se obteve essa informação.

Das quatro empresas que manifestaram relações com o Governo, duas - a Light Infocon e a Totall - tiveram como característica comum o fato de que pelo menos um de seus sócios fazia parte de associação do setor ou em parceria com o governo. Edilson Paterno, da Totall, pertencia a um grupo multi-institucional que envolvia a Prefeitura de Blumenau, o Instituto Gene da Universidade Regional de Blumenau, com apoio do CNPq e da Softex. Alexandre Moura, da Light Infocon, era membro da Softex e da Associação Brasileira das Empresas de Tecnologia da Informação (Assespro). Alexandre Moura, da Light Infocon, teve participação relevante na criação do escritório brasileiro na China. 
Apesar de relatos dos sócios apontarem para a evolução de alguns relacionamentos que se iniciam no âmbito dos negócios e acabam se tornando pessoais, poucas iniciativas de internacionalização foram originadas pelas últimas. Nos poucos casos em que a rede pessoal foi protagonista, percebe-se a incidência dos relacionamentos criados em universidades, como ilustra Alexandre Moura, da Light Infocon:

"Veja, nós continuávamos mantendo contato. Eu, por exemplo, quando meu irmão estava fazendo doutorado no Canadá, eu estava fazendo intercâmbio nos EUA, e evidentemente que fui para lá [Canadá]. Então tínhamos amizades, ou seja, gente que conhecíamos. [...] Tomamos, os três, a decisão de internacionalizar, mas montamos o negócio sabendo que não dava para viver só de Brasil, particularmente aqui no Nordeste. Para nós, vender daqui do Nordeste para São Paulo, ou vender para os EUA, não fazia diferença, principalmente com esses contatos, com essa network que nós tínhamos. Então, isso facilitou." (Alexandre Moura, fundador, Light Infocon)

Mesmo situações de acesso a rede pessoal podem ter surgido primeiramente de um relacionamento de negócios, ou seja, laços que se iniciaram como de negócios, mas que, ao longo do tempo, foram se tornando pessoais. A Fujitec passou por uma experiência com tais características. Um executivo de uma empresa que os procurou para uma parceria no Brasil tornou-se amigo dos sócios e ofereceu diversas oportunidades de negócios em variadas regiões do mundo à firma, como ressaltou o sócio Wicca Neves: "É uma pessoa que fez uma amizade. [...] É uma amizade verdadeira e, daí para a frente... Então, hoje sabemos que ele está brigando pela empresa."

Percebe-se que a utilização de laços de negócios predomina nas iniciativas internacionais identificadas no presente estudo. A literatura tem mostrado diversos aspectos em relação ao uso de laços pessoais ou de negócios na internacionalização de pequenas empresas, sendo comum que artigos tratem tanto as redes pessoais como as de negócio com igual importância na internacionalização das pequenas empresas (COVIELLO e MUNRO, 1995, 1997; FREEMAN et al., 2006; KISS \& DANIS, 2008). Evers e O'Gorman (2011) observaram em estudo de caso de três empresas, que a seleção do mercado estrangeiro ocorreu por meio da interação entre o empreendedor e diversos membros de suas redes (tanto pessoal quanto de negócios). Evers (2011) arguiu que, nas experiências internacionais, são mais frequentes os usos de laços oriundos de experiências anteriores gerenciais ou setoriais do que laços pessoais, 
como amigos e familiares, enquanto outros trabalhos descrevem o uso dos laços pessoais como fomentador de identificação de oportunidades (HOLMLUND \& KOCK, 1998; ELLIS, 2000), ou como meio de aceleração da internacionalização (EVERS \& O'GORMAN, 2011). No entanto, contradizendo esses estudos, Singh (1998) mostrou que haveria preferência pelo uso de contatos da rede pessoal (como família e amigos) por empreendedores em relação ao uso da rede de negócios (como bancos e advogados) para identificação de oportunidades.

Como os sócios das empresas analisadas no presente estudo tinham, em geral, pouca experiência internacional, principalmente relativas a haver residido ou estudado por certo período no exterior, é natural que disponham de poucos laços pessoais internacionais, que tenderiam a provir dessas experiências. Assim sendo, a predominância de laços de negócios é natural, até mesmo porque a principal experiência internacional prévia à fundação da empresa é ligada a haver trabalhado em multinacionais, o que tenderia gerar contatos de negócio.

\subsection{3. \\ Força de laços}

Os relacionamentos são muitas vezes responsáveis por abrir portas para atores de menor poder na rede (RODRIGUES \& CHILD, 2012). Kiss e Danis (2008) observaram que empreendedores de países menos desenvolvidos institucionalmente (países emergentes ou de transição) tendem a contar com redes que, via de regra, são formadas por laços fortes, já que não possuem número significativo de conexões com redes internacionais. Redes formadas por laços fortes podem facilitar acesso de empreendedores de países menos desenvolvidos institucionalmente a recursos que podem ser críticos à sua sobrevivência (BURT, 1992, 1997; PENG \& LUO, 2000). No entanto, segundo Granovetter (1973), firmas com maior concentração de laços fracos têm vantagem sobre aquelas que mantêm relações fortes, uma vez que tais laços exigem menos esforço de manutenção, além de oferecer maior diversidade de informações. Laços fracos permitem aumentar o escopo da rede, podendo trazer novas informações e recursos, pois executam o papel de pontes entre os diversos atores da rede. 
O Quadro 5.10 mostra a estimativa de laços fortes e fracos que marcaram o início de cada uma das 87 iniciativas internacionais estudadas nas oito empresas de software desta pesquisa. A avaliação da força dos laços realizada se baseia na descrição feita pelos entrevistados, marcadas pela utilização de termos como amizade, confiança e respeito.

\section{Quadro 5.10 - Força dos laços presentes nas iniciativas internacionais}

\begin{tabular}{|c|c|c|c|c|c|c|}
\hline \multirow[t]{2}{*}{ Empresas } & \multicolumn{2}{|c|}{ Iniciativas Internacionais } & \multicolumn{4}{|c|}{ Força de Laços } \\
\hline & No. & No. com laços & Fraco & Forte & Nenhum & $\begin{array}{l}\text { \% de laços } \\
\text { fracos }\end{array}$ \\
\hline \multicolumn{7}{|l|}{ Grandes } \\
\hline CI\&T & 6 & 5 & 4 & 1 & 1 & $67 \%$ \\
\hline Totvs $(*)$ & 14 & 3 & 3 & 0 & 10 & $23 \%(* *)$ \\
\hline \multicolumn{7}{|l|}{ Média } \\
\hline Ivia & 12 & 12 & 7 & 5 & 0 & $58 \%$ \\
\hline \multicolumn{7}{|l|}{ Pequenas } \\
\hline Fujitec & 8 & 7 & 4 & 3 & 0 & $57 \%$ \\
\hline $\begin{array}{l}\text { Light } \\
\text { Infocon }\end{array}$ & 16 & 15 & 10 & 5 & 1 & $67 \%$ \\
\hline MidiaVox & 16 & 16 & 0 & 16 & 0 & $0 \%$ \\
\hline Totall & 7 & 7 & 5 & 2 & 0 & $71 \%$ \\
\hline Xseed & 8 & 8 & 6 & 2 & 0 & $75 \%$ \\
\hline \multirow{3}{*}{\multicolumn{7}{|c|}{$\begin{array}{l}\text { Quadro } 5.10 \text { - Força dos laços presentes nas iniciativas internacionais } \\
\text { Fonte: própria } \\
\text { (*) Em uma iniciativa conduzida pela Totvs (Totvs Lab, nos EUA) não se obteve essa informação. } \\
\text { Foi considerado que o relacionamento com firmas adquiridas era fraco. } \\
\text { (**) Percentagem calculada sobre o total de } 13 \text { iniciativas. } \\
\qquad \text { A firma mais dependente de laços fortes é a MidiaVox e, embora tenha } \\
\text { perdido algumas oportunidades de negócios por estar associada a um único } \\
\text { parceiro, a multinacional Avaya, é a empresa que apresenta maior penetração } \\
\text { internacional, tanto em percentual de faturamento, quanto em escopo geográfico. } \\
\text { Seus sócios se orgulham da relação ética e de confiança que lograram estabelecer } \\
\text { com a Avaya, como reforçou Alcides Pires: }\end{array}$}} \\
\hline & & & & & & \\
\hline & & & & & & \\
\hline \multicolumn{7}{|c|}{$\begin{array}{l}\text { "Eu diria que tem a parte técnica [na relação de confiança entre as empresas] e } \\
\text { tem a parte da ética também, porque nesse período já vimos concorrentes nossos } \\
\text { que cresceram e morreram [na parceria com a Avaya] e, normalmente, mais por } \\
\text { questões éticas do que técnicas. Às vezes os próprios clientes nos pedem coisas } \\
\text { diretamente, porque provavelmente os custos seriam mais baixos. Mas nós dizemos } \\
\text { que não podemos fazer porque temos contrato de exclusividade 'não posso usar o } \\
\text { que aprendi com a Avaya concorrendo com ela'. Essa relação de confiança é } \\
\text { difícil de jogar fora." (Alcides Pires, fundador, MidiaVox) }\end{array}$} \\
\hline
\end{tabular}


Essa maneira de formar e gerenciar a rede da MidiaVox, gradual, gera aprendizado recíproco e aumenta paulatinamente a confiança mútua entre as empresas, trazendo mais negócios e reduzindo riscos. À medida que os novos negócios vão se sucedendo com sucesso, os laços se fortalecem e mais interações (ANDERSON, HAKANSSON, \& JOHANSON, 1994; JOHANSON \& VAHLNE, 2011). Contudo, essa forma de acesso a mercados externos, associando-se a uma MNC, também conhecida como piggy-backing, traz segurança em termos de crescimento, mas gera a possibilidade de criação de dependência (CHILD \& RODRIGUES, 2008)

Entretanto, três outras empresas com resultados internacionais expressivos se utilizaram fortemente de laços fracos e lograram sucesso, tanto no que tange o percentual de receita, quanto o escopo geográfico internacional. A Xseed tem uma rede dispersa por necessidade, já que seu produto atinge um nicho muito específico de mercado e, portanto, é preciso avançar no mundo todo. Suas estratégias para alcançar mais mercados centraram-se em participação em feiras na Europa e nos EUA e, mais recentemente, pela utilização da internet, que permite maior alcance a custos reduzidos. Como explicou Ronaldo Brandão:

"Mas até 2000, todo ano estivemos em feira nos Estados Unidos e algumas vezes na Alemanha. Íamos a duas feiras nos Estados Unidos: a Condex, que é geral, e uma feira setorial. Todo ano. [...] Agora, existem núcleos de negócios, a Austrália é um potencial grande, Japão é outro potencial grande. Temos que ter fôlego porque recebemos solicitação pela internet, já fizemos um piloto para o Alasca. Quer dizer, com esse mundo internetizado, na realidade eu não preciso estar necessariamente presente no local para vender essa solução. Entendeu? Eu posso começar os contatos de forma mais virtual." (Ronaldo Brandão, fundador, Xseed)

Da mesma forma, a Light Infocon usa a estratégia de estar presente com frequência em eventos do setor, participando das principais feiras de tecnologia nos EUA e na Europa. Além disso, seus sócios participam além, vão aos encontros pós eventos, buscando estreitar os relacionamentos e se manterem vivos nas mentes dos atores de suas redes. Com isso, os sócios passam a ter uma rede de contatos que abrem portas em novos mercados de forma frequente, como relata Alexandre Moura:

"É aquela historia quando você repete várias vezes o mesmo evento você começa a conhecer um monte de pessoas. Vou dar um exemplo: vou praticamente todo ano para o IT Expo em Orlando, nos EUA. Tem chineses que eu conheço há dez anos, porque sempre nos encontramos. Em um desses encontros, surge alguma oportunidade...”. (Alexandre Moura, fundador, Light Infocon) 
A abordagem da Light Infocon e da Xseed está mais em linha com os argumentos de Kiss e Danis (2008) que sugerem que as relações de laços fracos ajudam a sustentar o crescimento, pois oferecem maior contorno, agindo como "pontes locais" que alcançam oportunidades não inseridas nas redes mais fechadas.

\subsection{4.}

Origem de laços

Não há muita informação na literatura de empreendedorismo internacional sobre diferenças em relação à origem do laço - se doméstico ou internacional. Algumas evidências empíricas, no entanto, sugerem que laços domésticos também são importantes para que pequenas empresas tenham acesso a mercados externos (ELANGO \& PATTNAIK 2007; MESQUITA \& LAZZARINI 2008; ZHOU, WU, \& LUO, 2007). Manolova et al. (2010) encontraram efeitos positivos do tamanho da rede doméstica do empreendedor sobre o grau de internacionalização da firma, observando que a importância das redes domésticas diminui com o tempo.

Em estudo sobre o uso das redes em empresas de mercados emergentes comparadas com empresas de mercados desenvolvidos, Ciravegna, Lopez e Kundu (2014) encontraram evidências de que empresas da Costa Rica usavam relacionamentos com clientes-fornecedores domésticos em suas primeiras entradas em mercados externos, enquanto nos casos em que a internacionalização ocorreu por acaso, houve presença de laços domésticos e internacionais. Nos casos em que o empreendedor buscava de forma proativa a internacionalização, prevalecia o uso de laço internacional, por meio de participação em feiras internacionais, ou contratação de profissionais estrangeiros. Alguns estudos empíricos recentes sugerem que o acesso às rede domésticas por meio de participação em associação da indústria trazem benefícios importantes para a internacionalização de pequenas empresas. (YIU, LAU, \& BRUTON, 2007; BOEHE, 2013) .

Os dados referentes à utilização das redes domésticas ou internacionais nas empresas analisadas aparecem no Quadro 5.11. 


\begin{tabular}{|c|c|c|c|c|c|}
\hline \multirow[t]{2}{*}{ Empresas } & \multicolumn{2}{|c|}{$\begin{array}{c}\text { Iniciativas } \\
\text { Internacionais }\end{array}$} & \multirow[t]{2}{*}{$\begin{array}{c}\text { Origem do laço na } \\
1^{\mathrm{a}} \text { iniciativa } \\
\text { internacional }\end{array}$} & \multicolumn{2}{|c|}{$\begin{array}{c}\text { Origem do laço em todas as } \\
\text { iniciativas internacionais } \\
\text { estudadas }\end{array}$} \\
\hline & No. & $\begin{array}{l}\text { No. com } \\
\text { laços }\end{array}$ & & Doméstico (D) & Internacional (I) \\
\hline \multicolumn{6}{|l|}{ Grandes } \\
\hline CI\&T & 6 & 5 & $\mathrm{D}$ & 2 & 3 \\
\hline Totvs $(*)$ & 14 & 3 & Nenhum laço & 1 & 2 \\
\hline \multicolumn{6}{|l|}{ Média } \\
\hline Ivia & 12 & 12 & $\mathrm{D}$ & 7 & 5 \\
\hline \multicolumn{6}{|l|}{ Pequenas } \\
\hline Fujitec & 8 & 7 & Nenhum laço & 0 & 7 \\
\hline $\begin{array}{l}\text { Light } \\
\text { Infocon }\end{array}$ & 16 & 16 & I & 6 & 10 \\
\hline MidiaVox & 16 & 16 & $\mathrm{D}$ & 16 & 0 \\
\hline Totall & 7 & 7 & $\mathrm{D}$ & 5 & 2 \\
\hline Xseed & 8 & 8 & $\mathrm{D}$ & 2 & 6 \\
\hline
\end{tabular}

Quadro 5.11 - Origem dos laços presentes nas iniciativas internacionais

Fonte: própria

(*) Em uma iniciativa conduzida pela Totvs (Totvs Lab, nos EUA) não se obteve essa informação.

A maior parte das empresas estudadas iniciou sua trajetória internacional utilizando algum ator de sua rede doméstica, embora pareçam utilizar mais a rede internacional no total de seus avanços sobre os mercados, o que vai ao encontro dos achados de Manolova et al. (2010) de que as redes internacionais ganham mais protagonismo ao longo do processo de internacionalização. Esse movimento pode ser considerado natural, já que, conforme as empresas entram em novos mercados, sua rede de clientes, fornecedores e parceiros passa a contar com mais atores internacionais.

5.4 . Benefícios associados ao uso de redes na internacionalização

Pequenas empresas, especialmente aquelas de países emergentes, se utilizam de suas redes para vencer obstáculos diversos em seus processos de internacionalização, como acesso a recursos financeiros, humanos, tecnológicos, identificação de oportunidades, acesso a informações, referência pessoal e outros. De fato, Johannisson (1990) descreve "as redes pessoais do empreendedor como o recurso mais importante da firma". 
$\mathrm{Na}$ literatura sobre capital social e empreendedorismo, vários estudos apontam o uso da rede dos sócios de pequenas empresas como uma das principais forças a minimizar os desafios inerentes às firmas ao obter benefícios tais como acesso a novas fontes de conhecimento, conhecimento de novas oportunidades internacionais, conhecimento pela experiência ou pelo aconselhamento, solidariedade e referência por terceiros, influência, recursos financeiros, recursos humanos, melhora de desempenho (AUTIO et al., 1997; COVIELLO \& MARTIN, 1999; CRICK \& SPENCE, 2005; ELLIS, 2000; INKPEN \& TSANG, 2005; SASI \& ARENIUS, 2008; SCHWENS \& KABST, 2011; SINGH, 1998; ZHOU, W, \& LUO, 2007).

Nas entrevistas analisadas, destacaram-se quatro benefícios obtidos no uso da rede de relacionamentos em iniciativas de internacionalização das oito empresas selecionadas. São eles:

- Identificação de oportunidades - quando o relacionamento trouxe oportunidade de negócio para a empresa, tendo se concretizado ou não.

- Obtenção de conhecimento de mercado - quando o relacionamento trouxe informações sobre o mercado de destino, como por exemplo, processos burocráticos, maturidade do mercado em relação ao produto a exportar, clientes prováveis dentre outros.

- Obtenção de recursos - quando o relacionamento possibilitou acesso a recurso de forma mais vantajosa ou como única forma de obtenção. Os recursos podem ser financeiros, humanos, tecnológicos, espaço físico, parceria etc.

- Legitimidade - quando o relacionamento gera boa referência da firma no mercado ou para algum outro ator relevante para a iniciativa internacional.

Os dados referentes aos benefícios obtidos por cada empresa em suas iniciativas internacionais encontram-se no Quadro 5.12. Observe-se que mesmo aquelas iniciativas que não se originaram de rede acabaram por criar ou expandir as redes internacionais das empresas. No caso da Totvs, os franqueados selecionados em cada país acabaram por constituir a rede da empresa. No caso da CI\&T, a abertura de um escritório permitiu gerar novos contatos e expandir a rede da empresa nos EUA. 


\begin{tabular}{|c|c|c|c|c|c|}
\hline \multirow[t]{2}{*}{ Empresas } & \multirow{2}{*}{$\begin{array}{c}\text { No. de } \\
\text { Iniciativas } \\
\text { Internac. }\end{array}$} & \multicolumn{4}{|c|}{ Benefícios da atuação em rede } \\
\hline & & $\begin{array}{l}\text { Identificação de } \\
\text { oportunidade }\end{array}$ & Legitimidade & $\begin{array}{l}\text { Obtenção } \\
\text { de recursos }\end{array}$ & $\begin{array}{l}\text { Obtenção de } \\
\text { conhecimento }\end{array}$ \\
\hline \multicolumn{6}{|l|}{ Grandes } \\
\hline CI\&T & 6 & 4 & 3 & 1 & 1 \\
\hline Totvs (*) & 14 & 1 & 0 & 3 & 2 \\
\hline \multicolumn{6}{|l|}{ Média } \\
\hline Ivia & 12 & 7 & 2 & 5 & 6 \\
\hline \multicolumn{6}{|l|}{ Pequenas } \\
\hline Fujitec & 8 & 6 & 0 & 1 & 0 \\
\hline Light Infocon & 16 & 13 & 1 & 7 & 1 \\
\hline MidiaVox & 16 & 16 & 15 & 0 & 0 \\
\hline Totall & 7 & 6 & 2 & 1 & 3 \\
\hline Xseed & 8 & 5 & 0 & 3 & 0 \\
\hline
\end{tabular}

Quadro 5.12 - Benefícios obtidos nas iniciativas internacionais em rede $\left(^{*}\right)$

Fonte: própria

(*) Pode ocorrer mais de um benefício para uma mesma iniciativa.

A análise do Quadro 5.12 mostra que o principal benefício obtido pelo uso das redes foi a identificação de oportunidades, o que tem sido observado por diversos autores ligados ao estudo de empreendedorismo internacional (COVIELLO, 2006; EVERS \& O'GORMAN, 2011; KONTINEN \& OJALA, 2011; ZAHRA \& GEORGE, 2002; ZHOU, WU, \& LUO, 2007). Por exemplo, Singh (1998), pesquisando 303 empresas de Tecnologia da Informação, observou que $42 \%$ dos empreendedores identificaram os amigos e a família como a fonte de ideias para seus empreendimentos e $75 \%$ utilizaram as redes de relacionamento para transformar ideias em oportunidades. Por sua vez, Evers e O'Gorman (2011), por meio do estudo de caso de três empresas, constataram que os empreendedores se beneficiaram de suas redes de relacionamento e de negócio para identificar oportunidades em mercados estrangeiros.

Os casos onde o benefício de obtenção de conhecimento de mercado não aparece - Fujitec, MidiaVox e Xseed - podem ter explicação na forma como se internacionalizaram. Tanto a Fujitec quanto a MidiaVox usam a estratégia de parceria com multinacional, trabalhando no mercado externo sob o comando da empresa parceira, e portanto não precisam buscar informações sobre o mercado, como entraves burocráticos ou existência de potenciais clientes. A empresa Xseed, por atender um nicho muito específico de mercado, tem facilidade para identificar seus clientes e não raro é identificada pelo potencial cliente. 
A busca por recursos se manifestou primordialmente pela formação de parcerias. Esse é o caso da Totvs, que tem como estratégia avançar em mercados externos por meio de franquias. Seu modo de operação é quase sempre o mesmo: busca por empresas de pequeno porte, do setor de TI, porém que não sejam concorrentes, e então, por meio de um processo estruturado de certificação desse parceiro, torná-lo um franqueado com direito de venda de licença dos produtos da Totvs e agregá-lo à rede.

Há também as empresas que comercializam produtos prontos ou que se utilizam de modelos de fábrica de software (que permitem o desenvolvimento da solução nos centros de desenvolvimento espalhados pelo mundo) que escolhem o modelo de parcerias locais para a comercialização de seus produtos e serviços.

Alguns exemplos de relatos dessas empresas podem ilustrar as razões para a implementação de tal estratégia. Alexandre Menezes, da Ivia, assim explicou:

“O que nós sempre procuramos para atuar em novos mercados é a busca de uma empresa parceira. Porque, para comercialização, nós identificamos que é importante, em um tipo de empresa como a nossa, que a venda seja presencial, de uma empresa madura, consolidada no local. Isso aconteceu lá em Portugal e está acontecendo agora nos Estados Unidos. Mas, após uma certa frequência e uma carteira de clientes com um número bom, então pensamos na abertura de escritório. É o momento que estamos presenciando agora nos Estados Unidos.”

Alexandre Moura, da Light Infocon, usa estratégia similar, embora prefira começar com escritório próprio para então buscar parceria:

"Hoje não temos escritório nos Estados Unidos, só trabalhamos com parceiros. É a maneira mais barata de fazer exportação a partir do Brasil, sem ter uma estrutura muito grande. Principalmente com o advento da internet. Mas, para vender nos Estados Unidos ou em qualquer lugar é preciso você ter uma presença por um determinado período de tempo. Principalmente para empresas do nosso porte, empresas menores, para você poder fazer volume [...] Eu chamaria de incubação de venda. E depois, você pode sair, arranjar um parceiro correto porque, até você maturar um parceiro, mesmo você tendo contatos, leva um certo tempo."

O benefício legitimidade surge quando a iniciativa foi provocada por uma referência dada por alguma ator da rede, normalmente cliente, ex-cliente, ou exempregado, que teve a oportunidade de trabalhar com a empresa e atestar sua qualidade. Esse tipo de benefício é considerado como dos mais eficientes para geração de novos negócios, especialmente em um setor pouco reconhecido internacionalmente, como o setor de software no Brasil. 
Bruno Guiçardi, da CI\&T, destaca o valor desse tipo de recurso obtido das redes de relacionamento:

"Mas é um esforço bem mais difícil.. [...] É bem menos efetivo dos que os leads que nos chegam através da exploração das referências. Quando alguém chega: 'Ah,... escutei falar... fulano falou pra mim que trabalhou com vocês... vocês não querem dar um pulo aqui?’ Esse é o lead matador. Quando vamos cold call, no cold e-mail, a efetividade é muito mais baixa."

O depoimento de Alexandre Menezes, da Ivia, reforça o entendimento da relevância que as empresas de software brasileiras percebem em suas redes: "Uma pessoa que fez negócio conosco na Inglaterra conhece alguém nos Estados Unidos e faz indicação da Ivia. Porque, nesse mercado de criatividade, vendemos a nossa competência."

\section{5.}

\section{Gestão de redes}

As cinco empresas que mantiveram ou cresceram percentualmente no mercado externo, possuem ampla rede, formada por laços fortes ou fracos, percebendo-se significativos esforços e investimentos para mantê-las por parte de seus dirigentes.

Variados meios de manutenção da rede são usados nessas empresas, a destacar:

- Participação frequente e repetida anualmente nas mesmas feiras, notadamente em mercados desenvolvidos;

- Participação em eventos, especialmente os promovidos pelos institutos de pesquisa do setor;

- Associação em entidades do setor como Assespro, Abes e Brasscom;

- Participação em entidades e programas de fomento a exportação, como Apex e Softex;

- Manutenção diária da rede de contatos, por meio de e-mails, telefonemas e redes sociais como Linkedin.

A participação em feiras internacionais é vista como um investimento, pois permite que relações tênues tornem-se mais sólidas ano a ano. Diversas oportunidades de negócios originadas de tais relações foram identificadas nas entrevistas. 
Os eventos do setor geram notícias espontâneas, recomendações e artigos divulgados por analistas de renome no setor, ajudando a dar legitimidade às empresas referenciadas em tais canais. Com isso, se mantêm vivas nas mentes de prospects, fornecedores e consultores.

Algumas empresas empregam a abordagem mais pessoal, notadamente as empresas do Nordeste do Brasil, enquanto outras investem em manter contatos de negócios. $\mathrm{O}$ uso das redes sociais apareceu como ferramenta que auxilia a manter as relações, pois permitem acesso mais frequente e rápido, com conteúdo adequado para cada tipo de ator com o qual a empresa mantem contato.

\section{6.}

\section{Exploração quantitativa de relações entre variáveis}

Foi feita uma análise de dados de caráter exploratório, com o propósito de examinar possíveis relações entre os construtos. A matriz com os coeficientes de correlação de Spearman é apresentada na Tabela 5.1.

Foram identificadas as seguintes associações entre variáveis:

- Entrada em mercados desenvolvidos está positiva e significativamente associada a laços fortes e internacionais.

- Abordagens emergentes tendem a estar positiva e significativamente associadas a laços fortes.

- Abordagens emergentes estão associadas positiva e significativamente aos benefícios de identificação de oportunidades e obtenção de legitimidade; abordagens intencionais, aos benefícios de obtenção de recursos e obtenção de conhecimento.

- Laços fracos tendem a ser domésticos; laços fortes tendem a ser internacionais.

- Laços fortes apresentam uma associação positiva e significativa com com busca de oportunidades e legitimidade.

- Laços internacionais estão positiva e significativamente associados aos benefícios de busca de oportunidades e obtenção de recursos. 
- Os benefícios identificação de oportunidades e obtenção de legitimidade encontram-se positivamente associados entre si e negativamente associados aos demais benefícios; também os benefícios de acesso a recursos e acesso a conhecimento encontram-se positivamente associados entre si e negativamente associados aos demais.

- Os benefícios busca de recursos e de conhecimento mostraram-se positiva e significativamente associados à entrada em mercados internacionais desenvolvidos.

É importante notar que não foi observada nenhuma correlação entre as variáveis examinadas e a sequência de iniciativas internacionais, sugerindo que não existe um padrão ao longo do tempo. 


\begin{tabular}{|l|c|c|c|c|c|c|c|c|c|}
\hline & $\begin{array}{c}\text { No. } \\
\text { sequencial da } \\
\text { iniciativa }\end{array}$ & $\begin{array}{c}\text { Tipo de } \\
\text { mercado }\end{array}$ & $\begin{array}{c}\text { Abordagem } \\
\text { da iniciativa }\end{array}$ & $\begin{array}{c}\text { Força do } \\
\text { laço }\end{array}$ & $\begin{array}{c}\text { Origem do } \\
\text { laço }\end{array}$ & $\begin{array}{c}\text { Benefício: } \\
\text { Oportunidade }\end{array}$ & $\begin{array}{c}\text { Benefício: } \\
\text { Legitimidade }\end{array}$ & $\begin{array}{c}\text { Benefício: } \\
\text { Recursos }\end{array}$ & $\begin{array}{c}\text { Benefício: } \\
\text { Conhecimento }\end{array}$ \\
\hline $\begin{array}{l}\text { No. sequencial } \\
\text { da iniciativa }\end{array}$ & & & & & & & & & \\
\hline Tipo de mercado & -0.069 & & & & & & & & \\
\hline $\begin{array}{l}\text { Abordagem da } \\
\text { iniciativa }\end{array}$ & -0.046 & $-0,018$ & & & & & & \\
\hline Força do laço & -0.002 & $0.202^{*}$ & $-0.513^{* * *}$ & & & & & & \\
\hline Origem do laço & -0.018 & $0,267^{* *}$ & $-0,126$ & $0,394^{* * *}$ & & & & \\
\hline $\begin{array}{l}\text { Benefício: } \\
\text { Oportunidade }\end{array}$ & 0.099 & $-0,033$ & $-0,490^{* * *}$ & $0,446^{* * *}$ & $0,343^{* * *}$ & & & \\
\hline $\begin{array}{l}\text { Benefício: } \\
\text { Legitimidade }\end{array}$ & 0.072 & -0.036 & $-0,530^{* * *}$ & $0,408^{* * *}$ & $-0,171$ & $0,382^{* * *}$ & & & \\
\hline $\begin{array}{l}\text { Benefício: } \\
\text { Recursos }\end{array}$ & -0.048 & $0,371^{* * *}$ & $0,346^{* * *}$ & 0,125 & $0,248^{* *}$ & $-0,513^{* * *}$ & $-0,288^{* * *}$ & & \\
\hline $\begin{array}{l}\text { Benefício: } \\
\text { Conhecimento }\end{array}$ & -0.143 & $0,267^{* *}$ & $0,313^{* * *}$ & 0,031 & 0,162 & $-0,251^{* *}$ & $-0,187^{*}$ & $0,442^{* * *}$ & \\
\hline
\end{tabular}

Tabela 5.1. Coeficientes de correlação de Spearman para os construtos analisados

*** significativo a $1 \%$; ** significativo a $5 \%$; * significativo a $10 \%$ 


\section{7.}

\section{Análise de iniciativas específicas}

Nesta seção, analisam-se quatro iniciativas específicas para as quais foram obtidos relatos mais detalhados e que permitem acompanhar a evolução dos relacionamentos ao longo do tempo.

\subsection{1.}

\section{Iniciativa A - Cl\&T e J\&J: construindo uma rede de negócios}

A CI\&T, fundada em 1995 já com um contrato com a IBM para um projeto internacional, tornou-se fornecedora de desenvolvimento de sistemas da Johnson \& Johnson (J\&J) norte-americana em 2004, mantendo-se como o maior cliente da empresa até o ano de 2013, com cerca de 300 pessoas alocadas exclusivamente para esse cliente. A relação entre as duas empresas era parte da estratégia da J\&J de distribuir seus centros de competência em desenvolvimento de sistemas por diferentes países.

O Quadro 5.13. apresenta a evolução do relacionamento entre CI\&T e J\&J, subdividido em estágios, indicando-se ainda os resultados obtidos em cada estágio.

\begin{tabular}{|l|l|l|}
\hline Passos & Descrição & Resultados \\
\hline $\begin{array}{l}\text { 1. Pré- } \\
\text { relacionamento }\end{array}$ & $\begin{array}{l}\text { CI\&T apresenta proposta para realização } \\
\text { de um projeto para J\&J Brasil }\end{array}$ & $\begin{array}{l}\text { Proposta não é aceita, mas causa } \\
\text { boa impressão }\end{array}$ \\
\hline 2. Gatilho & $\begin{array}{l}\text { J\&J USA deseja montar centro de } \\
\text { desenvolvimento no Brasil em parceria e } \\
\text { consulta subsidiária }\end{array}$ & J\&J Brasil recomenda CI\&T \\
\hline $\begin{array}{l}\text { 3. Contatos } \\
\text { iniciais }\end{array}$ & $\begin{array}{l}\text { Visitas à CI\&T de funcionários da J\&J(8 } \\
\text { a 10 visitas de 6 a 10 funcionários) }\end{array}$ & Decisão favorável à CI\&T \\
\hline $\begin{array}{l}\text { 4. Formalização } \\
\text { de contrato } \\
\text { (2004) }\end{array}$ & $\begin{array}{l}\text { Celebração de contrato inicial para } \\
\text { desenvolvimento do projeto }\end{array}$ & $\begin{array}{l}\text { Contratação de 2,5 funcionários } \\
\text { pela CI\&T } \\
\text { Contrato executado com sucesso }\end{array}$ \\
\hline $\begin{array}{l}\text { 5. Expansão do } \\
\text { relacionamento } \\
\text { no Brasil }\end{array}$ & $\begin{array}{l}\text { Novos contratos entre CI\&T e J\&J para } \\
\text { execução no Brasil. }\end{array}$ & $\begin{array}{l}\text { Cerca de 300 funcionários da } \\
\text { CI\&T envolvidos (2013) }\end{array}$ \\
\hline $\begin{array}{l}\text { 6. Expansão } \\
\text { internacional } \\
\text { (EUA, 2005) }\end{array}$ & $\begin{array}{l}\text { Abertura de filial (escritório) da CI\&T } \\
\text { na Filadélfia }\end{array}$ & $\begin{array}{l}\text { C\&T se torna vendor global da } \\
\text { J\&J e conquista novos clientes } \\
\text { multinacionais }\end{array}$ \\
\hline $\begin{array}{l}\text { 7. Expansão } \\
\text { internacional } \\
\text { (Japão, 2009) }\end{array}$ & $\begin{array}{l}\text { Joint venture da CI\&T no Japão com } \\
\text { empresa japonesa (Rococo) e } \\
\text { estabelecimento de centro de } \\
\text { desenvolvimento na China }\end{array}$ & $\begin{array}{l}\text { Atendimento a J\&J na Ásia e } \\
\text { conquista de novos clientes. }\end{array}$ \\
\hline
\end{tabular}

$\mathrm{O}$ caso da evolução do relacionamento entre a $\mathrm{J} \& \mathrm{~J}$ reflete um processo lento e cuidadoso, de ambos os lados, de aprofundamento do relacionamento, por meio de movimentos de maior comprometimento. 
A própria CI\&T prospectou clientes dentro da rede de 84 empresas e respectivas subsidiárias que compunham o grupo $\mathrm{J} \& \mathrm{~J}$. A entrada nos Estados Unidos, marcando a passagem de uma internacionalização inward para a abertura de escritório, pretendia servir a $\mathrm{J} \& \mathrm{~J}$, aprofundando o relacionamento, assim como conquistar novos clientes. Embora o segundo objetivo não fosse satisfatoriamente atingido, o avanço dentro da rede da Johnson \& Johnson foi um sucesso: "Aceleramos ainda mais o crescimento na Johnson. Conseguimos conquistar lá dentro a posição de prefer de venda", o que permitiu à empresa se "qualificar para outros voos globais" (Bruno Guiçardi, sócio, CI\&T).

Em decorrência, outro benefício foi obtido ao conquistar lugar de destaque como fornecedor da J\&J: penetrar em outras redes de multinacionais, especificamente na indústria farmacêutica. Ainda usando a legitimidade que a relação com a J\&J proporcionou, a empresa se expandiu para o Japão, outro mercado desenvolvido, com o propósito de "atender clientes atuais, principalmente a J\&J ... em nova geografia". A entrada foi previamente validada com o parceiro, por meio de um "acordo de bigode", cumprido pela J\&J. Seguemse a abertura de novos escritórios nos EUA e de filais no Canadá e em Londres, sempre buscando servir os clientes atuais, entre os quais se inclui a J\&J, e prospectar novos clientes.

Esta iniciativa se caracteriza pelo estabelecimento de uma relação de negócios, baseada na construção de confiança ao longo do tempo, entre CI\&T e J\&J. A relação se iniciou com laços fracos, evoluindo para laços fortes (ANDERSON, HAKANSSON \& JOHANSON, 1994). Mesmo mantendo-os como laços estritamente de negócios, sem envolvimentos pessoais, foi possível gerar uma relação duradoura e de confiança por meio da prestação de bons serviços, obtendo, principalmente, o benefício da legitimidade, que pode ser um dos maiores trunfos para enfrentar a falta de reconhecimento das empresas de software brasileiras nos mercados externos, especialmente os desenvolvidos. Embora a literatura em empreendedorismo internacional tenda a encontrar mais casos de uso de laços pessoais na internacionalização em mercados emergentes (ANDERSSON, EVERS, \& GRIOT, 2003; SHARMA \& BLOMSTERMO, 2003), esse tema ainda é controverso (MASANGO \& MARINOVA, 2014). 
5.7.2.

Iniciativa B - MidiaVox e Avaya: internacionalizando-se por meio da rede de subsidiárias de uma multinacional

Relações como as que se estabeleceram entre a MidiaVox e a multinacional Avaya aparecem na literatura de negócios internacionais, porém têm recebido pouca atenção. Nesse tipo de relacionamento, a empresa alcançou um grau de internacionalização relevante, tanto geográfico, quanto em percentual de faturamento, com apenas uma forma de entrada nos mercados onde atua, o piggybacking. Ao se associar a uma grande multinacional da área de telecomunicações, após seis anos desde sua fundação, a MidiaVox logrou estar presente em países de quase todos os continentes, em uma relação que já dura 16 anos.

\begin{tabular}{|c|c|c|}
\hline Passos & Descrição & Resultados \\
\hline $\begin{array}{l}\text { 1. Pré- } \\
\text { relacionamento }\end{array}$ & $\begin{array}{l}\text { A MidiaVox e a Avaya eram fornecedoras } \\
\text { de uma mesma empresa cliente em Recife }\end{array}$ & $\begin{array}{l}\text { Gerente da Avaya gostou } \\
\text { do trabalho da MidiaVox }\end{array}$ \\
\hline 2. Contatos iniciais & $\begin{array}{l}\text { Convite do gerente da Avaya envolvido no } \\
\text { projeto em Recife para realizar projeto em } \\
\text { São Paulo }\end{array}$ & \\
\hline $\begin{array}{l}\text { 3. Formalização do } \\
\text { contrato }\end{array}$ & $\begin{array}{l}\text { Contrato para realização de um trabalho para } \\
\text { a Avaya em São Paulo }\end{array}$ & Projeto bem sucedido. \\
\hline $\begin{array}{l}\text { 5. Expansão do } \\
\text { relacionamento no } \\
\text { Brasil }\end{array}$ & $\begin{array}{l}\text { Indicação, pelo gerente responsável pelo } \\
\text { projeto anterior, para replicação do projeto } \\
\text { em outros locais no Brasil. }\end{array}$ & Projetos bem sucedidos. \\
\hline $\begin{array}{l}\text { 6. Expansão } \\
\text { internacional } \\
\text { (Chile, 2000) }\end{array}$ & $\begin{array}{l}\text { Indicação, pelo mesmo gerente, para } \\
\text { replicação do projeto no Chile. }\end{array}$ & Projeto bem sucedido. \\
\hline $\begin{array}{l}\text { 7. Formalização do } \\
\text { relacionamento }\end{array}$ & Contrato de parceria mais amplo & $\begin{array}{l}\text { Executivo da Avaya } \\
\text { promovido para nível } \\
\text { regional (América Latina). }\end{array}$ \\
\hline $\begin{array}{l}\text { 7. Expansão } \\
\text { internacional } \\
\text { (outros países da } \\
\text { América Latina, } \\
\text { início em 2001) }\end{array}$ & $\begin{array}{l}\text { Projetos realizados pela Midia Vox para } \\
\text { Avaya na América Latina (Argentina, } \\
\text { México, Colômbia, Venezuela, Costa Rica, } \\
\text { Porto Rico, Bahamas, Bermudas) }\end{array}$ & $\begin{array}{l}\text { Projetos bem sucedidos. } \\
\text { Executivo promovido para } \\
\text { diretor global da Avaya. }\end{array}$ \\
\hline $\begin{array}{l}\text { 8. Expansão } \\
\text { internacional } \\
\text { (global, início em } \\
\text { 2004) }\end{array}$ & $\begin{array}{l}\text { Projetos realizados pela Midia Vox para } \\
\text { Avaya na Ásia (Japão, 2004); na Europa } \\
\text { (Rússia, 2004; Itália e Alemanha, 2006), na } \\
\text { América do Norte (EUA, em 2007; Canadá, } \\
\text { em 2012). }\end{array}$ & $\begin{array}{l}\text { MidiaVox se torna } \\
\text { fornecedor global da } \\
\text { Avaya e único para esse } \\
\text { tipo de serviço. }\end{array}$ \\
\hline $\begin{array}{l}\text { 9. Serviços } \\
\text { solicitados por } \\
\text { contatos externos à } \\
\text { rede da Avaya, mas } \\
\text { gerados pela rede } \\
\text { (2008) }\end{array}$ & $\begin{array}{l}\text { Participação em licitação no Chile para } \\
\text { executivo que saiu de empresa cliente da } \\
\text { Avaya e foi trabalhar em outra empresa. }\end{array}$ & Licitação não foi ganha. \\
\hline $\begin{array}{l}\text { 10. Serviços para } \\
\text { outras empresas via } \\
\text { rede da Avaya }\end{array}$ & $\begin{array}{l}\text { Projetos para clientes da Avaya no Canadá e } \\
\text { na Guatemala, por indicação da própria } \\
\text { Avaya }\end{array}$ & Projetos realizados. \\
\hline
\end{tabular}


Nos primeiros anos, havia uma propagação de indicações e referências que não dependia de apenas um dos laços, como o primeiro executivo que os levou ao Chile. Houve casos em que mesmo em países distantes, algum executivo brasileiro os ajudava, e a cada novo projeto bem sucedido, conforme os executivos iam migrando para outros países, iam levando a referência da MidiaVox.

Como no caso da CI\&T, trata-se de um relacionamento puramente de negócios, não havendo envolvimento pessoal, já que os contatos na Avaya mudam dependendo do país onde os serviços são executados. Os contatos se dão por meio de reuniões via Skype ou por presença física, quando profissionais (muitas vezes técnicos e algumas vezes os sócios) precisam fazer uma visita ao cliente, o que é mais raro. Na opinião dos sócios, essa rede foi construída aos poucos, com investimentos na parceria sólida, na construção de confiança, mesmo ao custo de perder alguns negócios, tornando a empresa muito dependente da parceira (RODRIGUES \& CHILD, 2008). Assim como no caso da CI\&T, também aqui se percebe a importância do estabelecimento de um relacionamento de laço fraco, mas que se torna forte à medida que o tempo passa.

\subsection{3.}

Iniciativa C - Fujitec e VFJ/Chris Adams: construindo uma relação pessoal a partir de uma parceria internacional

A partir de uma iniciativa de um parceiro internacional, a Fujitec conquistou um aliado que envolveu a empresa em outras iniciativas pelo mundo. O parceiro internacional era a empresa australiana VFJ e o executivo, Chris Adams. As duas empresas participaram de várias licitações no Brasil, ganhando algumas e estabelecendo uma sólida parceria, que culminou no estabelecimento de laços pessoais entre os dirigentes da Fujitec e o executivo Chris Adams, que, por sua vez, gerou oportunidades em outros países, levando a Fujitec ao mercado internacional.

O Quadro 5.15 apresenta a evolução do relacionamento entre Fujitec e VFJ/Chris Adams, subdividido em estágios, indicando-se os resultados de cada estágio. 


\begin{tabular}{|c|c|c|}
\hline Passos & Descrição & Resultados \\
\hline $\begin{array}{l}\text { 1. Pré- } \\
\text { relacionamento }\end{array}$ & Nenhum & \\
\hline 2. Gatilho & $\begin{array}{l}\text { Governo do Rio de Janeiro abre licitação } \\
\text { (1996) }\end{array}$ & \\
\hline $\begin{array}{l}\text { 3. Contatos } \\
\text { iniciais }\end{array}$ & $\begin{array}{l}\text { Empresa australiana VFJ busca Fujitec } \\
\text { para parceria }\end{array}$ & Licitação é cancelada. \\
\hline $\begin{array}{l}\text { 4. Formalização } \\
\text { do } \\
\text { relacionamento }\end{array}$ & Fujitec assina parceria com VFJ & $\begin{array}{l}\text { VFJ fecha escritório no Brasil e } \\
\text { passa a ser representada por } \\
\text { Fujitec. }\end{array}$ \\
\hline $\begin{array}{l}\text { 5. Expansão do } \\
\text { relacionamento } \\
\text { no Brasil }\end{array}$ & $\begin{array}{l}\text { Novas licitações nas cidades de Natal e } \\
\text { Brasília ganhas pelos parceiros, gerando } \\
\text { contratos. }\end{array}$ & $\begin{array}{l}\text { Projetos executados com } \\
\text { sucesso. }\end{array}$ \\
\hline $\begin{array}{l}\text { 6. Construção de } \\
\text { relacionamento } \\
\text { pessoal }\end{array}$ & $\begin{array}{l}\text { Relações de amizade entre dirigentes da } \\
\text { Fujitec e Chris Adams }\end{array}$ & \\
\hline $\begin{array}{l}\text { 7. Expansão } \\
\text { internacional } \\
\text { (Itália, 2001) }\end{array}$ & $\begin{array}{l}\text { Projeto realizado pelos parceiros na } \\
\text { Itália gerado pela rede de } \\
\text { relacionamentos da VFJ/Chris Adams }\end{array}$ & Projeto concluído \\
\hline $\begin{array}{l}\text { 8. Expansão } \\
\text { internacional } \\
\text { (Havaí, EUA, } \\
\text { 2004) }\end{array}$ & $\begin{array}{l}\text { Projeto da Fujitec no Havaí, gerado pela } \\
\text { rede de relacionamentos de Chris } \\
\text { Adams, com participação da consultoria } \\
\text { Booz-Allen }\end{array}$ & $\begin{array}{l}\text { Projeto foi realizado mas cliente } \\
\text { não pagou todo o valor, com } \\
\text { prejuízo para Fujitec }\end{array}$ \\
\hline $\begin{array}{l}\text { 9. Expansão } \\
\text { internacional } \\
\text { (Colorado, EUA, } \\
\text { 2004) }\end{array}$ & $\begin{array}{l}\text { Convite da Booz-Allen à Fujitec para } \\
\text { participar de projeto no Colorado (2004) }\end{array}$ & $\begin{array}{l}\text { Fujitec teve participação } \\
\text { restrita, por ser muito pequena } \\
\text { para participar da licitação. }\end{array}$ \\
\hline
\end{tabular}

Quadro 5.15 - Evolução do relacionamento entre Fujitec e VFJ/Chris Adams

Fonte: própria

Neste caso, a relação de parceria entre empresas evoluiu para um relacionamento pessoal entre executivos, que Danilo Reis, da Fujitec, descreveu como sendo "uma amizade muito forte", "uma amizade verdadeira", baseada em "uma confiança muito grande", que "nos abriu essas portas, contatos, networking dele..." Posteriormente, o executivo deixou a empresa australiana, mas continuou servindo como referência para a Fujitec internacionalmente, inclusive atuando como consultor. No entanto, a atuação da Fujitec nos Estados Unidos se esgotou, ao perceberem os executivos que era necessário realizar investimentos para poder operar naquele país, mas mantinham os contatos e pensavam eventualmente voltar ao mercado americano.

Os empreendimentos em países de baixo desenvolvimento institucional são mais dependentes de seus relacionamentos, dadas suas restrições, falta de exemplos a seguir e insuficiência de legitimidade aos olhos dos clientes externos. O Brasil é um país de cultura coletivista (HOFSTEDE, 1980), onde as relações pessoais são valorizadas, tendendo a ser duradouras e baseadas em confiança (MCGRATH \& O’TOOLE, 2014). Os sócios da Fujitec prezavam o relacionamento com o executivo Chris Adams. 
O exemplo da relação da Fujitec com Chris Adams está em linha com o argumento de Harris e Wheeler (2005) de que laços pessoais fortes são capazes de prover comprometimento no mercado internacional quando representam a empresa, tornando-se, portanto, de grande valor. Nesse exemplo, a força da relação permitiu que a empresa avançasse nos EUA, um país desenvolvido, sem precisar investir em um escritório local.

Este exemplo reforça a importância da construção do primeiro relacionamento no mercado estrangeiro, que pode atuar como uma ponte, trazendo oportunidades e conhecimento em curto período de tempo (HOHENTHAL, JOHANSON, \& JOHANSON, 2014). Sharma e Blomstermo (2003) definem esse primeiro relacionamento como um laço fraco, o que se enquadra no papel inicial de Chris Adams, muito embora no decorrer do relacionamento esse laço tenha se transformado em laço forte, sem deixar de trazer oportunidades.

\subsection{4. \\ Iniciativa D - Ivia e Noesis/Marcio Braga: construindo uma rede de negócios a partir de um relacionamento pessoal}

Outra iniciativa que teve desdobramentos em rede foi a que ocorreu entre a Ivia e a Noesis, empresa portuguesa, por iniciativa de um diretor da Noesis, Marcio Braga, que havia trabalhado anteriormente com os sócios da Ivia na IBM e que estava residindo em Portugal. Ele proporcionou à Ivia a oportunidade de conduzir um pequeno serviço de treinamento no Banco Espírito Santo, naquele país. Depois dessa experiência, os sócios da Ivia resolveram se expandir para o mercado português e escolheram a Noesis como parceira. Os motivos da escolha, que se deu após uma busca estruturada de alternativas pela Ivia, envolviam o tipo de serviço que a empresa prestava, complementar ao da Ivia, sua boa carteira de clientes e o relacionamento já existente com o diretor da empresa. 


\begin{tabular}{|c|c|c|}
\hline Passos & Descrição & Resultados \\
\hline $\begin{array}{l}\text { 1. Pré- } \\
\text { relacionamento }\end{array}$ & $\begin{array}{l}\text { Dirigentes da Ivia e Márcio Braga, } \\
\text { diretor da Noesis, trabalharam juntos na } \\
\text { IBM. }\end{array}$ & \\
\hline $\begin{array}{l}\text { 2. Contatos } \\
\text { iniciais }(2002)\end{array}$ & $\begin{array}{l}\text { Contato com a Ivia para realização do } \\
\text { treinamento a ser feito pela Noesis para } \\
\text { o Banco Espírito Santo, em Portugal, } \\
\text { exigindo competências externas à } \\
\text { Noesis (2002) }\end{array}$ & $\begin{array}{l}\text { Treinamento realizado com } \\
\text { sucesso. }\end{array}$ \\
\hline 4. Gatilho & $\begin{array}{l}\text { Busca de parceiro na Europa (Portugal) } \\
\text { pela Ivia }\end{array}$ & Escolha da Noesis pela Ivia \\
\hline $\begin{array}{l}\text { 4. Formalização } \\
\text { do relacionamento } \\
\text { (2003) }\end{array}$ & $\begin{array}{l}\text { Contrato de parceria assinado entre Ivia } \\
\text { e Noesis (2003) }\end{array}$ & $\begin{array}{l}\text { Ivia envia um funcionário a } \\
\text { Portugal }\end{array}$ \\
\hline $\begin{array}{l}\text { 5. Entrada de } \\
\text { novo sócio na Ivia } \\
(2005)\end{array}$ & $\begin{array}{l}\text { Márcio Braga deixa a Noesis e ingressa } \\
\text { como sócio na Ivia (2005) }\end{array}$ & \\
\hline $\begin{array}{l}\text { 6. Expansão } \\
\text { internacional } \\
\text { (Portugal, 2006) }\end{array}$ & Abertura de filial da Ivia em Portugal & $\begin{array}{l}\text { Rentabilidade das operações em } \\
\text { Portugal maior do que no Brasil }\end{array}$ \\
\hline $\begin{array}{l}\text { 7. Atuação da } \\
\text { Noesis no Brasil }\end{array}$ & $\begin{array}{l}\text { Crise econômica na Europa, iniciada em } \\
2008\end{array}$ & $\begin{array}{l}\text { Esgotamento das vendas em } \\
\text { Portugal; Noesis busca negócios } \\
\text { no Brasil. }\end{array}$ \\
\hline
\end{tabular}

Nesse caso, a relação entre as empresas - Ivia e Noesis - continuou sendo uma relação de negócio, ainda que caracterizada como " super boa", mas a relação com Márcio Braga se fortaleceu, a tal ponto que esse executivo deixou a Noesis e se tornou sócio da Ivia.

"Então, quando a Ivia teve vontade de se internacionalizar, por volta de 2002, eu já conhecia os dois sócios, conheço a Ivia desde a fundação, todos ex-colegas da IBM, passamos um tempo separados e depois nos encontramos de novo. E aí, o Alexandre e o Edson entraram em contato comigo, e enfim, fizemos uma parceria super boa da Ivia com a Noesis, que é essa empresa que eu trabalhava lá em Portugal. Em 2004 eu pensei em voltar [ao Brasil] e em 2005 eles me convidaram, e eu entrei de sócio ...”

A experiência trazida pelo novo sócio agregou à empresa brasileira recursos como conhecimento de mercado e legitimidade, que custariam muito caro se, por exemplo, a Ivia decidisse abrir uma subsidiária própria em Portugal sem o uso da parceria. De fato, Marcio Braga trouxe consigo toda uma rede de relacionamentos na Europa, já que, quando residia em Portugal, teve a oportunidade de estabelecer contatos em diversos países europeus. 
A partir de 2008, com a crise econômica na Europa, as oportunidades de negócios na Península Ibérica desapareceram, forçando a própria Noesis a buscar negócios no Brasil, em um movimento que Alexandre Menezes explicou assim: “É essa mesma atividade de internacionalização que a Ivia fez, o parceiro de lá faz agora o caminho inverso, quando os negócios são mais favoráveis aqui." Apesar do esgotamento do mercado português e das oportunidades derivadas da parceria na Espanha e em colônias portuguesas da África, a parceria entre a Ivia e a Noesis permanece.

A análise desta iniciativa reforça a importância do uso de um primeiro relacionamento de laço fraco, que traga conhecimento e oportunidade para a empresa no novo mercado (CHETTY \& HOLM, 2000; SHARMA \& BLOMSTERMO, 2003). Além disso, trata-se de mais um processo de rede de relacionamentos em que o início de uma expansão internacional se faz por meio de um laço fraco, que, porém, ao longo do tempo, se transforma em laço forte, tanto no que se refere à relação de negócios entre Ivia e Noesis, como à relação pessoal ente os sócios originais da Ivia e Márcio Braga.

\subsection{5.}

\section{Um processo genérico de evolução dos relacionamentos}

A análise longitudinal dos quatro relacionamentos de negócios estudados mostra uma sequência de etapas que caracterizam sua evolução. Algumas etapas podem se suceder, ou ser simultâneas, e algumas podem não ocorrer, mas é possível falar de um processo genérico de evolução dos relacionamentos a partir das quatro iniciativas internacionais analisadas. Em algumas situações analisadas, relacionamentos pessoais encontram-se interconectados aos relacionamentos de negócios, mas em outros casos isso não ocorre. Observe-se ainda que, em alguns casos, o relacionamento pode se interromper por motivos alheios ao desejo das partes, mesmo que tenha sido bem sucedido.

A Figura 15 apresenta um processo genérico de passos na evolução de um relacionamento de negócios. 


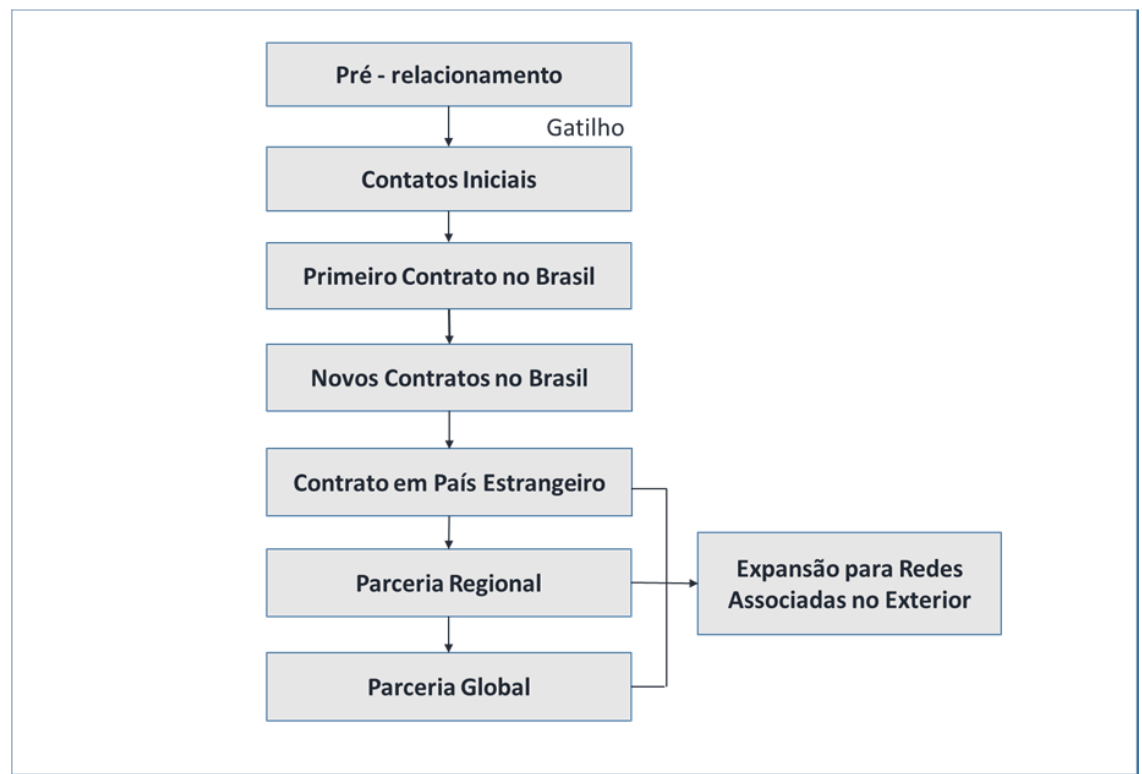

Figura 15- Processo Genérico de Evolução do Relacionamento Fonte: própria

O processo de formação de uma rede de negócios pode ter início em um pré-relacionamento, que se caracteriza por laços fracos, ou até mesmo por contatos que não geram nenhum tipo de laço. Esse pré-relacionamento pode ficar adormecido, até que um dos atores o recupere da memória por conta de algum "gatilho", evento ou situação. No caso da Ivia, havia um laço fraco entre excolegas da IBM que foi despertado quando uma das empresas buscou a outra. No caso da CI\&T, havia um contato anterior proveniente de uma proposta apresentada que não havia sido selecionada. Já a Avaya teve um contato preliminar com a MidiaVox pelo fato de ambas serem fornecedoras de uma terceira empresa. Apenas no caso da Fujitec não havia nenhum prérelacionamento. Observe-se que todos os pré-relacionamentos examinados ocorreram no âmbito doméstico.

Os contatos iniciais podem variar em termos de tempo requerido para o passo seguinte. No caso do relacionamento entre a CI\&T e a J\&J, os contatos levaram algum tempo, envolvendo muitas visitas de vários funcionários. Já no caso da relação entre Ivia e Noesis, os contatos iniciais foram mais rápidos, dada a existência de laço fraco entre os sócios da Ivia e o diretor da empresa portuguesa. 
Nos casos estudados, os contatos iniciais evoluíram para um primeiro contrato entre a empresa foco e a outra empresa. Claramente, trata-se de uma experiência inicial na construção do relacionamento, de cujo sucesso dependerá a continuidade do processo. Não há ainda, frequentemente, confiança mútua que leve ao estabelecimento da parceria. Isso é mais marcante nas situações examinadas em que a relação entre as empresas é muito desigual, em termos de tamanho e recursos, e quando inexistem laços pessoais entre os atores relevantes. Exemplos característicos são os relacionamentos entre CI\&T e J\&J e entre MidiaVox e Avaya.

Uma vez superado com sucesso o primeiro contrato, outros contratos são celebrados entre as empresas, em geral com maior abrangência geográfica, mas ainda baseados em contratos do tipo arm's length. Exceção, mais uma vez, é o caso da Ivia, em que se evolui diretamente para uma parceria.

Nos demais casos, a formalização da parceria tende a estar associada à passagem do mercado doméstico para o mercado internacional. É que então já houve tempo para construir a confiança mútua, tendo ocorrido aprendizado recíproco dos parceiros (como preconizam ANDERSON, HAKANSSON, \& JOHANSON, 1994) sobre suas respectivas formas de operar, que se mostraram afinadas. Os resultados satisfatórios dos projetos anteriormente realizados vão fortalecendo os laços entre os parceiros.

A passagem para o mercado internacional marca a expansão para outros pontos da rede (conforme JOHANSSON \& MATTSON, 1987, 1988), frequentemente descortinando novas oportunidades junto a clientes, fornecedores, ou parceiros dos parceiros (como no caso da MidiaVox no Chile e da Fujitec no estado do Colorado), ou, até mesmo, acesso a novas oportunidades que derivam, unicamente, de se estar presente em novas geografias (como no caso da presença da CI\&T nos Estados Unidos), como mencionaram Felzensztein et al. (2015).

Observe-se que esse processo ocorreu, nas quatro situações examinadas, por penetração na rede do parceiro e não por coordenação entre as redes das duas empresas (JOHANSSON \& MATTSON, 1993). Mesmo assim, no caso do relacionamento entre Ivia e Noesis, há posteriormente o movimento contrário, em que a Noesis recorre à rede doméstica da Ivia no Brasil, levada pela crise no mercado português. 
Nos relacionamentos que evoluem dentro de redes de multinacionais (CI\&T e MidiaVox), a progressão de status dentro da rede se dá ao se passar de fornecedor doméstico para fornecedor regional (América Latina) e, em um segundo movimento, para fornecedor global. Nos outros casos (Fujitec e Ivia), o avanço no relacionamento ocorreu devido ao estabelecimento de novas relações pessoais ou pelo fortalecimento de relações já existentes.

A expansão para redes associadas no exterior ocorreu em todos os casos, mas em momentos diferentes da evolução dos relacionamentos, até mesmo porque alguns desses desdobramentos são fortuitos. 


\section{6 \\ Conclusões}

Este capítulo apresenta cinco sessões, iniciando-se com um sumário do estudo, discorrendo desde seus objetivos até os resultados encontrados. Em seguida, apresentam-se as conclusões referentes a cada pergunta da pesquisa. A seção seguinte aborda recomendações para futuras pesquisas e, por fim, são realçadas as contribuições para empresas e governo que possam contribuir para o avanço da internacionalização das empresas do setor de software brasileiro.

\section{1.}

\section{Sumário do estudo}

O presente estudo teve como objetivo principal identificar de que maneira as redes de relacionamento influenciam o processo de internacionalização das empresas brasileiras de software. As questões que tornam esse tema importante estão associadas principalmente às dificuldades que as empresas brasileiras desse setor enfrentam para obterem sucesso. Além da concorrência doméstica que envolve participação de empresas multinacionais de países desenvolvidos, esse setor não tem poder de marca Brasil, ou seja, não há reconhecimento por parte dos players mundiais de que o Brasil tenha tradição em produtos ou serviços de tecnologia da informação. Diversos estudos, muitos dos quais sobre empresas de tecnologia, vêm apontando para a importância do uso da rede de relacionamento para superar os diversos obstáculos enfrentados no processo de internacionalização.

Portanto, a principal pergunta da pesquisa foi: Como as redesde relacionamento influenciam o processo de internacionalização das empresas brasileiras no setor de software ao longo do tempo?

Para obter a resposta a essa pergunta desdobraram-se algumas questões secundárias, gerando as categorias que nortearam as buscas na literatura e nos dados para melhor entendimento do uso das redes nos processos de internacionalização de empresas de software. 
A literatura que deu suporte à pesquisa focou as contribuições provenientes do campo do empreendedorismo internacional, assim como as teorias de redes e capital social e sua relevância para a internacionalização das empresas.

O método escolhido para realizar a pesquisa foi o de estudo de casos, adotando-se uma abordagem abdutiva, que se caracteriza por um processo evolutivo, não linear, envolvendo idas e vindas entre a literatura e os dados. Os estudos de casos foram longitudinais e retrospectivos. Optou-se por realizar um estudo de casos múltiplos, estratégia que pareceu mais adequada considerando-se a pergunta de pesquisa do presente estudo e o interesse em identificar e comparar processos longitudinais que podem ser distintos entre empresas.

A unidade de análise utilizada no presente estudo é a empresa. Dentro de cada caso foram identificadas sub-unidades de análise, que são as diversas iniciativas de entrada em mercados externos pelas empresas estudadas. Foram escolhidas no total oito empresas de software dentre as disponíveis na base de dados utilizada, sendo duas de maior porte e seis de menor porte. O processo de seleção dos casos utilizou como critérios serem empresas de software de capital nacional, de diversos tamanhos, internacionalizadas, que tivessem utilizado redes em pelo menos uma iniciativa de internacionalização, maduras no processo de internacionalização, que ainda pertencessem aos empreendedores originais, e para as quais houvesse entrevistas anteriores disponíveis na base de dados, e que concordassem em participar da pesquisa. A seleção das empresas buscou também alcançar certa dispersão geográfica, já que há variações econômicas e mesmo culturais entre as várias regiões brasileiras.

Foram identificadas e analisadas 87 iniciativas de internacionalização nas oito empresas brasileiras de software selecionadas para o presente estudo.

As fontes de dados foram primárias e secundárias, incluindo entrevistas pessoais realizadas para o estudo, transcrições de entrevistas anteriores provenientes de base de dados existente, publicações, casos acadêmicos publicados sobre as firmas selecionadas, documentos internos e sites das empresas. O procedimento de coleta de dados implementado permitiu análise retrospectiva e longitudinal de cada caso. 
A análise dos dados teve como objetivo avaliar a ocorrência ou não de padrões, por meio de quatro dimensões: o perfil das empresas e de seus dirigentes; as características das iniciativas internacionais das empresas; a forma de utilização das redes de relacionamento no processo de internacionalização; e a identificação de benefícios associados ao uso das redes nos processos de internacionalização. Além disso, buscou-se identificar se haveria um processo genérico de construção do relacionamento no decorrer do tempo, utilizando-se quatro dentre as iniciativas internacionais identificadas, para as quais se dispunha de mais dados.

Além de identificar o perfil das empresas (tamanho, dispersão geográfica, tempo de existência, e produtos e serviços oferecidos), buscou-se também identificar algumas características dos empresários consideradas relevantes para a internacionalização (experiência internacional anterior e orientação inernacional prévia). Na análise das iniciativas de internacionalização, investigou-se o número de iniciativas ao longo do tempo, o mercado de destino, se desenvolvido ou não, assim como a forma de abordagem das iniciativas, se emergentes ou intencionais. Essas análises buscaram entender padrões e mudanças de abordagens ao longo do tempo. Seguiu-se a análise do uso de capital social e redes nas iniciativas de internacionalização, abordando-se: os atores envolvidos nos relacionamentos; os tipos de laços presentes nas iniciativas, se pessoais, de negócios ou com o governo; a força desses laços, sendo considerado laços fortes aqueles que envolvem amizade, confiança e comprometimento e os fracos aqueles superficiais; e a origem dos laços, se domésticos ou internacionais. Em seguida, analisou-se a percepção de benefícios associados ao uso das redes na internacionalização, destacando-se quatro tipos: identificação de oportunidades, legitimidade, obtenção de conhecimento de mercado e obtenção de recursos. Ao final dessa análise fez-se uma exploração quantitativa de relação entre as variáveis identificadas nas iniciativas, com o objetivo de examinar as relações entre as variáveis. Por fim, analisaram-se as quatro iniciativas de internacionalização selecionadas, identificando os processos pelos quais se construiu o relacionamento em cada iniciativa e derivando-se um processo genérico de construção de relacionamento na internacionalização. 


\section{2 .}

\section{Conclusões}

Para formular as conclusões do estudo, responde-se a seguir a cada uma das perguntas de pesquisa relacionadas à pergunta geral que orientou o estudo.

\section{De que modo a pertinência a redes contribui nos primeiros passos de internacionalização?}

Não se identificou um padrão que explicasse o início dos processos de internacionalização estudados por meio de redes nas empresas de software analisadas. Muito ao contrário, identificou-se uma diversidade de possibilidades para o início da ação internacional.

No que se refere às abordagens utilizadas, identificaram-se, no primeiro movimento internacional, tanto abordagens emergentes, quanto intencionais. Nas abordagens emergentes, o início da internacionalização está associado a contatos externos à empresa, similares, na literatura de exportação, aos pedidos inesperados vindos do exterior. Já as abordagens intencionais são aquelas em que a própria empresa busca ativamente oportunidades e contatos, tendo em vista a internacionalização.

Tampouco foi identificado qualquer padrão com relação ao tipo de laço, a características dos contatos (negócios, pessoais, governo), ou à força do laço (fraco ou forte) no início do processo de internacionalização.

Já no que se refere à origem dos laços, parece haver uma tendência ao uso de laços domésticos para o início do processo de internacionalização, com exceção exatamente da única empresa cujos sócios tiveram experiência internacional relevante e que, de forma intencional, acionaram sua rede.

A diversidade de experiências iniciais e de fatores aparentemente associados sugere que os empreendedores mentalmente alertas a oportunidades internacionais exploram as oportunidades que buscam, ou que se apresentam, para dar início ao processo de internacionalização de suas empresas. 


\section{De que forma a pertinência a redes se modifica ao longo do processo} de internacionalização?

Mais uma vez, é difícil identificar padrões comuns ao longo do tempo. Pode-se afirmar que cada caso é um caso, no sentido de apresentar padrões próprios.

No que se refere à sequência temporal das abordagens utilizadas ao longo do processo de internacionalização das empresas estudadas, cobre-se um espectro amplo de possibilidades, desde um extremo em que todas as iniciativas internacionais foram emergentes, até o outro extremo em que todas as iniciativas internacionais foram intencionais, passando por diferentes sequências em que as duas abordagens se sucedem, de intencional para emergente e de emergente para intencional, com repetições.

Tampouco se observa qualquer padrão na sequência temporal de entrada em mercados desenvolvidos e não desenvolvidos. Da mesma forma, observa-se grande diversidade de tipos de atores nas iniciativas internacionais.

Claramente, no entanto, predominam os laços de negócios. Contudo, enquanto em algumas empresas predominam os laços fortes ao longo de sua trajetória, em outras predominam os laços fracos, e, em outras ainda há equilíbrio entre iniciativas com laços fortes e iniciativas com laços fracos.

Apesar disso, embora não se tenham identificado padrões ao longo do tempo, foram identificadas relações entre algumas variáveis. Observou-se que os laços fortes tendem a ser internacionais e associados a abordagens emergentes, enquanto os laços fracos tendem a ser domésticos e associados a abordagens intencionais. Além disso, laços fortes e internacionais parecem estar associados à entrada em mercados desenvolvidos.

\section{Como ocorre a gestão das redes no decorrer do processo de internacionalização?}

Identificaram-se tanto empresas com gestão proativa de suas redes quanto se obtiveram indícios de que outras podem estar investindo menos em sua manutenção e gestão. 
Dentre as abordagens intencionais, pode-se não utilizar laços existentes para novas entradas, preferindo-se prospectar um parceiro em cada geografia previamente escolhida pelos dirigentes da empresa. Outra escolha é a de fortalecer as redes, mantendo-as por meio de frequentes viagens e exposição em eventos e contatos constantes por meio de mídias sociais.

Mesmo as empresas que investem em suas redes, apresentam padrões de entrada diversificados. Há o formato de estabelecer presença física por um tempo para então firmar parceria com empresa local, como também há o padrão de iniciar com menos comprometimento e, depois de trabalhado o mercado, estabelecer escritório. A consequência, entretanto, em ambos os casos, é a de que a rede de relacionamentos vai se expandindo, criando mais oportunidades.

\section{Quais os benefícios do uso de redes no decorrer da internacionalização proporcionam benefícios para o avanço deste processo?}

O objetivo principal dos dirigentes das empresas em seus processos de internacionalização é a identificação de oportunidades, obtendo expansão nas vendas e receitas de forma rápida e direta. De fato, esse foi o benefício mais frequentemente observado nas iniciativas analisadas.

Conforme as empresas avançam em novos mercados, vão construindo mais redes de fornecedores, clientes, ex-clientes, empregados e ex-empregados. Essa rede, formada por indivíduos que lidaram diretamente com os dirigentes e com os colaboradores da empresa, se torna uma fonte preciosa de referências, especialmente quando percebem qualidade e ética na prestação dos serviços. Portanto, há indicações de que possa haver maior incidência do benefício legitimidade à medida que a rede se expande.

Abordagens emergentes encontram-se associadas positivamente aos benefícios de identificação de oportunidades e obtenção de legitimidade; abordagens intencionais, aos benefícios de obtenção de recursos e obtenção de conhecimento. 
Com relação à força dos laços, aquelas empresas que centram suas oportunidades em apenas um relacionamento e as que optam por criar parcerias em cada novo mercado desenvolvem laços mais fortes, mais frequentemente de origem internacional. Esses laços se caracterizam por relações de confiança mútua e respeito, trazendo novas oportunidades e o benefício da legitimidade, esse último fundamental para as empresas de software brasileiras, já que o Brasil não é reconhecido como produtor de tecnologia.

Os outros dois benefícios identificados - obtenção de conhecimento de mercado e obtenção de recursos - encontram-se mais diretamente associados às iniciativas intencionais. O conhecimento de mercado foi o benefício mais mencionado pelos entrevistados quando perguntados sobre os mais importantes benefícios obtidos por meio de suas redes. No entanto, nas entrevistas há poucos relatos de busca por esse benefício. Observou-se, porém que os benefícios obtenção de recursos e obtenção de conhecimento mostraram-se associados à entrada em mercados internacionais desenvolvidos.

A obtenção de recursos tecnológicos pouco apareceu como benefício do uso de redes, contrariamente ao que se esperava, considerando-se as diferenças de inovação entre o Brasil e países mais desenvolvidos. É provável que as empresas brasileiras que alcançam sucesso internacional o façam por apresentarem preços mais acessíveis em ofertas de serviços que não exijam tecnologia de ponta.

\section{Como evolui ao longo do tempo a construção de relacionamento?}

Por fim, propõe-se um modelo de um processo genérico de evolução de relacionamento, que se ajusta particularmente bem às iniciativas internacionais que unem empresas de software às redes de multinacionais. O modelo é menos adequado para ilustrar a evolução de relacionamentos entre empresas de tamanhos mais próximos, como pequenas-médias e médias-médias.

\section{3.}

\section{Contribuições teóricas}

Este estudo traz algumas contribuições teóricas relevantes ao estudo do uso de capital social e redes no processo de internacionalização das empresas, em especial as empresas de tecnologia. 
A primeira contribuição consiste em oferecer uma descrição densa, caracterizada por perspectiva simultaneamente longitudinal e retrospectiva, de como as redes se inserem nos processos de internacionalização de empresas de software. De fato, o estudo proporciona uma visão ampla e profunda desses processos, além de utilizar a perspectiva dos empresários, combinada a dados objetivos.

A segunda contribuição do estudo se refere a identificar a grande variedade de soluções e alternativas empregadas por empresas de software para atuar no mercado internacional por meio de redes. Em particular, cabe salientar que o tamanho das empresas não parece estar associado a qualquer padrão específico. A carência de estudos com empresas de maior porte foi levantada por Jones, Coviello e Tang (2011), em sua revisão da literatura de empreendedorismo internacional.

A terceira contribuição do estudo refere-se a proporcionar uma visão da temática estudada no contexto de empresas maduras e em países emergentes, situações que receberam pouca atenção na literatura (JONES, COVIELLO E TANG, 2011; KISS, DANIS, \& CAVUSGIL, 2012).

A quarta contribuição se refere à exploração da temática de benefícios provenientes de redes na internacionalização das empresas, em particular por empresas de países emergentes, proporcionando melhor entendimento da questão (KISS \& DANIS, 2008; KISS, DANIS, \& CAVUSGIL, 2012; ZAHRA \& GEORGE, 2002).

\section{4 .}

\section{Contribuições para empresas e governo}

O presente estudo pode ser útil às empresas de software brasileiras que têm a intenção de atingir mercados internacionais. Embora não seja possível fazer generalizações, os resultados apontam para o valor das redes de relacionamento dos empresários quando usadas nas iniciativas internacionais, em consonância com as indicações já existentes na literatura.

Identificou-se, ao longo do trabalho de campo, que aqueles empresários mais atentos à manutenção e à criação de laços internacionais conseguem com mais facilidade implementar suas estratégias, especialmente quando precisam de recursos e conhecimento de mercado. 
A tecnologia tem contribuído para facilitar a manutenção das redes, por meio dos diversos aplicativos de mídia social, que foram mencionados como ferramenta valiosa, particularmente por aqueles empreendedores mais comprometidos com suas redes de relacionamento.

Também pode-se identificar pelo estudo algumas recomendações úteis ao governo brasileiro, que despontam nas manifestações dos empresários em relação às dificuldades encontradas. Mesmo contando com a ajuda das redes, alguns empresários percebem que outros países emergentes lograram maior êxito em penetrar no setor global de TI com ajuda de seus governos. Os exemplos da Índia e da China surgem em diversas entrevistas, sugerindo necessidade de maior empenho do governo brasileiro na promoção do Brasil como exportador de software.

Outro ponto interessante foi a observação de que as redes formadas nas universidades estrangeiras, notoriamente as de países desenvolvidos, são valiosas tanto para identificação de oportunidades quanto na obtenção de conhecimento e de recursos nos países de destino.

Embora o Brasil venha investindo com alguns programas, ainda estamos muito aquém de outros países emergentes, como a Índia e a China, nesse aspecto.

O estudo pode contribuir para a melhoria da eficiência de políticas públicas de desenvolvimento, que têm indicado a busca pelo aumento da competitividade da estrutura produtiva e da participação do Brasil no comércio internacional de serviços de maneira geral, e de software em particular.

\section{5 .}

\section{Recomendações para futuras pesquisas}

Podem-se sugerir pesquisas complementares ao presente estudo, buscando aprofundar as evidências encontradas e explorar o mesmo fenômeno de formas distintas.

A primeira oportunidade que se apresenta decorre do presente estudo ter tido caráter exploratório, e portanto, pode ser frutífero explorar o uso das redes de relacionamentos por meio de pesquisa quantitativa, buscando identificar padrões ou tipologias. 
Outro caminho interessante a explorar seria a identificação de diferenças entre as regiões do Brasil. Sendo um país multicultural, pode ocorrer que padrões distintos sejam mais empregados ou mais eficientes em algumas regiões do que em outras. Por exemplo, pode ser observado o caráter mais relacional característico dos empresários nordestinos, que tornam seus laços mais pessoais. Seria essa característica mais eficaz na internacionalização ou não? Autores brasileiros também sugerem maiores investigações sobre o uso das redes nas empresas do país, ressaltando sua importância na cultura relacional característica do Brasil (DIB, ROCHA, \& SILVA, 2010).

Igualmente parece oportuno investigar o papel das mídias sociais digitais na construção e manutenção das redes de relacionamentos, não só dos empresários do setor de software, mas principalmente entre pequenas empresas, por ter baixo custo, embora seja interessante identificar o quanto é efetiva em substituir as interações físicas.

Distinto campo de pesquisa que poderia produzir achados interessantes seria explorar semelhanças e diferenças entre o uso das redes de relacionamento pelas empresas de software que se internacionalizam e aquelas que são focadas no mercado doméstico, ou ainda se as empresas utilizam suas redes de forma similar para avançar no mercado doméstico e no mercado internacional.

Pesquisas de empreendedorismo internacional que comparem características de mercados emergentes distintos ou entre mercados emergentes e desenvolvidos são requeridas, identificando o uso do capital e os resultados obtidos em diferentes contextos. 


\section{7 Referências bibliográficas}

ABES - Associação Brasileira das Empresas de Software - Mercado Brasileiro de Software: panorama e tendências, 2014 - 1 $^{\text {a }}$. ed. - São Paulo, 2014.

ADLER, P. S.; KWON, S. Social capital: prospects for a new concept. Academy of Management Review, v. 27, p. 17-40, 2002.

AGNDAL, H.; CHETTY, S.; WILSON, H. Social capital dynamics and foreign market entry. International Business Review, v. 17, p. 663-675, 2008.

AL-LAHAM, A.; SOUITARIS, V. Network embeddedness and new venture internationalization: Analyzing international linkages in the German biotech industry. Journal of Business Venturing, v. 23, p. 567-586, 2008.

ANDERSON, J. C.; HAKANSSON, H.; JOHANSON, J. Dyadic Business Relationships within a Business Network Context. Journal of Marketing, v. 58, p. 1-15, 1994.

ANDERSON, M. H. Social networks and the cognitive motivation to realize network opportunities: a study of managers' information gathering behaviors. Journal of Organizational Behavior, v. 29, p. 51-78, 2008.

ANDERSEN, P. H.; SKAATES, M. A. Ensuring validity in qualitative international business research. In: MARSCHAN-PIEKKARI, R.; WELCH, C. (Eds.), Handbook of qualitative research methods for international business. Cheltenham: Edward Elgar, p. 464-485. 2004.

ANDERSSON, S. The Internationalisation of the Firms from an Entrepreneurial Perspective. International Studies of Management and Organization, v. 30, n. 1, p. 63-92, 2000.

ANDERSSON, S.; EVERS, N.; GRIOT, C. Local and international networks in small firm internationalization: cases from the Rhône-Alpes medical technology regional cluster. Entrepreneurship \& Regional Development, v. 25, n. 9-10, p. 867-888, 2013.

ARENIUS, P. Creation of firm-level social capital, its Exploitation, and the process of early Internationalization. Helsinki University of Technology Institute of Strategy and International Business, Doctoral Dissertations. 2002. The Psychic Distance Postulate Revised: From Market Selection to Speed of Market Penetration. Journal of International Entrepreneurship, v. 3, p. 115-131, 2005. 
AUTIO, E.; YLI-RENKO, H.; SALONEN, A. International growth of young technology-based firms: A resource-based network model. Journal of Enterprising Culture, v. 5, n. 1, p. 57-73, 1997.

BARNEY, J. B. Firm resources and sustained competitive advantage. Journal of Management, v. 17, n. 1, p. 9-120, 1991.

BARON, R. A.; TANG, J. Entrepreneurs' social skills and new venture performance: Mediating mechanisms and cultural generality. Journal of Management, v. 35, n. 2, p. 282-306, 2009.

BATJARGAL, B. Social capital and entrepreneurial performance in Russia: A longitudinal study. Organization Studies. v. 24, n. 4, p. 535-556, 2003. .; HITT, M.; TSUI, A.; ARREGLE, J.; WEBB, J.; MILLER, T. Institutional Polycentrism, Entrepreneurs Social Networks, and New Venture Growth. Academy of Management Journal, v. 56, n. 4, p. 1024-1049, 2013.

.; LIU, M. M. Entrepreneurs' access to private equity in China: the role of social capital. Organization Science, v. 15, p. 159-172, 2004.

BAUM, J. A. C.; MCEVILY, B.; ROWLEY, T. J. Better with age? Tie longevity and the performance implications of bridging and closure. Organization Science, v. 23, n. 2 , p. $529-546,2012$.

BAUM, M.; SCHWENS, C.; KABST, R. A Typology of International New Ventures: Empirical Evidence from High-Technology Industries. Journal of Small Business Management, v. 49, n. 3, p. 305-330, 2011.

BELL, J. The Internationalization of small computer software firms - A further challenge to "stage" theories. European Journal of Marketing, v. 29, n. 8, p. 60$75,1995$.

BELLIVEAU, M. A.; O'REILLY III, C. A.; WADE, J. B. Social capital at the top: effects of social similarity and status on CEO compensation. Academy of Management Journal, v. 39, p. 1568-1593, 1996.

BILKEY, W. J.; TESAR, G. The export behavior of smaller-sized Wisconsin manufacturing firms, Journal of International Business Studies, v. 8, p. 93-8, 1977.

BIRKINSHAW, J.; BRANNEN, M. Y.; TUNG, R. L. From a distance and generalizable to up close and grounded: Reclaiming a place for qualitative methods in international business research. Journal of International Business Studies, v. 42, p. 573-581, 2011.

BLANKENBURG, D.; JOHANSON, J. Managing network connections in international business. Scandinavian International Business Review, v. 1, n.1, p. 5-19, 1992.

BOEHE, D. Collaborate at Home to Win Abroad: How Does Access to Local Network Resources Influence Export Behavior? Journal of Small Business Management. v. 51, p. 167-182, 2013. 
BON, A. C. Ethical decision-making: the role of future orientation, selfmonitoring and social networks. 212f. Tese de Doutorado - Pontifícia Universidade Católica do Rio de Janeiro, Departamento de Administração, 2014.

BOURDIEU, P. The forms of capital, In: RICHARDSON, J. G. (Ed.), Handbook of Theory and Research for the sociology of Education, New York: Greenwood Press, 1986.

BORGATTI, S. P.; FOSTER, P. C. The network paradigm in organizational research: a review and typology. Journal of Management, v. 29, p. 991-1013, 2003. 1168-1181, 2011.

; HALGIN, D. S. On Network Theory. Organization Science, v. 22, p.

BOSO, N.; STORY, V. M.; CADOGAN, J. W. Entrepreneurial orientation, market orientation, network ties, and performance: Study of entrepreneurial firms in a developing economy. Journal of Business Venturing, v. 28, p. 708-727, 2013.

BRIGATTO, G. Totvs cria unidade para atender Colômbia, Equador e Peru. Valor Econômico, Disponível em:

$<$ http://www.valor.com.br/empresas/4443196/totvs-cria-unidade-para-atendercolombia-equador-e-peru $>$. Acesso em: 18/02/2016.

BRITO, P. Fornecedores de TI contam com programas de apoio. Valor Econômico, Disponível em: $<$ http://www.valor.com.br/empresas/4096786/fornecedores-de-ti-contam-comprogramas-de-apoio $>$. Acesso em: 17/06/2015.

BUCIUNI, G.; MOLA, L. How do entrepreneurial firms establish cross-border relationships? A global value chain perspective. Journal of International Entrepreneurship. v. 12, p. 67-84, 2014.

BURT, R. S. Structural holes: the social structure of competition. Cambridge: MA, Harvard University Press. 1992.

CANNONE, G.; UGHETTO, E. Born Globals: A cross-country survey on hightech start-ups. International Business Review, v. 23, p. 272-283, 2014.

CARPENTER, M. A.; LI. M.; JIANG, H. Social network research in organizational contexts: a systematic review of methodological issues and choices. Journal of Management, v. 38, p. 1238-1361, 2012.

CARPENTER, M. A.; SANDERS, W.; GREGERSEN, H. Bundling human capital with organizational context: The impact of international assignment experience on multinational firm performance and CEO pay. Academy of Management Journal, v. 44, n. 3, p. 493-511, 2001.

CASILLAS, J. C.; ACEDO, F. J. Speed in the Internationalization process of the firm. International Journal of Management Reviews. v. 15, n. 1, p. 15-29, 2013. 
CASSON, M. Entrepreneurship and the theory of the firm. Journal of Economic Behavior \& Organization, v. 58, p. 327-348, 2005.

CAVUSGIL, S. T. On the internationalization process of the firm, European Research, v. 8, n. 6, p. 273-81, 1980.

CHEN, T.-J. Network resources for internationalization: the case of Taiwan's electronics firms. Journal of Management Studies, v. 40, n. 5, p. 1107-1130, 2003.

CHETTY, S.; HOLM, D. Internationalisation of small to medium-sized manufacturing firms: a networking approach. International Business Review, v 9, n. 1, p. 77-93, 2000.

CHILD, J.; HSIEH, L. H. Y. Decision mode, information and network attachment in the internationalization of SMEs: A configurational and contingency analysis. Journal of World Business. v. 49, p. 598-610, 2014.

CHONG, L.; GIBBONS, P. Corporate entrepreneurship: The roles of ideology and social capital. Group and Organization Management, v. 22, p. 10-30, 1997.

CIRAVEGNA, L.; LOPEZ, L.; KUNDU, S. Country of origin and network effects on internationalization: A comparative study of SMEs from an emerging and developed economy. Journal of Business Research. v. 67, p. 916-923, 2014. .; MAJANO, S. B.; ZHAN, G. The inception of internationalization of small and medium enterprises: The role of activeness and networks. Journal of Business Research. v. 67, p. 1081-1089, 2014.

COEURDEROY, R.; COWLING, M.; LICHT, G.; MURRAY, G. Young firm internationalization and survival: Empirical tests on a panel of 'adolescent' new technology-based firms in Germany and the UK. International Small Business Journal, v. 30, p. 472-492, 2012.

COLEMAN, J. S. Foundations of Social Theory. First Edition. MA: Harvard University Press. 1990.

COOMBS, J. E.; SADRIEH, F.; ANNAVARJULA, M. Two decades of international entrepreneurship research: what have we learned - where do we go from here? International Journal of Entrepreneurship, v. 13, p. 23-64, 2009.

COSENTINO, L.; HABERKORN, E.; CÍCERO, F. Genoma Empresarial, São Paulo: Editora Gentel, 2001.

COVIELLO, N. The network dynamics of international new venture. Journal of International Business Studies, v. 37, n. 5, p. 713-731, 2006. .; MARTIN, K.A.-M. Internationalization of service SMEs: An integrated perspective from the engineering consulting sector. Journal of International Marketing, v. 7, n. 4, p. 42-66, 1999.

.; MUNRO, H. J. Growing the entrepreneurial firm: networking for international market development. European Journal of Marketing, v. 29, n. 7, p. $49-51,1995$ 


\begin{abstract}
. Network Relationships and the Internationalisation Process of Small Software Firms. International Business Review, v. 6, n. 4 p. 361-386, 1997.
\end{abstract}

COVIN J. C.; SLEVIN, D. Strategic Management of small firms in hostile and benign environments. Strategic Management Journal, v. 10, p. 75-87, 1989.

CRICK, D.; SPENCE, M. The internationalization of "high performing" UK hightech SMEs: a study of planned and unplanned strategies. International Business Review, v. 14, p. 167-185, 2005.

CZINKOTA, M. R. Export Development Strategies: US Promotion Policy, Praeger, New York, NY, 1982.

DAILY, C.M.; CERTO, S. T.; DALTON, D. R. International experience in the executive suite: The path to prosperity? Strategic Management Journal, v. 21, p. 515-523, 2000.

.; MCDOUGALL, P. P.; COVIN, J. G.; DALTON, D. R. Governance and strategic leadership in entrepreneurial firms. Journal of Management, v. 28, p. $387-412,2002$

DANA, L.-P.; ETEMAD, H.; WRIGHT, R. The impact of globalization on SMEs. Global Focus, v. 11, n. 4, p. 93-105, 1999.

DANIS, W. M.; DE CLERCQ, D.; PETRICEVIC, O. Are social networks more important for new business activity in emerging than developed economies? An empirical extension. International Business Review, v. 20, p. 398-409, 2011.

DE CAROLIS, D. M.; SAPARITO, P. Social capital, cognition, and entrepreneurial opportunities: A theoretical framework. Entrepreneurship: Theory \& Practice, v. 30, p. 41-56, 2006.

DIB, L. A. O processo de internacionalização de pequenas e médias empresas e o fenômeno Born Global: estudo do setor de software do Brasil. Tese de doutorado - Universidade Federal do Rio de Janeiro, Instituto Coppead de Administração, 2008.

.; ROCHA, A M.; SILVA, J. F. The internationalization process of Brazilian software firms and the born global phenomenon: Examining firm, network, and entrepreneur variables. Journal of International Entrepreneurship, v. 8, p. 233-253, 2010.

DIMITRATOS, P.; AMORÓS, J. E.; ETCHEBARNE, M. S.; FELZENSZTEIN, C. Micro-multinational or not? International entrepreneurship, networking and learning effects. Journal of Business Research. v. 67, p. 908-915, 2014.

DIMITRATOS, P.; JONES, M. Future Directions for international entrepreneurship research. International Business Review. v. 14, p. 119-128, 2005 .

.; PLAKOYIANNAKI, E. Theoretical foundations of an international entrepreneurial culture. Journal of International Entrepreneurship, v. 1, p. 187-215, 2003. 
DUBOIS, A.; GADDE, L. Systematic combining an abductive approach to case research. Journal of Business Research, v. 55, p. 553-560, 2002.

ELLIS, P. Social ties and foreign market entry. Journal of International Business Studies, v. 31, n. 3 p. 443-469, 2000.

ETEMAD, H. International entrepreneurship as a dynamic adaptive system: Towards a grounded theory. Journal of International Entrepreneurship, v. 2, p. 5-60, 2004.

.; WYRIGHT, R. W.; DANA, L. P. Symbiotic international business networks: collaboration between small and large firms. Thunderbird International Business Review, v. 43, n. 4, p. 481-499, 2001.

EVERS, N. Why do new ventures internationalise? A review of the literature of factors that influence new venture internationalisation. Irish Journal of Management, p. 17- 46, 2011.

.; O'GORMAN, C. Improvised internationalization in new ventures:

The role of prior knowledge and networks. Entrepreneurship \& Regional Development, v. 23, n. 7-8, p. 549-574, 2011.

FELZENSZTEIN, C.; CIRAVEGNA, L.; ROBSON, P.; AMORÓS, J. E. Networks, Entrepreneurial Orientation, and Internationalization Scope: Evidence from Chilean Small and Medium Enterprises. Journal of Small Business Management, v. 53, p. 145-160, 2015.

FLAP, H. Creation and returns of social capital. In: FLAP, H.; VOLKER, B. (Ed.), Creation and returns of social capital: a new research program. London: Routledge, 2004.

FREEMAN, S.; EDWARDS, R.; SCHRODER, B. How Smaller Born-Global Firms Use Networks and Alliances to Overcome Constraints to Rapid Internationalization. Journal of International Marketing, v. 14, n. 3, p. 33-63, 2006.

GABRIELSSON, K.; KIRPALANI, V. H. M. Overview, background and historical origin of born globals; development of theoretical and empirical research. In: Handbook of research on Born Globals, Massachussets: Edward Elgar Publishing, Inc., 2012.

GEDAJLOVIC E.; HONIG B.; MOORE, C. B.; PAYNE, G. T.; WRIGHT, M. Social Capital and Entrepreneurship: A Schema and Research Agenda. Entrepreneurship Theory and Practice, v. May, p. 455-478, 2013.

GHAURI, P. Designing and Conducting Case Studies in International Business Research. In: MARSCHAN-PIEKKARI, R. e WELCH, C. (eds) Handbook of Qualitative Research Methods in International Business, p. 109-124. Cheltenham: Edward Elgar. 2004.

GRANOVETTER, M. S. Economic action and social structure: the problem of social embeddedness. American Journal of Sociology, v. 31, p. 481-580, 1985. 1360-1380, 1973. . The strength of weak ties. American Journal of Sociology, v. 78, p. 
GULATI, R. Network location and learning: the influence of network resources and firm capabilities on alliance formation. Strategic Management Journal, v. 20, p. 397-420, 1999

.; NOHRIA, N.; ZAHEER, A. Strategic Networks. Strategic Management Journal, v. 21, p. 203-215, 2000.

HAMAN, R. Conheça os Vales do Silício brasileiros. Site Tecmundo, 29.07.2014. Disponível em: $<$ http://www.tecmundo.com.br/brasil/59664-conheca-valessilicio-brasileiros-ilustracao.htm>. Acessado em: 31/07/2015.

HAN, M. Developing social capital to achieve superior internationalization: A conceptual model. Journal of International Entrepreneurship, v. 4, p. 99-112, 2006.

HARRIS, S., WHEELER, C. Entrepreneurs relationship for internationalization: functions, origins and strategies. International Business Review, v. 14, p. 187$207,2005$.

HASSETT, M. E.; PAAVILAINEN-MÄNTYMÄKI, E. Longitudinal research in organizations: an introduction. In: HASSETT, M. E. \& PAAVILAINENMÄNTYMÄKI, E. (Org.). Handbook of Longitudinal Research Methods in Organisation and Business Studies. Cheltenham, U.K.: Edward Elgar, p. 1-22, 2013.

HITE, J. M.; HESTERLY, W. S. The evolution of firm networks: from emergence to early growth of the firm. Strategic Management Journal, v. 22, p. 275-286, 2001.

HITT, M. A.; IRELAND, R. D.; CAMP, S. M.; SEXTON, D. L. Strategic entrepreneurship: Entrepreneurial strategies for wealth creation. Strategic Management Journal, v. 22, p. 479-491, 2001.

HOANG, H.; ANTONCIC, B. Network-based research in entrepreneurship A critical review. Journal of Business Venturing, v. 18, p. 165-187, 2003.

HOFSTEDE, G. Culture's Consequences: International Differences in WorkRelated Values. Beverly Hills CA: Sage Publications, 1980.

HOHENTHAL, J.; JOHANSON, J.; JOHANSON, M. Network knowledge and business-relationship value in the foreign market. International Business Review. v. 23, p. 4-19, 2014.

HOLMLUND, M.; KOCK, S. Relationships and the internationalization of Finnish small and medium-sized companies. International Small Business Journal, v. 16, n. 4, 1998.

HURLBERT, J. S.; HAINES, V. A.; BEGGS, J. J. Core networks and tie activation: What kinds of routine networks allocate resources in nonroutine situations? American Sociological Review, v. 65, p. 598-618, 2000. 
IBEH, K.; KASEM, L. The network perspective and the internationalization of small and medium sized software firms from Syria. Industrial Marketing Management, v. 40, p. 358-367, 2011.

INKPEN, A. C.; TSANG, W. K. Social capital, networks, and knowledge transfer, Academy of Management Review, v. 30, n. 1, p. 146-165, 2005.

IRELAND, R. D.; HITT, M. A.; SIRMON, D. G. A Model of Strategic Entrepreneurship: The Construct and its Dimensions. Journal of Management, v. 29, n. 6, p. 963-989, 2003.

JOHANNISSON, B. Economics of overview - guiding the external growth of small firms. International Small Business Journal, v. 9, p. 32-44, 1990.

JOHANSON, J.; MATTSSON, L-G. International Marketing and Internationalization Process - A Network Approach. Research of international marketing. p. 234-266. Room Helm, 1989.

;_ Internationalization in Industrial Systems - A Network Approach. In: HOOD, N. \& VAHLNE, J. E. (Eds), Strategies in Global Competition, London: Beckham, 1988.

.; VAHLNE, J. E. Business Relationship Learning and Commitment in the Internationalization Process. Journal of International Entrepreneurship, v. 1, p. 83-101, 2003.

.; VAHLNE, J. E. Markets as networks: implications for strategymaking. Journal of the Academy of Marketing Science, v. 39, p. 484-491, 2011.

.; VAHLNE, J. E. The internationalization process of the firm - a model of knowledge development and increasing foreign commitments, Journal of International Business Studies, v. 8, n. 1, p. 23-32, 1977. .; VAHLNE, J. E. The Mechanism of Internationalisation. International Marketing Review, v. 7, n. 4, p. 11-24, 1990.

.; VAHLNE, J. E. The Uppsala internationalization process model revisited: From liability of foreignness to liability of outsidership. Journal of International Business Studies, v. 40, n. 9, p. 1411-1431, 2009.

JOHANSON, J.; WIEDERSHEIM-PAUL, F., The internationalization of the firm - four Swedish case studies, Journal of Management Studies, v. 12, p. 305-322. 1975.

JONES, M. Future Directions for International Entrepreneurship Research. International Business Review, v. 14, p. 119-128, 2005.

The internationalization of small high technology firms. Journal of International Marketing, v. 7, n. 4, p. 15-41, 1999.

.; COVIELLO N. Internationalization: conceptualizing an

entrepreneurial process of behavior in time. Journal of International Business Studies, v. 36, p. 284-303, 2005.

.; COVIELLO N.; TANG, Y. International Entrepreneurship research (1989-2009): A domain ontology and thematic analysis. Journal of Business Venturing, v. 26, p. 632-659, 2011. 
KENNY, B.; FAHY, J. Network resources and international performance of high tech SMEs. Journal of Small Business and Enterprise Development, v. 18, n. 3, p. 529-555, 2001.

KEUPP, M. M.; GASSMANN, O. The past and the future of international entrepreneurship: a review and suggestions for developing the field. Journal of Management, v. 35, n. 3, p. 600-633, 2009.

KILDUFF, M.; BRASS, D. J. Job design: a social network perspective. Journal of Organizational Behavior, v. 31, p. 309-318, 2010.

KIM, P. H.; ALDRICH, H. E. Social capital and entrepreneurship. Boston: Now. 2005.

KISS, A. N.; DANIS, W. M. Country institutional context, social networks, and new venture internationalization speed. European Management Journal. v 26, p. 388-399, 2008.

.; _ _ _ CAVUSGIL S. International entrepreneurship research in emerging economies: A critical review and research agenda. Journal of Business Venturing, v. 27, p. 266-290, 2012.

KHANIN, D.; OGILVIE, K.; LEIBSOHN, D. International entrepreneurship, venture capital networks, and reinvestment decisions. Journal of International Entrepreneurship, v. 10, p. 1-24, 2012.

KLYVER, K.; GRANT, S. Gender differences in entrepreneurial networking and participation. International Journal of Gender and Entrepreneurship, v. 2, n. 3 , p. 213-227, 2010.

KNIGHT G. A.; CAVUSGIL S. T. The born global firm: A challenge to traditional internationalization theory. Advances in International Marketing, $v$. 8, p. 11-26, 1996.

KONTINEN, T.; OJALA, A. Network ties in the international opportunity recognition of family SMEs. International Business Review, v. 20, p. 440-453, 2011.

KWON, S.; ARENIUS, P. Nations of entrepreneurs: A social capital perspective. Journal of Business Venturing, v. 25, p. 315-330, 2010.

LEE, W. Y.; BRASCH, J. J. The adoption of export as an innovation strategy, Journal of International Business Studies, Vol. 9, No. 1, p. 85-93, 1978.

LEVITT, B.; MARCH, J. G. Organizational Learning. Annual Review of Sociology, v. 14, p. 319-340, 1988.

LIAO, J.; WELSCH, H. Roles of social capital in venture creation: Key dimensions and research implications. Journal of Small Business Management, v. 43, n. 4, p. 345-362, 2005. 
LIN, N. Building a network theory of social capital. In: LIN N.; COOK, K. S.; BURT, R. S. (Eds.), Social capital: Theory and research. New Brunswick, NJ: Transaction Publishers. 2001

LINDSTRAND, A.; MELÉN, S.; NORDMAN, E. R. Turning social capital into business: A study of the internationalization of biotech SMEs. International Business Review, v. 20, p. 194-212, 2011.

LOTURCO, R. A conquista da América ainda é sonho da maioria. Valor Econômico, Disponível em: <http://www.valor.com.br/brasil/4293712/conquistada-america-ainda-e-sonho-da-maioria $>$. 30/10/2015.

LOURY, G. The economics of discrimination: Getting to The core of the problem. Harvard Journal for African. v. 1, p. 91-11, 1992.

MACDONALD, S.; HELLGREN, B. The interview in international business research: problems we would rather not talk about. In: MARSCHAN-PIEKKARI, R.; WELCH, C. (eds) Handbook of Qualitative Research Methods in International Business, Cheltenham, UK: Edward Elgar, p. 264-281. 2004.

MACHADO-DA-SILVA, C. L.; CASALI, A. M.; FERNANDES, B. H. R. "Internationalization and Organizational Change: A Multi Case Study of Brazilian Organizations," Latin American Business Review, v. 2, n. 3/4, p. 6196, 2001.

MAINELA, T.; PERNU, E.; PUHAKKA, V. The development of a high-tech international new venture as a process of acting. A study of the lifespan of a venture in software business. Journal of Small Business and Enterprise Development, v. 18, n. 3, p. 430-456, 2011.

.; PUHAKKA, V.; SERVAIS, P. The Concept of International Opportunity in International Entrepreneurship: A Review and a Research Agenda. International Journal of Management Reviews, v. 16, p. 105-129, 2014.

MAIS, I.; CARVALHO, L. C.; AMAL, M. Redes, Inovação e Desempenho Exportador: Uma Abordagem Institucional. RAC, v. 18, n. 5, p. 551-576, 2014.

MANOLOVA, T. S.; MANEV, I. M.; GYOSHEV, B. S. In good company: The role of personal and inter-firm networks for new-venture internationalization in a transition economy. Journal of World Business, v. 45, p. 257-265, 2010.

MASANGO, S.; MARINOVA, S. Knowledge-based network ties in early rapidly internationalising small firms: a missing link? International Entrepreneurship Management Journal. v. 10, p. 471-486, 2014.

MATHEWS, J. A.; ZANDER, I. The international entrepreneurial dynamics of accelerated internationalization. Journal of International Business Studies, v. 38, n. 3, p. 387-403, 2007.

MAURER, I.; EBERS, M. Dynamics of social capital and their performance implications: Lessons from biotechnology start-ups. Administrative Science Quarterly, v. 51, p. 262-292. 2006. 
MCDONALD, F.; KRAUSE, J.; SCHMENGLER, H.; TUSELMANN, H.J. Cautious international entrepreneurs: the case of the Mittelstand. Journal of International Entrepreneurship, v. 1, n. 4, p. 363-381, 2003.

MCDOUGALL, P. P. International versus domestic entrepreneurship: New venture strategic behavior an industry structure. Journal of Business Venturing, v. 4, p. 387-400, 1989.

.; OVIATT, B. M. International entrepreneurship: The intersection of two paths. Guest Editor's Introduction, Academy of Management Journal, v. 43, n. 5, p. 902-908, 2000.

.; SHANE, S.; OVIATT, B. M. Explaining the formation of international new ventures: The limits of theories from international business research. Journal of Business Venturing, v. 9, n. 6, p. 469-487, 1994.

MELLO, R. C. O processo de internacionalização de empresas brasileiras de software: reconciliando diferentes correntes teóricas. 279 fls. Tese de doutorado. Universidade Federal do Rio de Janeiro - Coppe - UFRJ, 2009. .; MACUlAN, A.; CASOTTI, L. M. Fujitec e o Desafio do Crescimento Internacional. Enanpad, 2008.

MINTZBERG, H. The Nature of Managerial Work. New York: Harper \& Row. 1973

MOURA, A. Produção, comercialização e exportação de software: a experiência da Light Infocon Tecnologia S/A. in: O mercado de software no Brasil: problemas institucionais e fiscais. Brasília, 2007. Disponível em: $<$ http://bd.camara.gov.br/bd/bitstream/handle/bdcamara/3483/mercado_software_ gadelha.pdf? sequence=1>. Acesso em: 12/02/2016.

MURPHY, J. P. A 2 X 2 conceptual foundation for entrepreneurial discovery theory. Entrepreneurship Theory and Practice, v. 35, n. 2, p. 359-374, 2011.

MUSTEEN, M.; DATTA, D.; BUTTS, M. M. Do International Networks and Foreign Market Knowledge facilitate SME Internationalization? Evidence from the Czech Republic. Entrepreneurship Theory \& Practice. p. 749-774, 2014 .; FRANCIS, J., DATTA, D. The influence of international networks on internationalization speed and performance: A study of Czech SMEs. Journal of World Business, v. 45, p. 197-205, 2010.

NAHAPIET, J.; GHOSHAL, S. Social Capital, Intellectual Capital and the organizational advantage. Academy of Management Review, v. 23, p. 242-266, 1998.

O'GORMAN, C.; EVERS, N. Network intermediaries in the internationalization of new firms in peripheral regions. International Management Review, v. 28, n. 4, p. 340-364, 2011.

OVIATT, B. M.; MCDOUGALL, P. P. Challenges for Internationalization Process Theory: The Case of International New Ventures. Management International Review, v. 37, p. 85-99, 1997. 
; $\quad$. Defining International Entrepreneurship and Modeling the Speed of Internationalization. Entrepreneurship Theory \& Practice, p. 537-553, 2005.

.; Global start-ups: Entrepreneurs on a worldwide stage.

Academy of Management Executive, v. 9, n. 2, p. 30-43, 1995.

; _ International Entrepreneurship: The Intersection of Two

Research Paths. Academy of Management Journal, v. 43, n. 5, p. 902-906, 2000 .

.; . Toward a theory of international new ventures. Journal of International Business Studies, v. 25, n. 1, p. 45-64, 1994.

PAYNE, G. T.; MOORE, C. B.; GRIFFIS, S. E.; AUTRY, C. W. Multilevel challenges and opportunities in Social Capital research. Journal of Management, v. 37, p. 491-520, 2011.

PAUWELS, P.; MATTHYSSENS, P. The architecture of Multiple Case Study Research in International Business. In: MARSCHAN-PIEKKARI, R.; WELCH, C. (eds) Handbook of Qualitative Research Methods in International Business. Cheltenham: Edward Elgar, p. 125-143, 2004.

PEIRIS I. K.; AKOORIE M. E. M.; SINHA, P. International entrepreneurship: A critical analysis of studies in the past two decades and future directions for research. Journal of International Entrepreneurship, v. 10, p. 279-324, 2012.

PENG, M. W.; LUO, Y. Managerial ties and firm performance in a transition economy: The nature of a micro-macro link. Academy of Management Journal, v. 43, n. 3 , p. $486-501,2000$.

.; WANG, D. Y. L.; JIANG, Y. An Institution-Based View of International Business Strategy: A Focus on EmergingEconomies. Journal of International Business Studies, v. 39, n. 5, p. 920-936, 2008.

PERRY-SMITH, J. E.; SHALLEY, C. E. The social side of creativity: A static and dynamic social network perspective. Academy of Management Review, v. 28, p. 89-106, 2003.

PRASHANTHAM, S. How start-ups from emerging economies make inroads abroad. The Economist-Intelligence Unit, 2016. Disponível em: $<\mathrm{http} / / /$ viewswire.eiu.com/index.asp?layout=EBArticleVW3\&article_id=1893904 $173 \&$ channel_id $=778114477 \&$ category_id $=\&$ refm $=$ ebCh\&page_title $=$ Latest $>$. .; BALACHANDRAN, G. Local bridging ties and new venture internationalization: exploratory studies in Bangalore and Cambridge. In: JONES, M. V.; DIMITRATOS, P.; FLETCHER, M.; YOUNG, S. Internationalization, Entrepreneurship and the Smaller Firm. Cheltenham, U.K.: Edward Elgar p. 166-184, 2009.

.; BIRKINSHAW, J. Choose your friends carefully: home-country ties and new venture internationalization. Management International Review. v. 55, p. 207-234, 2015.

.; DHANARAJ, C. The Dynamic Influence of Social Capital on the International Growth of New Ventures. Journal of Management Studies, v. 47, p. 967-994, 2010. 
.; _ . KUMAR, K. Ties That Bind: Ethnic Ties and New

Venture Internationalization. Long Range Planning. v. 48, p. 317-333, 2015

PRESUTTI, M.; BOAN, C.; FRATOCCHI, L. Knowledge acquisition and the foreign development of high-tech start-ups: a social capital approach. International Business Review, v. 16, n. 1, p. 23-46, 2007.

PUTNAM, R. D. Bowling alone: America's declining social capital. Journal of Democracy, v. 6, p . 65-78, 1995.

REID, S. D. The decision-maker and export entry and expansion, Journal of International Business Studies, v. 12, n. 2, p. 101-12, 1981.

RENZULLI, L. A.; ALDRICH, H. Who can you turn to? Tie activation within core business discussion networks. Social Forces, v. 84, p. 323-341, 2005.

RODRIGUES, S. B.; CHILD, J. Building Social Capital for Internationalization. RAC, v. 16, n. 1, p. 23-38, 2012.

ROCHA, A.; Mello, R. C.; DIB, L. A. R.; MACUlAn, A. M. Processo de Internacionalização de Empresas Nascidas Globais: Estudo de Casos no Setor de Software. Enanpad, 2005.

.; SILVA, J. The Internationalization of Brazilian Firms: An Introduction to the Special Issue. Latin American Business Review, v. 10, p. 6171, 2009.

ROGERS, E. M. Diffusion of Innovations, Free Press, New York, NY, 1962.

SANDBERG, S. Experiential knowledge antecedents of the SME network node configuration in emerging market business networks. International Business Review. v. 23, p. 20-29, 2014.

SARASVATHY, S. Causation and effectuation: Toward a theoretical shift from economic inevitability to entrepreneurial contingency. Academy of Management Review. v. 26, n. 2, p. 243-263, 2001.

SASI, V.; ARENIUS, P. International new ventures and social networks: advantage or liability? European Management Journal, v. 26, p. 400-411, 2008.

SCHWEIZER, R.; VAHLNE, J. E.; JOHANSON, J. Internationalization as an entrepreneurial process. Journal of International Entrepreneurship, v. 8, p. 343-370, 2010.

SCHWENS, C.; KABST, R. Entry learning, age at internationalization, and foreign-venture performance of young technology firms. Schmalenbach Business Review, v. 63, p. 308-330, 2011.

.; How early opposed to late internationalizers learn:

Experience of others and paradigms of interpretation. International Business Review, v. 18, p. 509-522, 2009.

.; KABST, R. Internationalization of young technology firms: A complementary perspective on antecedents of foreign market familiarity. International Business Review, v. 20, p. 60-74, 2011. 
SEPULVEDA, F.; GABRIELSSON, M. Network development and firm growth: A resource-based study of B2B Born Globals. Industrial Marketing Management, v. 42, p. 792-804, 2013.

SHANE, S.; VENKATARAMAN, S. The promise of entrepreneurship as a field of research. Academy of Management Review, v. 25, p. 217-226, 2000.

SHARMA, D. D.; BLOMSTERMO, A. "The internationalization process of born globals: a network view". International Business Review, v. 12, n. 6, p. 739-753, 2003.

SHARMA, P.; CHRISMAN, J. J. Toward a reconciliation of the definitional issues in the field of corporate entrepreneurship. Entrepreneurship Theory and Practice, v. 23, n. 3, p. 11-27, 1999.

SHENKAR, O. Cultural Distance Revisited: Towards a More Rigorous Conceptualization and Measurement of Cultural Differences. Journal of International Business Studies, v. 32, n. 3, p. 519-535, 2001.

SIGMUND, S.; SEMRAU, T.; WEGNER, D. Networking Ability and the Financial Performance of New Ventures: Moderating Effects of Venture Size, Institutional Environment, and Their Interaction. Journal of Small Business Management. v. 53, n. 1, p. 266-283, 2015.

SINGH, R. P. Entrepreneurial opportunities recognition through social networks. Thesis University of Illinois, Chicago. 1998.

TANG, Y. K. The influence of networking on the internationalization of SMEs: Evidence from internationalized Chinese firms. International Small Business Journal, v. 29, n. 4, p. 374-398, 2011.

TIMMONS, J. A. New venture creation (4th ed.). Burr Ridge, IL: Irwin. 1994.

TORKKELI, L.; PUUMALAINEN, K.; SAARENKETO, S.; KUIVALAINEN, $O$. The effect of network competence and environmental hostility on the internationalization of SMEs. Journal of International Entrepreneurship, v. 10, p. 25-49, 2012.

TOURANGEAU, R.; RIPS, L. V.; RASINSKI, K. The psychology of survey response. Cambridge, Cambridge University Press, 2000.

TSAI, W.; GHOSHAL, S. Social capital and value creation: The role of intrafirm networks. Academy of Management Journal, v. 41, p. 464-476. 1998.

UZZI, B. Social relations and networks in the making of financial capital. American Society Review, v. 64, p. 481-505, 1999.

Social structure and competition in inter-firm networks: The paradox of embeddedness. Administrative Science Quarterly, v. 42, p. 35-67, 1997. 
VAARA, E.; TIENARI, J. Critical Discourse Analysis as a Methodology for International Business Studies. In: MARSCHAN-PIEKKARI, R.; WELCH, C. (eds) Handbook of Qualitative Research Methods in International Business. Cheltenham: Edward Elgar, p. 342--359, 2004.

VASILCHENKO, E.; MORRISH, S. The role of entrepreneurial networks in the exploration and exploitation of internationalization opportunities by information and communication technology firms. Journal of International Marketing, v. 19, n. 4, p. 88-105, 2011.

VENKATARAMAN, S. The distinctive domain of entrepreneurship research: An editor's perspective. In: KATZ, J.; BROCKHAUS, R. (eds) Advances in entrepreneurship, firm emergence and growth, Greenwich, CT: JAI Press. v. 3, p. 119-138.1997.

VISSA, B.; CHACAR, A. S. Leveraging ties: the contingent value of entrepreneurial teams' external advice networks on Indian software venture performance. Strategic Management Journal, v. 30, p. 1179-1191, 2009.

VOUDOURIS, I.; DIMITRATOS, P.; SALAVOU, H. Entrepreneurial learning in the international new high-technology venture. International Small Business Journal, v. 29, n. 3, p. 238-258, 2011.

WALKER, G.; KOGUT, B.; SHAN, W. Social capital, structural holes and the formation of an industry network. Organization Science, v. 8, p. 109-125, 1997.

WESTHEAD, P.; WRIGHT, M.; UCBASARAN, D. The internationalization of new and small firms: a resource-based view. Journal of Business Venturing, $v$. 16, n. 4, p. 333-358, 2001.

WIKLUND, J.; DAVIDSSON, P.; AUDRETSCH, D. B.; KARLSSON, C. The Future of Entrepreneurship Research. Entrepreneurship Theory and Practice, v. January, p. 1-9, 2011.

WOODSIDE, A. G. Case Study Research: Theory Methods Practice. 1a. edição. Emerald Group Publishing Limited, Bingley, UK, 2010.

WOOLCOCK, M. Social capital and economic development: Toward a theoretical synthesis and policy framework. Theory and Society, v. 27, p. 151208, 1998.

WRIGHT, R.; RICKS, D. A. Trends In International Business Research: TwentyFive Years Late. Journal of International Business Studies, v. 25, n. 4, p. 687701, 1994.

YIN, R. Case Study Research: design and methods. Sage Publications, Inc. California, 1989

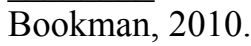

Estudo de Caso: Planejamento e Métodos. $4^{\mathrm{a}}$ ed. Porto Alegre: 
YLI-RENKO, H.; AUTIO, E.; SAPIENZA, H.J. Social Capital, Knowledge Acquisition, and Knowledge Exploitation in Young Technology-Based Firms. Strategic Management Journal, v. 22, n. 6/7, p. 587-613, 2001.

.; __ TONTTI, V. Social capital, knowledge, and the international growth of technology-based new firms. International Business Review, v. 11, p. 279-304, 2002.

YU, J.; GILBERT, B. A.; OVIATT, B.M. Effects of alliances, time, and network cohesion on the initiation of foreign sales by new ventures. Strategic Management Journal, v. 32, p. 424-446, 2011.

ZAHRA, S. A. A theory of international new ventures: a decade of research. Journal of International Business Studies, Vol. 36, p. 20-28, 2005.

.; GEORGE, G. International entrepreneurship: the current status of the field and future research agenda. In: HITT, M.; IRELAND, D.; SEXTO, D.; CAMP, M. (eds.) Strategic Entrepreneurship: Creating an Integrated Mindset, Blackwell: Oxford, p. 255-288, 2002.

.; HAYTON, J.; MARCEL, J.; O'NEILL, H. Fostering

Entrepreneurship During International Expansion: Managing Key Challenges.

European Management Journal, v. 19, n.4, p. 359-369, 2001.

.; IRELAND, D. R.; HITT, M. A. International expansion by new venture firms: International diversity, mode of market entry, technological learning and performance. Academy of Management Journal, v. 43, n. 5, p. 925-950, 2000b.

.; MATHERNE, B.; CARELTON, J. Leveraging technological resources for competitive advantage: The case of Software New Ventures. Proceedings of the $2^{\text {nd }}$ Annual McGill University Conference on Globalization. 2000a.

ZAIN, M.; NG, S. I. The impacts of network relationships on SMEs' internationalization process. Thunderbird International Business Review. v. 48, n. 2, p. 183-205, 2006.

ZHOU, L.; WU, W.; LUO, X. Internationalization and the Performance of BornGlobal SMEs: The Mediating Role of Social Networks. Journal of International Business Studies, v. 38, n. 4, p. 673-690, 2007. 


\section{SITES ACESSADOS:}

AGÊNCIA BRASIL - Disponível em: <http://agenciabrasil.ebc.com.br/pesquisae-inovacao/noticia/2014-09/reenviando-rio-info-debate-necessidade-de-fomentoao-setor-de-ti>.

BRASIL IT PLUS - Disponível em:

$<$ http://www.brasilitplus.com/brasilit/Portugues/detSegmentosDestaques.php>.

CONVERGÊNCIA DIGITAL (Redação) - Ci\&T nomeia três novos VPs de negócios, Disponível em:

$<$ http://convergenciadigital.uol.com.br/cgi/cgilua.exe/sys/start.htm?UserActiveTe mplate $=$ site\&infoid $=32530 \&$ sid $=47 \# . V v 7 N j \_k r K U k>.03 / 12 / 2012$.

EMPRESA CEARENSE GANHA EUROPA. Diário do Nordeste - 11/03/2008, Disponível em: $<$ http://diariodonordeste.globo.com/materia.asp?codigo $=519065>$. Acesso em: 23/03/2016.

INSTITUTE OF INTERNATIONAL EDUCATION - Relatório Open Doors. Disponível em: $\quad<\mathrm{http}: / / \mathrm{www}$.iie.org/Research-and-Publications/OpenDoors/Data/International-Students/Leading-Places-of-Origin/2013-15>. Acesso em: 23/03/2016.

OLHAR DIGITAL - Disponível em:

$<$ http://olhardigital.uol.com.br/noticia/governo-lanca-programa-para-apoiardesenvolvimento-de-software-no-

brasi1/50267?utm_campaign=newsletter_posicao_01\&amp;utm_medium=leia_ma is\&amp;utm_source $=$ newsletter>.

PORTAL BRASIL - Disponível em: <http://www.brasil.gov.br/ciencia-etecnologia/2015/08/lancado-nesta-terca-feira-programa-usinas-digitais $>$.

Totvs 2014a - Apresentação dos Resultados - 4o. Trimestre de 2014 (www.totvs.com.br, acessado em 21/02/2016).

Totvs 2014b: documento Modificações de Projeções Divulgadas - Fato Relevante, de 29/10/2014, no site da empresa www.totvs.com)

Totvs 2015a, Apresentação Institucional de 02/11/2015, acessado no site www.totvs.com.br em 20/02/2016

Totvs, 2015b Comunicado interno da empresa no site www.totvs.com.br_acessado em 22/02/2016. 
ANEXO

Lista detalhada das entrevistas analisadas

\begin{tabular}{|c|c|c|c|c|}
\hline Empresa & Ano & Entrevistado & Cargo & Entrevista \\
\hline \multirow{3}{*}{ CI\&T } & 2013 & Bruno Guiçardi & Sócio & Skype \\
\hline & 2013 & Leonardo Mattiazzi & Vice Presidente & Skype \\
\hline & 2016 & Bruno Guiçardi & Sócio & Skype \\
\hline \multirow{4}{*}{ Fujitec } & 2002 & Danilo Reis & Sócio & Pessoal \\
\hline & 2004 & Danilo Reis e Wicca Neves & Sócios & Pessoal \\
\hline & 2008 & Danilo Reis & Sócio & Pessoal \\
\hline & 2015 & Danilo Reis & Sócio & Telefone \\
\hline \multirow{5}{*}{ Ivia } & 2004 & Alexandre Menezes & Sócio & Pessoal \\
\hline & 2006 & Marcio Braga & Sócio & Pessoal \\
\hline & 2006 & Alexandre Menezes & Sócio & Pessoal \\
\hline & 2015 & Alexandre Menezes & Sócio & Telefone \\
\hline & 2016 & Alexandre Menezes & Sócio & Skype \\
\hline \multirow{3}{*}{$\begin{array}{l}\text { Light } \\
\text { Infocom }\end{array}$} & 2008 & Alexandre Moura & Sócio & Pessoal \\
\hline & 2015 & Alexandre Moura & Sócio & Telefone \\
\hline & 2016 & Alexandre Moura & Sócio & Skype \\
\hline \multirow{4}{*}{ MidiaVox } & 2007 & Alcides Pires & Sócio & Pessoal \\
\hline & 2008 & $\begin{array}{l}\text { Alcides Pires e Garibaldi } \\
\text { Rocha }\end{array}$ & Sócio & Pessoal \\
\hline & 2015 & Alcides Pires & Sócio & Telefone \\
\hline & 2016 & Alcides Pires & Sócio & Skype \\
\hline \multirow{4}{*}{ Totall } & 2008 & Edilson Paterno & Sócio & Pessoal \\
\hline & 2011 & Edilson Paterno & Sócio & Telefone \\
\hline & 2015 & Edilson Paterno & Sócio & Telefone \\
\hline & 2016 & Edilson Paterno & Sócio & Skype \\
\hline \multirow{2}{*}{ Totvs } & 2011 & Wilson de Godoy & $\begin{array}{l}\text { Vice Presidente } \\
\text { de Atendimento e } \\
\text { Relacionamento }\end{array}$ & Skype \\
\hline & 2012 & Alvaro Cysneiros & $\begin{array}{c}\text { Diretor de } \\
\text { Mercados } \\
\text { Internacionais } \\
\end{array}$ & Pessoal \\
\hline \multirow{5}{*}{ Xseed } & 2002 & Ronaldo Brandão & Sócio & Pessoal \\
\hline & 2004 & Ronaldo Brandão & Sócio & Pessoal \\
\hline & 2006 & Ronaldo Brandão & Sócio & Telefone \\
\hline & 2015 & Ronaldo Brandão & Sócio & Telefone \\
\hline & 2016 & Ronaldo Brandão & Sócio & Skype \\
\hline
\end{tabular}

